STRESS ACCELERATED GRAIN BOUNDARY OXIDATION OF INCOLOY ALLOY 908 IN HIGH TEMPERATURE OXYGENOUS ATMOSPHERES

by

MARTIN M. MORRA

Submitted to the Department of Materials Science and Engineering in Partial Fulfillment of the Requirements

for the Degree of

Doctor of Science in Metallurgy

at the

Massachusetts Institute of Technology

June 1995

(C) 1995 Massachusetts Institute of Technology

All rights reserved

Signature of Author

Department of Materials Science and Engineering

May 5, 1995

Certified by

Ronald G. Ballinger

Professor of Materials and Nuclear Engineering

Thesis Supervisor

Accepted by

Carl V. Thompson II

Professor of Electronic Materials

Chair, Departmental Committee on Graduate Students MASSACHUSETTS INSTTUUTE

OF TECHMOLOGY

JUL 201995 


\title{
STRESS ACCELERATED GRAIN BOUNDARY OXIDATION OF INCOLOY ALLOY 908 IN HIGH TEMPERATURE OXYGENOUS ATMOSPHERES
}

\author{
by
}

Martin M. Morra

Submitted to the Department of Materials Science and Engineering on May 5, 1995 in partial fulfillment of the requirements for the Degree of Doctor of Science in Metallurgy

\begin{abstract}
Constant load stress rupture tests were performed on alloy 908. The test matrix used varied oxygen concentration, applied load, temperature, and percent cold work. The effect of modifying surface residual stresses on intergranular oxidation and cracking was examined using constant strain C-ring tests.
\end{abstract}

The mechanisin for high temperature intergranular fracture in alloy 908 is stress assisted intergranular oxidation cracking. A direct correlation between percent intergranular fracture and oxygen concentration was observed. This result was comparable to the oxidation assisted, intergranular fracture behavior of alloy 718. Internal oxidation, for temperatures at or near $650^{\circ} \mathrm{C}$ and under an applied tensile stress, manifests itself as intergranular oxidation in alloy 908 . Intergranular oxidation penetrates to the same depth as predicted for internal oxidation. The concentration of $\mathrm{Cr}$ incorporated into the intergranular oxide increases with increasing test duration. This result is consistent with internal oxidation theory. The depth of intergranular oxidation is controlled by both the oxygen partial pressure and the $\mathrm{Cr}$ concentration of the alloy. These factors influence the growth of intergranular $\mathrm{Cr}_{2} \mathrm{O}_{3}$ and $\mathrm{NiCr}_{2} \mathrm{O}_{4}$ precipitates that serve to block the diffusion path for oxygen. Analogous to internal (matrix) oxidation, a transition from intergranular to external oxidation in alloy 908 occurs when the partial pressure of oxygen at the surface is below $7.6 \times 10^{-4}$ Torr.

The activation energy for intergranular oxidation in air was determined to be $202 \mathrm{~kJ} / \mathrm{mole}$ for this alloy. At low ( $<195 \mathrm{ppm}$ ) oxygen concentrations, the activation energy for intergranular oxidation increased to $500 \mathrm{~kJ} /$ mole. This higher value reflects the oxygen concentration dependence observed for intergranular oxidation. The dependence on alloy $\mathrm{Cr}$ concentration is similar to that observed for intergranular stress corrosion cracking in aqueous environments.

An oxygen concentration threshold based on zero percent intergranular fracture is a better indicator of the pntential for intergranular fracture during heat treatment than one based on time to rupture. An oxygen partial pressure below $1 \times 10^{-4}$ Torr is recommended for heat treatment of alloy 908 under residual or applied stresses. Shot peening appears to be relatively simple solution to the stress accelerated grain boundary oxidation problem.

Thesis Supervisor: Dr. Ronald G. Ballinger

Title: Professor of Materials and Nuclear Engineering 


\section{TABLE OF CONTENTS}

Section

Page

I. INTRODUCTION

A. Low Coefficient of Thermal Expansion Nickel-Iron Base

Superalloys

B. Cable-In-Conduit-Conductor $\mathrm{Nb}_{3} \mathrm{Sn}$ Magnets 17

C. Stress Accelerated Grain Boundary Oxidation 19

D. Remedies For Stress Accelerated Grain Boundary Oxidation 19

E. Microstructural Characteristics of Low Coefficient of Thermal 20

Expansion Nickel-Iron Base Superalloys

F. Stress Accelerated Grain Boundary Oxidation and Alloy 908

A. Fatigue Crack Growth Rate in Air Versus Vacuum 24

B. Tensile Embrittlement and Stress Rupture Life 25

C. Role of Microstructure and Alloy Chemistry 30

D. The Effect of Oxygen Partial Pressure 31

E. Effects of Oxygen Partial Pressure and Stress on Intergranular 32 Oxidation

F. Intergranular Oxidation 36

G. Application to Stress Accelerated Grain Boundary Oxidation in 41 Alloy 908

III. PROCEDURES

A. Material 43

B. Stress Rupture Test Procedure 44

C. C-Ring Residual Stress Modification Study 50

IV. RESULTS

A. Microhardness and Grain Size 53 


\section{TABLE OF CONTENTS}

$\underline{\text { Section }}$

Page

IV. RESULTS

53

B. Stress Rupture Results 56

C. Effect of Oxygen Concentration 61

D. Interrupted Flat Plate Tests, Microstructure and Chemistry 76

E. Round Bar Microstructure and Fractography 93

F. Grain Boundary Analysis $\quad 98$

G. Modification of Residual Stresses in C-Ring Test Samples 118

$\begin{array}{ll}\text { V. DISCUSSION } & 135\end{array}$

A. Stress Rupture Results 135

B. Grain Boundary Analysis 148

C. C-Ring Tests and Modification of Residual Stresses 156

F. Analysis of Stress Accelerated Grain Boundary Oxidation 159

$\begin{array}{ll}\text { VI. SUMMARY } & 170\end{array}$

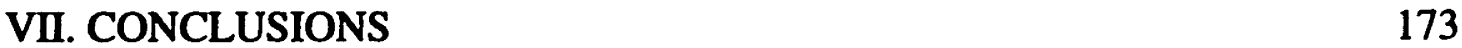

$\begin{array}{ll}\text { VIII. FUTURE WORK } & 175\end{array}$

$\begin{array}{ll}\text { APPENDIX } & 176\end{array}$

$\begin{array}{lc}\text { REFERENCES } & 181\end{array}$ 


\section{LIST OF FIGURES}

Figure

Description

$\underline{\text { Page }}$

1 Mean coefficient of expansion, from room temperature to temperature 16 shown, of alloy 903 for four levels of $\mathrm{Cr}$.

2 Crack growth rate in air as a function of temperature at, showing the 26 change in micromechanism of crack growth with changes in frequency.

$3 \quad$ Variation in fatigue crack growth rate with test frequency and temperature for alloy 718 at 550 and $650^{\circ} \mathrm{C}$.

4 Effect of a hold time applied at zero load on the fatigue crack growth rate ratio $\left(\mathrm{da} / \mathrm{dN}_{\text {hold }}\right) /(\mathrm{da} / \mathrm{dN})$.

5 Schematic comparison of stress accelerated grain boundary oxidation cracking mechanism proposed by McMahnon and Coffin and that proposed by Bricknell and Woodford.

6 Fatigue crack growth rate as a function of the oxygen partial pressure under constant $\Delta \mathrm{K}$ at $650^{\circ} \mathrm{C}$ in alloy 718 .

7 Percent intergranular fracture in alloy 718 slow strain rate test $\left(8.3 \times 10^{-4} \mathrm{~mm} / \mathrm{s}\right)$ at $650^{\circ} \mathrm{C}$ versus oxygen partial pressure.

8 Results of oxide identification by Auger spectroscopy on electropolished specimens of alloy 718 , showing transition time, $t_{p}$, between both forms of oxides as a function of oxygen partial pressure.

9 Influence of residual stresses on the transition in oxidation mechanism. 35 Cr-rich oxide is preferentially formed on shot peened specimens of alloy 718 at $650^{\circ} \mathrm{C}$.

10 Lateral growth of $\mathrm{Cr}_{2} \mathrm{O}_{3}$ layer originating from grain boundaries.

11 Intergranular oxide formation beneath $\mathrm{a}_{2} \mathrm{O}_{3}$ surface scale.

12 Transition from internal to external oxidation for $\mathrm{Ag}$-In alloys at $550^{\circ} \mathrm{C} .40$

13 Double edge notch stress rupture specimen, $K_{7}=4.5$. 46

14 Double notch round bar stress rupture specimen $K_{7}=4.1$.

15 Illustration showing of arrangement furnace, retort, and gas analyzers used for alloy 908 stress rupture tests.

16 C-ring specimen holder designed to maintain a constant plastic strain of $6 \%$ during heat treatment. 


\section{LIST OF FIGURES}

Figure

Description

Page

17 (a) Grain size and orientation of $3.43 \mathrm{~mm}$ thick sheet starting material, 54 heat $\mathrm{Y} 9401 \mathrm{~K}$, used for the flat plate stress rupture test samples.

(b) Grain size in stress rupture tested sample $61 \mathrm{P}\left(650^{\circ} \mathrm{C} / 118\right.$ hours $)$.

18 (a),(b) Optical micrographs showing grain size in the flat plate sample 49P and round bar sample 1B, respectively. (c), optical micrograph of elongated grain in $20 \%$ cold worked material, heat Y9210, (d) SEM micrograph of the same area as in (c) after $650^{\circ} \mathrm{C} / 200 \mathrm{~h}$ vacuum heat treatment.

$19650^{\circ} \mathrm{C} \mathrm{HVN}$ of all stress rupture test samples compared with the aging curves for solution annealed $\left(980^{\circ} \mathrm{C} / 1 \mathrm{~h}\right)$ and $20 \%$ cold work starting conditions.

20 Comparison of $650^{\circ} \mathrm{C}$ flat plate test sample stress rupture data for alloy 908 in argon with controlled oxygen concentration and the same heat treat of material but with $5 \%$ cold work and tested in air.

21 Distribution of times to failure versus oxygen concentration for flat plate samples tested at $650^{\circ} \mathrm{C}$ and in the stress range $651.5 \pm 18 \mathrm{MPa}$.

22 Effect of temperature on time to rupture versus stress for solution annealed flat plate samples at 750,700 and $550^{\circ} \mathrm{C}$ for different ranges of oxygen concentration.

23 Comparison of $20 \%$ cold work double notch round bar air data with low oxygen concentration test data for the same heat of material with $20 \%$ cold work, $10 \%$ cold work, and solution annealed starting conditions.

24 Comparison of time to rupture versus stress for vacuum ( $1 \times 10^{-5}$ torr) heat treated $\left(650^{\circ} \mathrm{C} / 200\right.$ hours) then tested samples with samples tested in their as received condition.

25 Micrographs of $650^{\circ} \mathrm{C}$ sample $9 \mathrm{P}\left(640 \mathrm{MPa}, 82.3 \mathrm{~h}, 6 \mathrm{ppm} \mathrm{O} \mathrm{O}_{2}\right)$. (a,b) Stereomicrographs of reconstructed specimen after failure showing deformation pattern in region of notch. (c) Optical micrograph of cross-section.

$26550^{\circ} \mathrm{C}$ sample $30 \mathrm{P}$ loaded at $644 \mathrm{MPa}$ in $1.2 \mathrm{ppm} \mathrm{\textrm {O } _ { 2 }}$. Test stopped after 478.3 hours. (a,b) SEM micrographs showing exterior of sample at notch section. (c) Optical micrograph showing cross section of unfailed notch.

27 Characteristics of flat plate stress rupture fracture surfaces as a function of oxygen concentration. 


\section{LIST OF FIGURES}

Figure

Description

Page

$28 \quad$ HVN from microhardness trace along the longitudinal axis (tensile) 68 of the stress rupture sample $5 \mathrm{P}\left(650^{\circ} \mathrm{C}, 652 \mathrm{MPa}, 44.1\right.$ hours, $53 \mathrm{ppm}$ oxygen). Trace extends, in cross section, from the rupture surface down the center of the sample on the LT plane.

29 HVN from microhardness trace along the transverse axis (notch to notch) of the stress rupture sample $5 \mathrm{P}\left(650^{\circ} \mathrm{C}, 652 \mathrm{Mpa}\right.$, 44.1 hours, $53 \mathrm{ppm}$ oxygen).

30 SEM micrographs comparing the intergranular fracture morphology in 71 $650^{\circ} \mathrm{C} / 650 \mathrm{MPa}$ samples as a function of oxygen concentration. (a) $31 \mathrm{P}$, $71.7 \mathrm{~h}$ to failure, $1 \mathrm{ppm} \mathrm{O} \mathrm{O}_{2}$, (b) $9 \mathrm{P}, 82.3 \mathrm{~h}$ to failure, $6 \mathrm{ppm} \mathrm{O}_{2}$, (c) $62 \mathrm{P}$, $122 \mathrm{~h}$ to failure, $38 \mathrm{ppm} \mathrm{O}$, (d) $24 \mathrm{P}, 111.4 \mathrm{~h}$ to failure, $1000 \mathrm{ppm} \mathrm{O}_{2}$.

31 (a-c) Optical micrographs of notch fractures and (d-f) SEM micrographs of fracture surfaces for three $650^{\circ} \mathrm{C}$ samples

32 Fully ductile fracture shown in (a) with creep voids present in cross section, grain deformation at notch. (b) Intergranular ledge at notch with no grain deformation visible in this zone, ductile zone after intergranular ledge shows grain deformation.

33 SEM micrographs showing the effect of temperature on fracture for a stress of $650 \mathrm{MPa}$ and $195 \mathrm{ppm} \mathrm{O}_{2}$.

34 Percent intergranular fracture versus oxygen concentration for $650^{\circ} \mathrm{C}$ and $651 \pm 18 \mathrm{MPa}$ stress range flat plate test samples.

35 Ratio of ductile fracture area to total fracture area versus oxygen concentration for flat plate samples at $650^{\circ} \mathrm{C}$ and $651.5 \pm 18 \mathrm{MPa}$ stress range.

36 Percent intergranular fracture versus oxygen concentration for all samples, flat plate and round bar, tested at $650^{\circ} \mathrm{C}$ and for all stress levels tested, range $535 \pm 140 \mathrm{MPa}$.

37 Comparison of $650^{\circ} \mathrm{C}$ Inconel 718 slow strain rate $\left(8.3 \times 10^{-4} \mathrm{~mm} / \mathrm{s}\right)$ tensile data with $650^{\circ} \mathrm{C}$ notched stress rupture data from alloy 908 at $649 \pm 18 \mathrm{MPa}$ stress range.

38 Micrographs comparing the notch morphologies of the $650^{\circ} \mathrm{C} / 540 \mathrm{MPa}$ samples.

39 Energy dispersive spectroscopy composition profile of $\mathrm{Fe}, \mathrm{O}, \mathrm{Ni}$, and $\mathrm{Cr}$ from the surface of the notch of sample 8P obtained by SEM at $12,000 x$ magnification. 


\section{LIST OF FIGURES}

Figure

Description

Page

40 Energy dispersive spectroscopy composition profile of $\mathrm{Fe}, \mathrm{Ni}, \mathrm{Nb}$, $\mathrm{Ti}, \mathrm{Al}$, and $\mathrm{Si}$ from the surface of the notch of sample obtained by SEM at $4000 x$ magnification.

41 Flate plate $650^{\circ} \mathrm{C}$ sample 38P,test stopped at 522 hours.

84

(a) Grain boundary microstructure at base of notch after test.

(b) Higher magnification of region analyzed by $\mathrm{x}$-ray mapping.

42 Energy dispersive spectroscopy composition profile of $\mathrm{Fe}, \mathrm{O}, \mathrm{Ni}$, and

$\mathrm{Cr}$ from the surface of the notch of sample 38P.

43 Energy dispersive spectroscopy composition profile of $\mathrm{Fe}, \mathrm{Ni}, \mathrm{Ti}$, $\mathrm{Nb}$ and $\mathrm{Al}$ from the surface of the notch of sample 38P.

44 EDS x-ray map of grain boundaries at base of notch in $650^{\circ} \mathrm{C}$ sample 38P.

45 (a), (b), (c) SEM micrographs and (d) optical cross-section of notch

89 from $650^{\circ} \mathrm{C}$ sample $60 \mathrm{P}$.

46 (a), (b) SEM micrographs from $650^{\circ} \mathrm{C}$ sample 60P showing

90 intergranular/ ductile transgranular fracture transition.

47 SEM micrographs (a-d) from $650^{\circ} \mathrm{C}$ sample 60P.

48 (a,d) Optical micrographs of notch cross-sections and (b,c,e,f) SEM micrographs of $650^{\circ} \mathrm{C}$ samples $31 \mathrm{P}$ and $32 \mathrm{P}$.

$4920 \%$ cold-worked $650^{\circ} \mathrm{C}$ round bar test sample 20cw31. (a) Grain structure showing large, elongated grains parallel to the rolling and tensile directions. (b) Cross-section near unfailed notch showing elongated grain at the notch and crack path. (c) Detail of crack path around elongated grain at notch.

50 SEM micrograph showing the fracture surface of the failed notch from the $650^{\circ} \mathrm{C}$ round bar sample $20 \mathrm{cw} 31$.

51 SEM micrograph of the failed notch in the $650^{\circ} \mathrm{C}$ round bar sample $1 \mathrm{~A}$.

52 (a) Normarski optical micrograph of the crack path at the unfailed notch in the $650^{\circ} \mathrm{C}$ round bar sample $10 \mathrm{cw} 2$. (b) SEM micrograph from a portion of an oxidized crack path extending from the unfailed notch in the $650^{\circ} \mathrm{C}$ round bar sample.

53 (a) Line scan profiles of elements across two grain boundaries in the $650^{\circ} \mathrm{C}$ sample 1B .(b) Enhanced oxygen line scan. (c) Area used for line scan across two grain boundaries. 


\section{LIST OF FIGURES}

Figure

Description

Page

54 EDS maps of the elements present at grain boundaries near root of

100 notch in $650^{\circ} \mathrm{C}$ round bar sample $1 \mathrm{~B}$.

55 (a) SEM micrograph and (b) oxygen $x$-ray map of grain boundaries in 102 $650^{\circ} \mathrm{C}$ sample $10 \mathrm{cw}$.

56 EDS X-ray map of elements present along grain boundaries at the unfailed notch of sample $10 \mathrm{cw}-2$.

57 Affected grain boundaries in $650^{\circ} \mathrm{C}$ sample 1B. (a) General region.

104

(b) Grain boundary at triple point selected for EDS composition profile.

58 EDS composition profile across a grain boundary in the $650^{\circ} \mathrm{C}$ round

105 bar sample 1B.

59 EDS composition profile across a grain boundary in the $650^{\circ} \mathrm{C}$ round 106 bar sample 1A.

60 EDS composition profile across an affect grain boundary in the $650^{\circ} \mathrm{C}$ round bar sample $1 \mathrm{~A}$.

61 (a) SEM micrographs of oxidized grain boundaries in $650^{\circ} \mathrm{C}$ flat plate

109 sample 62P. (b) Micrograph of grain boundary selected for compositional analysis by EDS.

62 EDS composition profile along grain boundary extending to terminus. $650^{\circ} \mathrm{C}$ flat plate sample $62 \mathrm{P}$.

63 EDS composition profile across grain boundary in the $650^{\circ} \mathrm{C}$ flat plate sample 62P.

64 SEM micrographs of $650^{\circ} \mathrm{C}$ flat plate sample. (a) Affected grain boundary extending in from failed notch. (b) Grain boundary used for compositional analysis.

65 EDS composition profile along grain boundary in the $650^{\circ} \mathrm{C}$ flat plate sample 49P.

66 EDS composition profile across grain boundary in the $650^{\circ} \mathrm{C}$ flat plate sample 49P).

67 (a) SEM micrograph of crack at notch in round bar sample $20 \mathrm{cw}-24$

(b) SEM micrograph of grain boundary at the farthest distance from notch used for compositional analysis.

68 EDS composition profile along grain boundary in the $650^{\circ} \mathrm{C}$ round bar sample $20 \mathrm{cw} 24$. 


\section{LIST OF FIGURES}

Figure

Description

Page

69 (a) Macrophoto of cracked C-ring S37. (b) SEM micrograph showing 119 intergranular through crack in $\mathrm{C}$-ring.

70 (a) Stereomicrograph showing dimpled surface of $C$-ring surface after shot peening. (b) SEM micrograph of shot peened surface at bend in C-ring S13.

71 (a-d) Optical micrographs showing cross sections of the outer surfaces of C-ring test samples heat treated at $650^{\circ} \mathrm{C}$ for 24 hours in a $4 \times 10^{-2}$ Torr vacuum.

72 Microhardness profile across thickness of C-ring sample S13.

73 Microhardness profile across thickness of C-ring sample S49.

74 Microhardness profile across thickness of C-ring sample S37.

75 Compositions of oxides (oxygen excluded from plot) electrolytically extracted from the surfaces of $\mathrm{C}$-rings that were heat treated under degraded vacuum conditions $\left(10^{-2}\right.$ Torr range).

76 SEM micrograph across intergranular crack in the C-ring S37.

77 High magnification SEM micrographs taken near the inside diameter of the cracked cross section of C-ring S37.

78 High magnification SEM micrographs taken along the cracked cross section of C-ring S37 after failing within 24 hours at $650^{\circ} \mathrm{C}$ in a $4 \times 10^{-2}$ Torr vacuum.

79 High magnification SEM micrographs of the intergranular fracture surface from a cross section of the C-ring C33.

80 (a) SEM micrograph taken from the intergranular fracture surface from a cross section of the $\mathrm{C}$-ring C 33 . (b) Oxide particles captured on an extraction replica of the C-ring fracture surface. (c) Comparable SEM micrograph from the flat plate stress rupture sample 49P.

81 Larson-Miller parameter plot for all flat plate test data, grouped by oxygen concentration with $\mathrm{C}=20$.

82 Larson-Miller parameter plot of low oxygen concentration flat plate test data compared with $5 \%$ cold work flat plate test data.

83 Larson-Miller parameter plot of round bar low oxygen concentration data for $20 \%$ cold work and solution annealed conditions compared with round bar data for $20 \%$ cold work material in air. 


\section{LIST OF FIGURES}

Figure

Description

Page

84 Larson-Miller parameter plot of combined round bar and flat plate test data.

85 Larson-Miller parameter plot of flat plate test data at low oxygen oxygen concentrations grouped by percent intergranular fracture.

86 Plot of isostress lines and least squares fits for 650 and $540 \mathrm{MPa}$ stresses.

87 Plot of isostress lines and least squares fit for 650 and $540 \mathrm{MPa}$ stresses.

88 "Master curve" for solution annealed flat plate stress rupture data based on new material constant $\mathrm{C}=30$.

89 Arrhenius activation energy, $Q_{g b}$ plot for intergranular oxidation in alloy 908 in air.

90 Arrhenius activation energy, $Q_{g b}$ plot for intergranular oxidation in alloy 908 in 195 ppm oxygen.

91 Arrhenius activation energy, $Q_{\mathrm{gb}}$ plot for intergranular oxidation in alloy 908 in 38-195 ppin oxygen.

92 Arrhenius activation energy, $Q_{g b}$ plot for intergranular oxidation in alloy 908 in 6-1000 ppm oxygen. Based on flat plate stress rupture data.

93 Concentration profile for the exclusive internal oxidation of alloys. 162

94 SEM micrograph showing cross section through the oxidized surface 162 of heat treated alloy 905 .

95 Comparison of experimental and calculated intergranular oxidation depths.

96 Calculated time to reach depth of intergranular oxidation observed in stress rupture tests at $650^{\circ} \mathrm{C}$ and $650 \mathrm{Mpa}$.

97 Intergranular oxidation zone (of depth $\xi$ ) developed under tensile loading.

98 Time to develop a $0.5 \mathrm{~mm}$ deep zone of internal oxidation in three alloys at $650^{\circ} \mathrm{C}$ as a function of oxygen concentration and mole fraction $\mathrm{Cr}$. 


\section{LIST OF FIGURES}

Figure

Description

$\underline{\text { Page }}$

99 Percent intergranular fracture as a function of grain boundary $\mathrm{Cr}$ level 169 in $\mathrm{Ni}-\mathrm{Cr}$-Fe alloys obtained from constant extension rate tests at room temperature. 


\section{LIST OF TABLES}

Table

Description

Page

1 Compositions of the 9XX-Type LCIN Superalloys.

17

2 Chromium Concentration In Dilute Ni-Cr Alloys at the Advancing

Front of Internal Oxidation.

3

Compositions of Alloy 908 Used for Stress Rupture Testing.

44

$4 \quad$ Test Matrix Used For Stress Rupture Tests.

45

5 Alloy $908 \mathrm{C}$-Ring Test Results at $650^{\circ} \mathrm{C}, 6 \%$ Plastic Strain.

118

6 Compositions of Surface and Grain Boundary Oxides From

149 Alloy 908 Stress Rupture Samples.

1A Nominal Compositions of Some Superalloys

176

2A Alloy 908 Stress Rupture Data I.

$177-178$

3A Alloy 908 Stress Rupture Data II.

$179-180$ 


\section{ACKNOWLEDGMENT}

This thesis is dedicated to the memory of

\section{Ralph Hamilton Marler, Jr.}




\section{INTRODUCTION}

Alloy 908 was developed as a Nb3Sin Cable-In-Conduit-Conductor (CICC) magnet sheathing material. [1] It can be characterized as a low coefficient of thermal expansion iron-nickel base superalloy that contains 4 weight percent chromium. Its chemistry, microstructure and mechanical properties have been optimized for Cable-In-ConduitConductor use while maintaining a coefficient of expansion that is compatible with this application. The development of alloy 908 centered on three areas that were necessary for its successful application as a low coefficient of expansion cryogenic structural material. These were; its mechanical properties at cryogenic temperatures, welding, and its susceptibility to intergranular oxygen embrittlement. The latter of these is the area with which this thesis will deal. The application, development, and properties have been reported in other publications, so these will be mentioned here only briefly or when applicable. $[1,2,3]$

\section{A. Low Coefficient of Thermal Expansion Iron-Nickel Base Superalloys}

The low coefficient of thermal expansion iron-nickel base (LCIN) superalloys form a subset of the general class of multicomponent face centered cubic ( $\mathrm{fcc}$ ), ferromagnetic, NiFe base superalloys. The thermal expansion of a low coefficient of thermal expansion ironnickel base superalloy, however, does not exhibit a continuous increase with increasing temperature. [4,5] Although the compositions of alloys in this group have been modified to provide high temperature strength, all are derivatives of a binary $\mathrm{Ni}-\mathrm{Fe}$ alloy called Invar. The Invar designation corresponds to an alloy whose composition (36 at.\% Ni-Fe) produces the minimum value of coefficient of expansion $(\alpha)$. [5,6] Since the thermal expansion anomaly always occurs in the vicinity of the Curie point, where the magnetic transformation from ferromagnetic to paramagnetic occurs, most theories assume that the origin of the low $\alpha$ is associated with the ferromagnetism of Invar alloys. [5, 6, 7] This effect is thought to be related to a decrease in the normal thermal expansion of the lattice by volume magnetostriction. [5] This produces the anomalously low mean coefficient of thermal expansion, $\left(\alpha_{m}\right)$, of these alloys. $[4,7,8,9]$ In practical terms, if $\left(\alpha_{m}\right)$ of these alloys is measured over an extended temperature range, starting at $4 \mathrm{~K}$ and with increasing temperature $\alpha_{m}$ will appear to be constant until the inflection temperature, $\left(T_{i}\right)$, is reached, after which it begins to increase. 
The applications for which low coefficient of thermal expansion iron-nickel base superalloys were designed, include close tolerance components such as seals in gas turbine engines that require a constant $\alpha_{\mathrm{m}}$ over the temperature range from $25^{\circ} \mathrm{C}$ to $650^{\circ} \mathrm{C}$. [10] Other than the matrix balance of $\mathrm{Ni}, \mathrm{Fe}$ and $\mathrm{Co}$, the primary compositional change that distinguishes these alloys from conventional superalloys is their low chromium content. This is due to the strong effect of $\mathrm{Cr}$ in lowering the Curie temperature, and hence the onset of volume magnetostriction. The effect of increasing $\mathrm{Cr}$ on $\alpha_{\mathrm{m}}$ is shown in Figure 1. A typical low coefficient of thermal expansion iron-nickel base superalloy contains less than 1 weight percent $\mathrm{Cr}$ to maintain a constant $\alpha_{\mathrm{m}}$ from 25 to $650^{\circ} \mathrm{C}$. $[4,10]$ The base $\mathrm{Ni}-\mathrm{Fe}$ chemistries are adjusted to compensate for the loss of $\mathrm{Ni}$ to the strengthening precipitate during precipitation hardening heat treatments. This results in the Ni content of the $\gamma$ phase, after precipitation hardening, approximating that of an Invar-type alloy. [4, 11] Table 1 lists the compositions of some of the 9XX-type low coefficient of thermal expansion iron-nickel base superalloys.

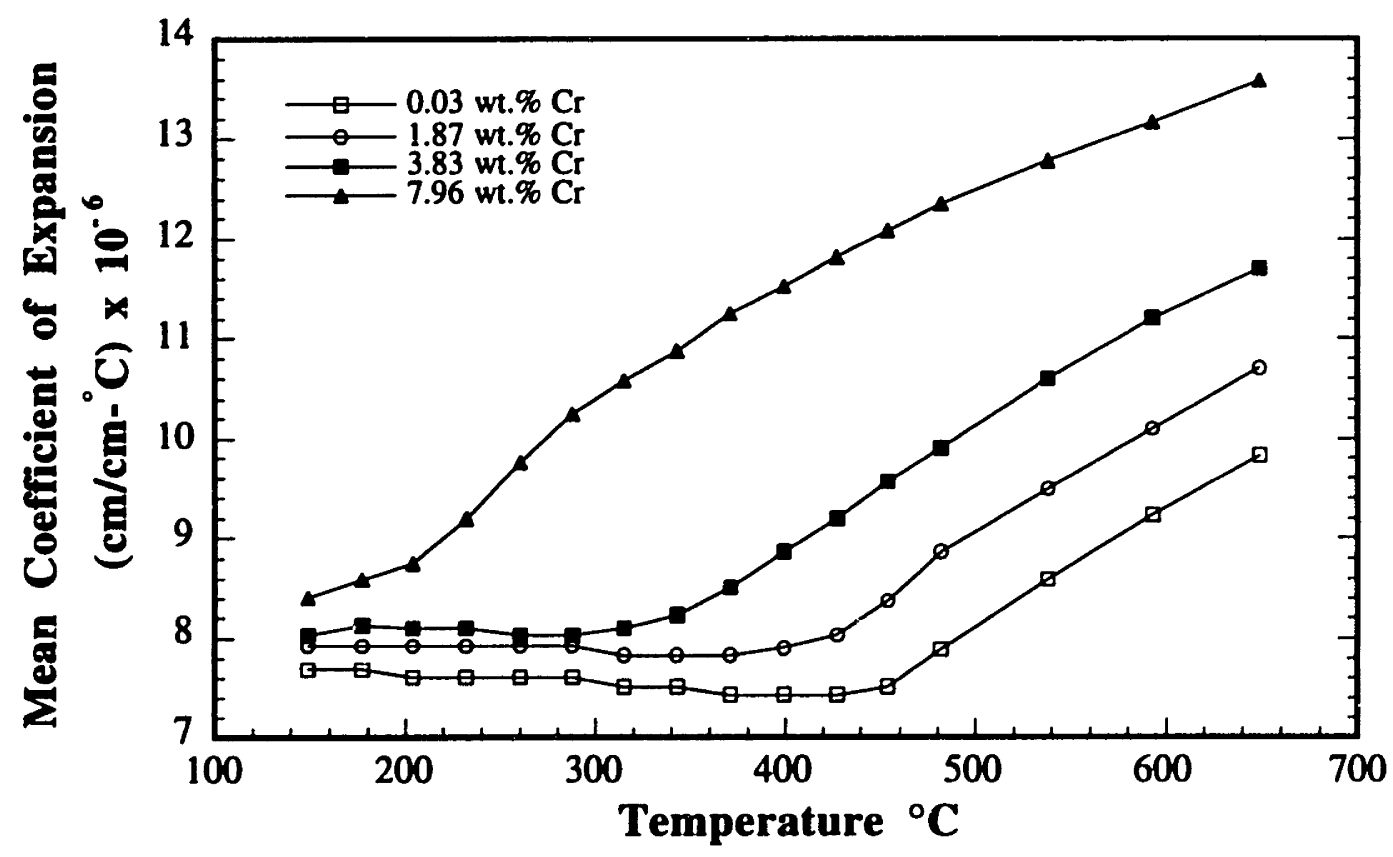

Figure 1. Mean cuefficient of expansion, from room temperature to temperature shown, of alloy 903 for four different levels of Cr. [1] 
Table 1. Compositions of the 9XX-Type Low Coefficient of Thermal Expansion Iron-Nickel Base Superalloys

\begin{tabular}{|c|c|c|c|c|c|c|c|c|c|c|c|c|}
\hline Alloy & \multicolumn{10}{|c|}{ Composition (weight percent) } \\
\hline & $\mathrm{Fe}$ & $\mathrm{Cr}$ & $\mathrm{Ni}$ & $\mathrm{Co}$ & $\mathrm{Nb}$ & $\mathrm{Ti}$ & $\mathrm{Al}$ & $\mathrm{Mo}$ & $\mathrm{Mn}$ & $\mathrm{C}$ & $\mathrm{Si}$ & $\begin{array}{c}\mathrm{Ti}+\mathrm{Al}^{*} \\
\mathrm{Nb}\end{array}$ \\
\hline 903 & 40.9 & - & 38.0 & 15.0 & 3.00 & 1.40 & 0.90 & 0.50 & 0.20 & 0.03 & - & 1.89 \\
\hline $903 \mathrm{~A}$ & 41.8 & - & 37.5 & 14.0 & 5.00 & 1.60 & 0.02 & - & - & 0.01 & - & 0.63 \\
\hline 905 & 44.4 & - & 48.9 & 0.33 & 4.70 & 1.59 & 0.04 & - & 0.05 & 0.01 & - & 0.68 \\
\hline 907 & 42.3 & - & 38.4 & 13.0 & 4.70 & 1.50 & 0.03 & - & - & & 0.10 & 0.64 \\
\hline 908 & 40.8 & 4.12 & 48.7 & --- & 3.04 & 1.54 & 1.10 & - & 0.09 & 0.01 & 0.17 & 2.22 \\
\hline 909 & 40.7 & - & 38.2 & 16.0 & 3.00 & 1.75 & 1.00 & - & - & 0.03 & 0.40 & 0.64 \\
\hline * Based on atomic \% & & & & & & & & & & \\
\hline
\end{tabular}

\section{B. Cable-In-Conduit-Conductor Nb33 $\mathrm{Sn}$ magnets}

The most recent use for one member of the general class of 9XX-type low coefficient of thermal expansion iron-nickel base superalloys, alloy 908 , is in the non-conventional application as a structurai alloy in advanced high magnetic field $\mathrm{Nb}_{3} \mathrm{Sn}$ superconductor magnets. $[12,13,14,15]$ The "Cable-In-Conduit-Conductor" is an example of this magnet type. In this application, the low $\alpha_{\mathrm{m}}$ superalloy is incorporated as a conduit that houses the brittle $\mathrm{Nb} 3 \mathrm{Sn}$ superconductor to provide both structural support and a coolant channel through which liquid $\mathrm{He}$ at $4.2 \mathrm{~K}$ will flow.

Along with the requirement of a low $\mathrm{Cr}$ content, a low coefficient of thermal expansion iron-nickel base superalloy, when used in Cable-In-Conduit-Conductor applications, must not contain cobalt. This is an important consideration since cobalt has a high activation cross section in the presence of a neutron flux and one potential application for Cable-InConduit-Conductor magnets is in neutron producing fusion reactors.

It was first proposed by Steeves, et al., that the low thermal expansion characteristics of the 9XX series of alloys could be used to advantage in Cable-In-Conduit-Conductor applications. [16, 17] The low $\alpha_{m}$ 's and precipitation hardening characteristics of these alloys act in unison both to reduce the amount of thermal strain imposed on the conductor and to provide mechanical support for the superconductor, respectively. The strain sensitivity of $\mathrm{Nb}_{3} \mathrm{Sn}$, coupled with thermal strain induced lowering of critical current 
density, is the single most important factor in selecting a low coefficient of thermal expansion iron-nickel base superalloy for the Cable-In-Conduit-Conductor application. $[18,19]$ The source of thermal strain sterns from the contraction of the conduit material when the Cable-In-Conduit-Conductor structure is cooled from heat treatment temperature down to an operating temperature of $4.2 \mathrm{~K} .[16,17,19,20]$ In the specific Cable-InConduit-Conductor application for which the $9 \mathrm{XX}$ series of alloys were evaluated, the conduit alloy must remain microstructurally stable during an $\mathrm{Nb}_{3} \mathrm{Sn}$ heat treatment cycle. For this application, a stable microstructure is one in which the precipitation hardening phase(s) will not coarsen to the extent that the $4.2 \mathrm{~K}$ yield strength falls below $1200 \mathrm{MPa}$, nor should the elongation be reduced by intergranular or interdendritic fracture due to the formation of embrittling phase(s), and the fracture toughness should be at or above 200 MPa $\sqrt{ }$. $[1,21]$ These criteria, however, must be met using heat treatments designed to optimize the solid state reactions necessary for the formation of superconducting $\mathrm{Nb}_{3} \mathrm{Sn}$ from elemental $\mathrm{Nb}$ and $\mathrm{Sn}$. [22] The elemental precursors for this reaction are present in a cabled "composite" wire that can either be composed of filamentary $\mathrm{Nb}$ surrounding $\mathrm{Sn}$ cores in a $\mathrm{Cu}$ matrix, or filamentary $\mathrm{Nb}$ in a $\mathrm{Sn}$-Cu bronze matrix. [23] As will be discussed below, heat treatments designed to optimize $\mathrm{Nb}_{3} \mathrm{Sn}$ formation are not optimal for most structural materials.

One processing scheme that has been successful utilizes a tube mill. The cabled wire is fed onto a strip of annealed alloy that is then formed around the cable and closed by autogenous inert gas tungsten-arc (GTA) welding. [12, 13, 24] After welding, the conduit undergoes a reduction in cross-section in the tube mill. Finally, the magnet is given a sequential heat treatment that extends over a temperature range starting at $375^{\circ} \mathrm{C}$ up to a possible maximum of $750^{\circ} \mathrm{C}$. The typical heat treatment practice used with Cable-InConduit-Conductor magnets involves the continuous flow of gettered helium through the internal void space in the conduit/cable composite and an exterior vacuum greater than $1 \times 10^{-4}$ Torr. $[14,15]$

Heat treatment practice used for the magnet structure places two important constraints on the structural alloy. The first of these is that, since $\mathrm{Nb}_{3} \mathrm{Sn}$ conductors, and therefore heat treatments, are constantly evolving, it is imperative that the conduit alloy's precipitation hardening window be flexible enough to overlap that of the conductor being used. In addition, resistance to environmental embrittlement and cracking in a variety of furnace atmospheres must be considered. Early tests showed that most of the thenavailable low coefficient of thermal expansion iron-nickel base superalloys were found to be deficient in one of these areas. $[25,26,27]$ This was to be expected, since the original 
processing, time, and temperature envelopes for most of these alloys were developed around optimizing properties for gas turbine applications. These envelopes do not overlap well with those that are optimal for $\mathrm{Nb}_{3} \mathrm{Sn}$ formation, nor with the unique processing scheme developed for the Cable-In-Conduit-Conductor magnets. As a result, the $\mathrm{Nb}-\mathrm{Sn}$ conductor heat treatments often produce an overaged microstructure with reduced mechanical properties compared with those of the peak age hardened condition. [26, 27]

\section{Stress Accelerated Grain Boundary Oxidation}

A long recognized limitation in the use and fabrication of low coefficient of thermal expansion iron-nickel base superalloys is their susceptibility to environmentally induced intergranular cracking. $[28,29,30]$ The particular form of environmentally induced cracking to which these alloys are susceptible is termed stress accelerated grain boundary oxidation (SAGBO). The term "stress accelerated grain boundary oxidation" originated with the work of McMahon and Coffin. [31] As the name indicates, it is a synergistic effect of residual (plastic) stress or imposed stress, temperature, and the presence of oxygen. Examination of fracture surfaces produced by stress accelerated grain boundary oxidation show severe intergranular cracking accompanied by substantial intergranular oxide formation. [25] Stress accelerated grain boundary oxidation cracking is a subclass of the general environmental degradation phenomena termed stress corrosion cracking (SCC). Mechanisms proposed for stress accelerated grain boundary oxidation will be discussed in the Literature Review.

Some of the general characteristics of stress accelerated grain boundary oxidation in low coefficient of thermal expansion iron-nickel base superalloys are preferential oxide formation along grain boundaries, decreased stress-rupture life in the $550^{\circ} \mathrm{C}$ to $800^{\circ} \mathrm{C}$ temperature range in air, and intergranular cracking at notch sections of stress-rupture specimens or in bend sections of U-bend samples. High temperature $\left(>900^{\circ} \mathrm{C}\right)$ air exposure of unstressed low coefficient of thermal expansion iron-nickel base superalloys produces varying depths of internal oxidation along with preferential oxidation of grain boundaries within the internally oxidized region.

\section{Remedies For Stress Accelerated Grain Boundary Oxidation}

Several remedies for stress accelerated grain boundary oxidation do exist. With varying degrees of success they include: changes in alloy chemistry, modified precipitation hardening heat treatments that alter the grain boundary microstructure, thermomechanical 
processing, or oxidation resistant coatings. Alloy chemistry modifications are geared towards producing a stable oxide layer or adding beneficial grain boundary segregants. [32] Although this last remedy may seem to be the most straightforward solution to the stress accelerated grain boundary oxidation problem, retaining a low $\alpha_{m}$ places constraints on how far the alloy chemistry can be successfully modified. In high temperature aerospace applications with relatively narrow operating temperature ranges, any compromise in an alloy's $\alpha_{m}$ may be unacceptable.

The Cable-In-Conduit-Conductor application is a good example of a limited high temperature exposure ( $\mathrm{Nb}_{3} \mathrm{Sn}$ heat treatment) that lends itself to a broader range of alloy chemistries. This is because the large temperature range (1000K to $4 \mathrm{~K})$ involved and greatly extended low temperature regime produce less of an overall effect on $\alpha_{\mathrm{m}}$. If the expected maximum service temperature is low enough (below or near $\mathrm{T}_{\mathrm{i}}$ ), up to $5 \mathrm{wt} . \%$ chromium can be added to these alloys to give improved resistance to stress accelerated grain boundary oxidation. [30] Addition of $2 \mathrm{wt} . \% \mathrm{Cr}$ to an experimental Ni-Fe-Co base low coefficient of expansion superalloy, in combination with a modified grain boundary microstructure, has been shown to double the stress-rupture life over a similar chemistry alloy without Cr. [33] When compared with alloy 903, the same alloy showed a 2000 fold increase in stress-rupture life. Adding $5 \mathrm{wt} . \% \mathrm{Cr}$ to another $\mathrm{Ni}$-Fe-Co base low coefficient of expansion alloy improved both its overall oxidation resistance and stress-rupture life. [34] In the development of alloy 908 , the temperature range of interest, $4 \mathrm{~K}$ to $1000 \mathrm{~K}$, permitted the addition of $4 \mathrm{wt}$. \% chromium with a tolerable increase in $\alpha_{\mathrm{m}}$ over that temperature range. $[1,2]$

\section{E. Microstructural Characteristics of Low Coefficient of Thermal Expansion Iron-Nickel Base Superalloys}

In position among other nickel-iron-base superalloys, the low coefficient of thermal expansion superalloys are either $\gamma$ (ordered fcc [Ni3( $\mathrm{Al}, \mathrm{Ti})]$ ) strengthened, (alloy 908 and alloy 903) or $\gamma^{\prime \prime}$ (bct Ni3Nb) strengthened, (alloy 905). [1, 3] Although the exact nature of the strengthening phase has not been reported in the literature, alloys 907 and 909 have high $(\mathrm{Ti}+\mathrm{Al}) / \mathrm{Nb}$ ratios, that promotes $\gamma$ " strengthening. [35] The precipitate formed in these alloys is dependent upon the percentages of $\mathrm{Nb}, \mathrm{Al}$, and Ti present. Alloys such as 905,907 , and 909 have low $\mathrm{Al}$ contents. $[30,36]$ To compensate for the low Al levels and 
maintain the same volume fraction of strengthening phase(s), the amount of $\mathrm{Nb}$ is increased. Because of this, these low coefficient of thermal expansion iron-nickel base superalloys also exhibit relatively dynamic intergranular microstructures, with corresponding variable grain boundary chemistries in the SAGBO temperature regime. The role of intergranular precipitates in oxygen embrittlement in the $550^{\circ} \mathrm{C}$ to $800^{\circ} \mathrm{C}$ range, either through their effect on local chemistry or oxidation of grain boundaries, has not been fully explored.

\section{F. Stress Accelerated Grain Boundary Oxidation and Alloy 908}

Present interest in stress accelerated grain boundary oxidation, from a cryogenic materials viewpoint, stems from research leading to the development of alloy 908 as the sheathing material used on the US-DPC magnet. [1, 3]

Stress-rupture tests performed during the development stage of alloy 908 showed that the addition of 4 weight percent $\mathrm{Cr}$ improved its notch-rupture behavior in air over that of the extremely notch-sensitive alloy 903. [3] Experience has shown that a magnet constructed of alloy 908 can be successfully heat treated in vacuum. [14] Tolerance to degraded furnace environments, either vacuum or inert gas, had not been established.

Stress-rupture behavior of alloy 908 at high temperature in air show characteristics that indicate its susceptibility to stress accelerated grain boundary oxidation. [37]. While the data indicated adequate life expectancy in air for very low stress levels ( $<200 \mathrm{MPa})$, the actual stresses in the pre-heat treatment conduit, from. plastic deformation during conduit fabrication and from magnet winding, have not been established. This is because a wide variety of possible fabrication methods and magnet designs are under consideration. It is anticipated that residual stresses from tube forming and/or extrusion, winding and elastic strains due to constraining the coil after winding will be present. For the magnet designers, a map of the stress accelerated grain boundary oxidation regime for alloy 908 in terms of stress, time, and furnace atmosphere, will be essential for the successful heat treatment of large scale Cable-In-Conduit-Conductor magnets.

There is no question that such structures can be successfully heat treated in vacuum. For economic reasons, however, very large scale magnets, such as those to be designed for the International Thermonuclear Experimental Reactor (ITER), heat treatment in an argon atmosphere may be considered. The problem with this approach is that the oxygen concentrations in inert gases may exceed the threshold level for alloy 908 .

The goal of this study is threefold. First, from the perspective of Cable-In-ConduitConductor magnet heat treatments, is to determine what level of environmental control over 
oxygen concentration is required to prevent intergranular cracking. Second, and more basically, what is the relationship between oxygen concentration, stress and temperature that leads to intergranular failure in this alloy? And lastly, the role of the above variables as related to the fundamental mechanism of stress accelerated grain boundary oxidation cracking. The effect of modification of surface residual stresses on stress accelerated grain boundary oxidation will also be examined.

The following literature review will cover the extent of research into oxygen embrittlement phenomena in Ni-Fe base superalloys. An interesting point of comparison is that the heat treatment temperature selected for the International Thermonuclear Experimental Reactor conductor, $650^{\circ} \mathrm{C}$, corresponds to the prevalent temperature used for high temperature gas turbine materials research. The difference is that the International Thermonuclear Experimental Reactor magnet coil will be required to undergo a single cycle high temperature exposure corresponding to $\mathrm{Nb}_{3} \mathrm{Sn}$ heat treatment, while the turbine materials face multiple cycles over their lifetimes. 


\section{LITERATURE REVIEW}

When the literature is reviewed with respect to the specific topic of stress accelerated grain boundary oxidation in low coefficient of expansion iron-nickel base superalloys, there appears to be a dearth of information on this specific phenomenon. When the search is expanded to cover the area of oxygen embrittlement in fcc materials in general, and $\mathrm{Ni}$ or $\mathrm{Ni}-\mathrm{Fe}$ base superalloys in particular, a large area of research that has developed in the past two decades emerges.

There are three primary areas of research that deal with oxygen's intergranular behavior. The first of these are studies that are concerned with the effect of oxygen embrittlement on high temperature fatigue, creep and stress rupture in $\mathrm{Ni}$ and $\mathrm{Ni}-\mathrm{Fe}$ base superalloys. Second are intergranular oxidation studies covering a range of materials. In many aspects, these first two areas overlap. Finally, research into intergranular embrittlement by oxygen of $\mathrm{Ni}_{3}(\mathrm{Ti}, \mathrm{Al})$ intermetallics has followed a somewhat parallel course to that of superalloys. The primary focus of this review will be the first of these topics, as it has the most direct connection with low coefficient of expansion iron-nickel base superalloys. Coincident research in intergranular oxidation and intermetallics will be covered where applicable to stress accelerated grain boundary oxidation and points of similarity reviewed. This review is organized in a semi-chronological order that traces the development of understanding of oxygen effects on material properties. The nominal compositions of the superalloys mentioned in this review are given in Table $1 \mathrm{~A}$ in the Appendix.

The phenomenon of oxygen induced embrittlement in materials had been recognized early on to explain differences in mechanical behavior between vacuum and air. While the success of most high temperature alloys has not been hampered by its existence, there are different degrees to which this phenomenon manifests itself, depending upon the material.

The list of $\mathrm{Ni}$ and $\mathrm{Ni}-\mathrm{Fe}$ base superalloys that have been reported to exhibit intergranular oxygen effects is fairly extensive. With respect to the effect of oxygen on fatigue fracture, two reviews provide a fairly wide coverage. Ericsson provides an extensive listing of researchers and materials studied, in which the effect of oxygen on fatigue fracture has been examined. [38] Gell and Duquette have reviewed some of the proposed mechanisms for oxygen's effect on fatigue fracture. [39] A more recent work by Pineau provides an update on some of these mechanisms and provides a more specific overview of oxidation related mechanisms. [40] 


\section{A. Fatigue Crack Growth Rate in Air Versus Vacuum}

Early studies on fatigue crack growth reported on the interaction of oxidation processes with dislocation motion that prevents slip band reversal. [41, 42] Other researchers reported higher crack growth rates for fatigue tests performed in air compared with those performed in vacuum. $[43,44]$ The effect of oxygen can be seen on transgranular and single crystal crack growth rates, as well as intergranular crack growth. [39] . In examining these studies, it is important to distinguish between intergranular and transgranular effects. The stress accelerated grain boundary oxidation phenomenon in low coefficient of expansion iron-nickel base alloys is essentially an intergranular effect, so the following discussion will center on behavior leading to increased intergranular crack growth rates.

Intergranular crack growth during fatigue loading is encountered at high temperatures (above $500^{\circ} \mathrm{C}$ ), in combination with oxygen containing environments and low frequencies $(\leq 0.05 \mathrm{~Hz}) .[45,46,47,48,49,50,51,52]$ Similar environmental effects have been found in creep crack growth studies on $\mathrm{Ni}$-base and $\mathrm{Ni}$-Fe base superalloys. [46, 53, 54, $55,56]$ The fatigue crack growth process is time dependent if it increases with increasing temperature and/or decreasing frequency, at which time the crack path changes from transgranular to intergranular. [57] In contrast to dynamic loading, under static loading, the crack growth processes are completely time dependent. Sadananda, et al., reviewed the effects of test variables and environment on crack growth in Ni-base superalloys. [58] The time dependent fatigue crack growth regime is where intergranular stress assisted oxidation is found to occur. Merrick, et al., observed significant increases in crack growth at low frequencies at $650^{\circ} \mathrm{C}$ in Waspaloy and $\mathrm{P} / \mathrm{M}$ Astroloy. [46] The increased fatigue crack growth rate was associated with a transition to intergranular crack propagation. This is illustrated in Figure 2 that shows how the crack growth mechanism changes with frequency and temperature in air. Oxidation assisted fatigue crack growth rate in alloy 718 at $650^{\circ} \mathrm{C}$ increases as the fatigue frequency is decreased, and when a tensile hold time is superimposed on the fatigue cycle. $[45,47,48,50,54,51]$ Pédron, et al., attributed these results in alloy 718 to stress-assisted oxidation. A plot of their $\mathrm{da} / \mathrm{dN}$ versus frequency data is shown in Figure 3, to illustrate the effect of decreasing frequency. The slope of the $\mathrm{da} / \mathrm{dN}$ versus frequency curve at low frequencies, and $650^{\circ} \mathrm{C}$ was found to close to -1. [47] This indicates that at low frequencies the fatigue crack growth rate is time dependent. As occurs in corrosion fatigue, the reason that time dependency becomes prevalent at lower 
frequencies is because there is more time for environmental attack to occur. The plot shown in Figure 4 illustrates the effect of hold time on the fatigue crack growth ratio $(\mathrm{da} / \mathrm{dN})_{\text {hold }} /(\mathrm{da} / \mathrm{dN})$. The mechanical and environmental variables found to influence fatigue crack growth in alloy 718 have been catalogued in two recent review papers by Ghonem, et al. [51, 59]

Floreen and Kane performed an extensive study on the effects of many different furnace environments on fatigue crack growth in alloy 718. [60] Their test methodology utilized low frequency (less than $0.1 \mathrm{~Hz}$ ) fatigue loading to study environment-dependent crack growth. Another factor considered in their study was the water vapor concentration in the test atmosphere. Here, Floreen and Kane found that relatively high amounts $(50,000$ $\mathrm{ppm}$ ) of water vapor in He produced fatigue crack growth rates comparable to those in 100 ppm oxygen in He. The same amount of water vapor in hydrogen gas produced fatigue crack growth rates between those of air and helium. The addition of water vapor to air did not result in any significant increase in fatigue crack growth rate. They concluded from $\mathrm{He}$ plus oxygen and the He plus water vapor tests that oxygen was produced by the reaction between the alloy and water vapor, and was responsible for the increase in fatigue crack growth rate. [60] Gell, et al., showed no difference in cycles to failure in wet versus dry air in single crystal MAR-M200. [39] The same material showed large differences between air and vacuum behavior. [39]

\section{B. Tensile Embrittlement and Stress Rupture Life}

Results from Chang's early research showed high temperature tensile embrittlement of several Ni-base superalloys. He attributed this embrittlement to interactions between grain boundary $\gamma^{9}$ and oxygen. [61]

In a series of papers, Woodford and Bricknell examined the effect of intergranular oxygen diffusion on the tensile embrittlement in different purity grades of Ni. [62, 63, 64, 65] Their test methodology involved very high temperature $\left(1000^{\circ} \mathrm{C}\right)$ air or vacuum 


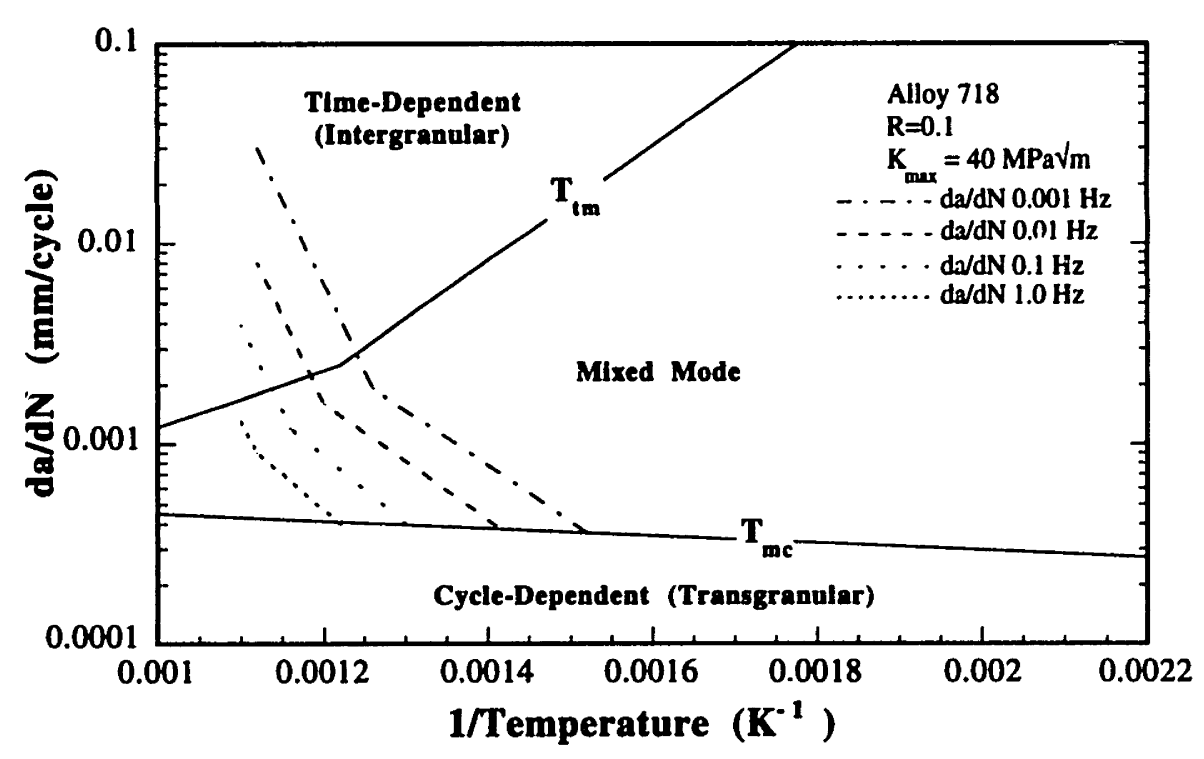

Figure 2. Crack growth rate in air as a function of temperature at, $K_{\max }=40 \mathrm{Mpa} \sqrt{\mathrm{m}}$, showing the change in micromechanism of crack growth with changes in frequency. $T_{\mathrm{tm}}=$ Mixed mode to intergranular transition temperature. $T_{m c}=$ Mixed mode to transgranular transition temperature. From Ghonem, et al., [51]

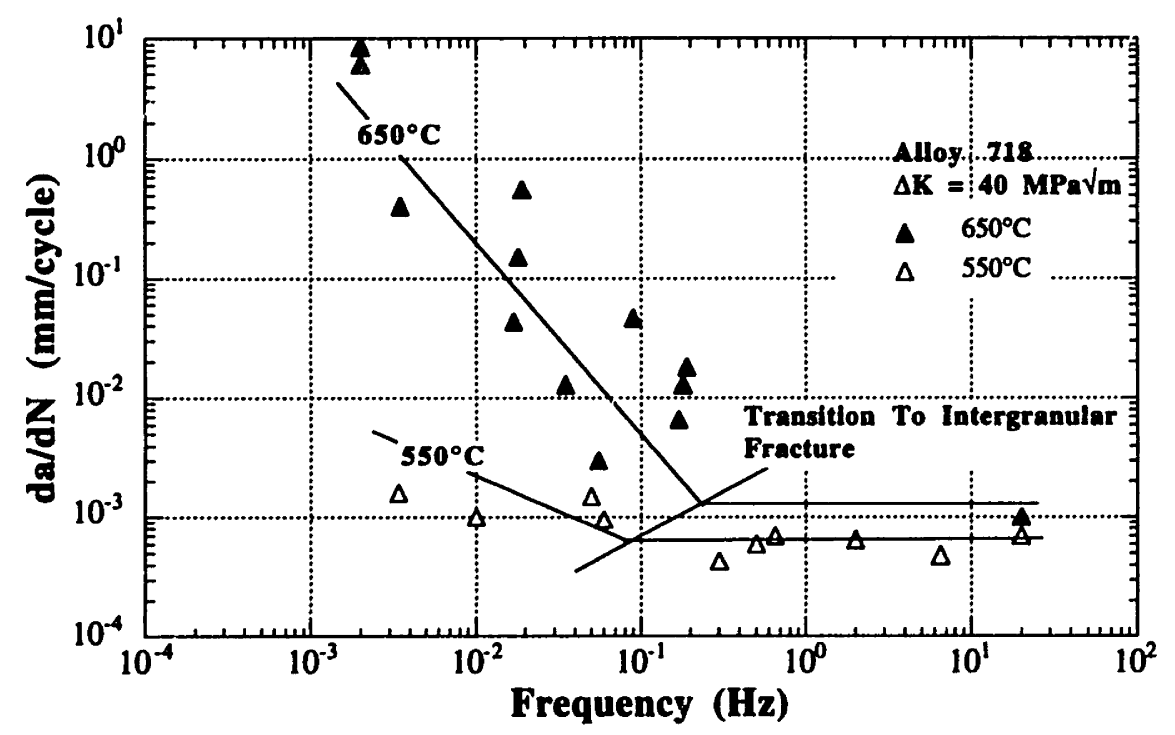

Figure 3. Variation in fatigue crack growth rate with test frequency and temperature for alloy 718 at 550 and $650^{\circ} \mathrm{C}(\Delta \mathrm{K}=40 \mathrm{Mpa} \sqrt{\mathrm{m}})$. From Pedron, et al., [47] 


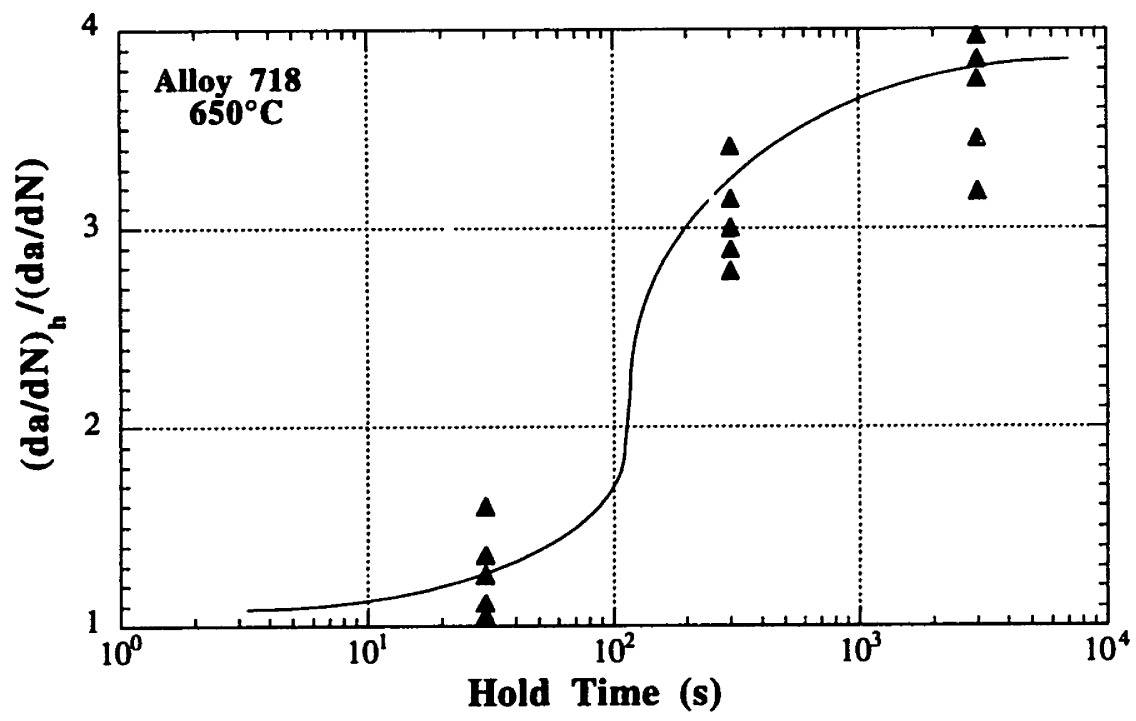

Figure 4. Effect of a hold time applied at zero load on the fatigue crack growth rate ratio $\left(\mathrm{da} / \mathrm{dN}_{\text {hold }}\right) /(\mathrm{da} / \mathrm{dN})$ in alloy 718. From Pineau. [40]

exposure followed by tensile tests in argon ( $>99.996 \%$ Ar) at temperatures ranging from 25 to $1000^{\circ} \mathrm{C}$. Through the use of a series different test atmospheres they identified oxygen as the embrittling species. The effect of oxygen on the temperature dependence of tensile embrittlement was postulated to be the result of decreased grain boundary mobility as a result of oxygen penetration. $[62,63]$ The intergranular fractures and metallographic cross sections produced in their experiments showed clear signs of grain boundary cavitation. Based on experimental results for $\mathrm{Ni}$, they surmised that cavity formation was the result of the gaseous byproduct of a reaction between carbon and oxygen, and occurred at oxygen partial pressures below those at which $\mathrm{NiO}$ is stable. [64] The same work reported general internal oxidation along with the formation of grain boundary oxides. Pandey, et al., reported reductions in creep life in alloy X-750 that they attributed to intergranular cavity formation at low $\mathrm{P}\left(\mathrm{O}_{2}\right)$. [66] Although metallographic cross sections from this work showed clear intergranular oxidation, no fracture surfaces were shown to confirm that intergranular cavitation had occurred. Iri addition to studies on $\mathrm{Ni}$, Bricknell and Woodford also examined the effect of prior air exposure on the stress rupture life of some Ni-base and Co-base superalloys. [67, 68] Woodford found that prior exposure in air at 900 and $1000^{\circ} \mathrm{C}$ of the cast alloy 738 resulted in severe loss of ductility and rupture life. [68] An important finding from this study that may have application to low coefficient of expansion iron-nickel base superalloys is that Co-base coatings (CoCrAlY) were found to 
be more effective at preventing oxygen damage than Ni-base coatings. Related to this study was the finding, based on stress rupture and tensile tests, that Co-base superalloys are somewhat immune to oxygen damage. [67] In one of the first comprehensive studies on low coefficient of expansion iron-nickel base superalloys, Bricknell and Woodford proposed an alternate mechanism for stress accelerated grain boundary oxidation in these alloys. [28, 29] From their analysis of samples that had received comparable high temperature air or vacuum exposure prior to testing, Bricknell and Woodford proposed an alternate mechanism. They suggested that a grain boundary is first embrittled by intergranular oxygen diffusion, the embrittled grain boundary fails in tension, and the newly-exposed surfaces are then oxidized. $[28,29]$ The process propagates as oxygen diffuses down the grain boundary ahead of the crack tip, embrittling the next segment of grain boundary. This was based on their observation that there was no preferential grain boundary oxidation of these alloys in the absence of stress, i.e., no intergranular oxidation preceding cracking. Of most importance is the link their work provided between the oxygen effects in high temperature fatigue and creep behavior to the stress accelerated grain boundary oxidation phenomena in low coefficient of expansion iron-nickel base superalloys. [32] Their mechanism can be compared to the earlier mechanism suggested by McMahon and Coffin. [31] The mechanism they proposed starts with intergranular oxidation. The intergranular oxide then cracks in tension, allowing new oxide to form at the crack tip, with the process then repeating itself. A schematic illustration of the two mechanisms is shown in Figure 5.

One problem with using Bricknell and Woodford's analysis of this phenomenon is that they utilized high temperature $\left(100\right.$ hours at $1000^{\circ} \mathrm{C}$ ) air exposure, essentially in the realm of intergranular oxidation, prior to testing. $[28,29]$ Since no TEM studies on this particular alloy were included, it cannot be assumed that intergranular oxidation had not occurred during the high temperature exposure. Although tests were performed on samples in which the internal oxide zone was machined away, as will be discussed in a coming section, intergranular oxidation can extend beyond the internal oxide zone. Also, based on their work with oxygen embrittlement in $\mathrm{Ni}$, they dismissed any direct role of grain boundary microstructure in superalloys as being necessary for oxygen embrittlement. Subsequent work by other researchers has shown that grain boundary microstructure does play an indirect role in oxygen embrittlement, and this topic will be discussed next. 


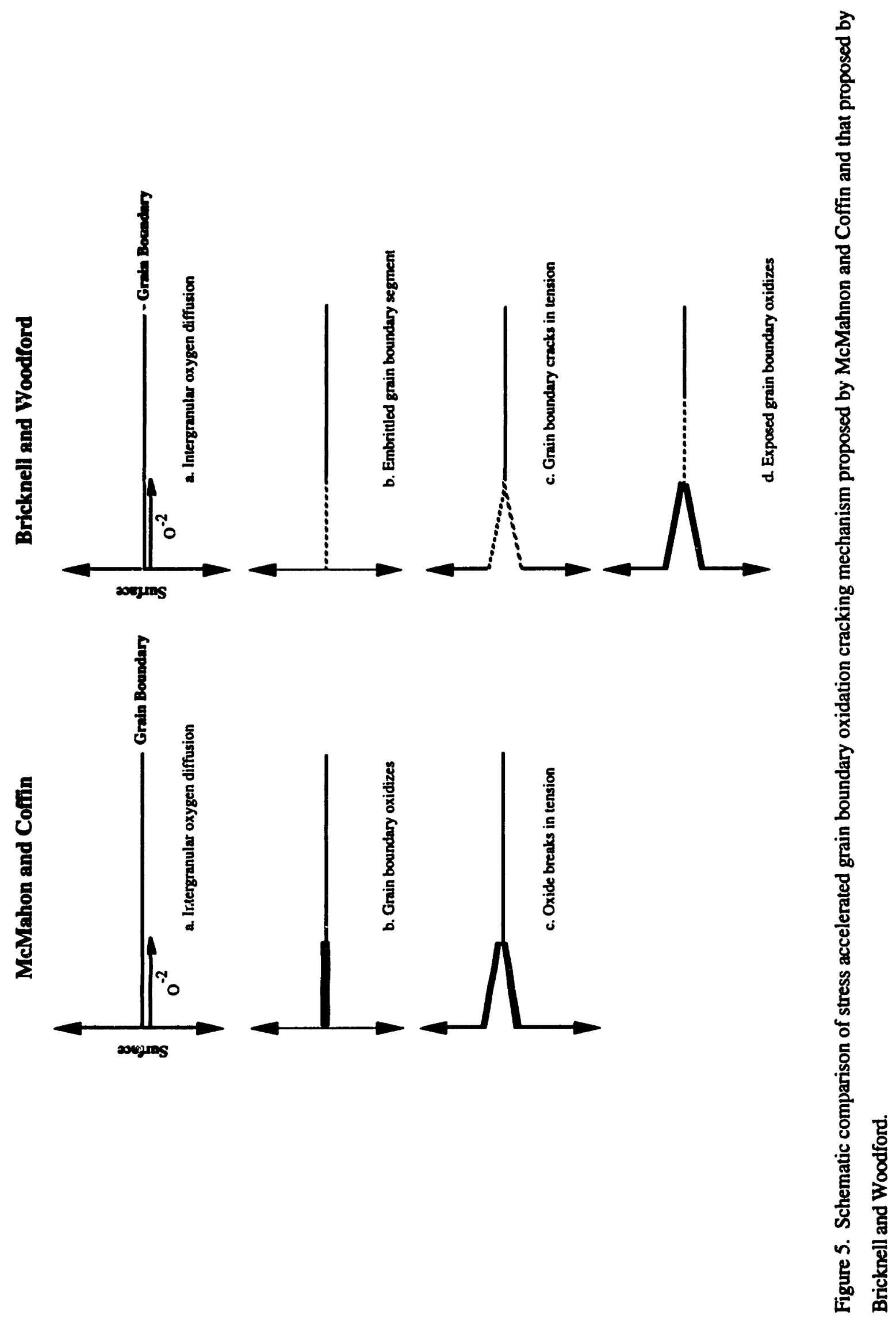




\section{Role of Microstructure and Alloy Chemistry}

The role of grain boundary microstructure appears to influence oxygen embrittlement in two ways. First, and most directly, grain boundary phases act to getter oxygen diffusing along the grain boundary by oxidizing. Second, and less directly, the precipitation and growth of intergranular phases alters grain boundary chemistry, and hence oxidation characteristics.

Pédron, et al., reported three microstructural features in alloy 718 that reduced the creep crack growth rate in air. [47] Those were increased grain size, coarsening of the $\gamma^{\prime \prime}$ $\left(\mathrm{Ni}_{3} \mathrm{Nb}\right)$ strengthening precipitate, and intergranular precipitation of orthorhombic $\delta$ $\left(\mathrm{Ni}_{3} \mathrm{Nb}\right)$. Chang found that a deformed grain structure in alloy 718 reduced the fatigue crack growth rate but found less grain size dependence. [50] Floreen, et al., reported that overaging of alloy 718 reduced both the fatigue and creep crack growth rates. [45] Coarse grain size has been reported to reduce crack growth rates. [46] Oxidation of primary ( $\mathrm{Nb}, \mathrm{Ti}) \mathrm{C}$ carbides has been observed in many superalloys, and it has been suggested that preferential carbide oxidatior may be a factor that contributes to grain boundary embrittlement. [31, 56, 69]

Woodford found that hafnium and boron additions to alloy 738 alleviated the detrimental effects of oxygen. [68] Other work showed that boron added to $\mathrm{Ni}$ and alloy 903A segregated to grain boundaries due to its low matrix solubility and eliminated intergranular embrittlement. $[28,29,65]$ Chang reported that $\mathrm{Cr}$ additions to alloy 718 improved cracking resistance in the time dependent fatigue crack growth regime. [50].

Early work by Wilson examined the effect of microstructure on stress-rupture properties of alloys 718 and Waspaloy. [70, 71] He reported time-dependent notch sensitivity in the temperature range of $482-649^{\circ} \mathrm{C}$, with cracking occurring in the intergranular mode. Overaging resulted in reduced notch sensitivity. In alloy 718 the overaging treatment that resulted in improved properties introduced intergranular $\delta$ (orthorhombic $\mathrm{Ni}_{3} \mathrm{Nb}$ ) phase. These results were similar to those of Pédron discussed above. Other grain boundary microstructures can have detrimental effects on stress rupture properties. Reductions in stress rupture lives have been reported in $\mathrm{Ni}$-base superalloys in which intergranular $\gamma$ precipitation occurs. [61, 72]

The experimental results cited above are of particular interest since changes in intergranular microstructure that have been reported to reduce fatigue and creep crack growth rates and improve stress rupture properties are similar to those used to reduce the 
suscentibility to stress accelerated grain boundary oxidation of low coefficient of expansion iron-nickel base superalloys. Reducing or eliminating Al from low coefficient of expansion iron-nickel base superalloys appears to be somewhat effective in reducing the effect of stress accelerated grain boundary oxidation. [30] This is an indirect benefit that appears to result from increasing the concentrations of the other hardening elements, $\mathrm{Nb}$ in particular. This makes the alloy's microstructure more susceptible to overaging by changing the strengthening precipitate from $\gamma^{\prime}$ to $\gamma^{\prime}$. The higher $\mathrm{Nb}$ concentration results in a complex, intergranular microstructure containing $\mathrm{Nb}$-rich phases. It is for this reason that alloys 905,907 , and 909 have reduced levels of aluminum. [30] Alloy 907 (also designated 903A), for example, depends upon its low aluminum content (less than 0.1 wt.\%) and heat treatment to generate $\mathrm{Nb}$-rich intergranular phases to improve stress rupture life. [30] Adding Si to alloy 909 has improved the notch rupture strength of this alloy. Studies suggest that the improvement in stress accelerated grain boundary oxidation resistance was due to the formation of intergranular iron silicides. [36] Recently, it has been found that stress accelerated grain boundary oxidation resistance could be improved by increasing the $\mathrm{Al}$ content to above $5 \mathrm{wt} . \%$. [73] This improvement was correlated with the formation of coarse, intergranular $\beta$ (bcc NiAl) phase.

Additions of boron, hafnium and zirconium have been shown to improve the resistance of low coefficient of expansion iron-nickel base superalloys to stress accelerated grain boundary oxidation, though their effectiveness appears to depend upon alloy chemistry. $[28,29,30,36,74]$

\section{The Effect of Oxygen Partial Pressure}

The composite goal of all the research categorized above was to attain an understanding of how the chemistry of oxygen and the affected grain boundary interacts to produce embrittlement. This is particularly important if oxidation is part of the embrittlement mechanism. Similar studies in aqueous systems appear to be more detailed with respect to understanding the various chemical relationships. [75]

The studies cited above have focused on changes that occur when testing is performed either in air versus vacuum or in air versus inert gas. One problem with the use of inert gas testing is that a finite oxygen concentration is present in most "inert" gases. Experiments that are more pertinent to understanding and controlling furnace atmospheres to prevent stress accelerated grain boundary oxidation in alloy 908 are those that have studied the 
effect of changing the partial pressure of oxygen during testing. These studies are less numerous in the literature.

In most cases, the effect of changing oxygen partial pressure manifests itself as a sigmoidal curve, with the abscissa being the partial pressure of oxygen and the ordinate some mechanical test parameter. Typically, the upper and lower plateaus in these curves correspond to oxygen partial pressures above or below which the test parameter shows no change. An early study by Achter, et al., showed that the reverse bending fatigue strength of $\mathrm{Ni}$ and Type 316 stainless steel decreased with increases in oxygen pressure. [44] For $\mathrm{Ni}$, they found a leveling off point in cycles-to-failure at oxygen partial pressures below $1 \times 10^{-3}$ Torr at $300^{\circ} \mathrm{C}$ and below $1 \times 10^{-4}$ Torr at $816^{\circ} \mathrm{C}$. Smith, et al., observed a similar transition in the fatigue crack growth of type 316 stainless steel occurring near $5 \times 10^{-4}$ Torr at $500^{\circ} \mathrm{C}$ and at approximately $1 \times 10^{-3}$ Torr at $800^{\circ} \mathrm{C}$. [43] The mode of cracking in this experiment was transgranular. Smith, et al., performed similar experiments on $\mathrm{Ag}$ and found a transition in fatigue crack growth rate at an oxygen pressure partial pressure of $1 \times 10^{-2}$ Torr at $21^{\circ} \mathrm{C}$. [76] Interestingly, a transition in fatigue crack growth rate was not observed at $350^{\circ} \mathrm{C}$ and was attributed to the instability of $\mathrm{AgO}$ at that temperature.

\section{E. Effects of Oxygen Partial Pressure and Stress on Intergranular Oxidation}

With the exception of the early studies described above, surprisingly few studies have been carried out to study the effect of oxygen partial pressure on fatigue or creep crack growth rate until relatively recently. Most of the recent research in this area has been focused on alloy 718, and many of the results from work on that alloy may be applicable to understanding the oxygen embrittlement phenomenon in alloy 908 .

One of the most recent and complete studies that examined the effect of changing oxygen partial pressure on intergranular crack tip oxidation in fatigue was performed by Andrieu. $[77,78,79]$ Similar to the results of earlier research described above, Andrieu observed a change in fatigue crack growth rate with changing oxygen partial pressure. A plot illustrating his $\mathrm{da} / \mathrm{dN}$ versus oxygen partial pressure results is shown in Figure 6. As seen in this figure there are two transitions in da/dN, one between $1 \times 10^{-3}$ and $1 \times 10^{-2}$ Torr and the other near 1 Torr. The most significant result of this research is the proposal of a crack tip oxidation mechanism to explain the effects seen with changes in oxygen partial pressure. [78] Unlike earlier work, this research involved fairly detailed analysis of the oxidation products formed on fracture surfaces.

The mechanism they proposed is linked to the slow strain rate test results for 718 that showed an increase in the percent intergranular fracture surface with increasing oxygen 
partial pressure. [77] These results are shown in Figure 7. A transition between all intragranular fracture and mixed transgranular/intergranular was found to occur between $1 \times 10^{-4}$ and $1 \times 10^{-3}$ Torr. The relationship between percent intergranular fracture and oxygen partial pressure is similar to the fatigue crack growth rate behavior observed for alloy 718 as a function of oxygen partial pressure. [79] These results were correlated with Andrieu's Auger analysis of oxides formed on electropolished surfaces of alloy 718 at $650^{\circ} \mathrm{C}$. [77] In this analysis, the composition of the oxide(s) formed was determined as a function of oxygen partial pressure. The results are illustrated in Figure 8. [77] The transition time was not quantified but estimated to be equal to $1000 \mathrm{~s}$ for alloy 718 . This value was based on the fatigue loading hold time after which there was no further increase in the crack growth rate. This hold time was termed the "oxide saturation" time by Andrieu. [78] The curve shown in Figure 4 illustrates the plateau in fatigue crack growth rate with increasing hold time after $1000 \mathrm{~s}$. Fatigue loading hold time experiments on alloy 718 latter determined the "oxide saturation" time to be $600 \mathrm{~s}$. [78]

Based on the similarity in the surface oxidation behavior and the sigmoidal shape of the percent intergranular fracture versus oxygen partial pressure curve a two-stage oxidation was hypothesized. In the proposed mechanism, at high oxygen partial pressures, the first stage of oxide formation would be predominated by the formation of $\mathrm{FeO}$ and $\mathrm{NiO}$ and their spinels. [78] This is shown in the Auger results in Figure 8. After a transition time, $\mathrm{T}_{\mathrm{p}}$, the porous ( $\left.\mathrm{Ni}, \mathrm{Fe}\right) \mathrm{O}$ external oxide would reduce the oxygen partial pressure at the (Ni,Fe)O-metal interface low enough for $\mathrm{Cr}$-rich oxides to be favored. The kinetics of this process depends upon; the diffusion rate of oxygen through the porous $(\mathrm{Ni}, \mathrm{Fe}) \mathrm{O}$, temperature, $\mathrm{P}\left(\mathrm{O}_{2}\right)$, and localized stress and strain. [78] After the transition time, the $\mathrm{Cr}$ rich oxide sublayer is fully developed and passivates the material by blocking further oxygen diffusion. A related diagram is shown in Figure 9 and illustrates the effect of surface preparation on oxidation of alloy 718. [40] As seen in this illustration, imposing a compressive residual stress on the surface of alloy 718 favors the formation of $\mathrm{Cr}$-rich oxides over the entire oxygen partial pressure range. In contrast, mechanical polishing results in the formation of duplex oxide types with the same oxygen partial pressure dependency seen for electropolished surfaces. Ghonem and Zheng have developed a model that attempts to quantify many of the above experimental observations. [80, 81] In correspondence to Andrieu's work, they invoke a two-stage oxidation process to explain fatigue crack tip oxidation. Their proposed model depends upon the rate of formation of $\mathrm{Cr}$-rich versus that of other oxide types. In this model, the rate at which $\mathrm{Cr}$-rich oxides form depends upon both the intergranular diffusion of oxygen and the transport of $\mathrm{Cr}$ from the alloy matrix via a mobile dislocation network. [80] 


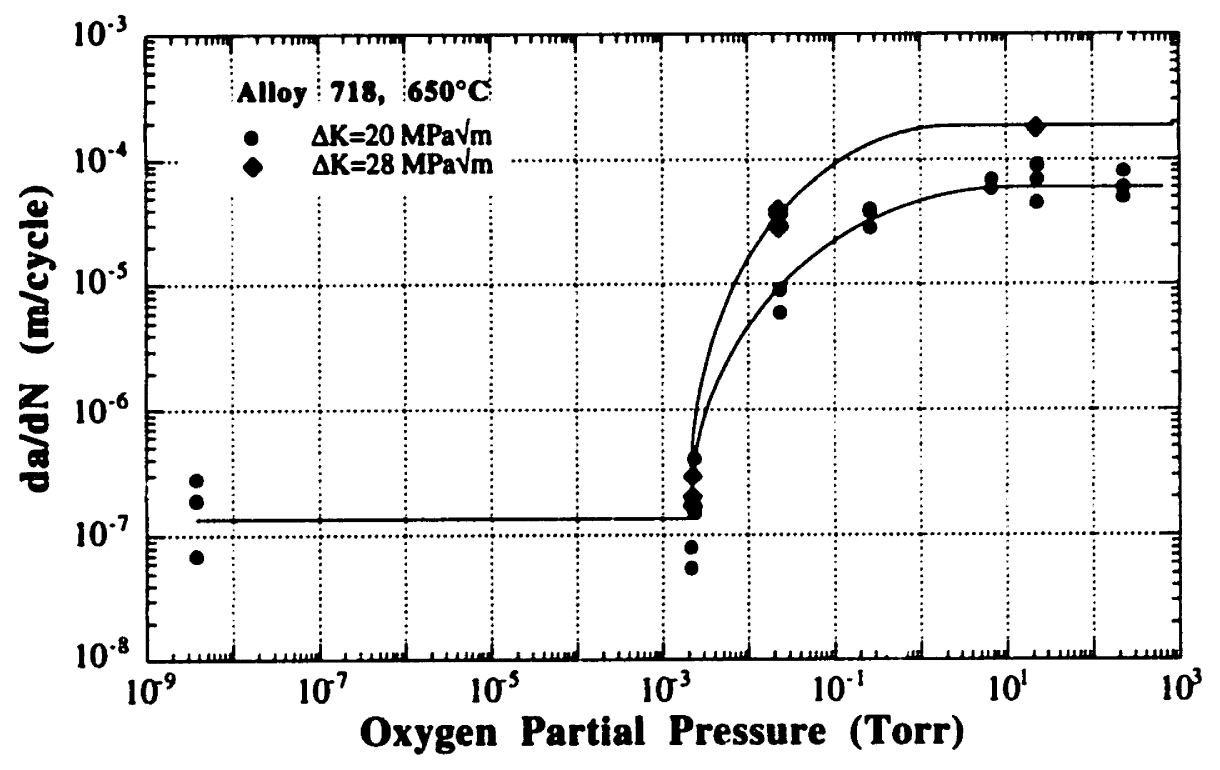

Figure 6. Fatigue crack growth rate as a function of the oxygen partial pressure under constant $\Delta K(20$ and $28 \mathrm{Mpa} \sqrt{\mathrm{m}}$ ) at $650^{\circ} \mathrm{C}$ in alloy 718 . From Andrieu, et al. [79]

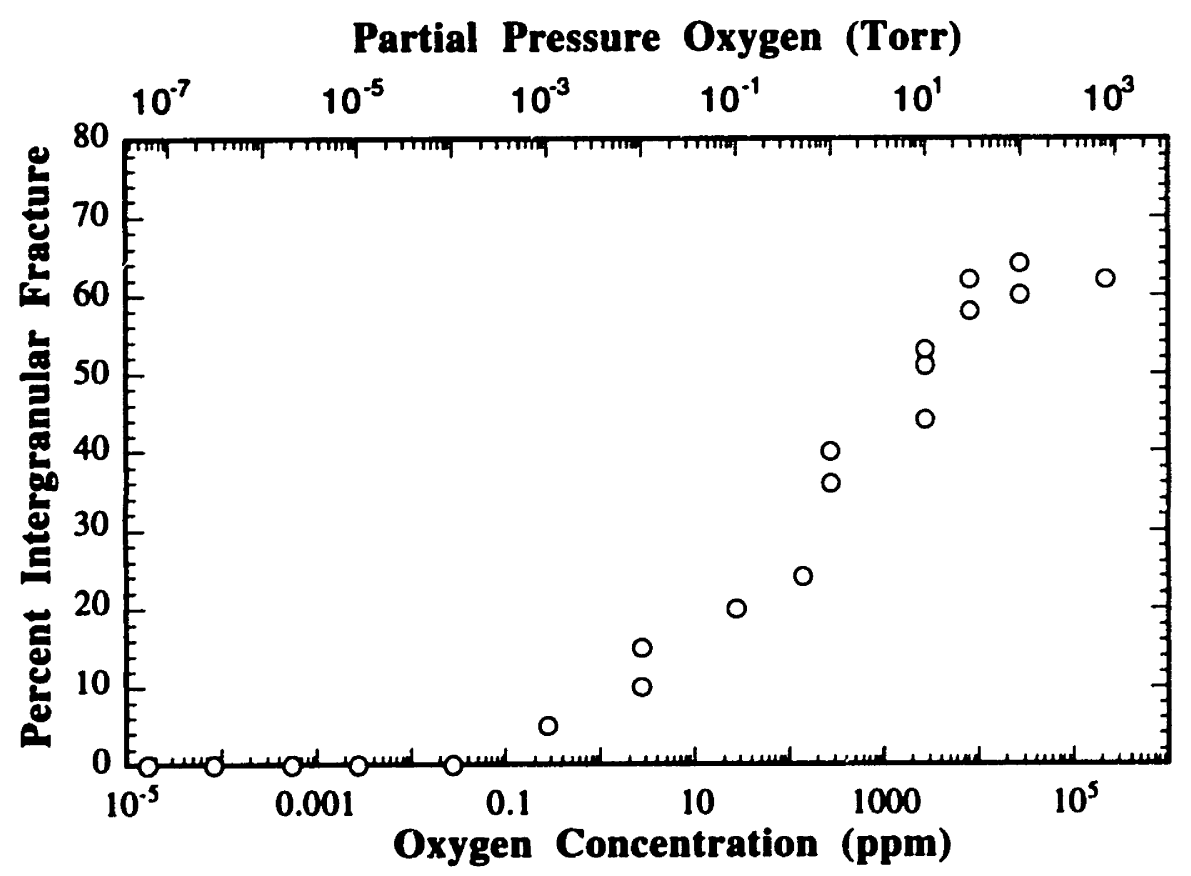

Figure 7. Percent intergranular fracture in alloy 718 slow strain rate test $\left(8.3 \times 10^{-4} \mathrm{~mm} / \mathrm{s}\right)$ at $650^{\circ} \mathrm{C}$ versus oxygen partial pressure. Data from Andrieu. [77] 


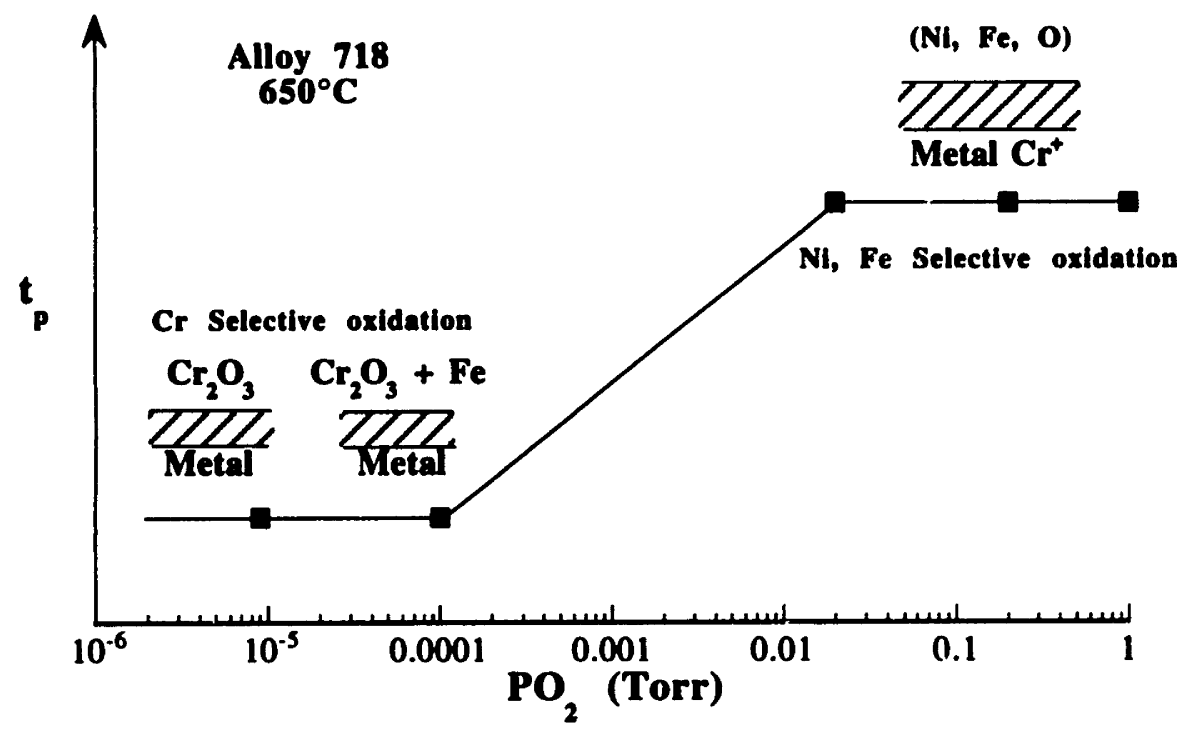

Figure 8. Results of oxide identification by Auger spectroscopy on electropolished specimens of alloy 718 , showing transition time, $t_{p}$, between both forms of oxides as a function of oxygen partial pressure. From Pineau. [40]

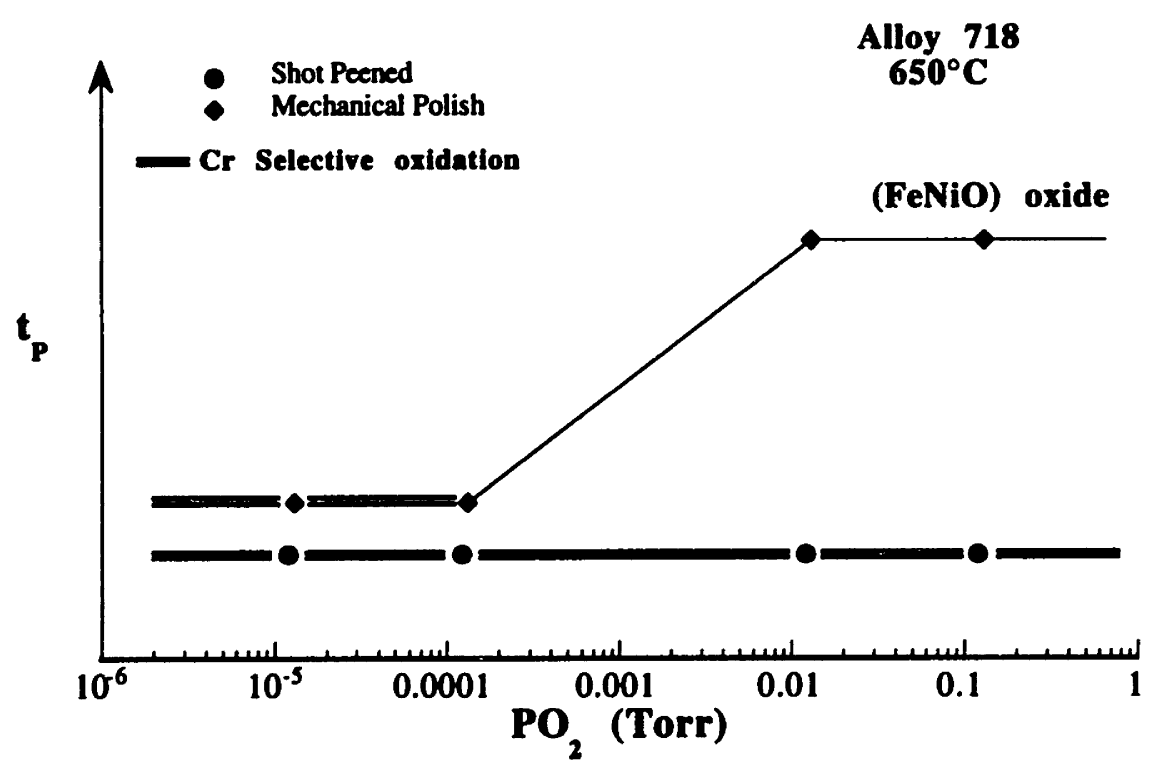

Figure 9. Influence of residual stresses on the transition in oxidation mechanism. $\mathrm{Cr}$-rich oxide is preferentially formed on shot peened specimens of alloy 718 at $650^{\circ} \mathrm{C}$. From Pineau. [40] 


\section{F. Intergranular Oxidation}

With the research cited above concerning oxide formation the relevance of controlled oxygen partial pressure becomes more apparent. Studies on $\mathrm{Ni}-\mathrm{Cr}$ alloys provide some clues as to the effect of oxygen partial pressure and $\mathrm{Cr}$ concentration on intergranular oxidation. Rapp has classified the $\mathrm{Ni}-\mathrm{Cr}$ system as Class 3. [82] Materials that fall into this class are dilute alloys of the base metals $\mathrm{Ni}, \mathrm{Fe}$, Co alloyed with $\mathrm{Cr}, \mathrm{Al}, \mathrm{V}$, and $\mathrm{Ti}$. [82] Because their oxidation behaviors fall into the same class, the oxidation of $\mathrm{Ni}-\mathrm{Cr}$ alloys can be used to model oxidation of $\mathrm{Ni}$ and $\mathrm{Ni}-\mathrm{Fe}$ base superalloys. $[82,83]$ The primary oxide types ( $\mathrm{NiO}$ and $\mathrm{Cr}_{2} \mathrm{O}_{3}$ ) formed in this class are p-type, cation deficient. The surface oxide is formed by cation diffusion from the metal into the scale and then through the scale to the oxide/gas interface.

Intergranular oxidation can be defined as oxide formation at prain boundaries that extends deeper into an alloy than predicted by internal oxidation. [84] Internal oxidation is the process by which oxygen diffuses into an alloy and causes subsurface precipitation of the oxides of one or more alloying elements. $[82,85]$ The alloying elements that oxidize must form oxides that are more thermodynamically stable than those of the solvent metal. [86] For internal oxidation without external scaling, the oxygen partial pressure in the environment must be greater than that required to oxidize the alloying element but less than that required to oxidize the solvent metal. [85] Under internal oxidation conditions, grain boundary oxide precipitation is favored because grain boundaries are preferred nucleation sites and the oxidizable alloying elements may be segregated at the grain boundaries. [85] The combination of the low solubility of oxygen in $\mathrm{Ni}$ and the fast grain boundary path for oxygen diffusion promotes intergranular oxidation. Based on internal oxidation experiments, the lattice diffusivity of oxygen in $\mathrm{Ni}$ has been estimated to be $1.14 \times 10^{-11} \mathrm{~m}^{2} / \mathrm{s}$ at $1000^{\circ} \mathrm{C}$, and approximately $4.27 \times 10^{-16} \mathrm{~m}^{2} / \mathrm{s}$ at $650^{\circ} \mathrm{C}$. $[87,88] \mathrm{In}$ contrast, the grain boundary diffusivity in $\mathrm{Ni}$ has been estimated to be on the order of $2.5 \times 10^{-12} \mathrm{~m}^{2} / \mathrm{s}$ at $650^{\circ} \mathrm{C}$. [89] These estimates were obtained from Hwang and Balluffi's work. [89] Grain boundary diffusion of the oxidizable solute elements can also be expected to be faster than lattice diffusion. In a $\mathrm{Ni}-20 \mathrm{Cr}$ alloy at $1000^{\circ} \mathrm{C}$, for example, the ratio of tracer diffusion coefficients of $\mathrm{Cr}$ and $\mathrm{Ni},\left(\mathrm{D}^{*}{ }_{\mathrm{C}} / \mathrm{D}^{*}{ }_{\mathrm{Ni}}\right)_{\mathrm{g} . \mathrm{b}}$, equals 11. [90] For lattice diffusion in $\mathrm{Ni}-\mathrm{Cr}$ alloys at $1020^{\circ} \mathrm{C},\left(\mathrm{D}^{*}{ }_{\mathrm{C}} / \mathrm{D}^{*}{ }_{\mathrm{Ni}}\right)_{\text {latrice }}$ equals 1.7. [90] Also, as the temperature is lowered, grain boundary diffusion of $\mathrm{Cr}$ becomes more rapid relative to lattice diffusion. 
Some general observations on the oxidation of $\mathrm{Ni}-\mathrm{Cr}$ alloys will be enumerated before citing specific experimental observations on intergranular oxidation in $\mathrm{Ni}-\mathrm{Cr}$ alloys.

- The critical minimum $\mathrm{Cr}$ content to ensure the formation of a protective surface oxide is approximately 20 to $25 \mathrm{wt} . \%$. [91].

- The oxide growth rate for $\mathrm{NiO}$ is faster than that of $\mathrm{Cr}_{2} \mathrm{O}_{3}$. $[83,92]$

- The fast growing $\mathrm{NiO}$ nuclei overgrow the slower growth $\mathrm{Cr}_{2} \mathrm{O}_{3}$ nuclei. [83]

- An intermediate layer of the spinel $\mathrm{NiCr}_{2} \mathrm{O}_{4}$ forms. $[82,83]$

- Preferential growth of the $\mathrm{Cr}_{2} \mathrm{O}_{3}$ layer down grain boundaries is linked to the short circuit diffusion path provided for $\mathrm{Cr}$ by the grain boundaries. [83, 91]

- The $\mathrm{Cr}_{2} \mathrm{O}_{3}$ sublayer grows laterally from grain boundary/surface intersections until it forms a continuous layer, this is illustrated in Figure 10. [83, 91]

- The surfaces of fine-grained materials develop better surface area coverage with $\mathrm{Cr}_{2} \mathrm{O}_{3}$ than large grain materials. A fine grain size results in more sites for diffusion of $\mathrm{Cr}$ and shorter lateral growth distances. [93]

- Growth of the $\mathrm{Cr}_{2} \mathrm{O}_{3}$ layer results in depletion of $\mathrm{Cr}$ from the matrix. [83, 91]

- For all Ni-Cr alloys with $\mathrm{Cr}$ mole fractions between $10^{-9}$ and 0.1 , the concentration of $\mathrm{Cr}$ in the matrix at the $\mathrm{Ni} / \mathrm{NiO}$ interface after internal oxidation should be approximately $10^{-3} \mathrm{ppm}$. [82]

- Between 800 and $1200^{\circ} \mathrm{C}$ and when the concentration of $\mathrm{Cr}$ is less than $5 \mathrm{wt} . \%$, $\mathrm{Cr}_{2} \mathrm{O}_{3}$ is formed internally both at grain boundaries and within the interior of the grains. Under these conditions the alloy is covered by a NiO layer. [91]

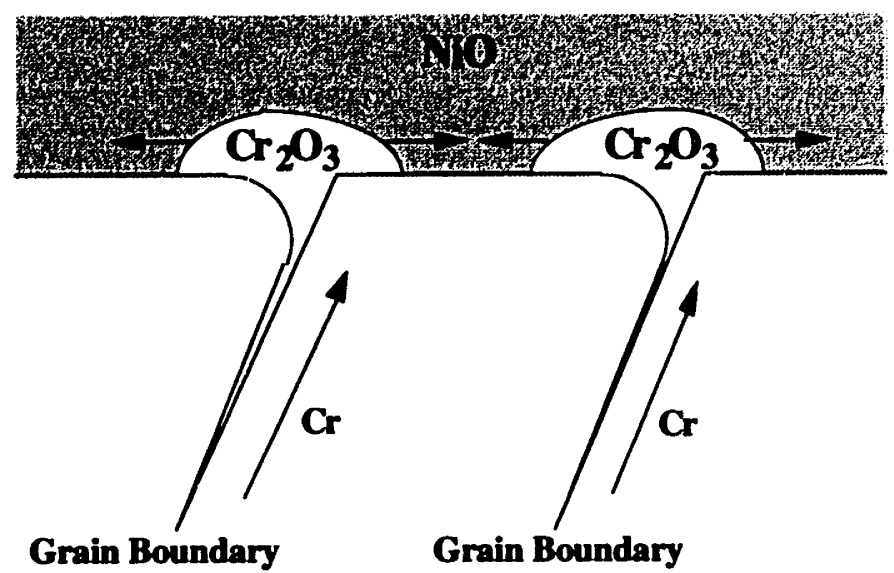

Figure 10. Lateral growth of $\mathrm{Cr}_{2} \mathrm{O}_{3}$ layer originating from grain boundaries. 
Research by Wood, et al., and by Shida, et al., has clarified the role of $\mathrm{Cr}$ in the intergranular oxidation in $\mathrm{Ni}-\mathrm{Cr}$ alloys. $[90,94]$ Shida, et al., correlated the depth of maximum penetration of intergranular oxide with the depth of the $\mathrm{Cr}$ depletion zone in a Ni40Cr alloy. [90] They postulated that the $\mathrm{Cr}$ depleted zone beneath the $\mathrm{Cr}_{2} \mathrm{O}_{3}$ layer allowed $\mathrm{Cr}_{2} \mathrm{O}_{3}$ to supply oxygen of sufficiently high activity to oxidize $\mathrm{Cr}$ deeper in the alloy. The generated oxygen penetrates down the grain boundary through a porous intergranular oxide to react with $\mathrm{Cr}$ and form $\mathrm{Cr}_{2} \mathrm{O}_{3}$ as an intergranular oxide. [90] A schematic based on their experimental results is shown in Figure 11. The voids formed at the matrix/oxidized grain interface were postulated to develop by vacancy injection as the $\mathrm{Cr}^{3+}$ ions incorporate into the oxide.

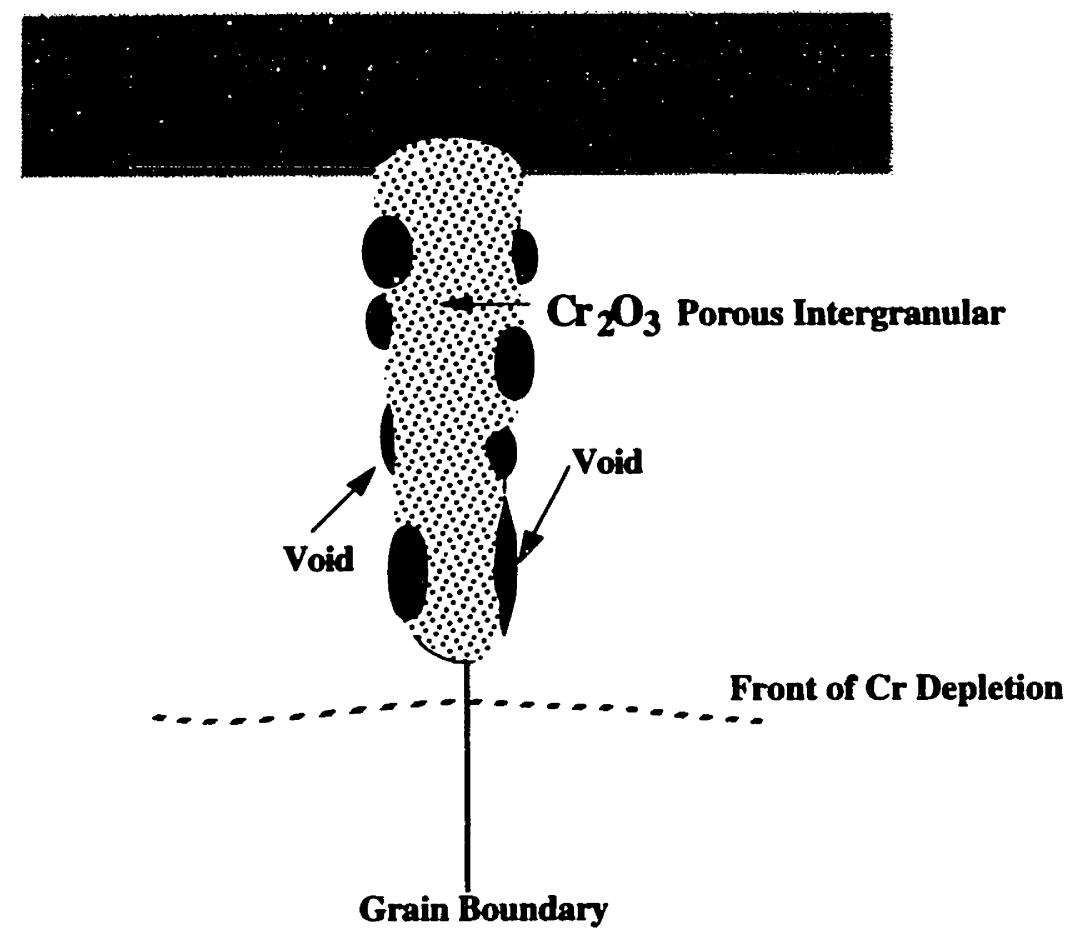

Figure 11. Intergranular oxide formation beneath $\mathrm{a}_{2} \mathrm{O}_{3}$ surface scale. From Shida, et al. [90]

Wood, et al., examined $\mathrm{Ni}-\mathrm{Cr}$ alloys with $\mathrm{Cr}$ concentrations ranging from 1 to $5 \mathrm{wt} . \%$. [94] One general observation from their study was that grain boundary diffusion was more significant than lattice diffusion at low temperatures $\left(<1000^{\circ} \mathrm{C}\right)$. Under low $\mathrm{P}\left(\mathrm{O}_{2}\right)$ conditions, they observed greater intergranular $\mathrm{Cr}_{2} \mathrm{O}_{3}$ formation than at high $\mathrm{P}\left(\mathrm{O}_{2}\right)$, where NiO formation was favored. [94] They tabulated the $\mathrm{Cr}$ concentration at the internal 
oxidation/intergranular oxidation front as a function of alloy $\mathrm{Cr}$ content, time, and temperature. Their data are shown in Table 2. Intergranular oxidation also resulted in a $\mathbf{C r}$ depletion zone adjacent to the oxidized grain boundaries. This was attributed to diffusion of $\mathrm{Cr}$ from grains adjacent to the grain boundary.

\section{Table 2. Chromium Concentration In Dilute Ni-Cr Alloys at the Advancing Front of Internal Oxidation. From Wood, et. al. [94]}

Test Condition $1100^{\circ} \mathrm{C}, 10 \mathrm{~h}$

$1000^{\circ} \mathrm{C}, 20 \mathrm{~h}$

$900^{\circ} \mathrm{C}, 40 \mathrm{~h}$

$800^{\circ} \mathrm{C}, 160 \mathrm{~h}$
Alloy

$\begin{array}{ll}\mathrm{Ni}-1 \% \mathrm{Cr} & 0.20 \\ \mathrm{Ni}-2 \% \mathrm{Cr} & 0.85 \\ \mathrm{Ni}-3 \% \mathrm{Cr} & 0.77 \\ \mathrm{Ni}-5 \% \mathrm{Cr} & 0.84 \\ \mathrm{Ni}-5 \% \mathrm{Cr} & 1.14 \\ \mathrm{Ni}-5 \% \mathrm{Cr} & 2.25 \\ \mathrm{Ni}-2 \% \mathrm{Cr} & 1.46 \\ \mathrm{Ni}-5 \% \mathrm{Cr} & 3.0\end{array}$

The composition and formation of intergranular oxides in $\mathrm{Ni}-15 \mathrm{Cr}-1.1 \mathrm{Al}$ alloys has been investigated by Stott, et al. [84]. They found the intergranular oxides that formed to be composed of $\mathrm{Al}_{2} \mathrm{O}_{3}$, with $\mathrm{Cr}_{2} \mathrm{O}_{3}$ growing within the intergranular voids formed by vacancy annihilation at the intergranular oxide/matrix interface. [84] It was postulated that, for $\mathrm{Al}$, the rate of diffusion down the grain boundaries was rapid. As a result, the diffusion of $\mathrm{Al}$ from the matrices of the adjacent grains was the rate limiting step for the formation of intergranular $\mathrm{Al}_{2} \mathrm{O}_{3}$.

The transition from external to internal oxidation is of importance since it links the effects of changes in oxygen partial pressure to intergranular oxidation. According to Rapp, the transition from internal to external oxidation is a passivation process. [82] In the case of internal/intergranular oxidation, the reaction proceeds until sufficient intergranular oxide precipitates form to block further reaction between oxygen atoms and solute atoms. [82] Rapp demonstrated the effect of oxygen partial pressure on the external to internal oxidation transition in his experiments on Ag-In alloys. [82] In these experiments he varied both the concentration of the internal oxidant indium and the partial pressure of oxygen. His results are shown in Figure 12. The effect of decreasing the partial pressure 
of oxygen and increasing the mole fraction of internal oxidant can be seen in this figure as promoting external oxidation or passivation. Based on these results Rapp suggested that preheat treatment of structural alloys at reduced oxygen partial pressures will produce a passivating external scale. [82] These results have been applied to $\mathrm{Ni}-\mathrm{Cr}$ alloys. Wood, et. al., found that $\mathrm{Ni}-\mathrm{Cr}$ alloys with higher $\mathrm{Cr}$ contents underwent a more rapid transition from internal/intergranular oxidation to external oxidation. [94] The oxygen partial pressure at the surface is also important. As the concentration of oxygen is decreased, a critical value is reached at which a transition from internal to external oxidation occurs. [94]

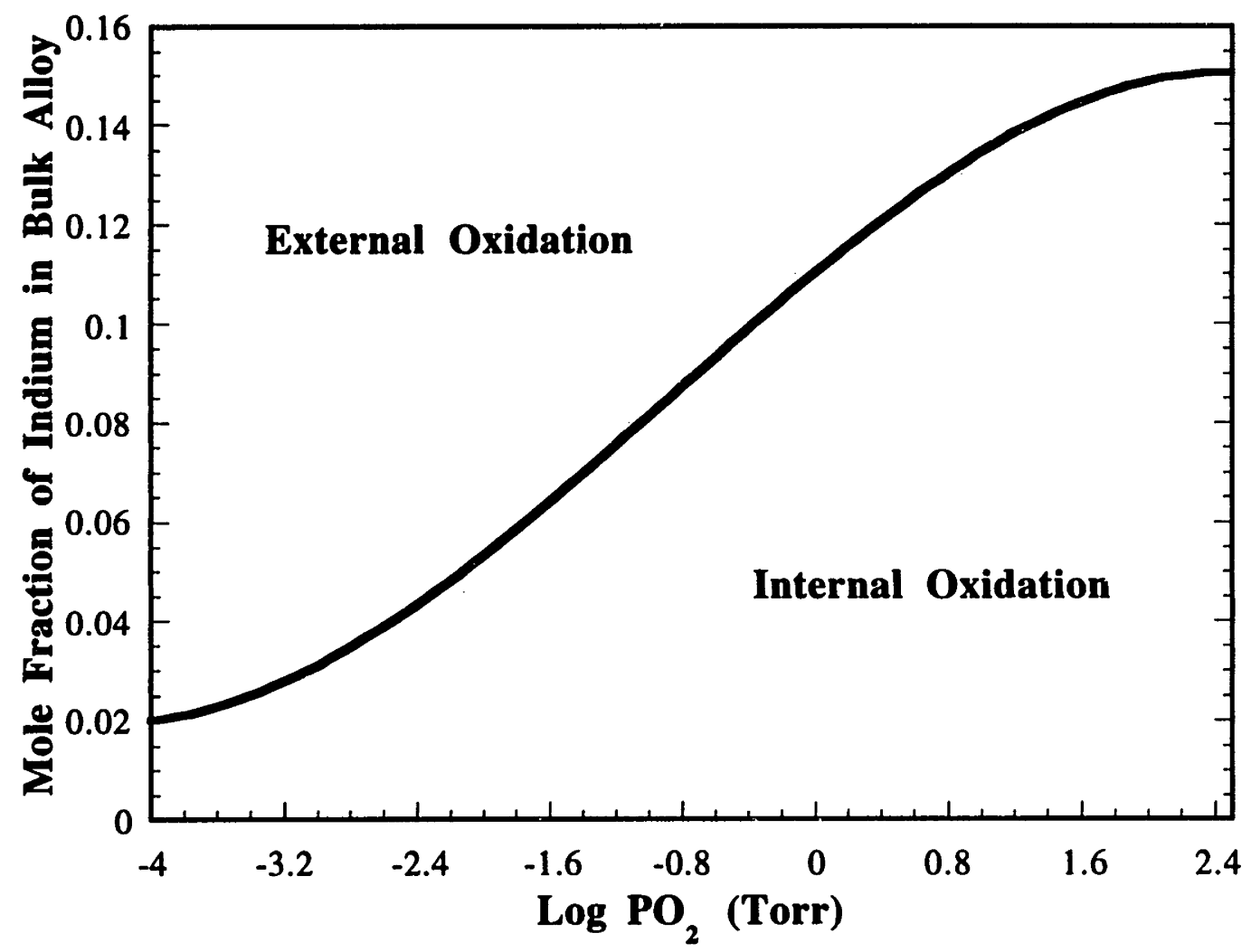

Figure 12. Transition from internal to external oxidation for $\mathrm{Ag}$-In alloys at $550^{\circ} \mathrm{C}$. From Rapp. [82]

The internal/intergranular oxidation experiments described above were generally static tests. Stress accelerated grain boundary oxidation also requires that the influence of stress on intergranular oxidation be recognized. In their study of $\mathrm{Ni}-\mathrm{Al}$ alloys, Stott, et. al., and Shida, et. al., have found that intergranular oxidation is facilitated by stresses developed from the increase in volume produced when surface and internal oxides form. [95, 96] 
This effect was most prominent at low temperatures (below $800^{\circ} \mathrm{C}$ ), which the authors ascribed to the lesser extent of stress relief at that temperature.

It has been suggested that stresses generated by the formation of an internal or intergranular oxide are relieved by diffusion in the base metal. [97] The effect of an imposed tensile stress is to accelerate the rate of intergranular oxidation by helping to create space to accommodate oxide formation. [97] Emsley's, et al., study of $20 \mathrm{Cr}-25 \mathrm{Ni}-\mathrm{Nb}$ stabilized stainless steel showed that the intergranular $\mathrm{Si}$ oxidation rate was controlled by the diffusion of $\mathrm{Cr}$ and/or $\mathrm{Fe}$ to the surface. [98] Mino, et al., found that intergranular oxidation of alloy 617 was enhanced under an applied tensile stress at 800 and $900^{\circ} \mathrm{C}$ [99]

\section{G. Application to Stress Accelerated Grain Boundary Oxidation in Alloy 908}

Susceptibility to the oxygen embrittlement phenomenon, by whichever mechanism, can be arranged by alloy group. The hierarchy of this arrangement would appear as, \{Ni aluminides $>$ LCIN superalloys $>$ Ni-Fe base superalloys $\geq$ Ni-base superalloys $\}$. In this ordering $\mathrm{Ni}$ aluminides $\left(\mathrm{Ni}_{3} \mathrm{Al}\right)$ are the most susceptible to intergranular oxygen embrittlement. [100, 101, $102,103,104]$ The embrittlement research path in this material group parallels that discussed above for superalloys. Low coefficient of expansion ironnickel base superalloys are next in line followed by the $\mathrm{Ni}-\mathrm{Fe}$ and $\mathrm{Ni}$ base superalloys. Co-Cr base superalloys are not ranked because they are much less susceptible to oxygen effects due to their greater intrinsic ductility at high temperature. [32] The ranking listed above correlates well with decreasing amounts of $\mathrm{Cr}$ found in each material, $0 \mathrm{wt}$. \% for $\mathrm{Ni}$ aluminides, 0-5 wt. \% in low coefficient of expansion iron-nickel base superalloys, and 10 to $20 \mathrm{wt} . \%$ in superalloys.

One result suggested by these studies is that the addition of small quantities ( $<10 \mathrm{wt}$. $\%$ ) of chromium may not be of help to stress accelerated grain boundary oxidation. As most of the above research indicates, alloys with relatively high $\mathrm{Cr}$ concentrations ( $18 \mathrm{wt}$. \%) experience similar oxidation assisted cracking. The one beneficial effect of having increased $\mathrm{Cr}$ levels may be in accelerating the rate of external oxidation (passivation). In the oxidation of $\mathrm{Ni}-\mathrm{Cr}$ alloys, higher $\mathrm{Cr}$ contents translate to more rapid transition from internal to external oxidation.[94] Since stress accelerated grain boundary oxidation is an internal oxidation process, increasing the $\mathrm{Cr}$ content will, in effect, accelerate the formation of a passivating surface oxide. Chang's work on alloy 718 demonstrated this. [50] This is especially true if intergranular cracking occurs by the two-stage oxidation process 
suggested by Andrieu. [77, 78, 79] One solution to stress accelerated grain boundary oxidation is increasing the concentration of $\mathrm{Cr}$. Coefficient of expansion sonsiderations restrict increases in $\mathrm{Cr}$ in low coefficient of expansion iron-nickel base alloys. In this case, reducing the diffusion rate of oxygen down grain boundaries may be of greater practical value. Grain boundary precipitation or segregation of oxygen getter phases and elements, respectively, is one example of this approach. 


\section{PROCEDURES}

The effect of heat treatment atmosphere on intergranular cracking in alloy 908 will be examined through the use of controlled atmosphere notched stress-rupture tests. Normally utilized to establish the stress limits to be designed into components operating at high temneratures, this test method is also an indicator of a material's sensitivity to environmental damage in combination with stress concentrations.

Similar methods are used to conduct stress-rupture and creep tests. They both use similar equipment to measure the time to failure at a constant temperature and load. Stressrupture tests usually run 1 to 1000 hours, allowing a full characterization of stress verses time to failure (rupture) in a shorter time span, as opposed to 1000 to 10,000 hours in creep tests. By design, stress-ruptuire tests focus on the time to failure, and do not provide for measurement of deformation during testing. By using a time-temperature parameter that correlates time, temperature, and stress, stress rupture data can be extrapolated to long times (iecades) that are not feasible for testing.

The effect of modification of surface residual stresses on stress accelerated grain boundary oxidation will be examined using constant strain, $\mathrm{C}$-ring tests. After surface modification the samples will be heat treated under known stress accelerated grain boundary oxidation conditions.

\section{A. Material}

The primary material used in this program was obtained in the form of $3.43 \mathrm{~mm}$ thick sheet (heat Y9401K) from INCO Alloys International Inc., Huntington, West Virginia. The material chemistry is given in Table 3 . The processing history started with an electroslag remelted ingot $305 \mathrm{~mm} \times 864 \mathrm{~mm} \times$ length. The ingot was then hot rolled at $1121^{\circ} \mathrm{C}$ to $7.6 \mathrm{~mm} \times 737 \mathrm{~mm} \times$ length, followed by annealing at $954^{\circ} \mathrm{C}$ in a continuous anneal and pickling (CAP) line. This annealed form was then cold rolled to $3.43 \mathrm{~mm} \times 737$ $\mathrm{mm} \mathrm{x}$ length and annealed in the CAP line at $982^{\circ} \mathrm{C}$. This heat, with the addition of a final cold rolling step to obtain 5\% cold-work, is the same as that used for air stress-rupture tests performed at INCO. [105]

The material used for the double notch round bar stress-rupture tests in this study had a different history and was obtained from heat Y9210 (chemistry given in Table 3). The processing steps followed for this material were vacuum induction melt, homogenize at $1191^{\circ} \mathrm{C}$ for 16 hours and fast cool. A series of forging and reheat steps produced approximately $25.4 \mathrm{~mm}$ thick plates that were mill annealed at $980^{\circ} \mathrm{C}$ for 1 hour. The final 
processing step involved the cold rolling of strips cut from the plates to obtain 10 and $20 \%$ cold work. [37] The $20 \%$ cold work material was the same as that used by Nicol in his air stress rupture tests. [37]

Table 3. Compositions of Alloy 908 Used for Stress Rupture Testing.

\begin{tabular}{|l|c|c|c|c|c|c|c|c|c|c|c|c|c|}
\hline Heat & \multicolumn{10}{|c|}{ Composition (weight percent) } \\
\hline & $\mathrm{Ni}$ & $\mathrm{Fe}$ & $\mathrm{Cr}$ & $\mathrm{Nb}$ & $\mathrm{Ti}$ & $\mathrm{Al}$ & $\mathrm{Si}$ & $\mathrm{Mn}$ & $\mathrm{C}$ & $\mathrm{Co}$ & $\mathrm{Mo}$ & $\mathrm{P}$ & $\mathrm{S}$ \\
\hline Y9401K & 49.3 & 40.8 & 3.99 & 3.04 & 1.55 & 1.01 & 0.16 & 0.05 & 0.01 & 0.01 & 0.01 & 0.004 & 0.001 \\
\hline Y9210 & 49.5 & 40.9 & 3.86 & 2.99 & 1.57 & 0.97 & 0.13 & 0.04 & 0.01 & - & - & - & 0.001 \\
\hline HV5107 & 48.7 & 40.8 & 4.12 & 3.04 & 1.54 & 1.10 & 0.17 & 0.09 & 0.01 & 0.01 & 0.001 & 0.002 & 0.002 \\
\hline
\end{tabular}

Additional double notch round bar samples were manufactured from heat HV5107 that started as a $21 \mathrm{~kg}$ vacuum induction melt ingot produced by INCO, chemistry given in Table 3. The ingot was homogenized at $1191^{\circ} \mathrm{C}$ for 16 hours, fast cooled, and then forged at $1191^{\circ} \mathrm{C}$ to plate $31 \mathrm{~mm}$ thick by $102 \mathrm{~mm}$ wide by $1170 \mathrm{~mm}$ long. The material was then annealed at $980^{\circ} \mathrm{C}$ for 1 hour and air cooled. Cold rolling introduced approximately $20 \%$ cold work.

\section{B. Stress Rupture Test Procedure}

The primary sample type used for argon atmosphere testing was a flat plate $(3.15 \mathrm{~mm}$ thick) double-edge-notch design, for subsize sheet materials. The specimen geometry was chosen to closely replicate thin wall $(<3 \mathrm{~mm})$ conduit designs. The notch produces an elastic stress-concentration factor $\left(\mathrm{K}_{\mathfrak{t}}\right)$ at the root of the notch of 4.5. A drawing of the specimen design is shown in Figure 13. Two sample orientations were machined for this sample geometry. One set of samples was machined so that their tensile axes were parallel with the longitudinal direction, with crack growth in the transverse direction, LT orientation. The other set was machined in the TL orientation, with their tensile axes parallel to the transverse direction and crack growth in the longitudinal direction. The LT oriented samples were the primary ones used for this study. The other sample type utilized is a double-notch-round-bar sample that incorporates the British standard V-notch with a $\mathrm{K}_{\mathbf{t}}$ =4.1. [106] This sample design is shown in Figure 14. To study the effect of heat treatment on stress rupture properties, several samples from both designs were heat treated in a $10^{-5}$ Torr vacuum at $650^{\circ} \mathrm{C}$ for 200 hours. All of these samples were in the LT orientation. 
The test methodology closely followed ASTM E292-83 which provides a standard method for conducting time to rupture tensile tests for notched materials. [107] The stress rupture test matrix is shown in Table 4. The matrix was established first around stresses that would neither produce rapid tensile failure nor a stress rupture life in excess of 500 hours, dependent upon sample geometry. Using these stresses, the oxygen concentration and temperature were varied. An Applied Test Systems (ATS) lever arm test frame with auto load leveling and auto loading was used. The system incorporates an Inconel alloy 713 retort that serves as the environmental chamber. The retort is surrounded by a tubular, three zone, electric-resistance furnace with a programmable controller. To insure accurate temperature measurements, a thermocouple cold-junction compensator was used to monitor the temperature at the sample for the duration of the test.

Both oxygen and water vapor analyzers were used. A Delta F Corporation electrochemical process oxygen analyzer was used to measure oxygen concentration in gas sampled from the notch region of the test sample. As configured, the analyzer has a detection range of 0.01 to $50 \mathrm{ppm}$ oxygen that was selected for sensitivity at low oxygen concentrations. Oxygen concentration in the testing retort was continuously measured by passing the exit gas through the analyzer at a flow rate of $5.66 \times 10^{-2} \mathrm{~m}^{3} / \mathrm{h}$ with an at gage delivery pressure of 129 Torr. The concentration of water vapor was measured with an EG\&G analyzer that utilizes a phosphorus pentoxide electrochemical sensor.

Table 4. Test Matrix Used For Stress Rupture Tests. FP=Flat Plate Specimen(s), RB= Round Bar Specimen(s).

\begin{tabular}{|c|c|c|c|}
\hline $\begin{array}{c}\text { Temperature } \\
\left({ }^{\circ} \mathrm{C}\right)\end{array}$ & \multicolumn{2}{|c|}{ Stress (MPa) } & $\begin{array}{c}\text { Oxygen } \\
\text { (ppm) }\end{array}$ \\
\hline & 550 & $650 \quad 700$ & \\
\hline 550 & & $\sqrt{F P}$ & $0.5-1$ \\
\hline \multirow[t]{6}{*}{650} & \multirow[b]{6}{*}{$\sqrt{ } \mathrm{RB} / \mathrm{FP}$} & $\sqrt{\mathrm{FP}} \quad \sqrt{\mathrm{FP}}$ & $<0.5$ \\
\hline & & V FP & $0.5-1$ \\
\hline & & $\checkmark$ FP & $3-6$ \\
\hline & & $\checkmark$ FP & $33-53$ \\
\hline & & $\checkmark$ FP & 195 \\
\hline & & V RB/FP & 1000 \\
\hline \multirow[t]{2}{*}{700} & \multirow[t]{2}{*}{$\sqrt{\text { FP }}$} & \multirow[t]{2}{*}{$\sqrt{F P}$} & $0.5-1$ \\
\hline & & & 195 \\
\hline 750 & $\sqrt{\mathrm{FP}}$ & $\sqrt{F P}$ & 195 \\
\hline
\end{tabular}




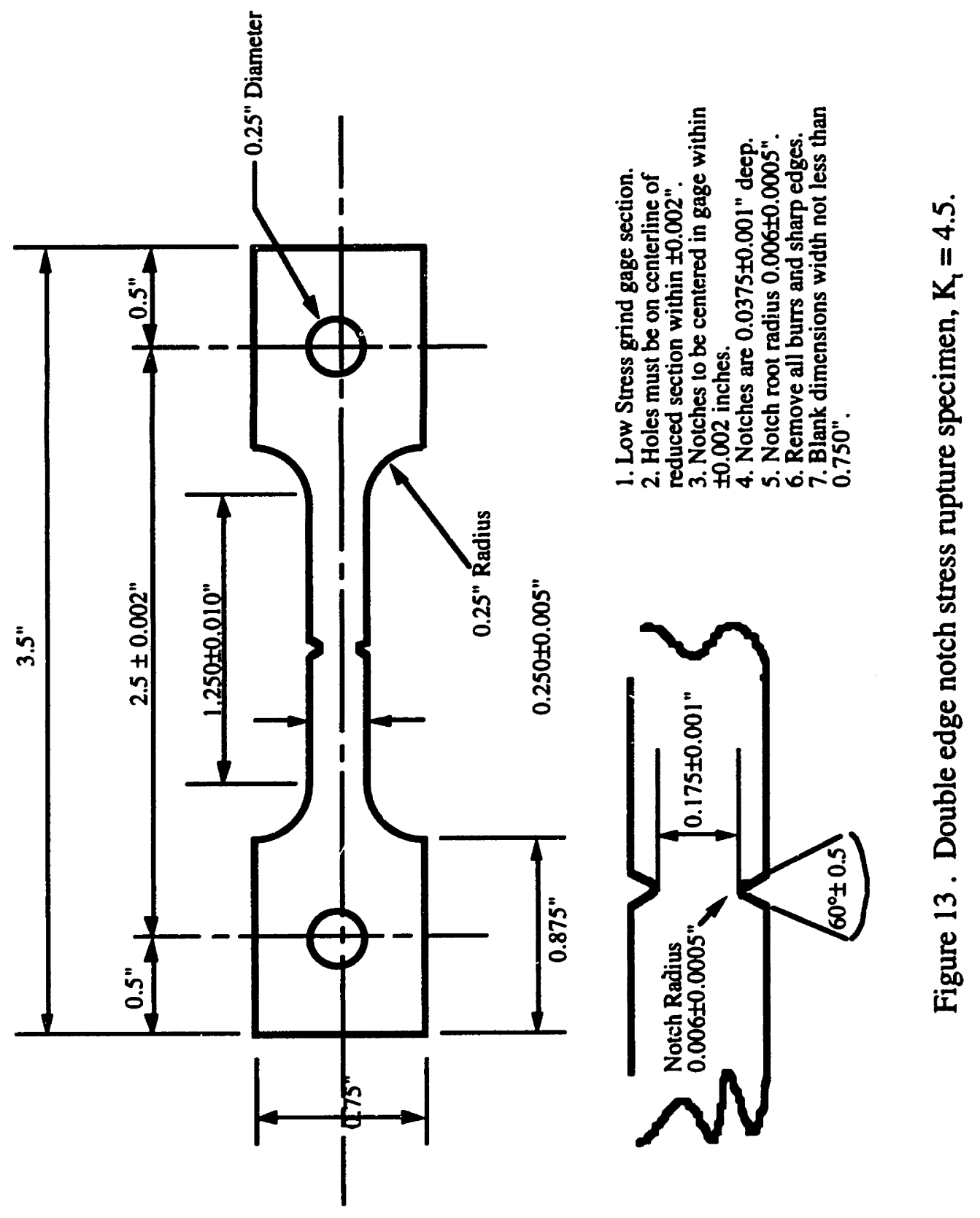

$q$ 

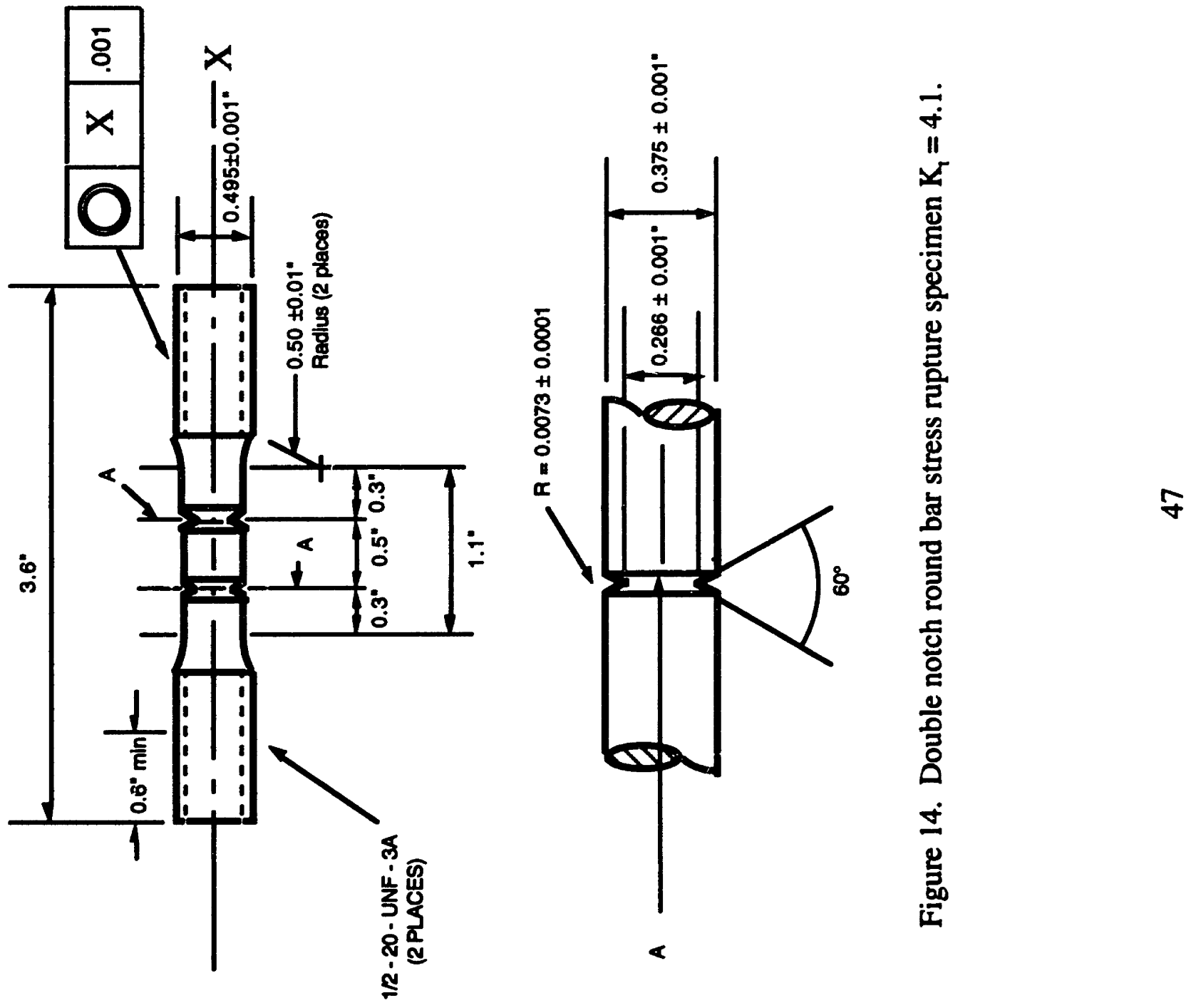
Proper positioning of the two detectors with respect to one another was critical.

Arrangement in series on the exit gas posed a problem because the oxygen analyzer uses an aqueous electrochemical cell that produces a wet exit gas. Additionally, the water vapor analyzer produces oxygen as a byproduct of its electrochemical reaction. A parallel arrangement on the exit gas line was also ruled out since the oxygen analyzer requires a tight, no leaks, supply to maintain a constant oxygen reading with fluctuations of $\pm 2.8 \times 10^{-2}$ $\mathrm{m}^{3} / \mathrm{h}$ in the analyzer gas flow rate. Based on these considerations, the water vapor analyzer was placed in the supply gas line to the retort. This placement was acceptable since water vapor in the supply gas was being measured but not controlled for these tests, and in all cases the water vapor concentration of the supply gas remained constant throughout the tests.

For the argon tests, the gas was supplied to the retort using a high purity two-stage regulator. Either commercial argon gas of different grades or analyzed oxygen-argon mixtures were used to obtain the required oxygen concentration. Each new gas cylinder was sampled for oxygen and water vapor prior to testing. For low oxygen concentration tests $(\leq 50 \mathrm{ppm})$, the standard procedure employed to attain a constant oxygen concentration was to continuously flow supply gas through the retort and supply lines at a 129 Torr regulator gage pressure until the oxygen concentration of the retort exit gas matched the initial cylinder reading. The time required to achieve this depended upon how long the retort and sample load train were exposed to atmosphere. To minimize contamination of other parts of the system, the supply and exit lines were kept shut and under argon during sample loading and cylinder changes. For high oxygen concentration tests ( $\geq 50 \mathrm{ppm}$ ) using pre-analyzed argon-oxygen mixtures, the retort was first purged with inexpensive 99.997 grade argon until the oxygen concentration from the retort matched that of the cylinder. The analyzed mixed gas was then introduced into retort for 30 minutes prior to testing. During the initial heatup of the retort and sample the oxygen concentration generally increased for the first several minutes as trapped oxygen and organics were baked out, but returned to the initial supply gas reading rapidly after that. Initial tests with low oxygen concentrations $(<1.0 \mathrm{ppm})$ showed that the new retort could significantly getter oxygen down to $0.01 \mathrm{ppm}$ levels. This necessitated that the oxygen analyzer be placed on the exit gas side. Heating the retort in air at $1100^{\circ} \mathrm{C}$ to passivate it was not done, since a thick oxide coating would also serve as an effective oxygen and water vapor trap for future tests. A schematic of the arrangement of the equipment used in the experiment is shown in Figure 15. 


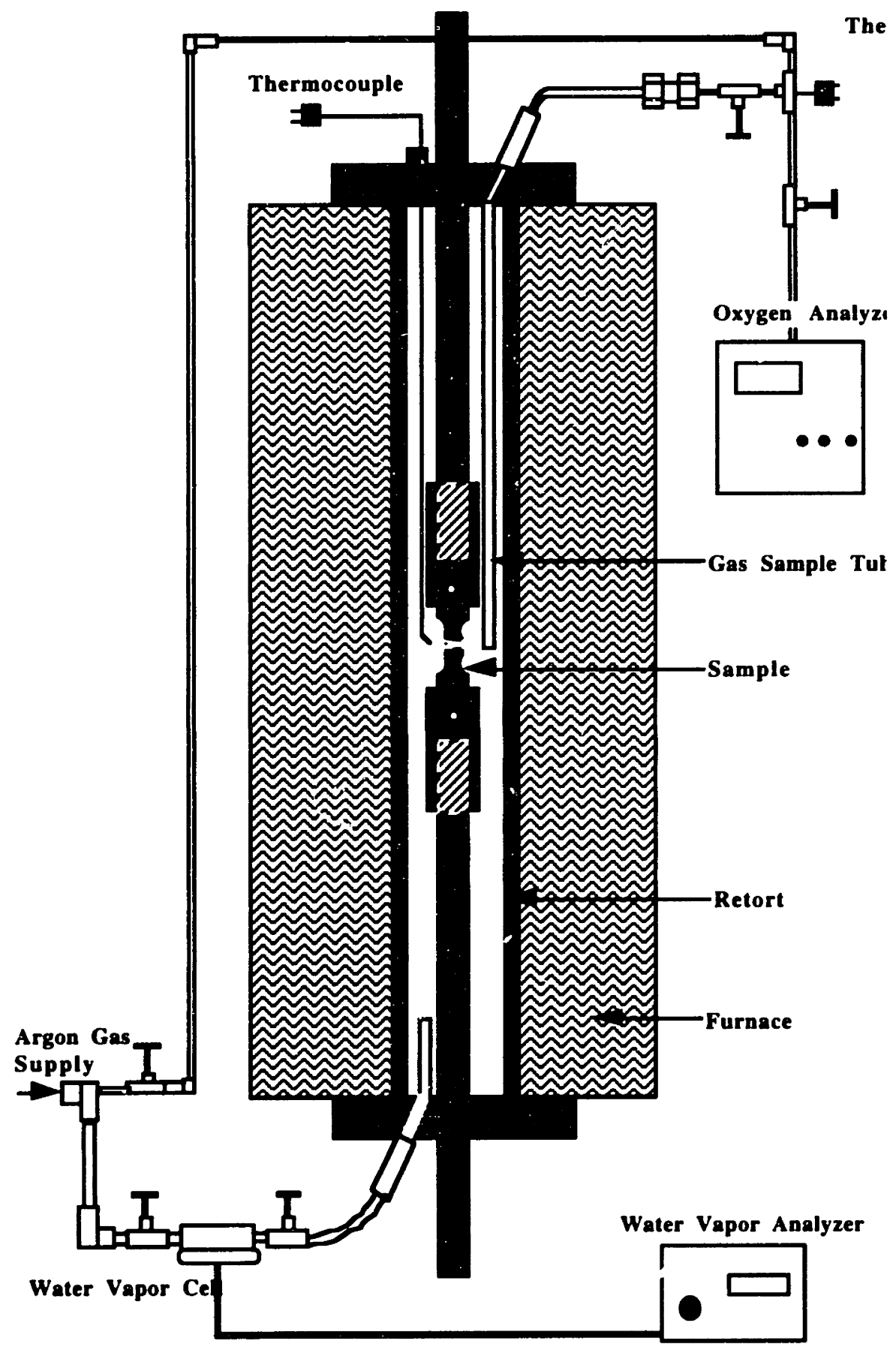

Figure 15. Illustration showing of arrangement furnace, retort, and gas analyzers used for alloy 908 stress rupture tests. 
The samples were cooled in the retort under flowing argon at the completion of each test. This prevented the fresh fracture surfaces from oxidizing. Every sample was examined using scanning electron microscopy (SEM) to establish failure mode and fracture morphology. In the case of the flat plate samples, SEM fractography was performed on one half of the fracture, the other was prepared for metallographic examination. Fractography of the round bar samples was done using SEM on one half of the failed notch, and the unfailed notch was prepared for metallographic examination. Metallographic sections for both sample types were made so that the view was of the plane parallel to the tensile axis. Samples for SEM and energy dispersive $x$-ray spectroscopy analysis (EDS) were prepared by diamond grinding to $20 \mu \mathrm{m}$ followed by polishing with diamond suspensions down to a final $3 \mu \mathrm{m}$ polish. To prevent charging near the mounting resin and at oxides, all the SEM samples were coated by vacuum evaporation of carbon. Samples used for grain size determination were immersed for 30 to 60 seconds in an etchant composed of $15 \mathrm{~mL}$ hydrochloric acid, $10 \mathrm{~mL}$ acetic acid, $10 \mathrm{~mL}$ nitric acid, and 6 drops glycerin.

A TOPCON ABT-150 scanning electron microscope equipped with $\mathrm{a} \mathrm{LaB}_{6}$ filament was used for the fractographic, microstructural, and chemical analyses. The ABT-150 is linked with a Noran Pioneer energy dispersive $\mathrm{x}$-ray detector capable of light element detection. Semiquantitative analyses of collected spectra were performed using a Noran Voyager $\mathrm{x}$-ray analyzer and software. Unless otherwise specified, spectra were collected at $15 \mathrm{kV}$ and at a $17 \mathrm{~mm}$ working distance. The microscope was operated to give an approximate spot size of between 0.1 and $0.05 \mu \mathrm{m}$. [108] Area measurements on fracture surfaces were performed from SEM micrographs with fractographic features manually traced into a Zeiss image analysis system. Grain diameter measurements were done in a similar fashion.

\section{C.Ring Residual Stress Modification Study}

A parallel study on the modification of residual stresses was performed. C-ring test samples manufactured from tubing were used. The material had been solution annealed at $980^{\circ} \mathrm{C}$ for 1 hour in a hydrogen furnace that left it in a bright condition, i.e., it was free of any surface scale or subsurface oxidation. The tube had a radius of $23 \mathrm{~mm}$ and a wall thickness of $3 \mathrm{~mm}$. The grain diameter of the starting material was $73 \mu \mathrm{m}$. Samples where placed in test fixtures designed to produce $6.0 \pm 0.08 \%$ plastic strain at the outer 
surface of the C-ring. [109] The test fixtures were machined from alloy 908 io eliminate strain relief due to differential thermal expansion between the $\mathrm{C}$-ring and fixture. An illustration of a test fixture with a $\mathrm{C}$-ring in place is shown in Figure 16.

The test samples were divided into three groups; solution annealed (starting condition), stress relieved, and shot peened. The stress relief treatment consisted of heat treating the $\mathrm{C}$-rings, in their test fixtures, in a $1 \times 10^{-6} \mathrm{Torr}$ vacuum at $650^{\circ} \mathrm{C}$ for 16 hours. The shot peened test samples were first mounted in their fixtures. The samples were then commercially shot peened using 230 mesh (maximum $63 \mu \mathrm{m}$ diameter) steel shot at 10-12 A intensity, with $100 \%$ coverage of the exposed outer surface of the C-ring obtained. The test environment used to evaluate the samples consisted of a vacuum furnace with a degraded vacuum of $3 \times 10^{-2}$ to $4 \times 10^{-2}$ Torr (approximately 11-8 ppm oxygen), measured by thermocouple gage. Heat treatment cycles were based on inspections for cracking that occurred after exposure intervals of 24,70 , and 200 hours at $650^{\circ} \mathrm{C}$. 

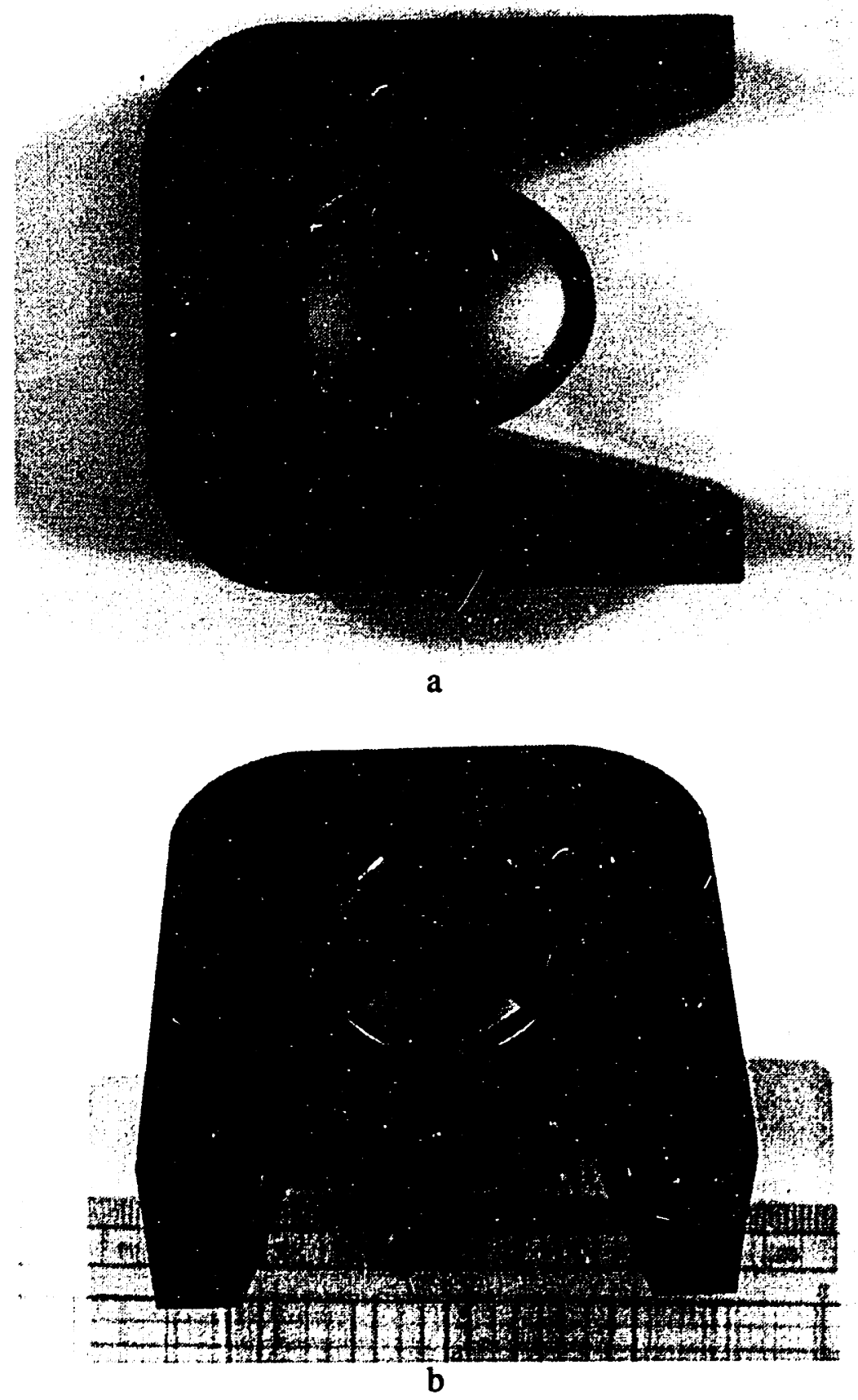

Figure 16. (a),(b) C-ring specimen holder designed to maintain a constant plastic strain of $6 \%$ during heat treatment. 


\section{RESULTS}

\section{A. Microhardness and Grain Size}

Heat Y9401K had a starting grain diameter of $13 \mu \mathrm{m}$. The grain size and orientation of the starting material is shown in Figures $17 \mathrm{a}$ and $17 \mathrm{~b}$. After stress rupture testing at $650^{\circ} \mathrm{C}$, the grain diameters in several samples were measured and an average value of $14.5 \mu \mathrm{m}$ was calculated. A micrograph showing the grain structure in one sample after stress rupture testing is shown in Figure 18a. Vacuum heat treatment at $650^{\circ} \mathrm{C}$ for 200 hours prior to testing did not contribute to further grain growth. The grain diameter for this condition, $14.2 \mu \mathrm{m}$, is essentially the same as that of the other stress rupture samples, as shown in Figure 18a. The $20 \%$ cold work material, heat HV5107, that was vacuum heat treated at $650^{\circ} \mathrm{C}$ for 200 hours, has a duplex grain size, as can be seen in Figure $18 \mathrm{~b}$. The small size grains that form the predominant volume fraction, have a diameter of $25.2 \mu \mathrm{m}$. The large grains in this material are essentially equiaxed, have a diameter of $200 \mu \mathrm{m}$, and show no texturing with rolling direction.

The $20 \%$ cold work material, heat Y9210, also has a duplex size distribution. In this material, however, the large grains were extremely elongated and oriented with the cold rolling direction. [37] The small size fraction had a grain diameter of $15.8 \mu \mathrm{m}$. The large elongated grains were acicular in shape and had a grain length, based on the c-axis of the grain, of $534 \mu \mathrm{m}$, the a-axis was of the same dimensions as that of the surrounding small equiaxed grains. The microhardness within any elongated grain was the same as that of the surrounding matrix. An etched metallographic sample of this material was heat treated at $650^{\circ} \mathrm{C}$ for 200 hours in a $1 \times 10^{-6}$ Torr vacuum. This procedure was used to determine if the grains were unrecrystallized grains that had been elongated during the cold rolling operation and whether recrystallization would occur during stress rupture testing at $650^{\circ} \mathrm{C}$. The optical micrograph shown in Figure $18 \mathrm{c}$ has had one elongated grain labeled with microhardness indentations. The same grain, after the vacuum heat treatment, can be seen in the SEM micrograph shown in Figure 18d. As can be seen by comparing these micrographs, the elongated grain did not recrystallize during heat treatment. As a microstructural feature these grains will, therefore, not change during stress rupture testing at $650^{\circ} \mathrm{C}$. 


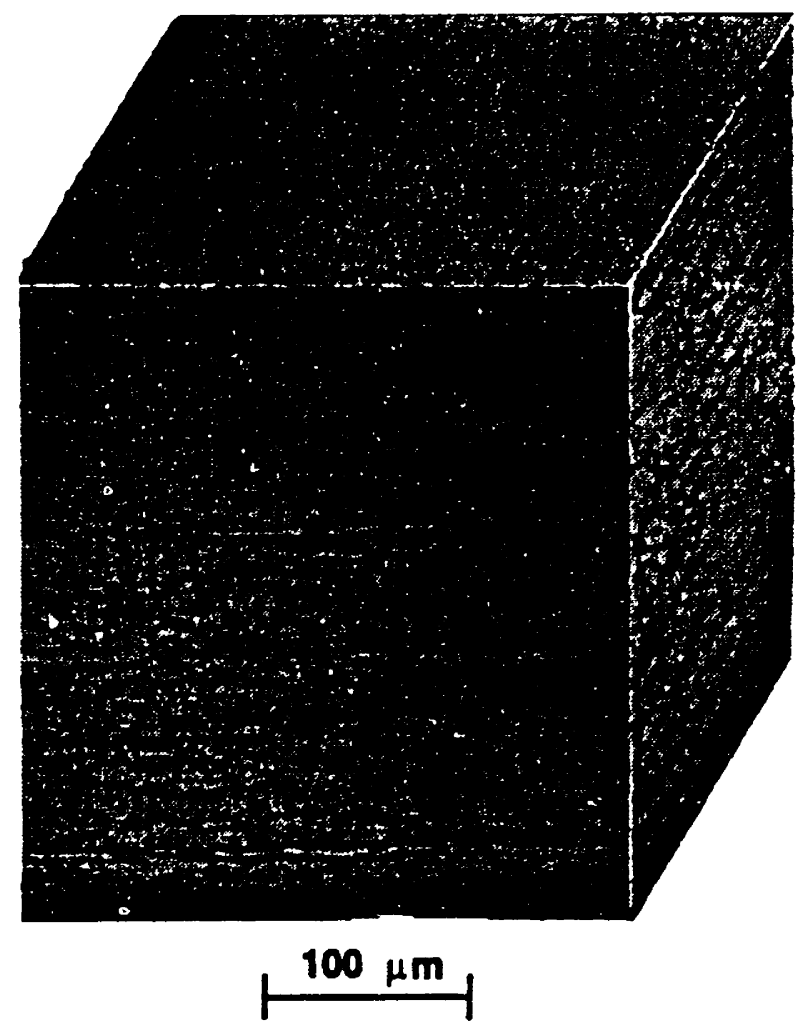

(a)
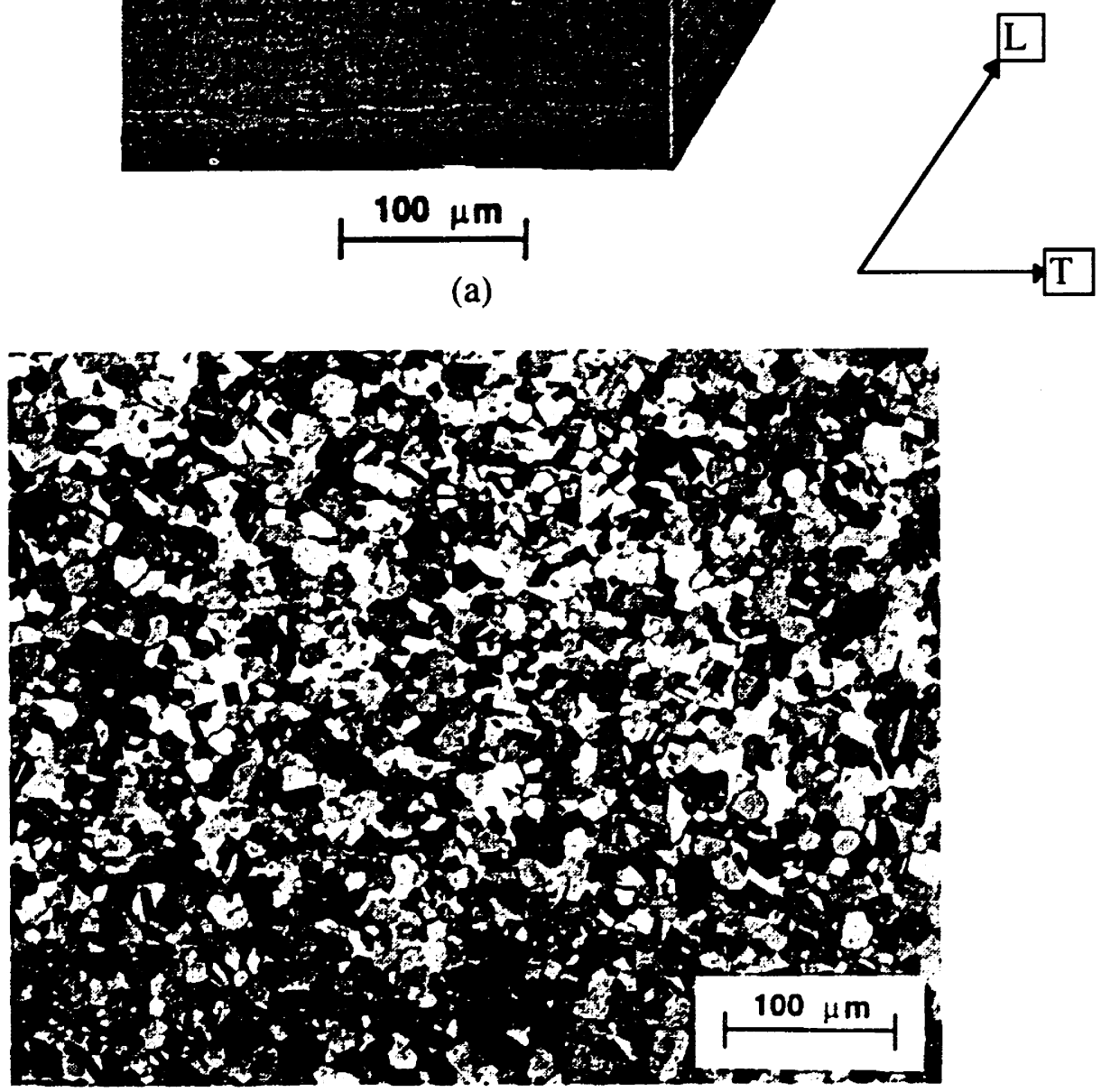

Figure 17. (a) Grain size and orientation of $3.43 \mathrm{~mm}$ thick sheet starting material, heat Y9401K, used for the flat plate stress rupture test samples, grain diameter $13 \mu \mathrm{m}$, Hardness $266 \mathrm{HVN}$. (b) Grain size in stress rupture tested sample $61 \mathrm{P}\left(650^{\circ} \mathrm{C} / 118\right.$ hours $)$ grain diameter $14.8 \mu \mathrm{m}$, hardness $484 \mathrm{HVN}$. 


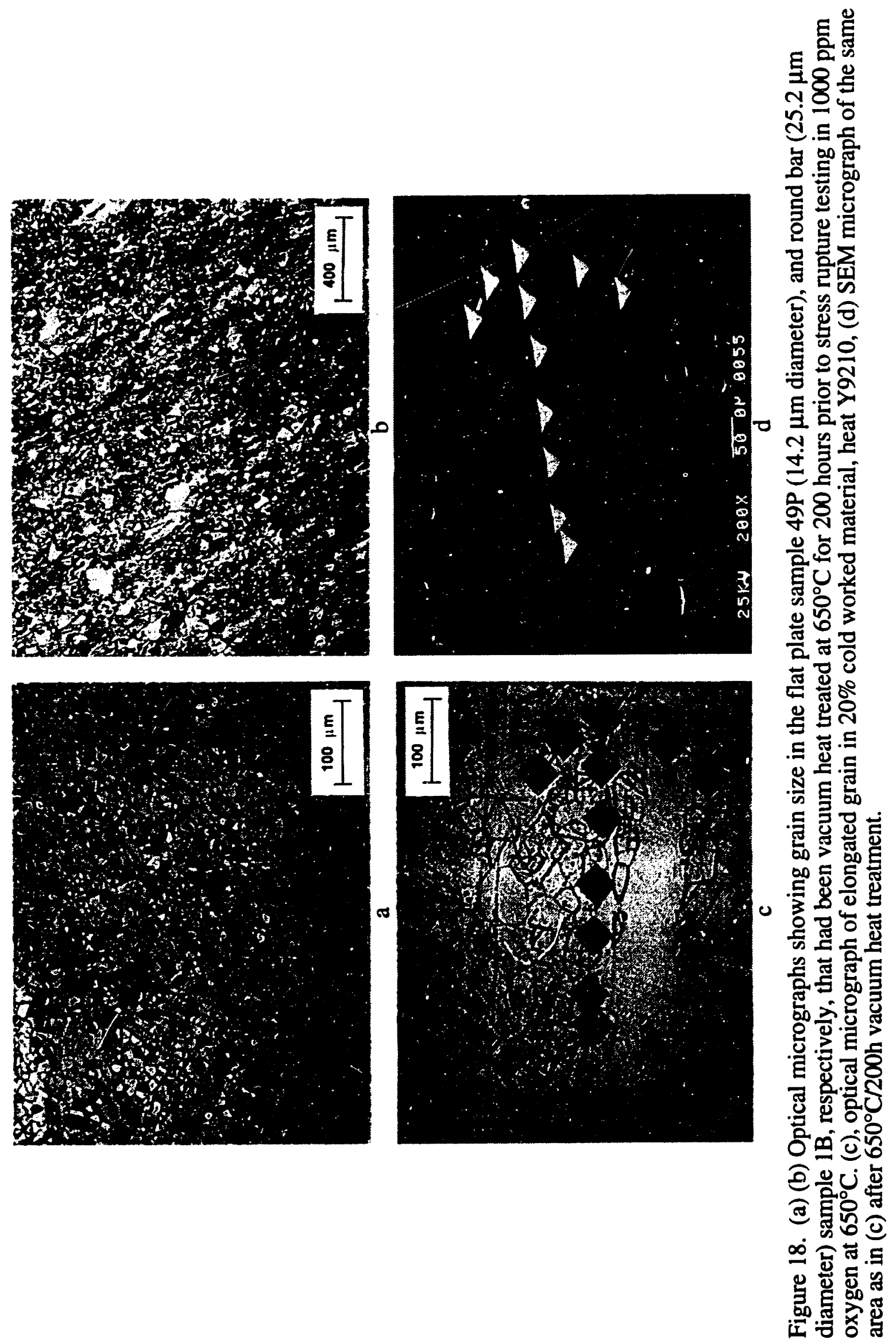


Growth of the $\gamma^{\prime}$ precipitate will occur during testing. The $\boldsymbol{\gamma}^{\prime}$ growth rate for the cold worked material has heen shown to be faster than for the solution annealed material. [1] A faster hardening response is therefore expected in the $20 \%$ cold work starting condition. In Figure 19, the evolution of microhardness for the two representative starting conditions, $980^{\circ} \mathrm{C} / 1 \mathrm{~h}$ solution annealed and $20 \%$ cold work, is shown along with that of the solution annealed flat plate and $20 \%$ cold work round-bar stress-rupture samples. The times given for the stress rupture samples in this plot represent the entire time at temperature for the samples, heat up to cool down, and are therefore longer than the times to rupture. As can be seen, the hardness values of the stress rupture samples fall between the aging lines for the solution annealed and the $20 \%$ cold work materials. Hardness values peak at approximately 200 hours, with little decline up to 1000 hours. The $20 \%$ cold work material hardens more rapidly. As had been previously reported, the $20 \%$ cold work material contains $\gamma^{\prime}$ prior to heat treatment. This, along with higher dislocation density, accounts for the rapid hardening response shown in this plot for this condition.[1]

\section{B. Stress Rupture Results}

Tables 2A and 3A, in the Appendix, contain a detailed tabulation of all the stress rupture test data. In Figure 20, the stress-rupture data are plotted to show the time to rupture versus stress for all the $650^{\circ} \mathrm{C}$ solution annealed samples tested in low/controlled $\mathrm{O}_{2}$ in argon atmospheres. The argon atmosphere data have been grouped by oxygen concentration range for the flat plate samples to maintain plot clarity. These data are compared with air data generated at INCO Alloys International, Huntington, West Virginia for the same material heat but with 5\% cold work applied before testing. The shift to increased rupture timu for the low $\mathrm{O}_{2}$ samples compared with the air data is immediately evident. Also evident is the grouping of failed, solution annealed low $\mathrm{O}_{2}$ samples around a rupture time of approximately $108 \pm 36$ hours at $651 \pm 18 \mathrm{MPa}$ stress, as shown in Figure 21. The time to rupture in this stress range was independent of oxygen concentration, as is evident in Figure 21. The sample group for the $540 \mathrm{MPa}$ stress range was insufficient (1 sample failed at 452.5 hours) to establish whether this independence of rupture time on oxygen concentration held at lower stresses.

The effect of test temperature, oxygen concentration, and stress for the flat plate samples can be seen in Figure 22. From this plot a general trena of increasing rupture life with decreasing test temperature can be seen and is expected. The mechanical properties of the material decrease and the creep rate in $>$ reases with increascd temperature. $[110,111]$ 


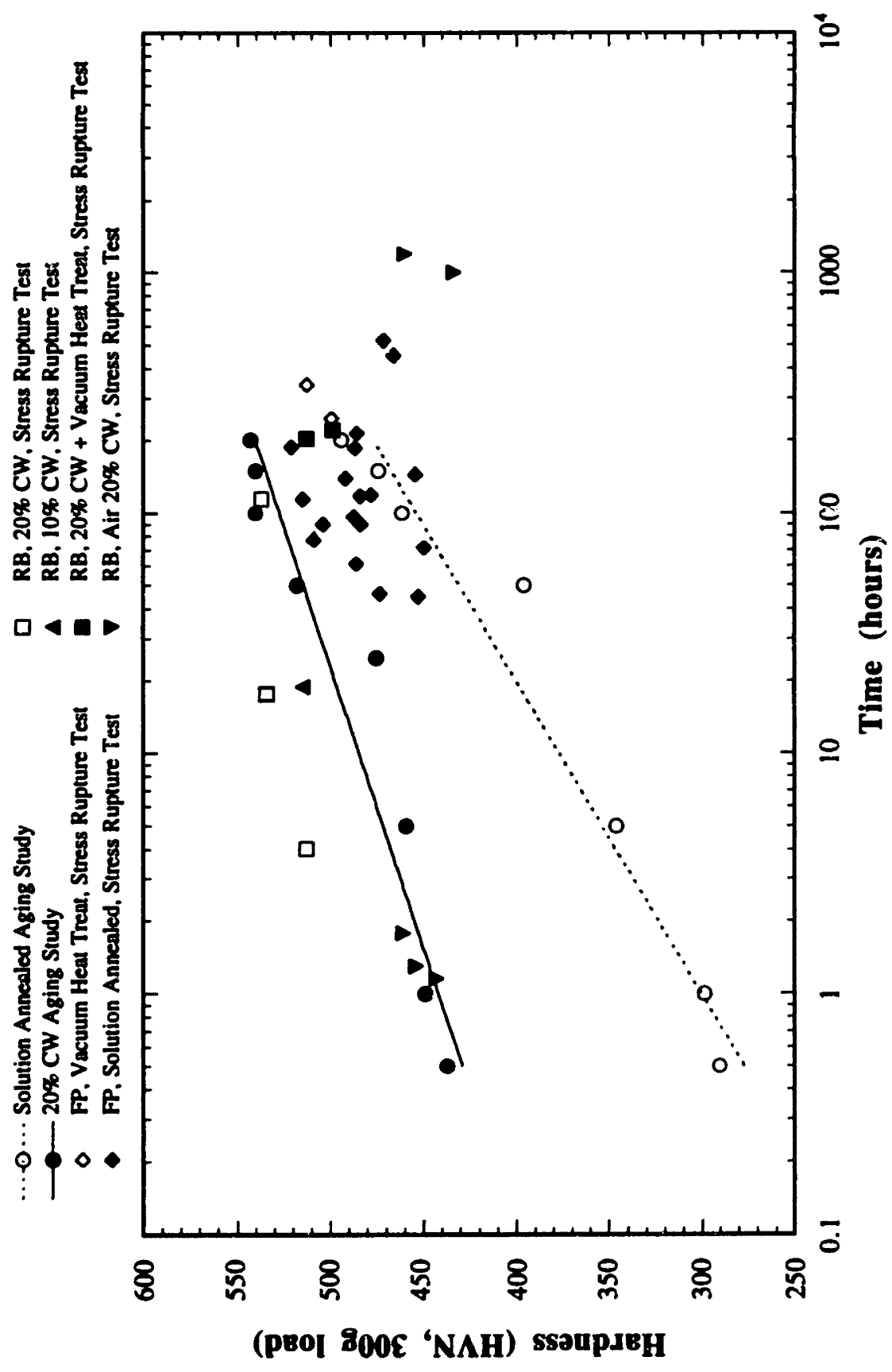

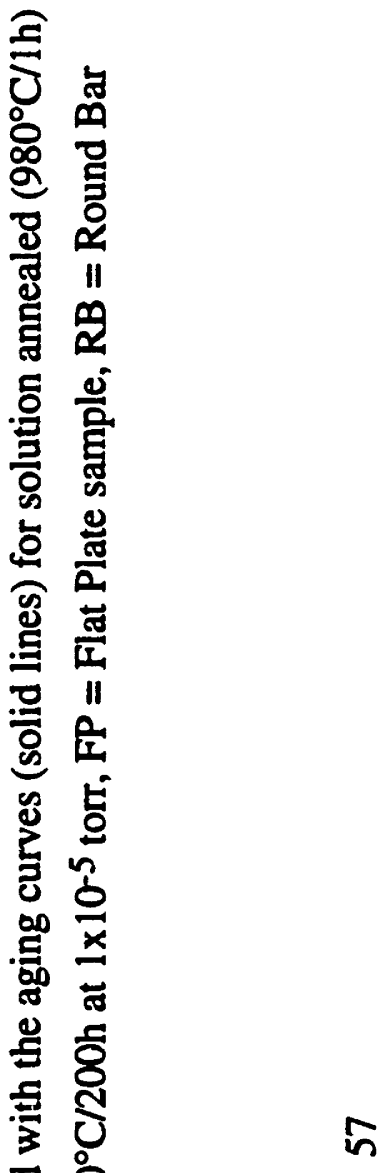




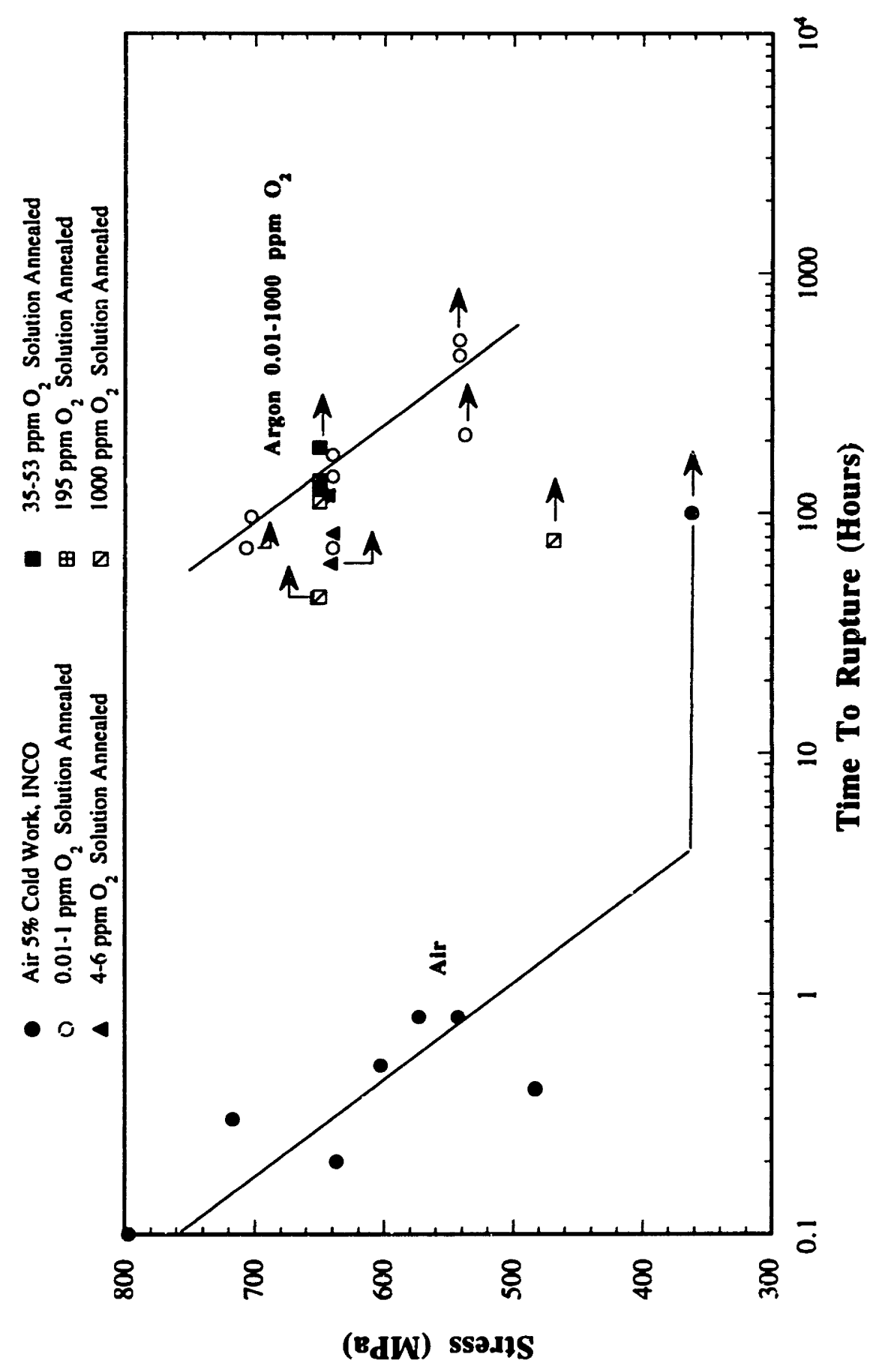

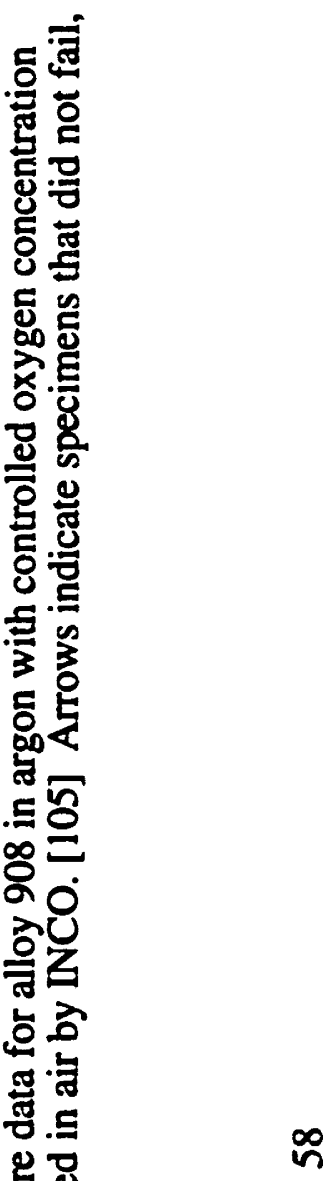

吾

을

음

政

究

03

톡응

58

ब的

올

궁

䓅

ㄴ. 코

웡

음

ठั

ธี

5

롱

ช छั

용

包

다은 


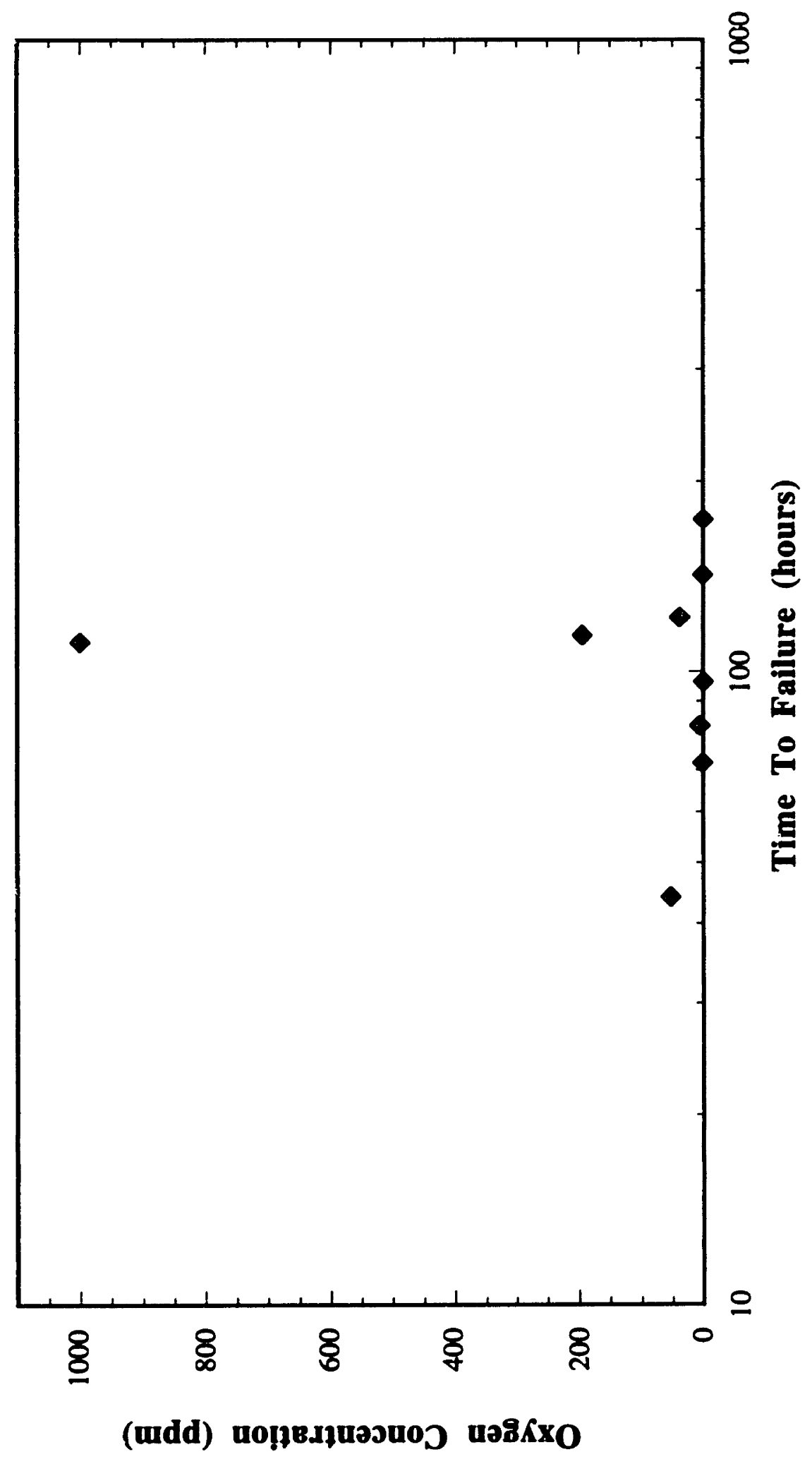

늠

究豆

为

点焉

.

.등

흉

들

(1)

융ํㅇ

똟ㅁ

망

.

$\underset{0}{0}$

늠

틈

क

훙

口.

형

훙 후

을 点

봉

ํํㅇ

H

¿

도음

久ิ돌

E

แั

응

.气

莒

के

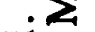

ते

할

ํㅗㅇำ 

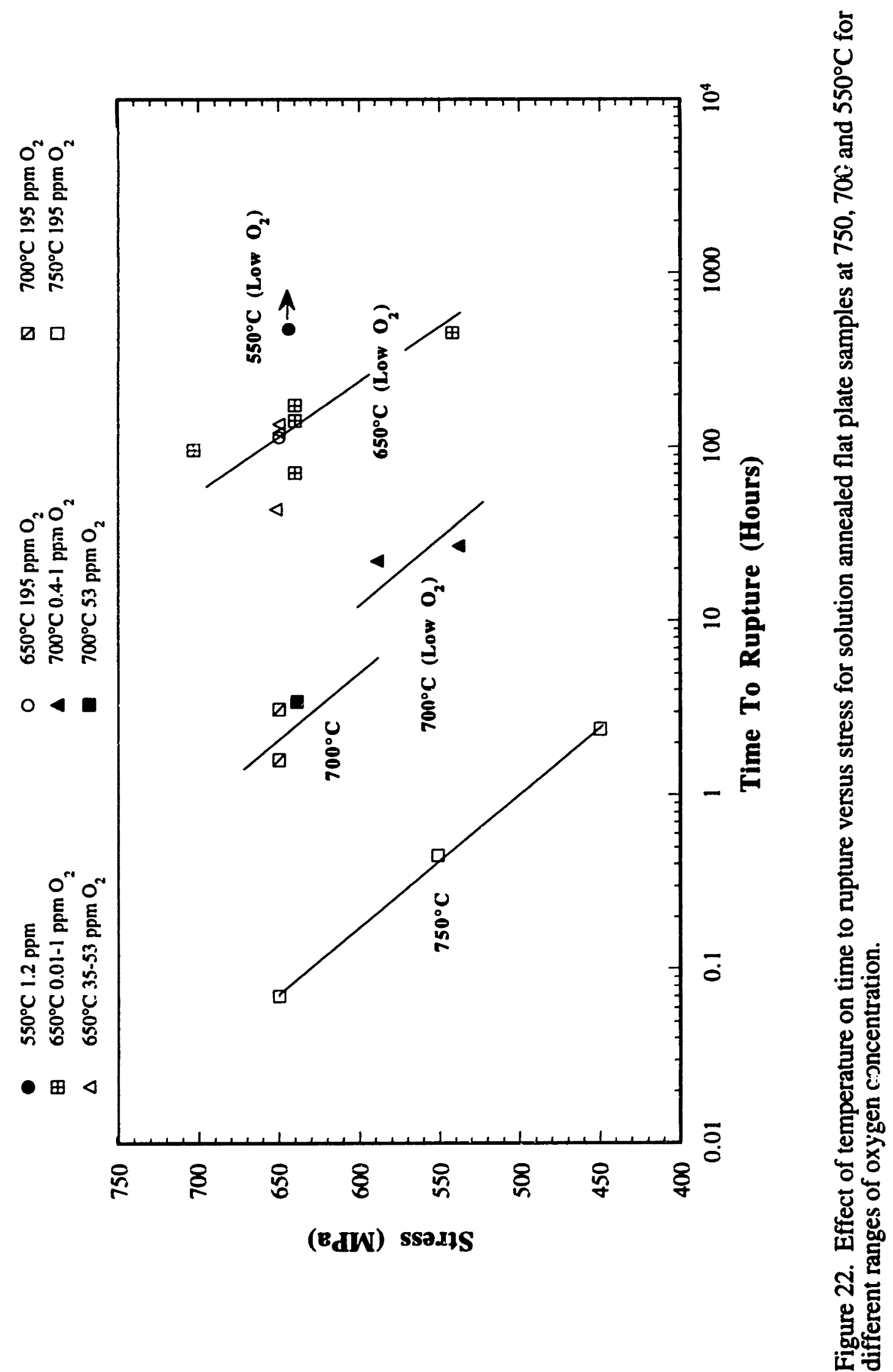
Test results for the round bar material tested at $650^{\circ} \mathrm{C}$ in low/controlled $\mathrm{O}_{2}$ in argon atmospheres are compared in Figure 23 with air data obtained for the same material heat by Nicol. [37] This plot shows several trends for this material and sample geometry. There is a substantial increase in rupture life with decreasing oxygen concentration. When compared with flat plate sample results, the effect of oxygen concentration on rupture life for the round bar samples is more pronounced, with better time to rupture separation for the 1000,44 , and $3 \mathrm{ppm} \mathrm{O}_{2}$ samples. The effect of prior processing is also evident in this plot, with the solution annealed sample showing an extended life at $1000 \mathrm{ppm}$ oxygen over the $20 \%$ cold work samples. No difference in behavior was observed for the $10 \%$ cold work sample tested at $1000 \mathrm{ppm}$ oxygen and $469 \mathrm{MPa}$, and its time to rupture was within the range of the $20 \%$ cold worked samples tested under the same conditions.

Prior vacuum heat treatment resulted in no substantial change in rupture life for either of the sample geometries, as is shown in Figure 24. In one instance, a non-heat treated, 1000 ppm oxygen flat plate sample had a significantly longer rupture life than its heat treated counterpart, but they exhibited similar percentages of intergranular fracture at failure. The round bar samples, under identical conditions, ruptured within a short time of each other, as seen in Figure 24.

\section{Effect of Oxygen Concentration}

Optical and scanning electron fractography of failed and interrupted flat plate samples extended the picture of the influence of oxygen concentration on stress rupture test results. The relationship between oxygen concentration and percent intergranular fracture was first examined for the flat plate test data that formed the bulk of the testing done for this thesis.

Figures $25 \mathrm{a}$ and $25 \mathrm{~b}$ show the macrographic character of a failed flat plate stress rupture sample tested in $6 \mathrm{ppm}$ oxygen at $650^{\circ} \mathrm{C}$ and $640 \mathrm{MPa}$. For these samples, intergranular cracking proceeds along a flat front that extends in from the notch. Intergranular cracking from the sides was observed, but only in very limited areas and at shallow penetrations (1-10 grains deep) in samples tested at higher oxygen concentration. The concave areas in the region between the notches are the shear lips. The shear lip regions are slanted, have a smooth/ductile fracture appearance, and represent the predominant source of reduction in area observed in these samples. The crack paths along the shear lips are oriented $45^{\circ}$ with respect to the tensile axis. An example of this can be seen in the notch cross-section of an interrupted $550^{\circ} \mathrm{C}$ test specimen shown in Figures 26a-c. The fracture morphologies observed in the flat plate test samples as a function of 


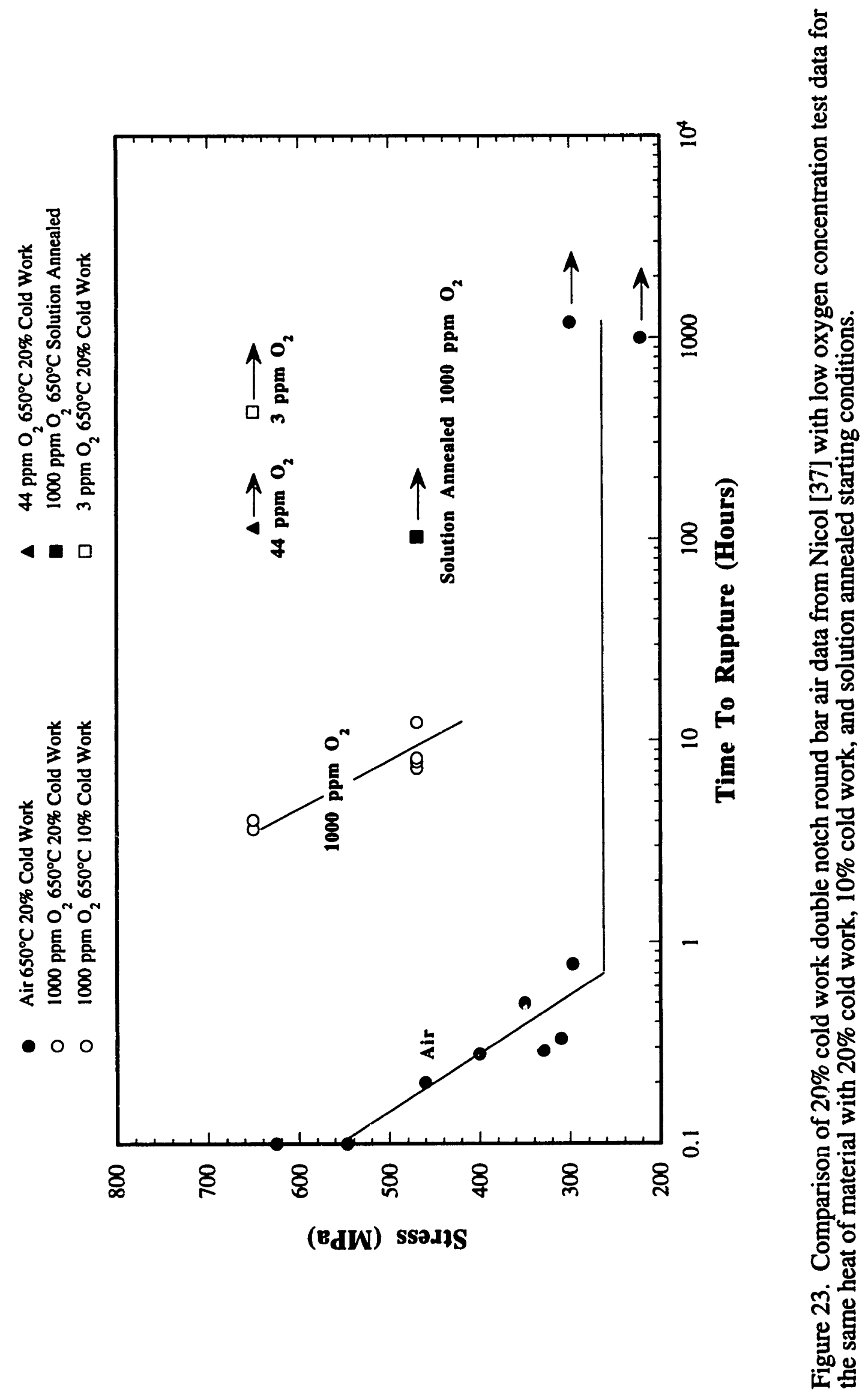



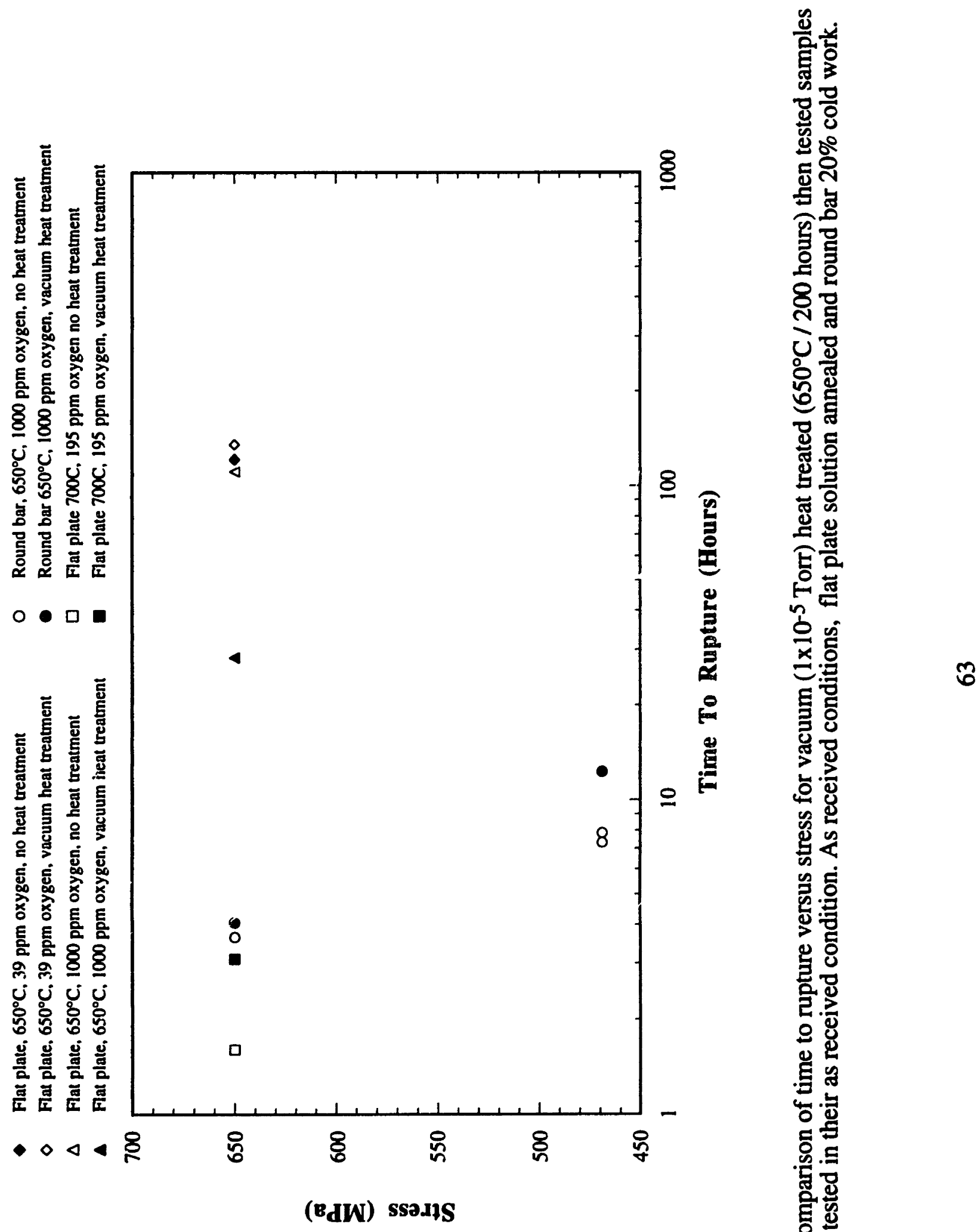

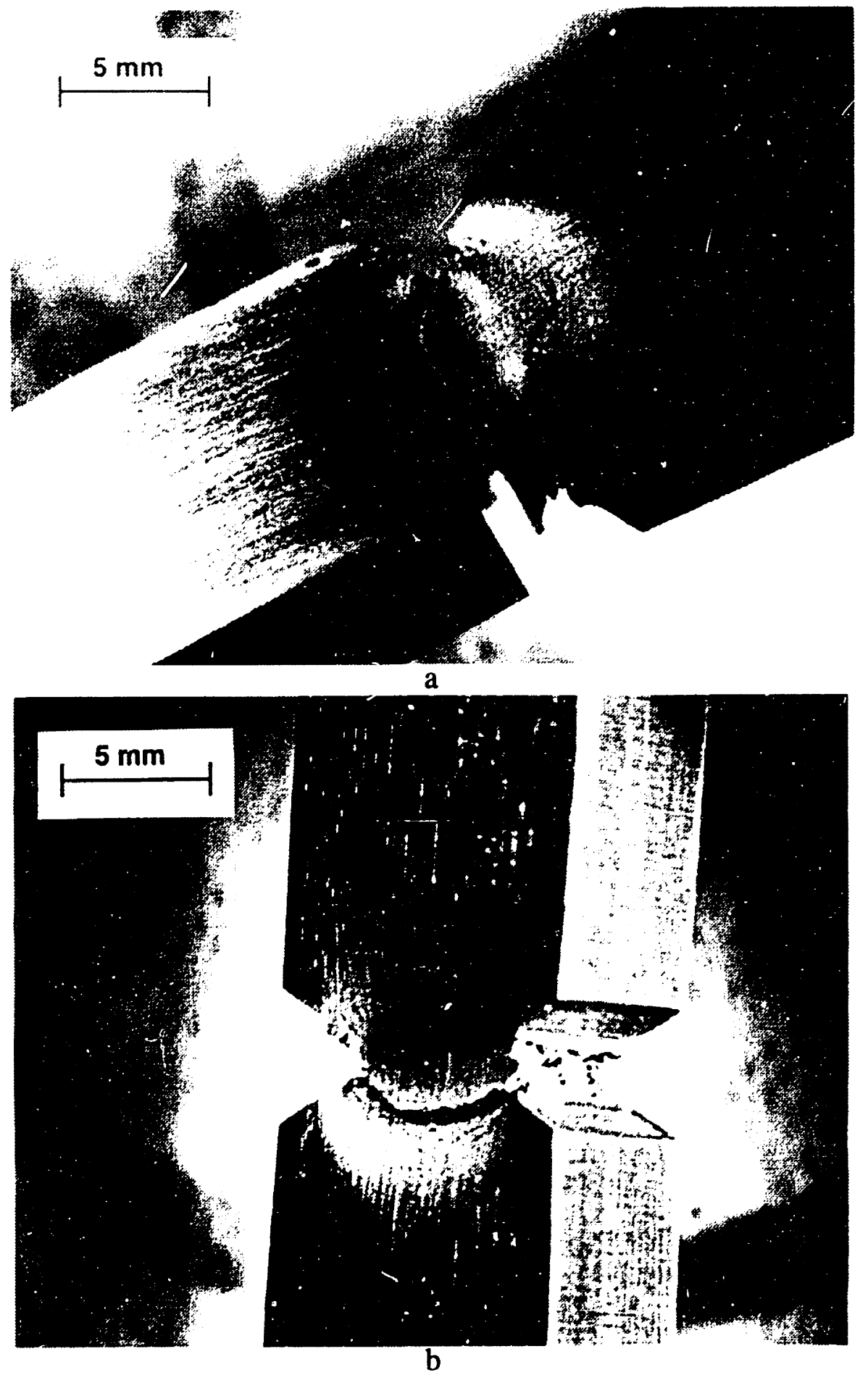

Figure 25. Micrographs of $650^{\circ} \mathrm{C}$ sample $9 \mathrm{P}(640 \mathrm{MPa}, 82.3 \mathrm{~h}, 6 \mathrm{ppm} \mathrm{O})$. (a,b) Stereomicrographs of reconstructed specimen after failure showing deformation pattern in region of notch. 


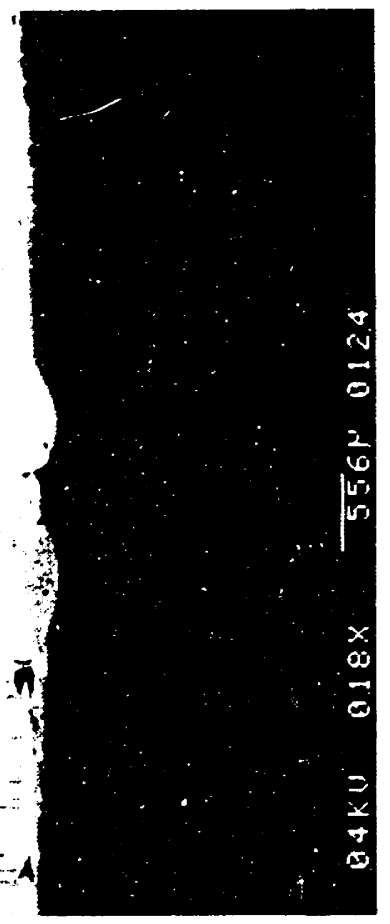

a
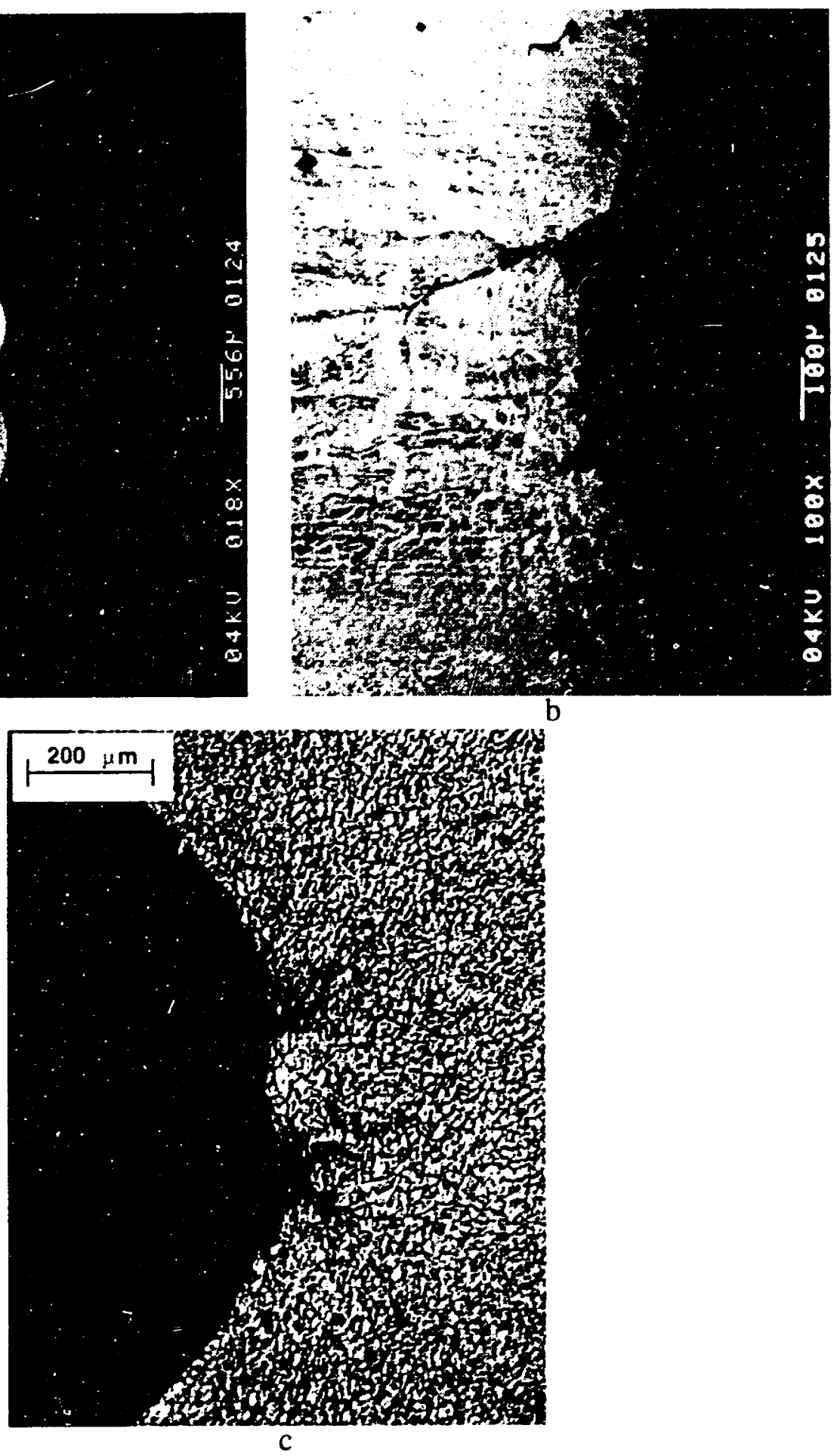

Figure 26. $550^{\circ} \mathrm{C}$ sample $30 \mathrm{P}$ loaded at $644 \mathrm{MPa}$ in $1.2 \mathrm{ppm} \mathrm{O}_{2}$. Test stopped after 478.3 hours. (a,b) SEM micrographs showing exterior of sample at notch section. (c) Optical micregraph showing cross section of unfailed notch.Cracking observed in this sample was not intergranular in character. 
oxygen concentration are illustrated in Figure 27. As shown in this illustration, two or three distinct fracture morphologies can be found in these samples depending upon oxygen concentration. Starting at the bottom figure, with no intergranular fracture originating at the notches, and moving up, with increasing oxygen concentration, the planar intergranular fracture region is seen to penetrate further into the sample from the notches. No evidence of ductility is observed on the intergranular fractures. The second fracture morphology seen in the flat plate samples, and in this illustration, is the V-shaped region extending into the sample from each notch. These regions are ductile with relatively large microvoids developed by creep cavitation. [112] Creep at the test temperatures employed in this study is possible in alloy 908 given that its' homologous temperature, $\mathrm{T}_{h}$, at $650^{\circ} \mathrm{C}$ is 0.56 and 0.5 at $544^{\circ} \mathrm{C}$. As illustrated, the V-shaped regions become smaller as the intergranular crack front progresses further into the sample. The semicircular areas in between are the shear lips that formed at final fracture. From a ductility or region of necking analysis, this illustration shows an increase in the pinned or brittle regions at the notches as the oxygen concentration is increased and a corresponding decrease in the shear lip areas. This observation is consistent with a decreasing percentage of shear lip area corresponding to increasingly brittle behavior. [113] In this case, intergranular embrittlement increases with increasing oxygen concentration. In cross section, the intergranular fracture path appears as a flat ledge perpendicular to the tensile axis. The length of the ledge corresponds to the depth of intergranular cracking, beyond which the crack path changes orientation and morphology to smooth/ductile along the shear lips. Based on fracture morphology, a plane stress condition exists for the flat plate samples examined in this study. An approximation of the plastic zone size for the flat plate samples was obtained from microhardness measurements in the vicinity of the notches of failed samples. Failed halves of test samples, with their longitudinal-transverse (LT) faces oriented for metallographic viewing, were used for the microhardness traces. The microhardness trace shown in Figure 28 starts at the rupture surface and runs in the longitudinal direction down the center of the sample to a distance of $7.8 \mathrm{~mm}$. Subtracting the distance traversed over the shear lip, the plastic zone extends approximately $4800 \mu \mathrm{m}(4.8 \mathrm{~mm})$ vertically. This estimation is based on microhardness values that exceed the unstressed matrix value, shown in the plot as the double line. The transverse, notch to notch, microhardness trace is shown in Figure 29. Based on sample design, the notch to notch distance is $4.45 \mathrm{~mm}(4450 \mu \mathrm{m})$. The material between the notches has a higher microhardness than that of the unstressed matrix. This indicates that the plastic zone extends across this distance and overlaps for the two notches. This was verified on visual examination of these samples, and can be seen in Figures 25a 

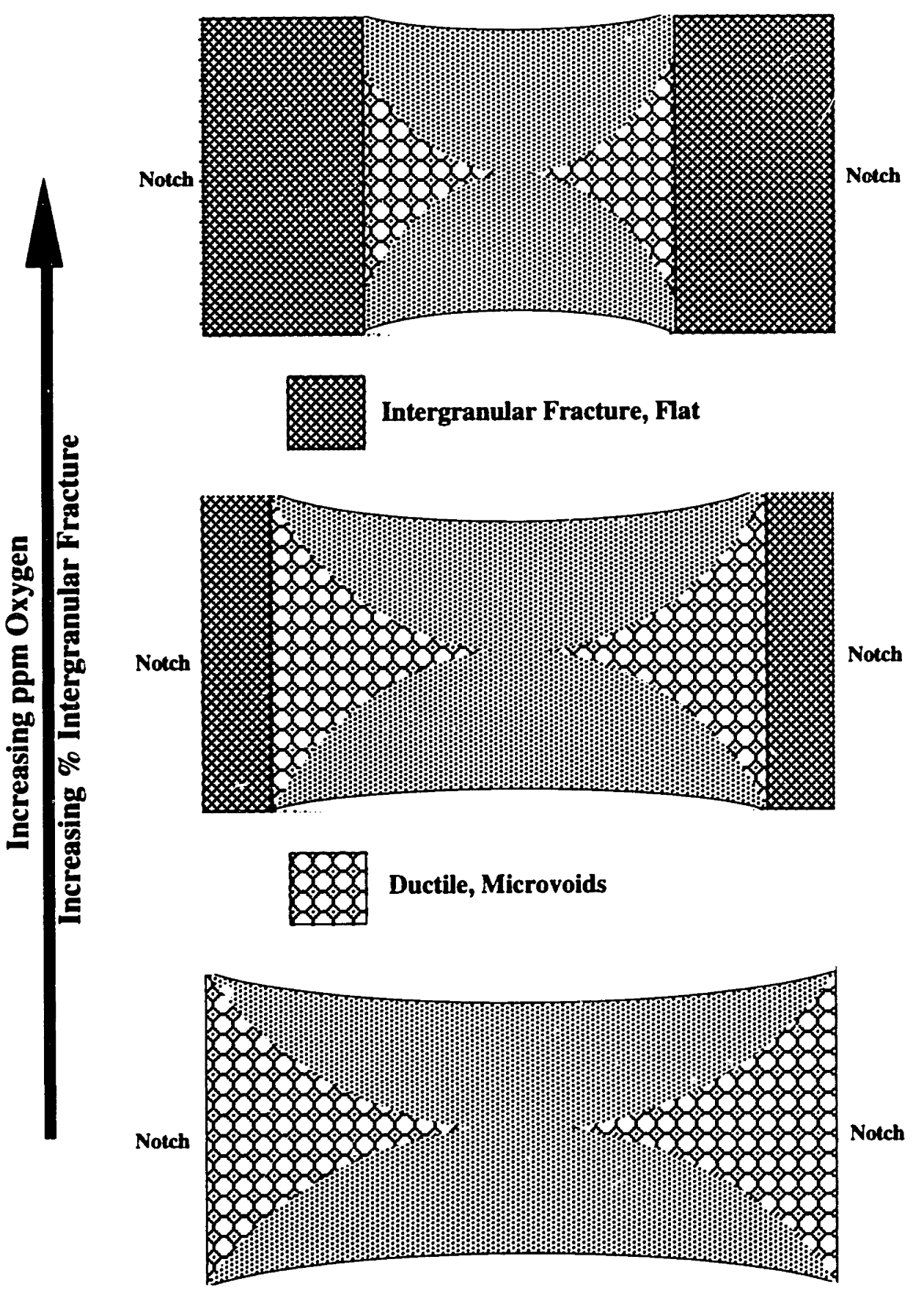

Shear Lips, Smooth Ductile

Figure 27. Characteristics of flat plate stress rupture fracture surfaces as a function of oxygen concentration. 


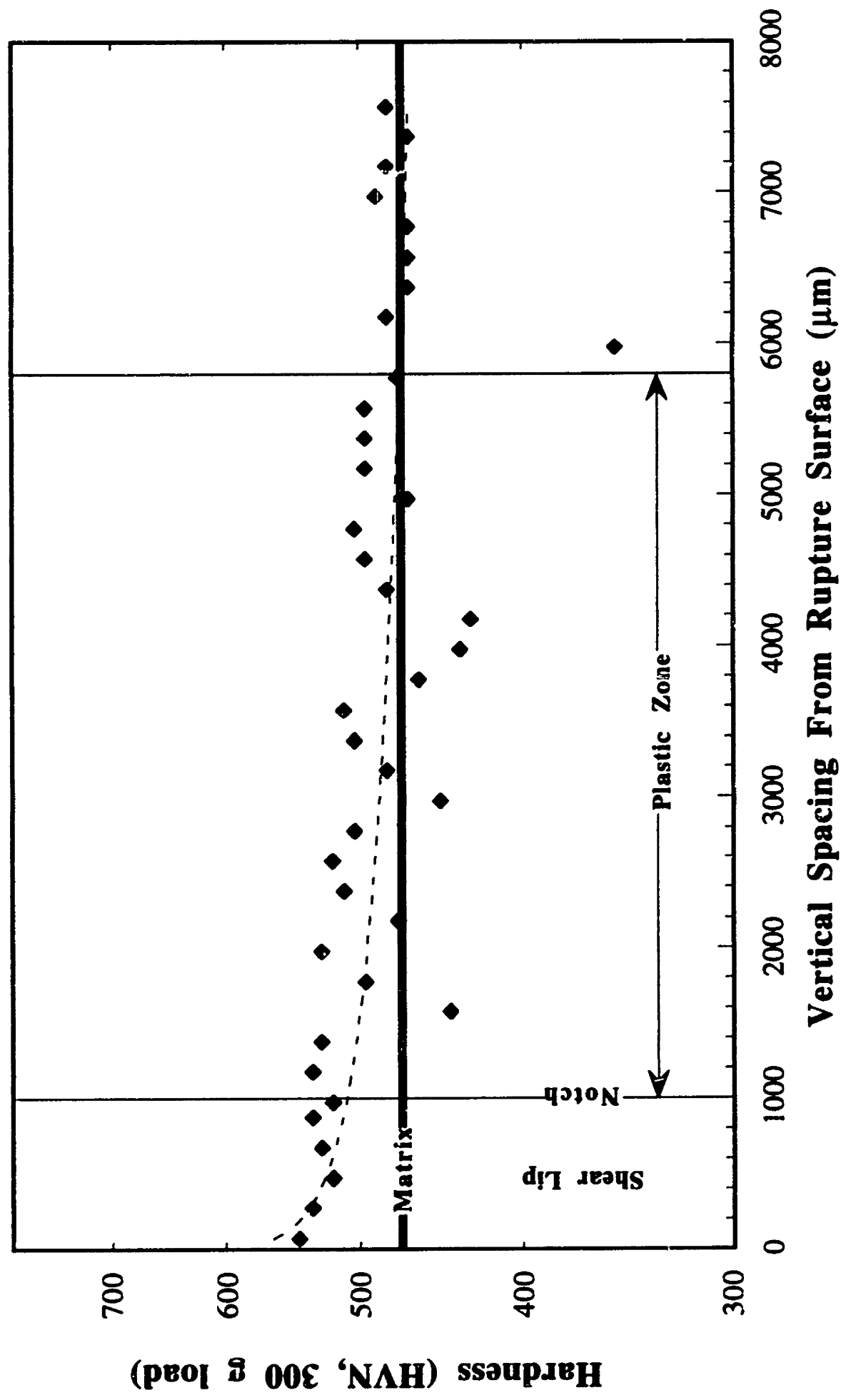

$\overline{7}$

总突

กีผ

ن롱

융ㄷํ

일

的吕

옹

로

कึ

은운

들

己

\&े

o

ป

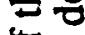

엉

可胥

5

巳્ટ

สํㅗㄹ

콜

쫑

앤

드영

롱

000

응 옹

สิ

ষ్․․

옹

各

过

항

응

옹

F

홍

은

Z 증

II

믐 舲

总骂 


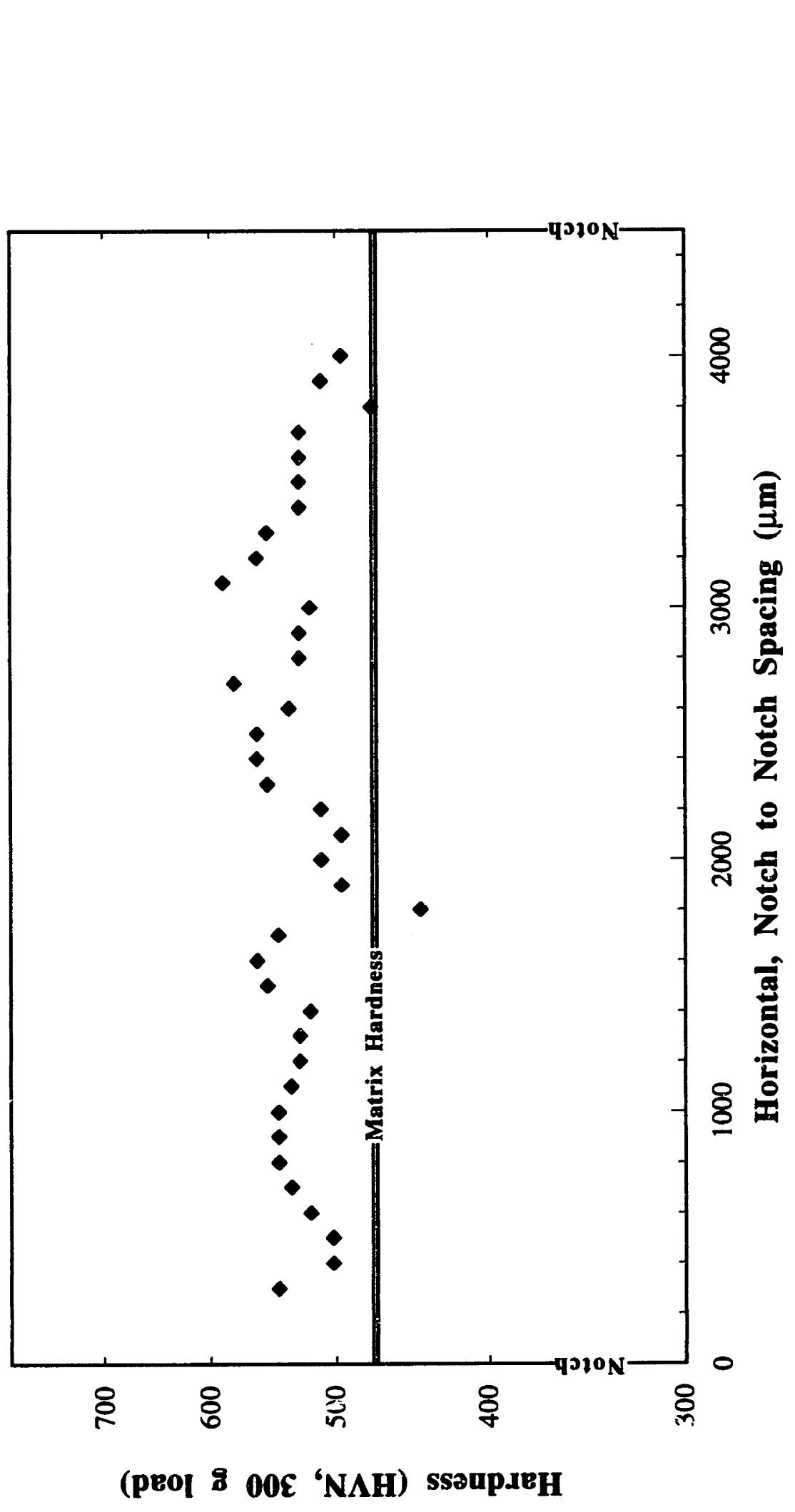

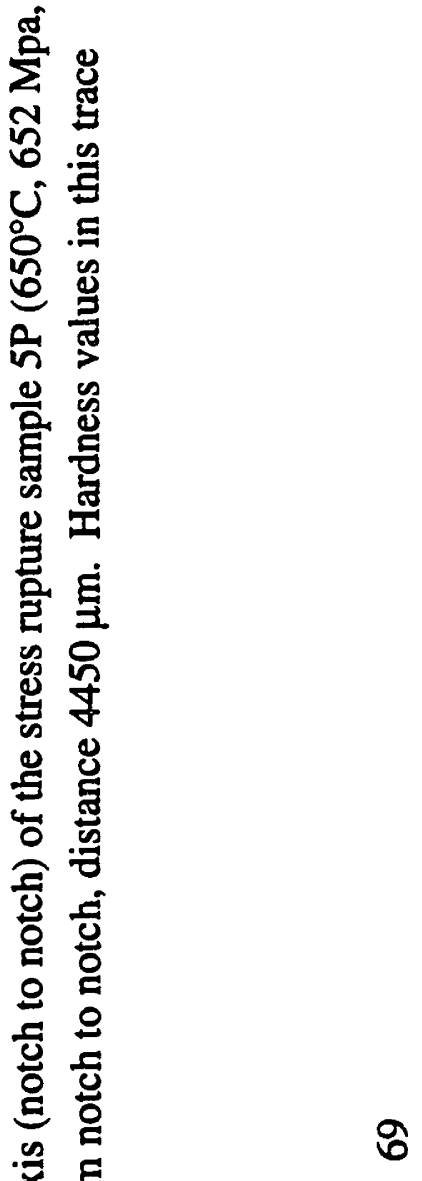


and 25b. The large plastic zone, relative to sample thickness $\left(r_{p} \geq t\right)$, confirms that these samples v'ere under plane stress conditions during testing and is consistent with fractographic evidence.

The actual frastographic characteristics observed with increasing oxygen concentration, as discussed above, can be seen in the SEM micrographs snown in Figures 30a-d. There is ro correspondence between time tu failure and increasing percent intergranular fracture. The micrographs shown in Figures 31a-f illustrate the effect of oxygen concentration on fracture characteristics at $650^{\circ} \mathrm{C}$. Figures $31 \mathrm{a}$ and $31 \mathrm{~d}$ show a fully ductile fracture that occurred after 96.4 hours in $0.01 \mathrm{ppm}$ oxygen. In this sample, the grains at the root of the notch are deformed and evidence of some creep cavitation is present in the cross section view. [112] As seen in Figures 31b and 31e, testing in 0.75 ppm oxygen results in intergranular cracking that extends 2-3 grain diameters in from the notch, while the remaining material exhibits fully ductile fracture characteristics. When the oxygen concentration is increased to $53 \mathrm{ppm}$ the intergranuiar fracture area increases to $41 \%$ and, as shown in Figures $31 \mathrm{c}$ and 31f, the intergranuiar fracture path has progressed along fronts parallel to the notches, and the remaining center band of material has failed in a ductile manner. The grains in the region that has failed in an intergranular mode .re not deformed, as is evident in the cross section view seen in Figure 31c. A compaiable set of $700^{\circ} \mathrm{C}$ fracture surfaces and cross section are shown in Figure 32a-d. At this higher test temperature the fracture surface shows more ductile area than the lower temperature samples at similar oxygen concentrations, but with typically shorter rupture lives. The alignment of creep cavities along the tensile axis is more prominent at this temperature, as can be seen in Figures $32 \mathrm{~b}$ and $32 \mathrm{~d}$. This is the expected result of the increase in creep rate with temperature. The overall effect of increasing temperature on stress rupture fractography can be seen in Figures 33a-c for 750,700 , and $650^{\circ} \mathrm{C}$ tests. As can be seen in comparing these fractures obtained at identical stress $(650 \mathrm{MPa})$ and oxygen coricentration (195 ppm), the rupture time and percent intergranular fracture increase while reduction in area decreases with decreasing temperature. The ductile rupture component of the failure becomes more prevalent at higher temperatures when the other variables remain constant. [112]

No trend was observed between time to ripture and oxygen concentration. A definite correlation between oxygen concentration and percent intergranular fracture was observed. The data shown in Figure 34 are from flat plate stress rupture tests performed at $650^{\circ} \mathrm{C}$ and in the stress range $651 \pm 18 \mathrm{MPa}$ ard at different oxygen concentrations. As can be seen in this figure, the percent intergranular fracture increases as the oxygen concentration or 


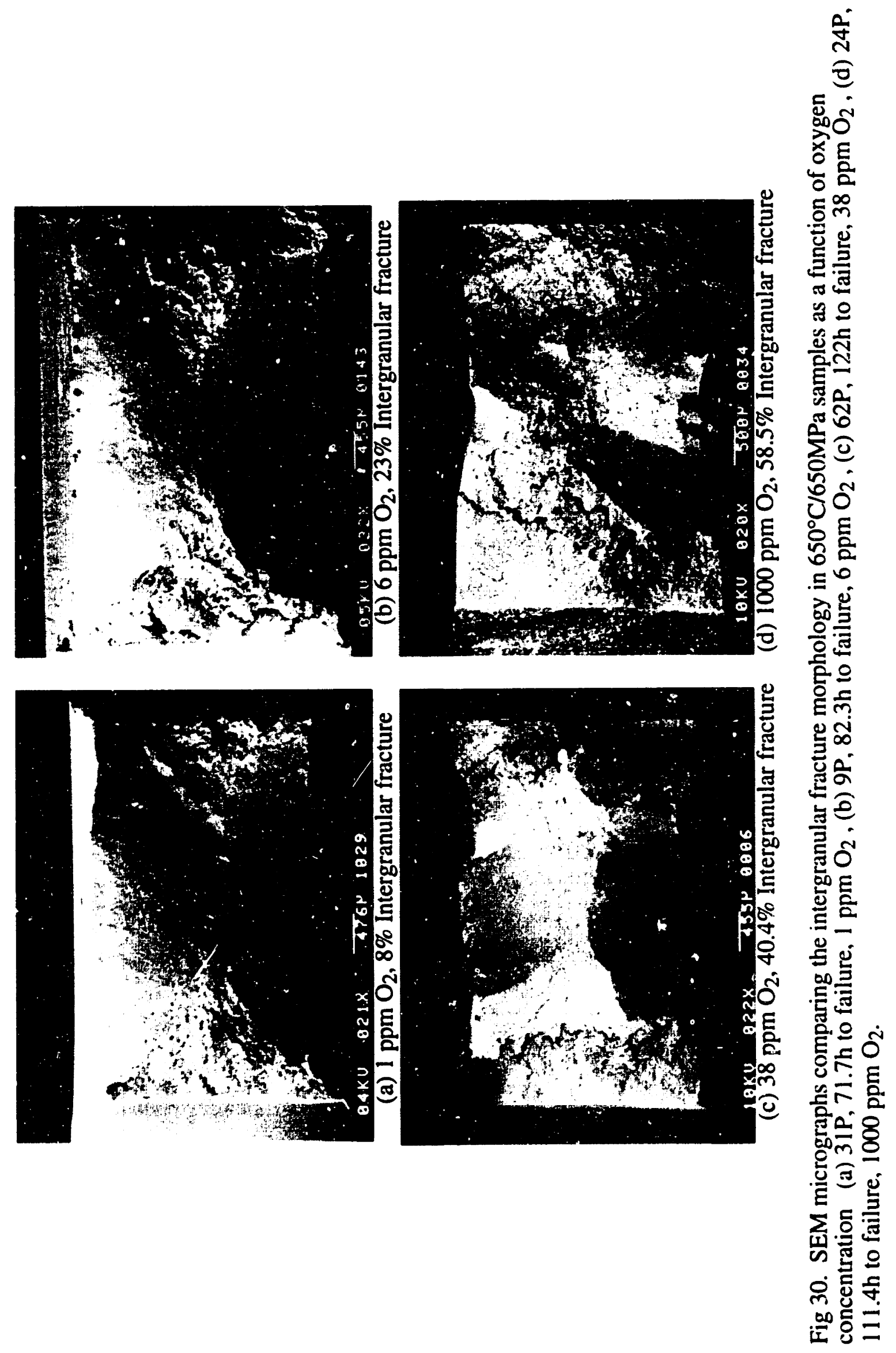




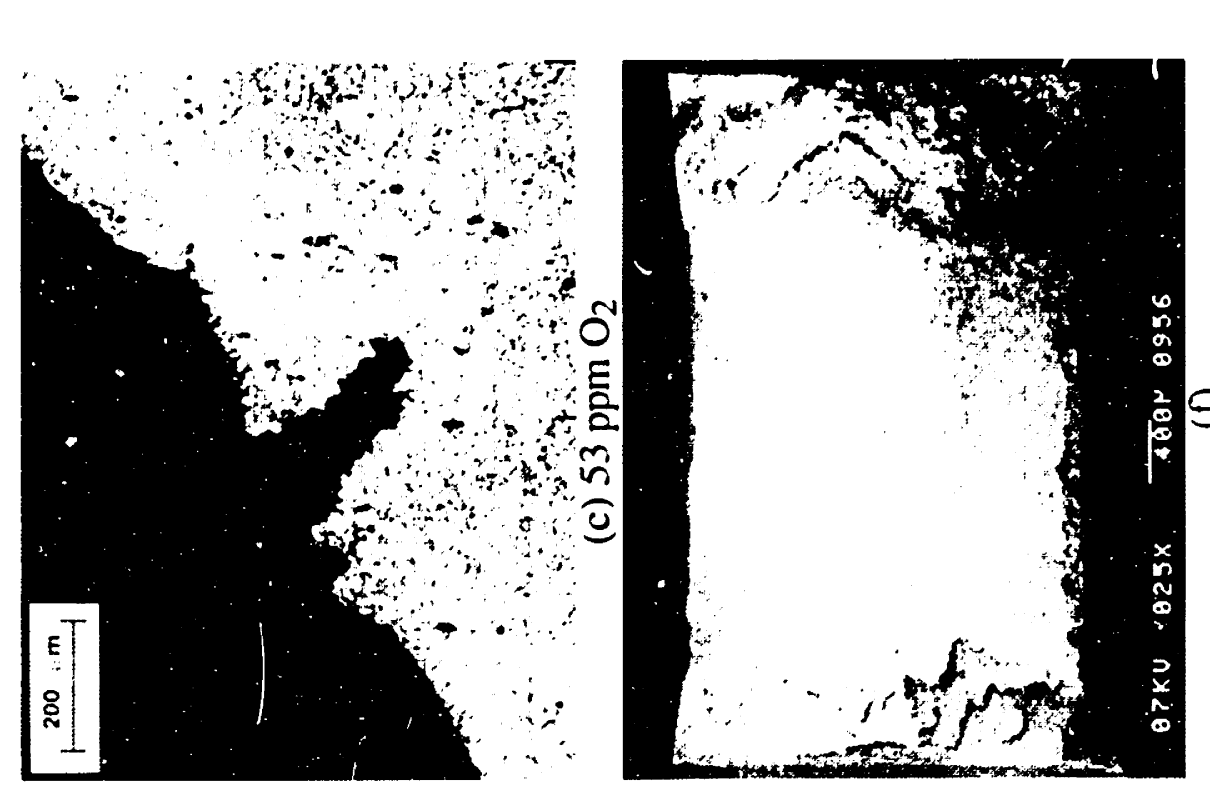

톤을

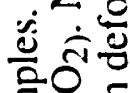

余

U而

ㅇํㅇ 年

过

正.

들

유ㅇㅛㅛ

氜氖导

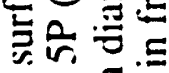

늘

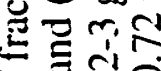

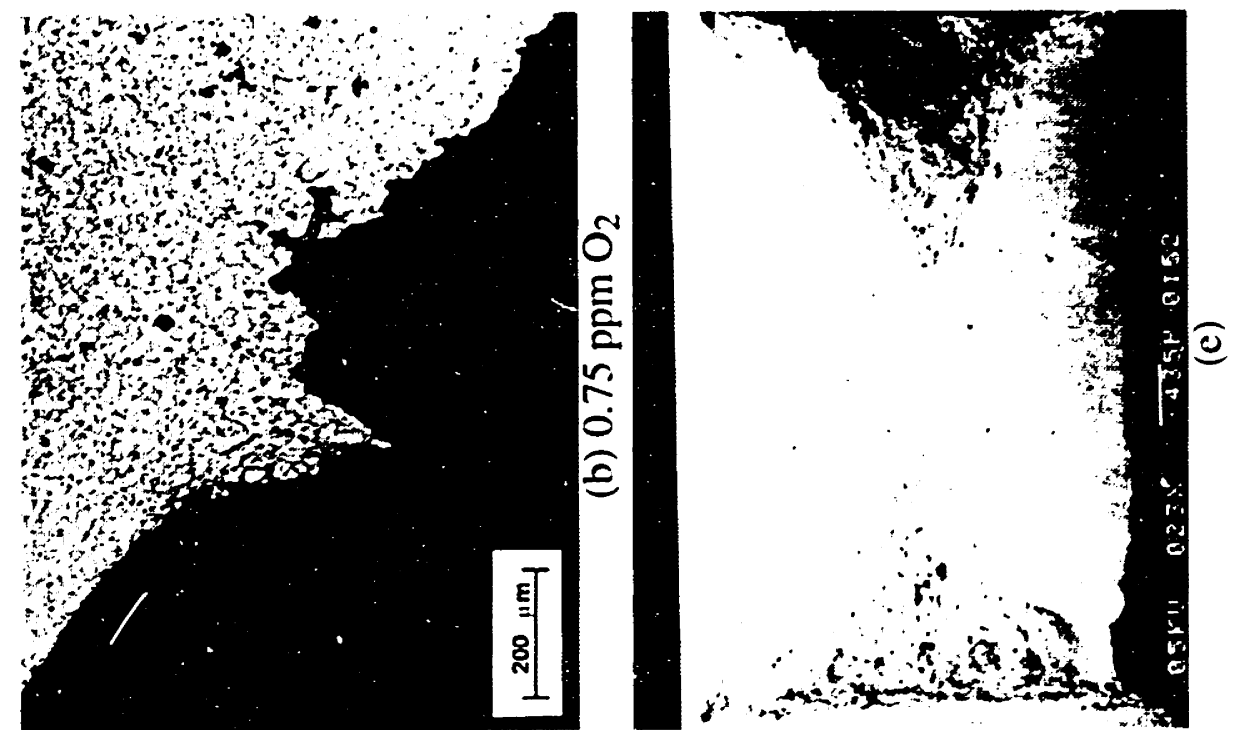

둥

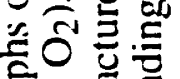

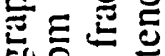

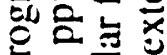

次瓷

官官苛

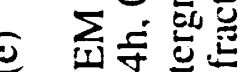

足氙

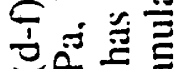

司全苛

웅을

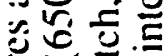

全员

包家

拧三

롱

过

它完

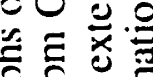

实言关

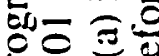

눙 $=$

起.

可施

递灾

ठิ远

议远

ড়

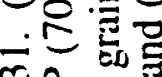

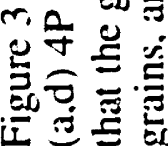




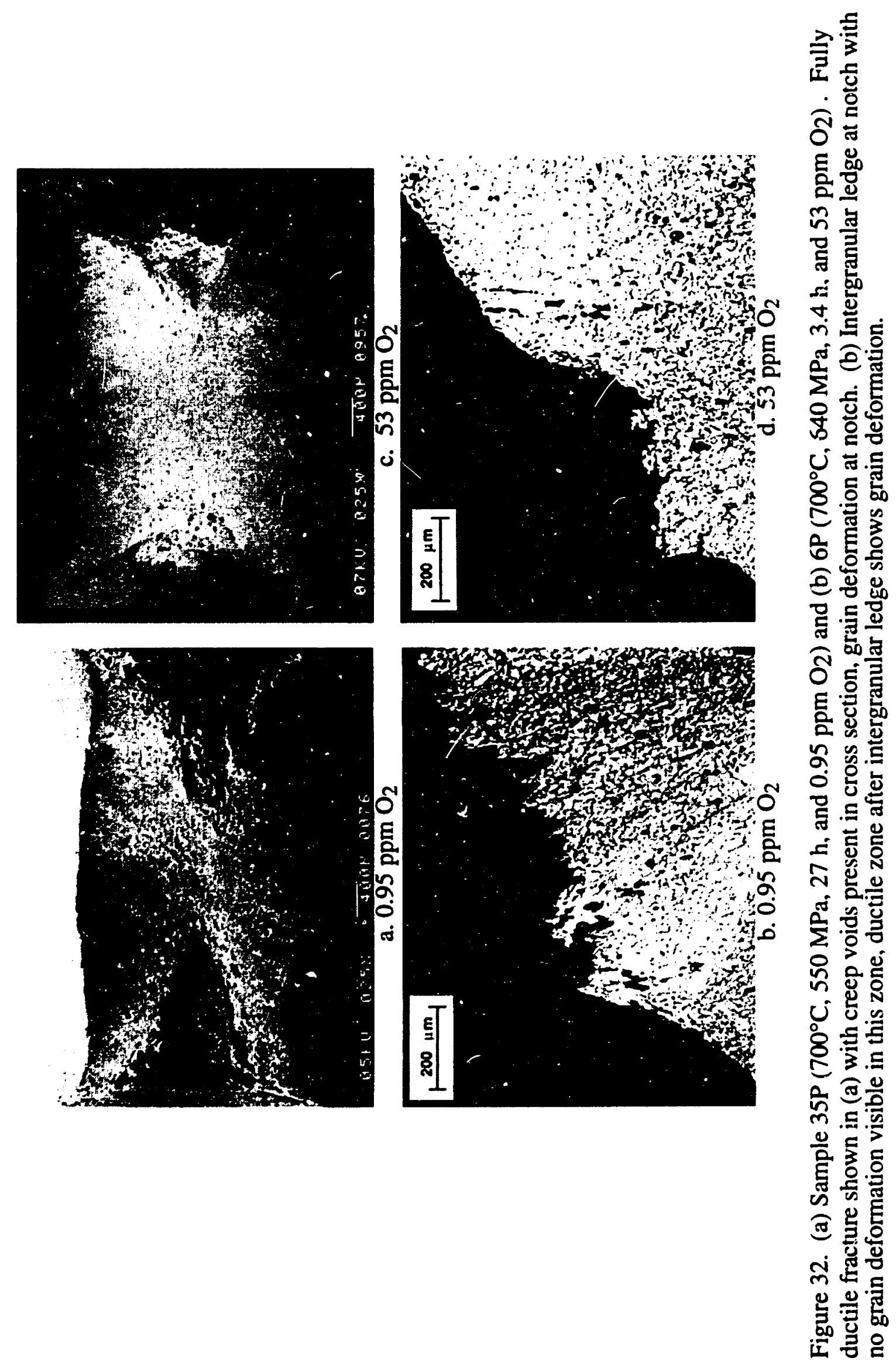




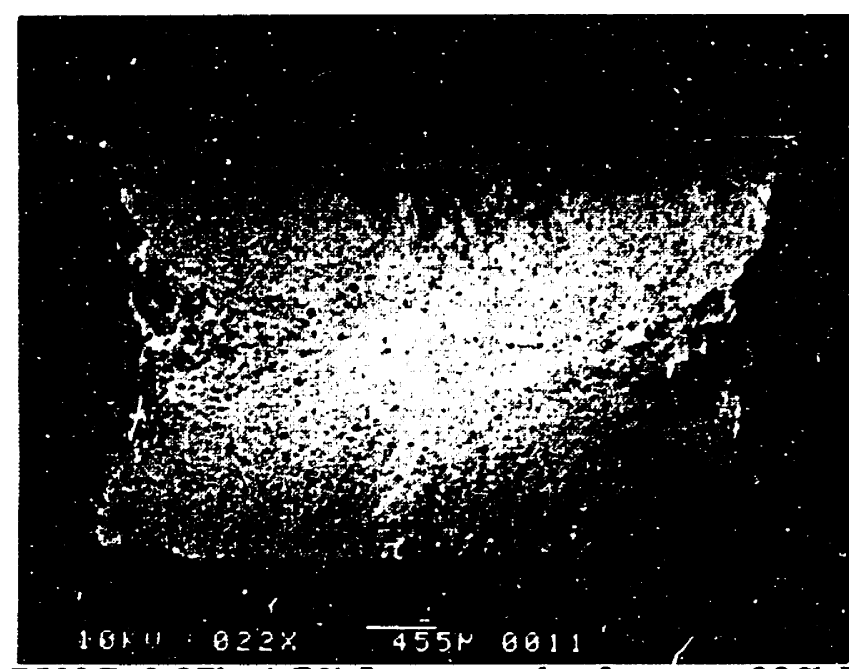

a. $750^{\circ} \mathrm{C}, 0.07 \mathrm{~h}, 1.7 \%$ Intergranular fracture, $32 \% \mathrm{RA}$

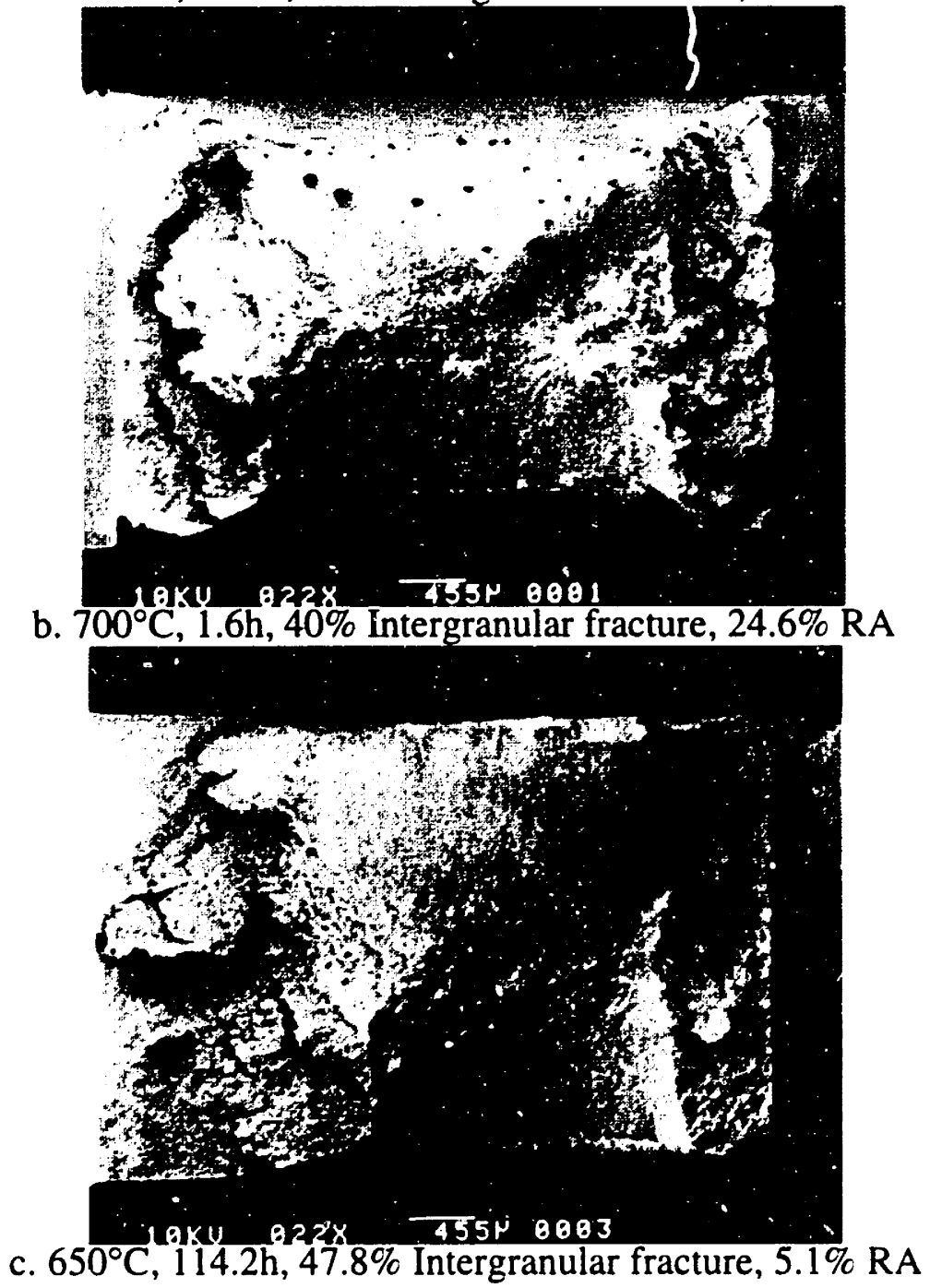

Figure 33. SEM micrographs showing the effect of temperature on fracture for a stress of $650 \mathrm{MPa}$ and $195 \mathrm{ppm} \mathrm{O}_{2}$. (a) Sample $65 \mathrm{P}, 750^{\circ} \mathrm{C}$ failure in 0.07 hours, $1.7 \%$ intergranular fracture. (b) Sample $64 \mathrm{P} 700^{\circ} \mathrm{C}$ failure in 1.6 hours, $40 \%$ intergranular fracture. (c) Sample $63 \mathrm{P} 650^{\circ} \mathrm{C}$, failure in 114.2 hours, $47.8 \%$ intergranular fracture. 


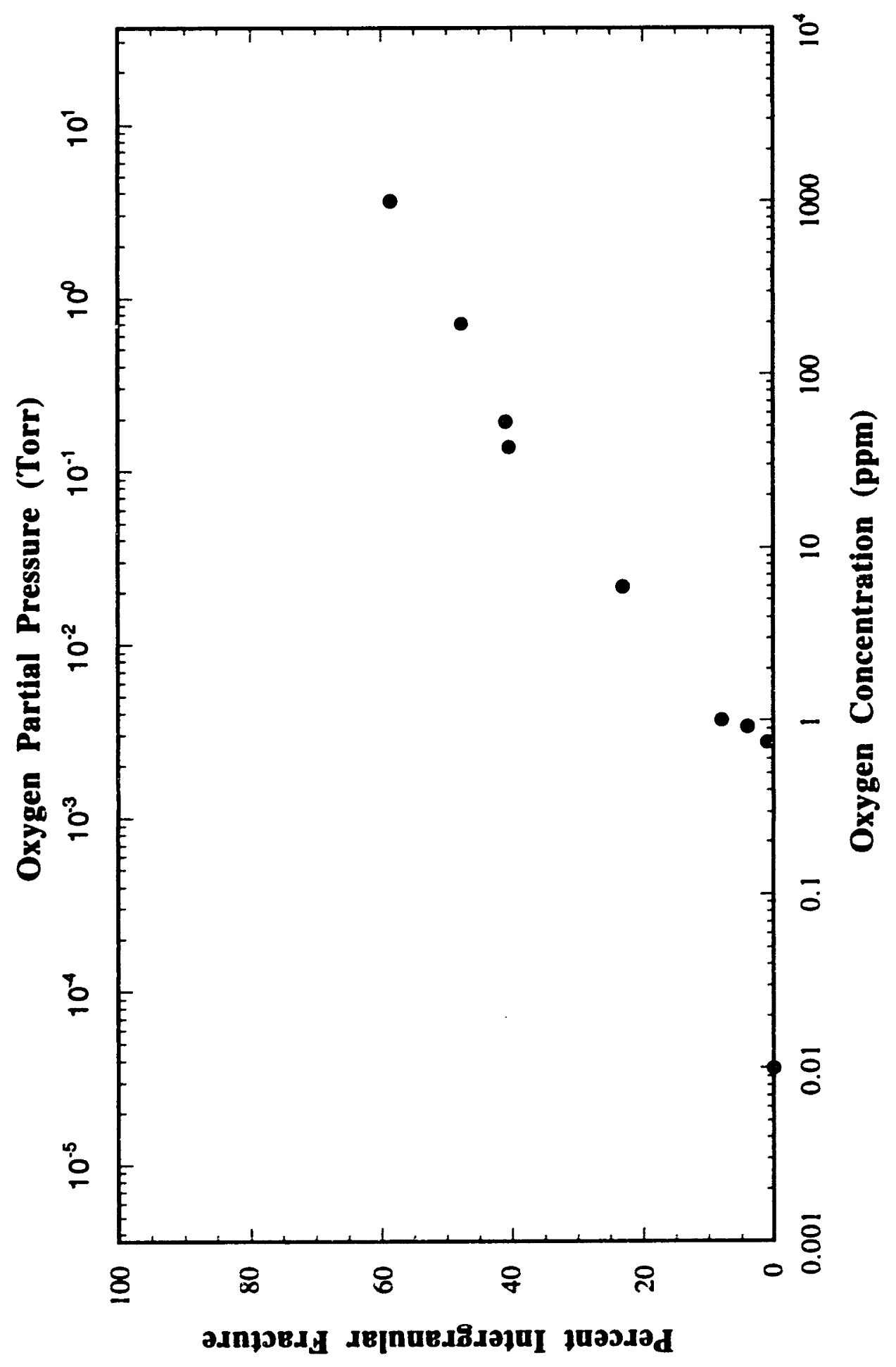

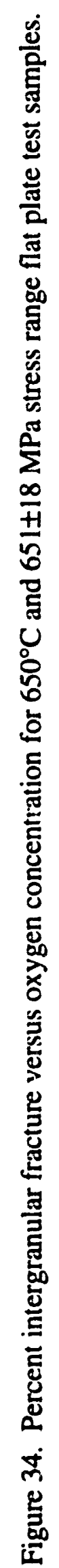


partial pressure increases. As shown in Figure 35, a similar but inverse relationship is seen between the ratio of ductile fracture area to total area and oxygen concentration. Figure 36 shows a plot for all sample types (flat plate and round bar), in four starting conditions: solution annealed, $20 \%$ cold work, and either solution annealed or cold worked with the addition of a vacuum $\left(1 \times 10^{-5} \mathrm{Torr}\right)$ heat treatment of 200 hours at $650^{\circ} \mathrm{C}$. As can be seen from Figure 36, the curve develops a sigmoidal shape, with a low ppm oxygen transition at between $5 \times 10^{-3}$ and $1 \times 10^{-4}$ Torr, and a similar plateau as the oxygen concentration approaches that of air ( $760 \mathrm{Torr})$. This data is compared with the $650^{\circ} \mathrm{C}$ slow strain rate test results from Andrieu for alloy 718 in Figure 37. [77] As can be from this plot, both data sets follow the same trend, with the alloy 908 stress rupture data falling on top of those for alloy 718. With respect to oxygen concentration, the curve shape and transition points seen here also follow those seen in $\mathrm{da} / \mathrm{dN}$ versus oxygen partial pressure and cycles to failure versus oxygen partial pressure curves for alloy 718 . [40]

\section{Interrupted Flat Plate Tests, Microstructure and Chemistry.}

Crack morphology prior to final rupture was examined on several interrupted samples. The samples shown in Figures 38a-d illustrate this for the low stress (540 MPa) condition that produced extended rupture times, but percent intergranular fractures in the same range as high stress $(650 \mathrm{MPa})$ samples at similar oxygen levels. An optical micrograph of the notch cross section shown in Figure 38a shows elongation of the notch section after 522 hours and some delineation of the grain boundaries at the notch due either to oxidation or precipitation. A SEM micrograph of the surface of the notch in this sample shown in Figure 38c. The notch in this figure shows evidence of intergranular tearing that is 1-2 grain diameters deep $(20 \mu \mathrm{m})$. The notch cross section from a sample exposed to identical test conditions that failed at an earlier time (452 hours) is shown in Figure $38 \mathrm{~b}$ for comparison. The notch cross section seen in Figure 38d is from a test that was stopped at 211 hours ( $0.9 \mathrm{ppm}$ oxygen). There was no indication of intergranular cracking or grain boundary delineation in this sample. Internal oxidation was found to extend to a depth of 5-10 $\mu \mathrm{m}$ below the surface of the notch. A composition profile extending in from the surface of this sample was produced by EDS using spot analysis in the SEM. The profile was divided into element groupings to enhance its clarity and is shown in Figures 39 and 40. This composition profile shows several features. Most noticeable is the increase in niobium concentration extending $15 \mu \mathrm{m}$ below the notch surface. Oxygen is present over the same depth. This indicates the association of the two elements in the form of an oxide. 


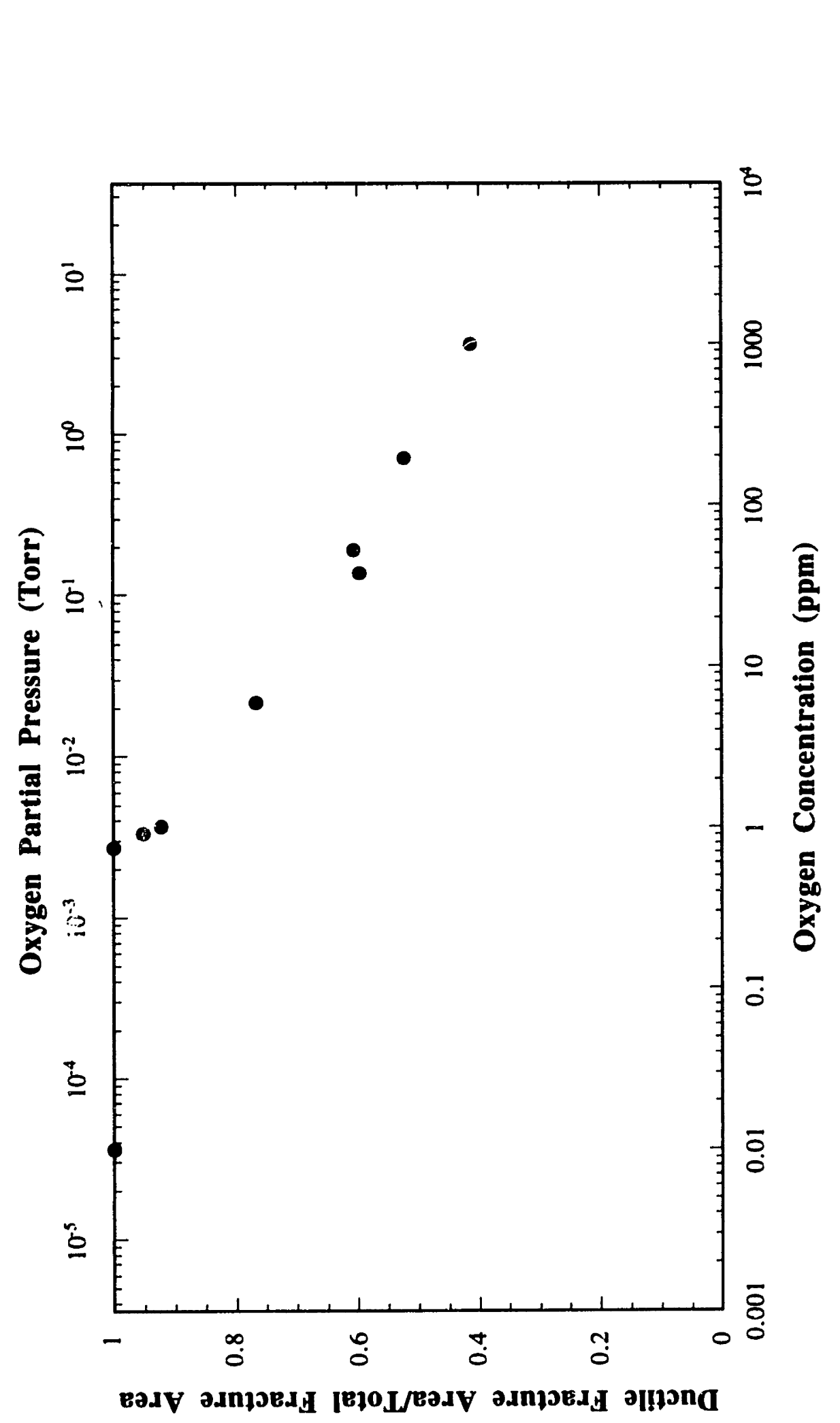

$\stackrel{\infty}{+1}$

ที่

몰

ํํㅇ

范

d)

葛

产

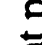

矛

홀

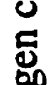

Хิ่

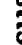

$N$ 


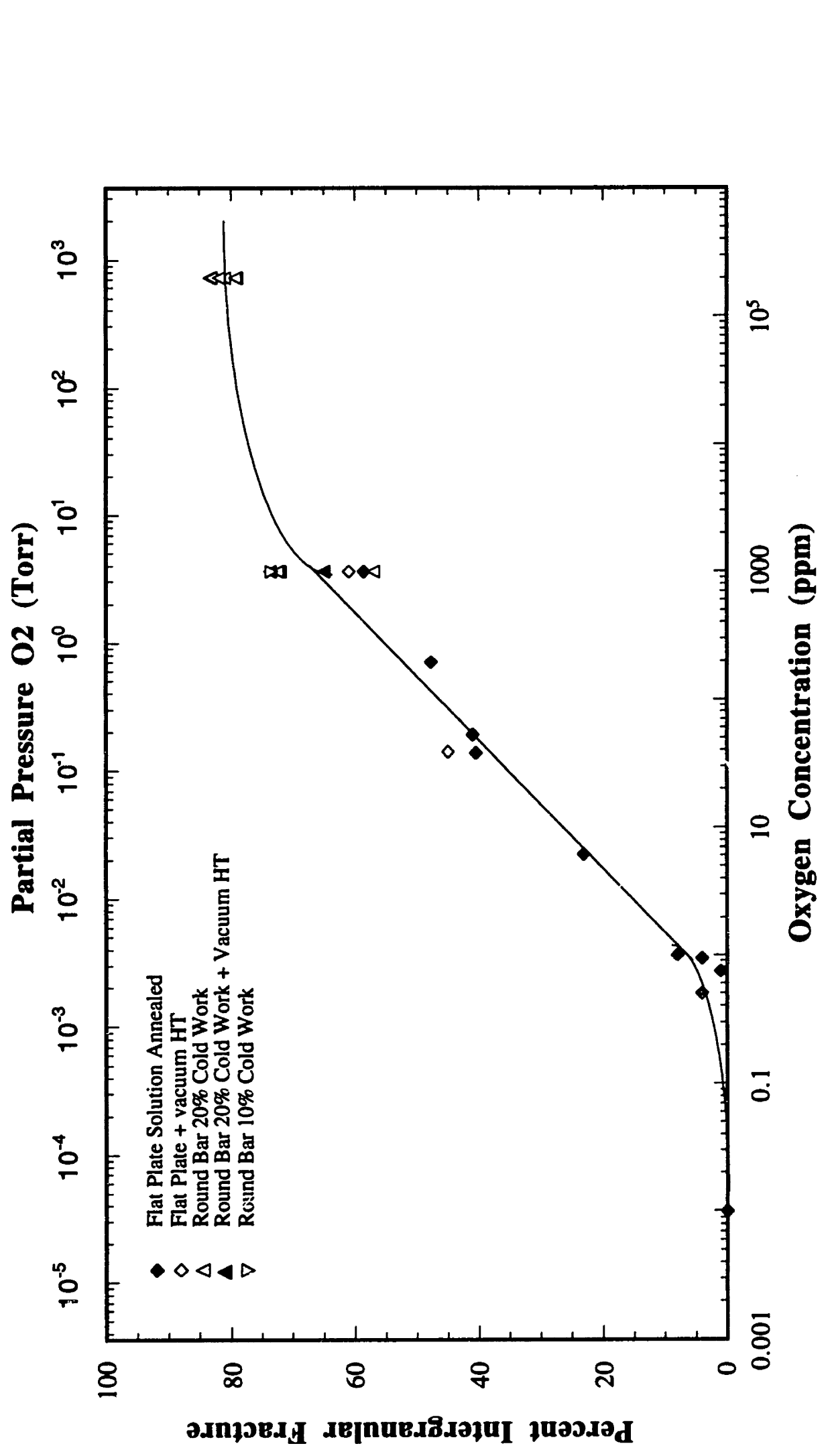

콘

U

ที่

ส

త্

ชี้

뭉

항

్ㅗ

$\stackrel{3}{3}$

줌

\&

్ㅗㄹ

สี

눙

옹

$\infty$

O

ธ్ำ

ฉูર

氙

$\$$

อ

웅

尔 +1

药

:

递

.

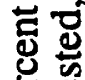

造

A

일

y

的点 


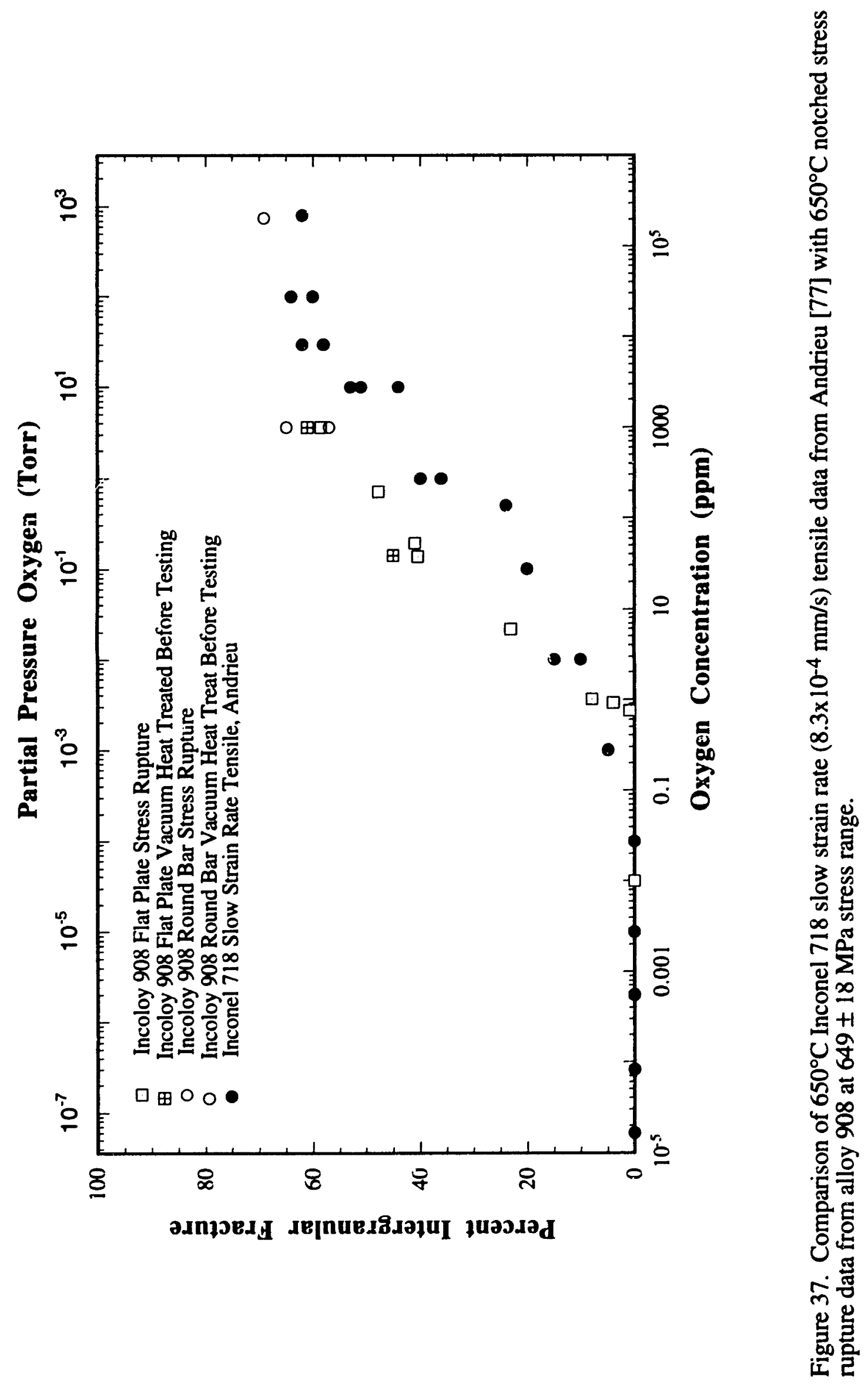




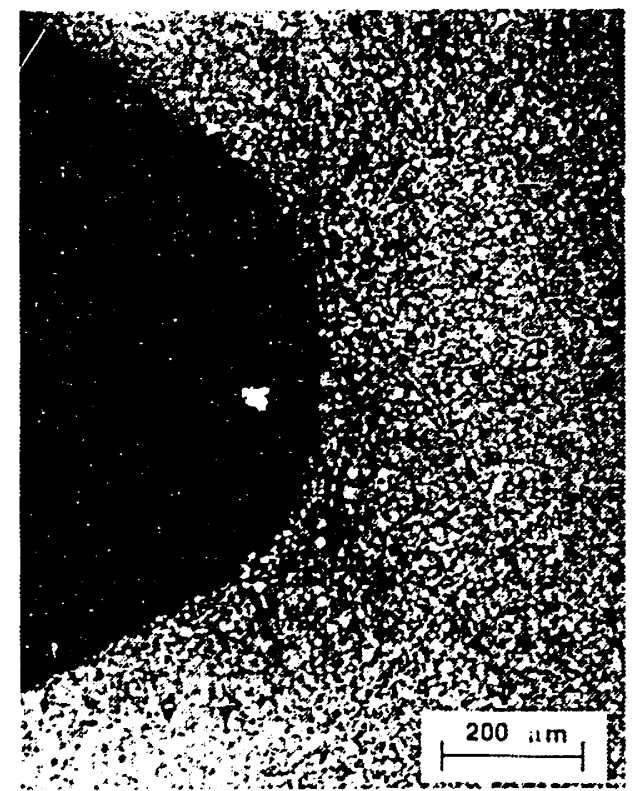

(a) $522 \mathrm{~h}$ Stop Test

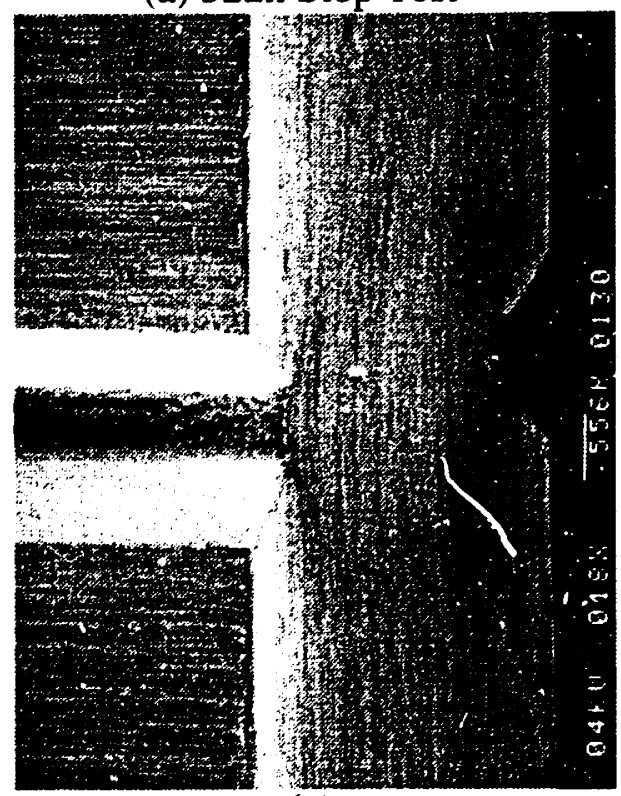

(c)

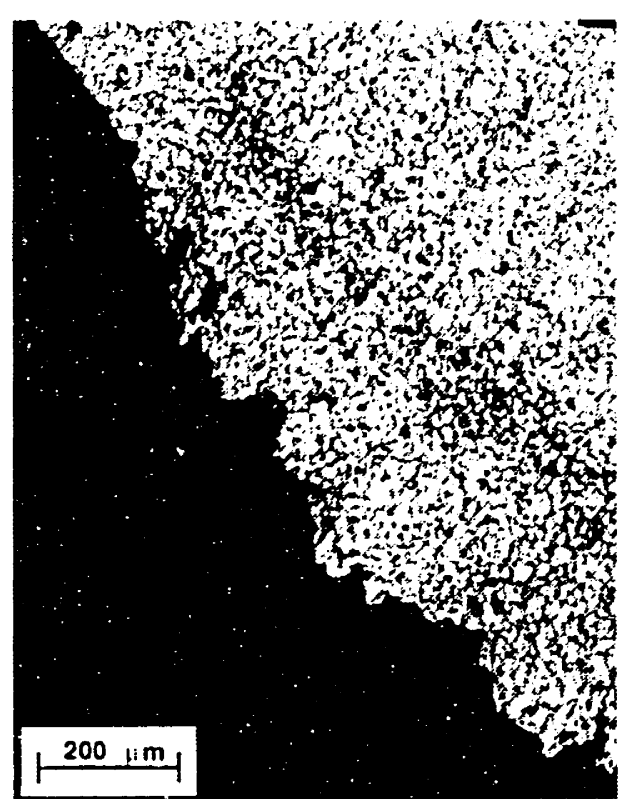

(b) 452h Rupture

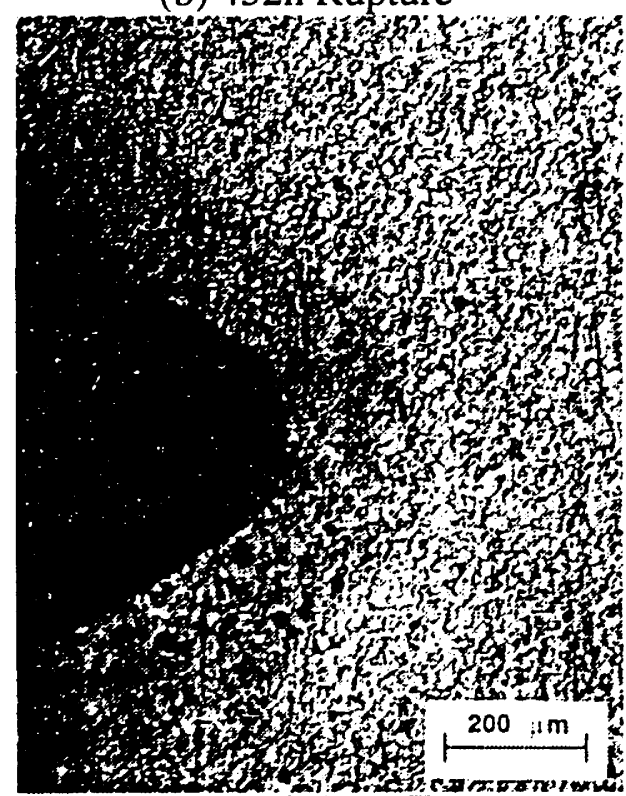

(d) $211 \mathrm{~h}$ Stop Test

Figure 38. Micrographs comparing the notch morphologies of the $650^{\circ} \mathrm{C} / 540 \mathrm{MPa}$ samples (a) (c) $38 \mathrm{P}\left(0.5 \mathrm{ppm} \mathrm{O}_{2}, 522 \mathrm{~h}\right.$ test stopped), (b) $37 \mathrm{P}\left(0.5 \mathrm{ppm} \mathrm{O}_{2}, 452 \mathrm{~h}\right.$ failure) and (d) $8 \mathrm{P}(0.9 \mathrm{ppm} \mathrm{O}$, test stopped at $21 \mathrm{lh})$. Note elongation of notch in (a) compared with (d). 


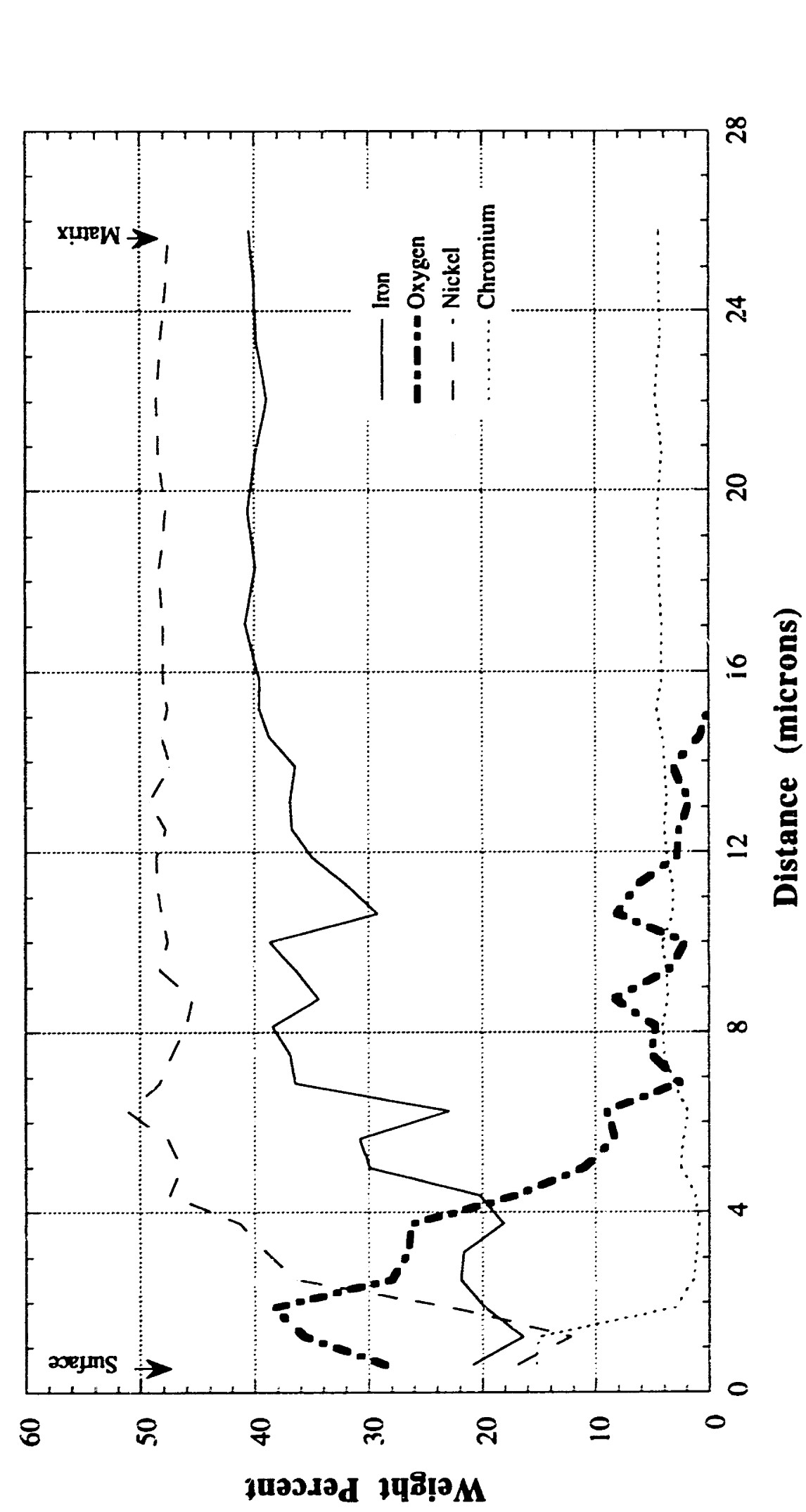

$ن$
$\vdots$
0

$\infty$

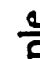

畓

4

응

ב

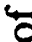

త

莺

巳

도

送

捠

국

ํㅡㅇ

흥

으이

实

ठิ

ह응

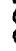

증옹

응

넝

分。

를

웅

후ㅇㅝㅡ

त्र

롱

四

م

\& 

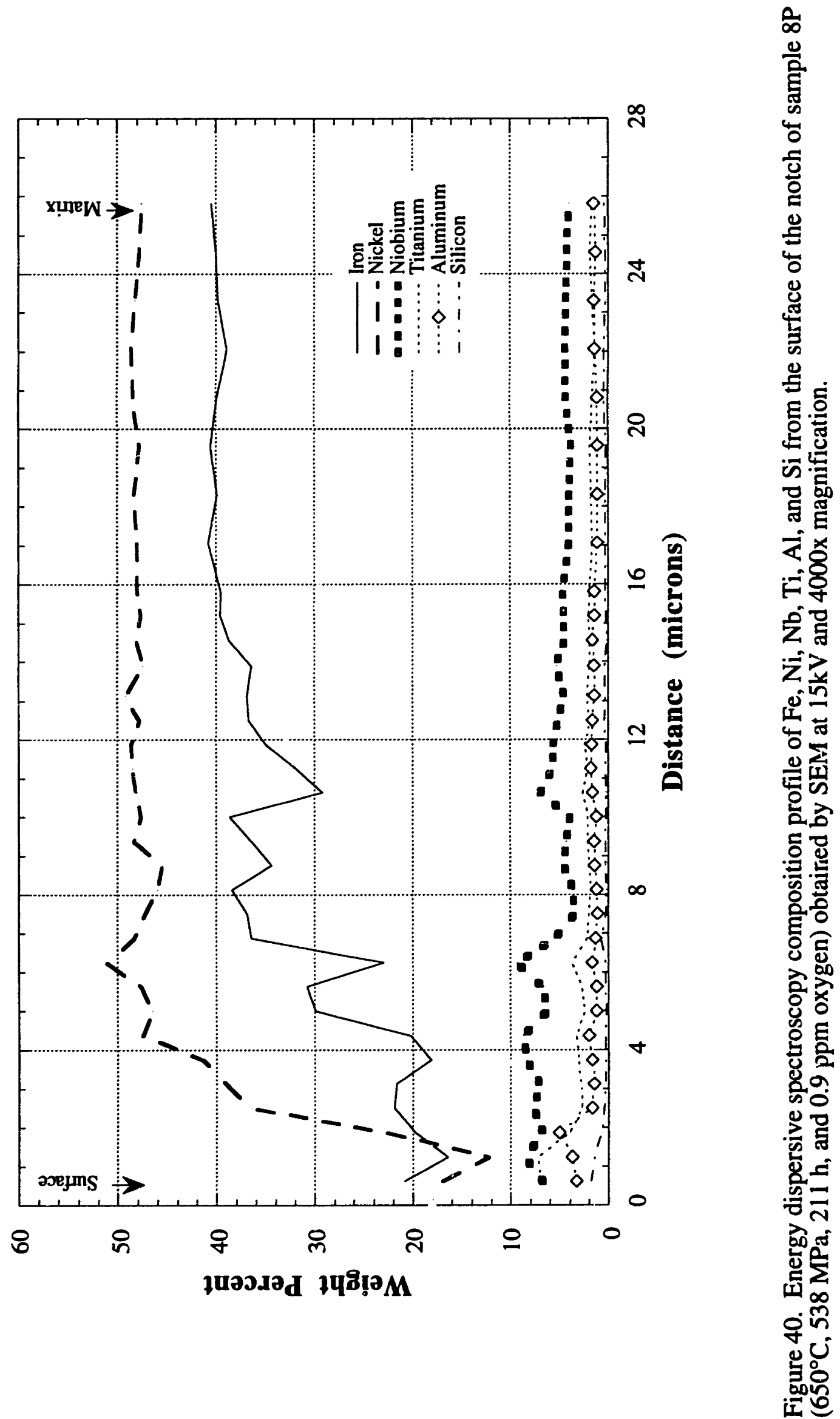
The surface oxide found on this sample is 1-3 microns deep, and associated with this oxide is an enrichment in $\mathrm{Cr}, \mathrm{Ti}$ aud $\mathrm{Al}$ as seen in the $0-3 \mu \mathrm{m}$ region of the profile shown in Figures 39 and 40 . The presence of $\mathrm{Cr}, \mathrm{Al}$, and $\mathrm{Ti}$ in the surface oxide scale was expected since the oxides of these elements are the most thermodynamically stable and require only low oxygen activities to form. [86]

Although no clear grain boundary elemental segregation could be found in the short time, 211 hour, sample, further examination of the grain boundary delineation seen in the 522 hour sample was performed using SEM and EDS. The SEM micrographs shown in Figures $41 \mathrm{a}$ and $41 \mathrm{~b}$ are from a region at the base of the notch shown in Figure 38a. The grain boundaries, as shown in these micrographs, are decorated with acicular and globular precipitates. The grain boundary precipitate region extends to a depth of $75 \mu \mathrm{m}$ below the surface of the notch. The plots, shown in Figures 42 and 43, were obtained from a near surface ( $5 \mu \mathrm{m}$ deep) region at the base of the notch using EDS. As was seen previously in the 211 hour interrupted test, the surface oxide is enriched in $\mathrm{Cr}, \mathrm{Ti}$, and $\mathrm{Al}$ to a depth of approx imately $2 \mu \mathrm{m}$. Niobium enric'.ment can be seen to occur deeper below the surface starting at approximately $3 \mu \mathrm{m}$, along with a corresponding decrease in the concentration of Fe. To distinguish elemental segregation associated with the grain boundary delineation seen in this sample, an EDS $x$-ray map was obtained for the region shown in Figure 4lb and can be seen in Figure 44. As can be seen from this map, the grain boundaries in this region show elevated levels of oxygen and niobium along with depletion of Fe. No clear pattern of segregation of the other elements was demonstrated by this technique. These results suggest that an oxide of niobium has formed at the grain boundaries. Another possibility is that a niobium rich phase such as niobium carbide formed at the grain boundaries. The niobium-rich phase gettered oxygen diffusing along the boundary, and then oxidized. $[56,69]$ Because this was a long time test, the latter explaration appears to be the most likely, given that long term heat treatments have been found to form a $\mathrm{Nb}$ rich intergranular phase in alloy 908. [1]

The intergranular fracture surfaces of all of the flat plate test specimens that ruptured had oxidized sufficiently to obsc' 're fine microstructural details. Initially it was th. ught that this oxidation had occuned during the interim beiween failure and furnace ccol down. The ductile fracture surfaces resulting from final fracture did not show a detectable surface oxidation layer. The intergranular fracture surfaces did. In order to examine how the fracture morphology and oxidation characteristics appeared prior to final fracture, a test was stopped before failure, cooled down, and fractured in air at 


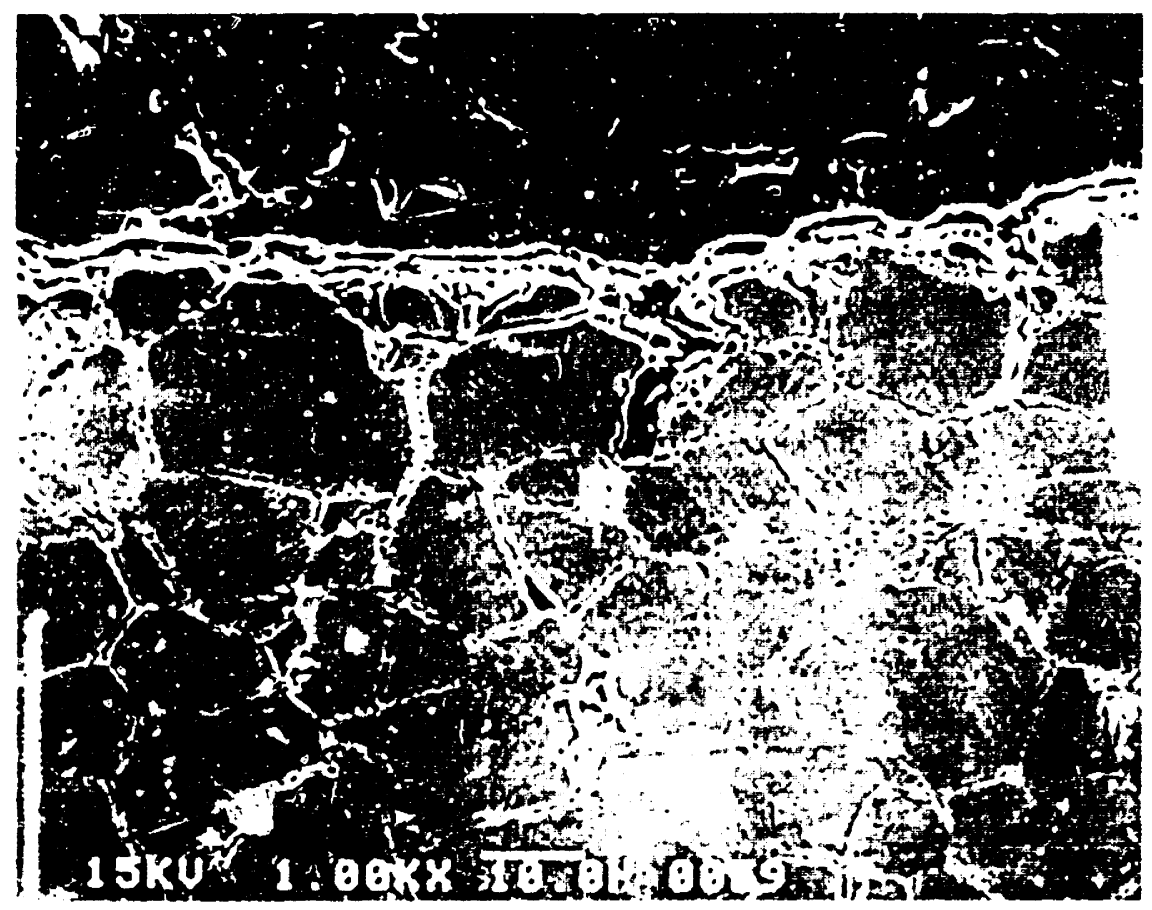

a

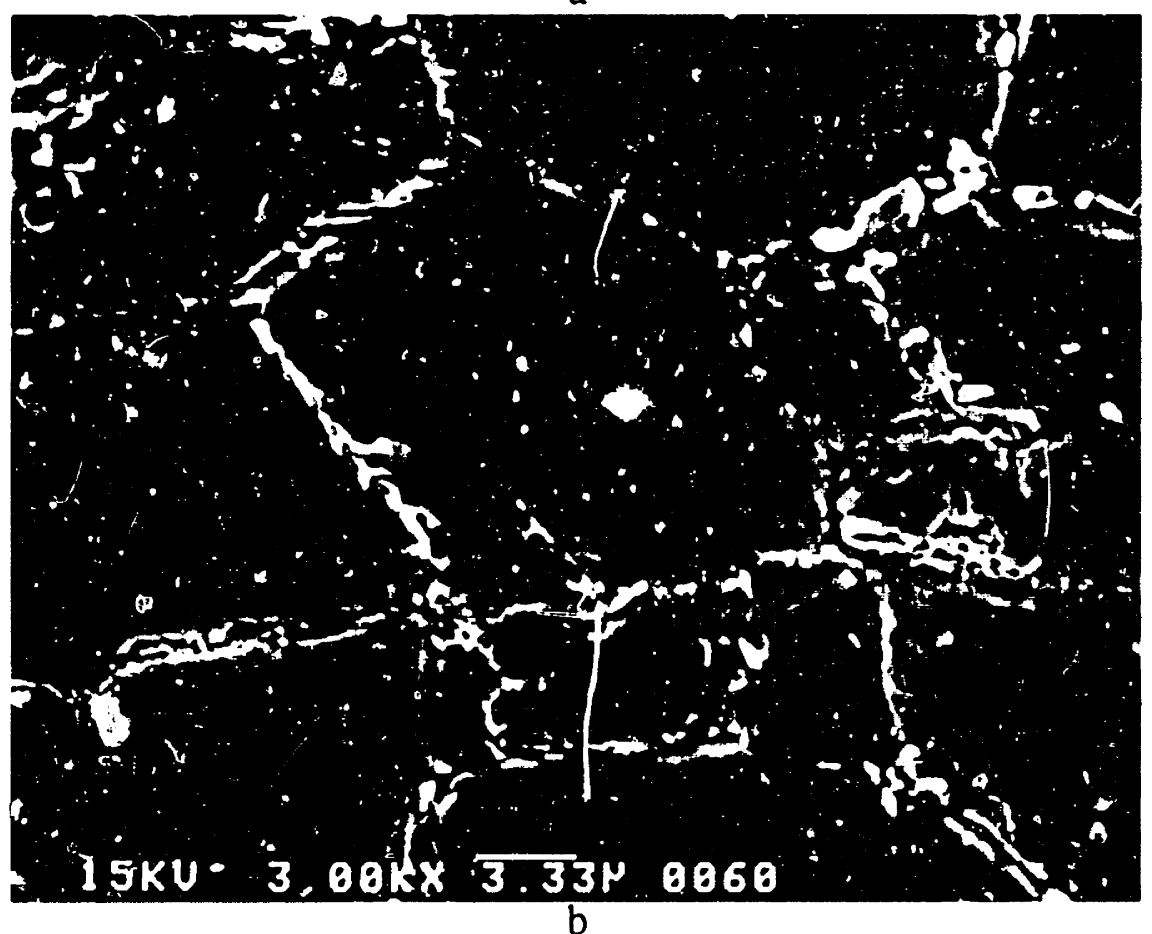

Figure 41 . Flate plate $650^{\circ} \mathrm{C}$ sample $38 \mathrm{P}\left(0.75 \mathrm{ppm} \mathrm{O}_{2}, 542 \mathrm{MPa}\right)$ test stopped at 522 hours. (a) Grain boundary microstruc ure at base of notch after test. (b) Higher magnificarion of region analyzed by $\mathrm{x}$-ray mapping. 


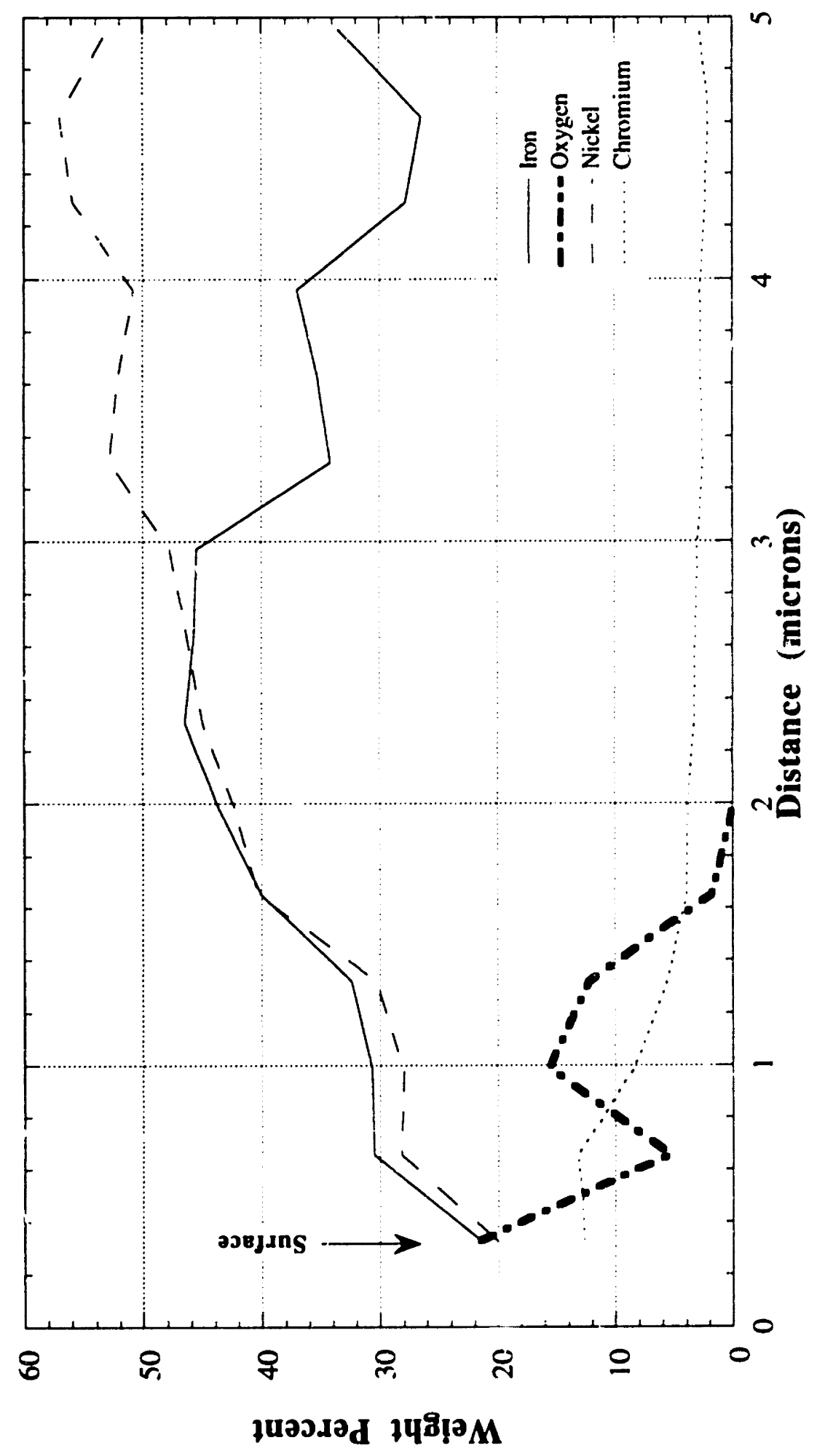

$\infty$

है

造

已

与

통

옹

பㅇㅇㅇ

은

흐음

$0 ?$

叫

少

○

론

은

등

吾.

응

통

웡

응

\&

는

造年

을

\&

ชู่

वृㅁำ

롤

(I) $\mathrm{Y}$ cin

ป 

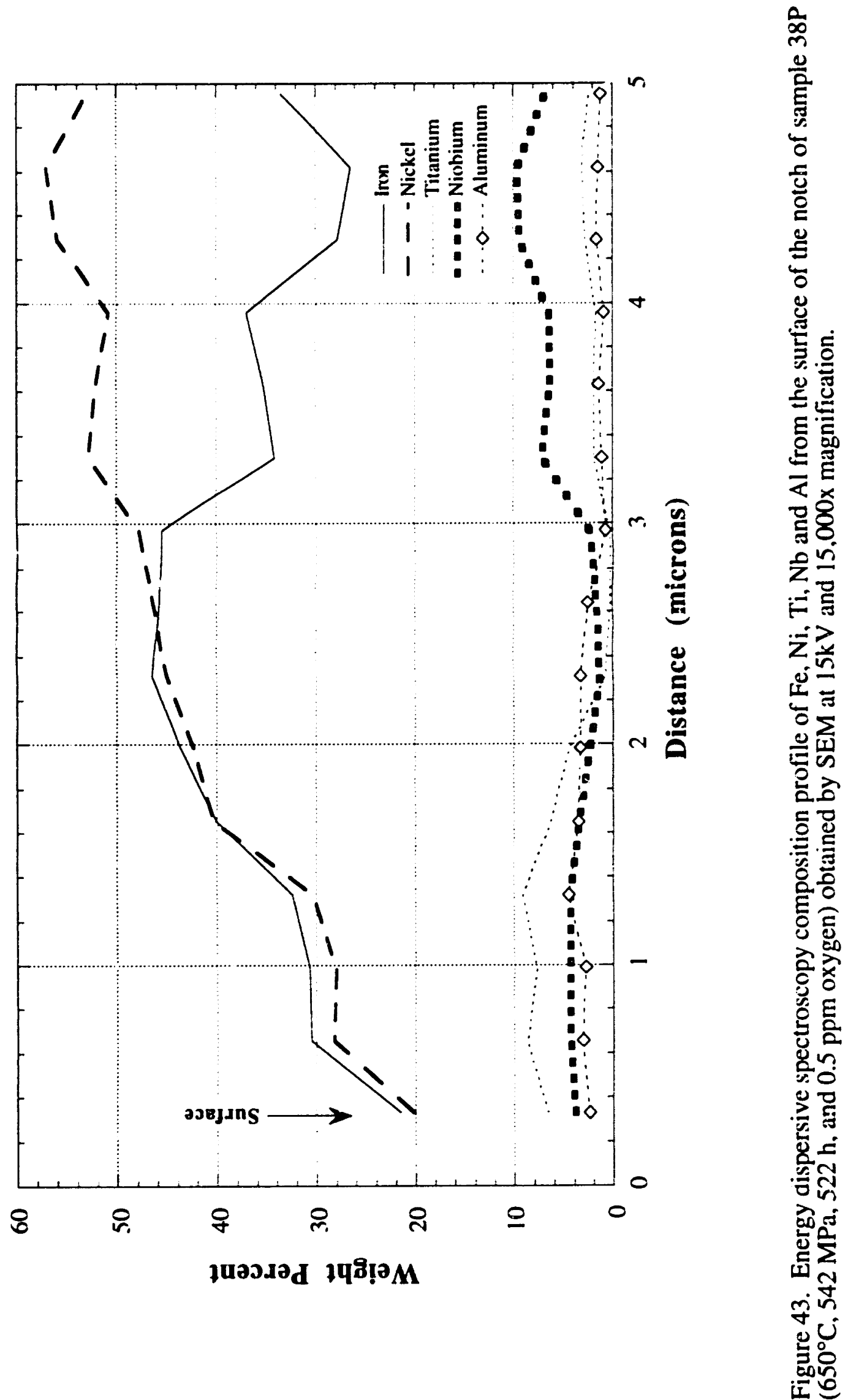


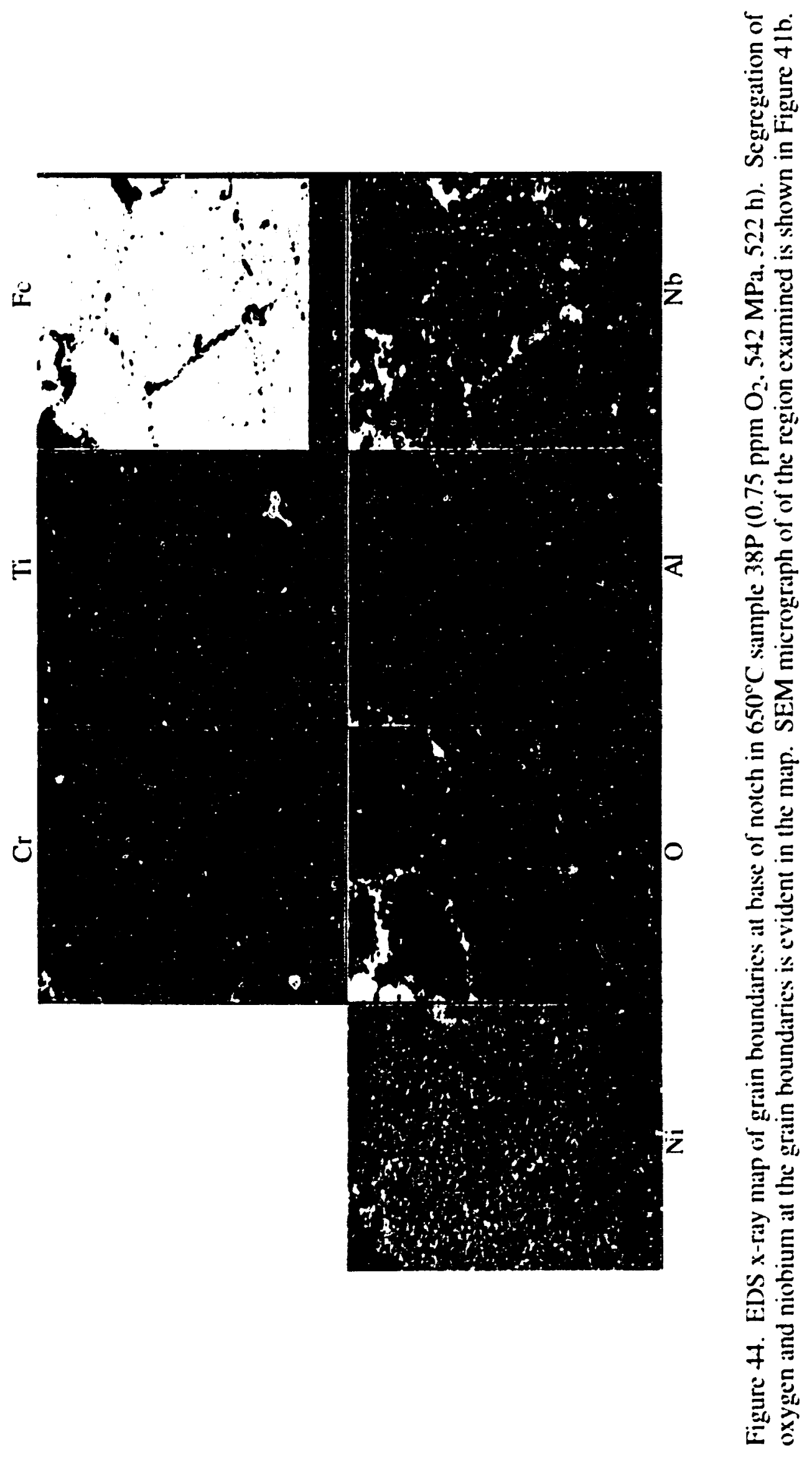


$22^{\circ} \mathrm{C}$. The sample, shown in Figure $45 \mathrm{a}-\mathrm{d}$, was exposed to $35.5 \mathrm{ppm}$ oxygen at $650^{\circ} \mathrm{C}$ and $650 \mathrm{MPa}$ stress before the test was interrupted at 188 hours. The exterior SEM micrographs in Figures 45a and 45b show cracking at the root of the sample's notch, and the cross section of the notch shown in Figure 45d shows the intergranular ledge at the notch. Area fraction measurements from Figure $45 \mathrm{c}$ showed there to be $19.4 \%$ intergranular fracture compared with $40 \%$ intergranular fracture seen in a failed sample at a similar oxygen concentration and stress. The SEM micrographs shown Figures $46 \mathrm{a}$ and $46 \mathrm{~b}$ show the boundary between the intergranular and ductile transgranular fracture regions at low and high magnifications, respectively. The transition between intergranular and ductile transgranular is fairly abrupt as can be seen in Figure 46b. If it is assumed that the intergranular fracture occurred at temperature during testing, then it should show signs of surface oxidation, while the ductile transgranular fracture that presumably occurred at room temperature when the sample was broken open should be free of surface oxidation. The high magnification micrographs shown in Figures $47 \mathrm{a}-\mathrm{d}$ were taken at the intergranular/ductile transgranular interface. The intergranular fracture surfaces shown in these micrographs are covered with an thin oxide layer. The ductile transgranular regions are not oxidized, indicating that ductile fracture occurred when the sample was broken open at $22^{\circ} \mathrm{C}$. The presence of oxide free intergranular fracture surfaces at the ductile/brittle interface should be expected if it is assumed that the grain boundaries fail by intergrantiar oxygen embrittlement. If this were true, then this sample should have contained sorne, oxide-free embrittled intergranular fractures at the fracture interface. There was no evidence of oxide free intergranular fracture surfaces or cracks in this or any of the other test samples examined. This point will be developed further when the chemistry of the oxidized grain boundaries is discussed in the next section.

A related investigation involved placing companion, not loaded, (dummy) flat plate notched test specimens in the retort with loaded test specimens. At the conclusion of the test the dummy test samples were removed from the retort and fractured in air at $22^{\circ} \mathrm{C}$. This test procedure was performed at $650^{\circ} \mathrm{C}$ and $700^{\circ} \mathrm{C}$ in 1 and $0.95 \mathrm{ppm}$ oxygen environments, respectively. Optical micrographs of the notch cross sections and SEM fractographs of the $650^{\circ} \mathrm{C}$ loaded and dummy test specimens are shown in Figures 48a-c and Figures 48d-f, respectively. In Figures 48a,b and $c$ the loaded test sample shows intergranular cracking extending in from the root of the notch, with no grain deformation in the intergranular fracture region. Comparable images of the dummy test specimen in Figures $48 \mathrm{~d}, \mathrm{e}$, and $\mathrm{f}$ show elongation of the notch section before failure and no intergranular cracking in the SEM fractographs. Similar results were obtained for the $700^{\circ} \mathrm{C}$ dummy sample. These results clearly indicate that the intergranular 


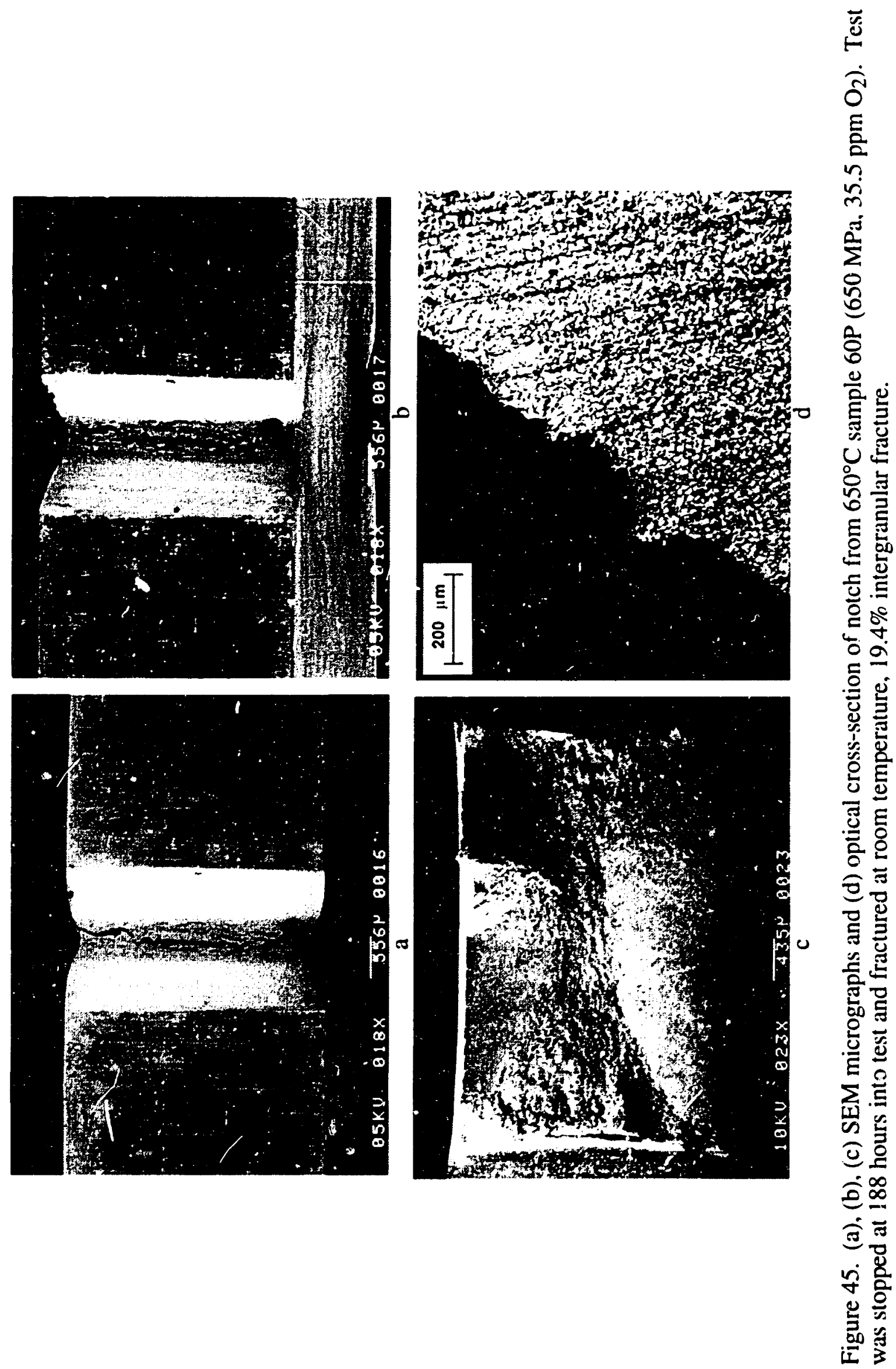




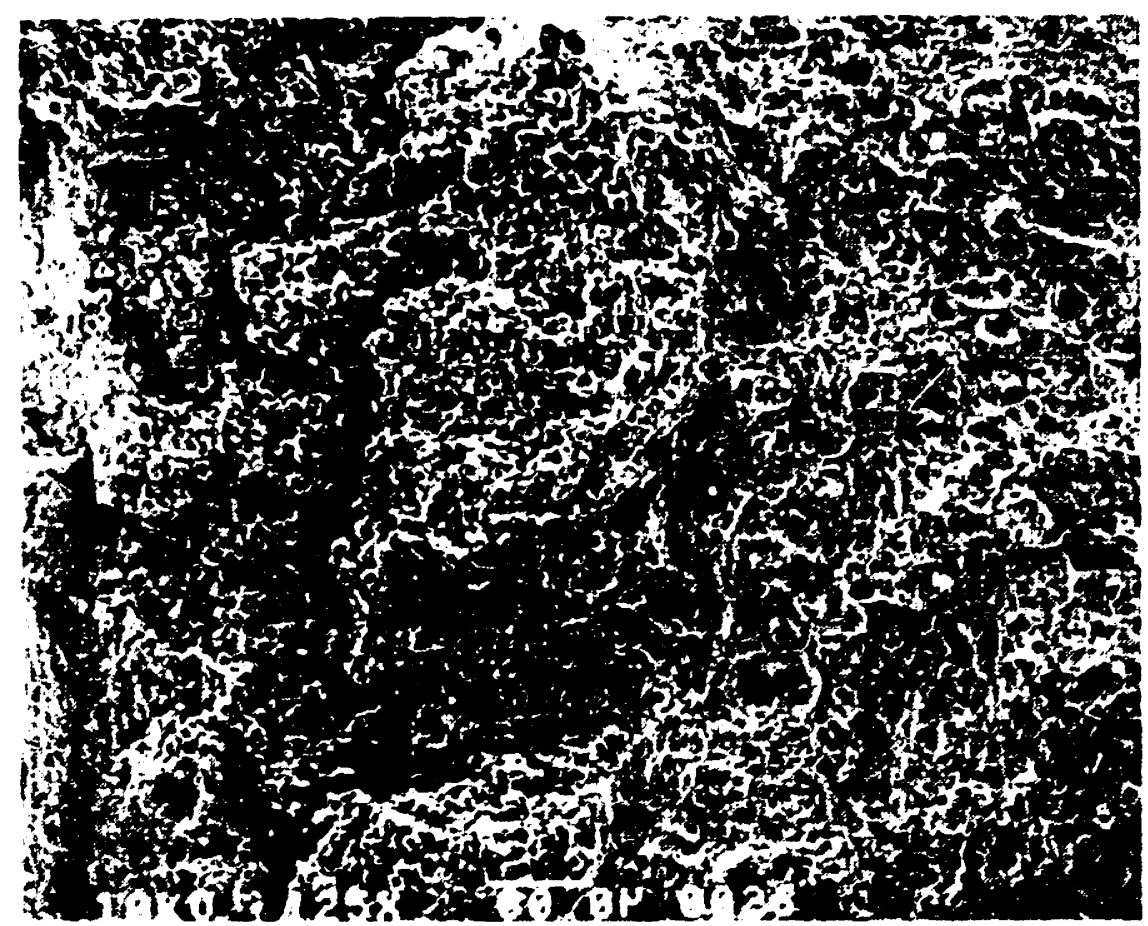

a

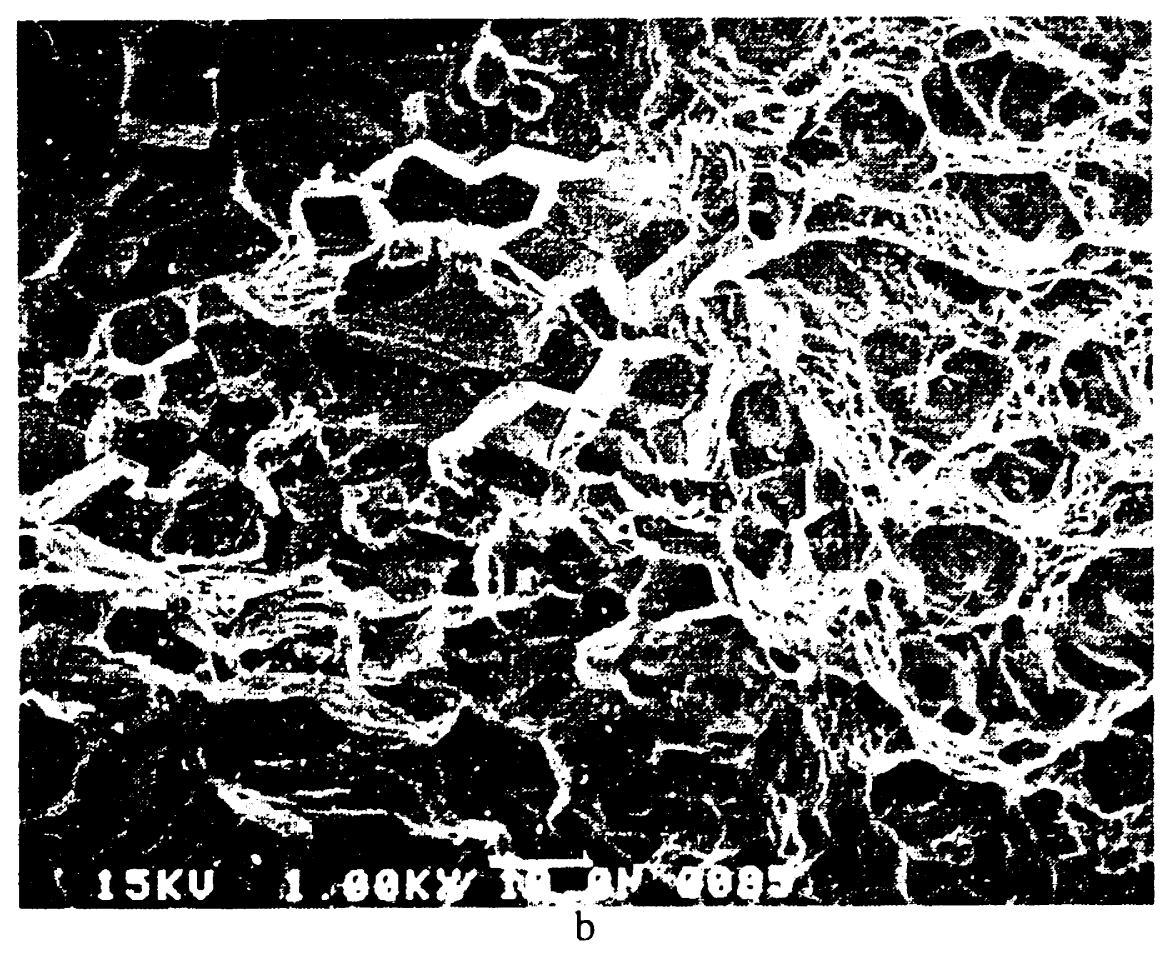

Figure 46. (a), (b) SEM micrographs from $650^{\circ} \mathrm{C}$ sample 60P (650 MPa, $35.5 \mathrm{ppm} \mathrm{O}$ ) showing intergranular / ductile transgranular fracture transition. Test was stopped at 188 hours into test and fractured at room temperature, $19.4 \%$ intergranular fracture. 


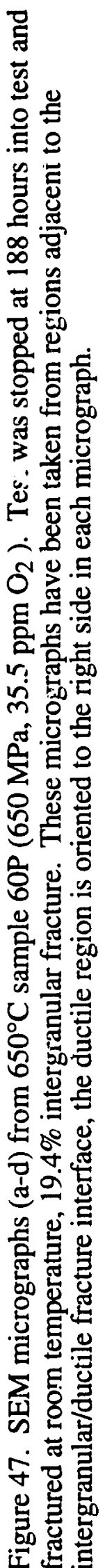




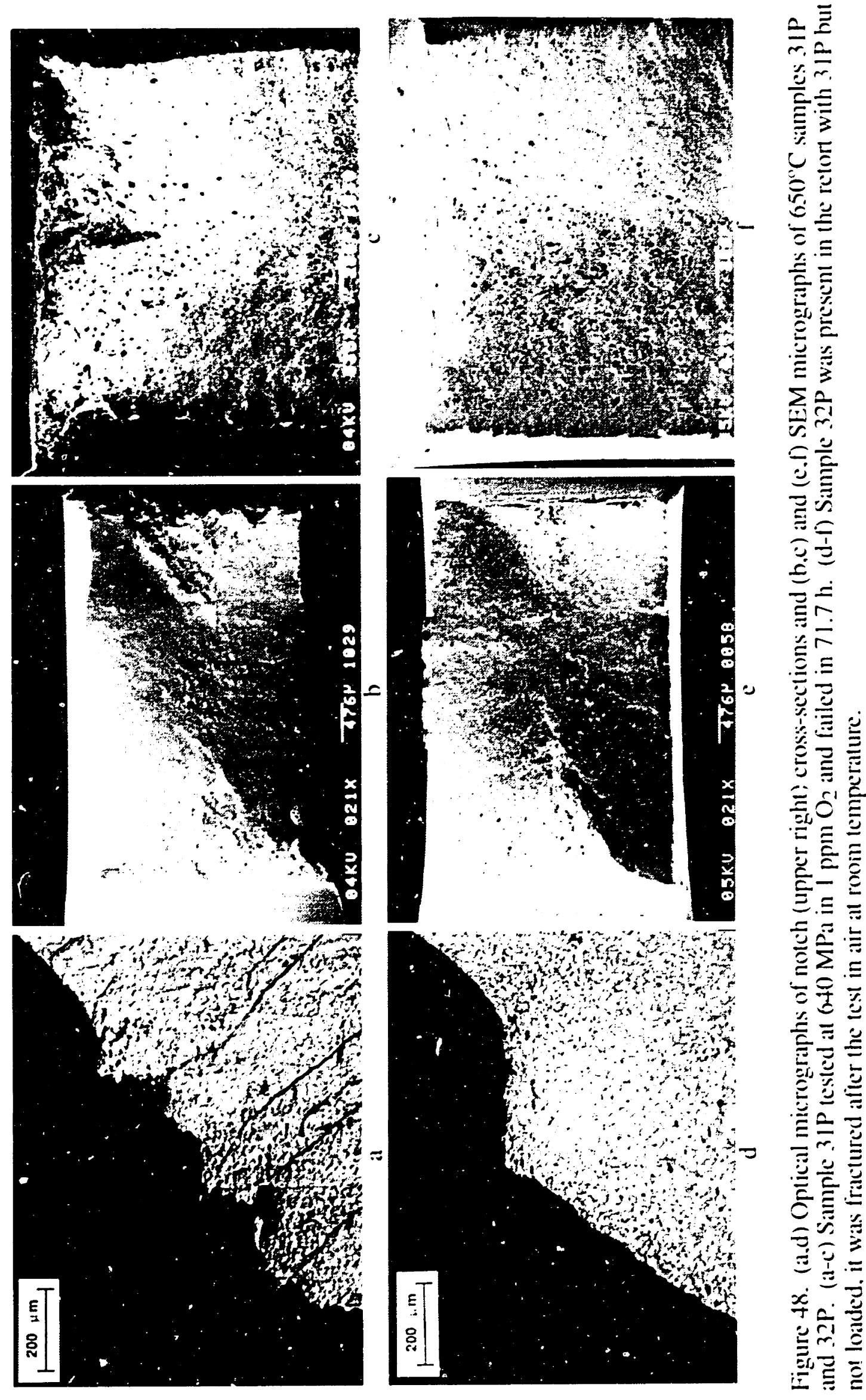


oxidation and fracture observed in this material requires a stress component and is not due solely to intergranular oxidation.

\section{E. Round Bar Microstructure and Fractography}

To obtain an intact notch at failure for microstructural and chemical studies double notch round bar test samples were utilized. Thus, the test atmospheres used were limited to a relatively high oxygen $(1000 \mathrm{ppm})$ environment to produce rapid fractures with high percentages of irtergranular failure, but without the gross oxidation of the fracture surfaces that limits detailed SEM and EDS analysis of material tested in air. The grain structure of this materia!, consisting of elongated grains with their c-axis parallel to the rolling direction of the plate, apparently had little influence $\mathrm{cn}$ crack propagation. This is because the intergranular regions associated with these grains failed in the same manner as the equiaxed grains observed in the flat plate test samples. A good exampie of this is illustrated in the optical micrographs shown in Figures 49a-c. In these micrographs an elongated grain can be seen at the root of the unfailed notch in a round bar sample tested at $650^{\circ} \mathrm{C}$ in $1000 \mathrm{ppm}$ oxygen. As can be seen in Figure 49c, the crack has started at the surface of the elongated grain and has propagated around it into the equiaxed grains behind it, and from that point the crack propagates into the sample in two branches separated by approximately $90^{\circ}$. An SEM micrograph of the fracture surface from a $20 \%$ cold work sample with elongated grains is shown in Figure 50. As seen in Figure 50, the fracture surface from this and all the other samples manufactured from this material show a texture corresponding to the orientation of the elongated grains. The same results were observed by Nicol in his air tests performed on this material. [37] A micrograph of a fracture surface from a sample manufactured from material without the elongated grains is shown in Figure 51. [1] Intergranular cracks in this material grow along a more planar front due to the absence of the large, elongated grains around which they must propagate. Comparing the two micrographs demonstrates that the texture seen in these fractures is due to the elongated grains.

In general, the cracks in the unfailed notches were closed with an intact oxide along the intergranular boundaries. One example of an intact crack can be seen in Figure 52a. This notch was not deformed or the crack opened when the second notch failed. The oxide present in the crack has been highlighted by vacuum evaporating carbon onto the sample then photographing it using Normarski interference-contrast illumination in a reflected light optical microscope. The main branches of this crack extend $0.6 \mathrm{~mm}$ into the sample. At 

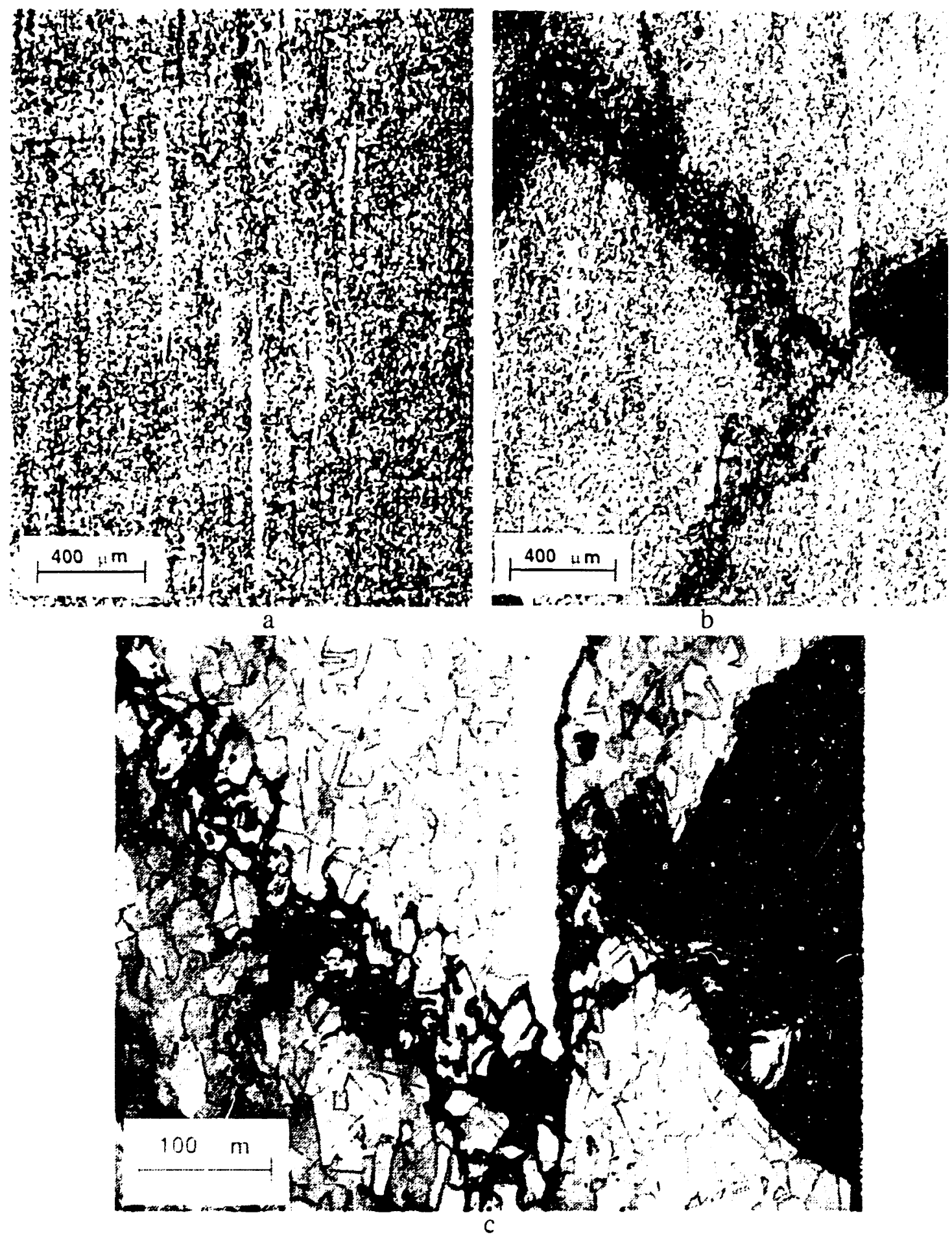

Figure 49. 20\% cold-worked $650^{\circ} \mathrm{C}$ round bar test sample $20 \mathrm{cw}-31$ (469 MPa, $7.3 \mathrm{~h}$, $1000 \mathrm{ppm} \mathrm{\textrm {O } _ { 2 }}$ ). (a) Grain structure showing large, elongated grains parallel to the rolling and tensile directions. (b) Cross-section near unfailed notch showing elongated grain at the notch and crack path. (c) Detail of crack path around elongated grain at notch. 


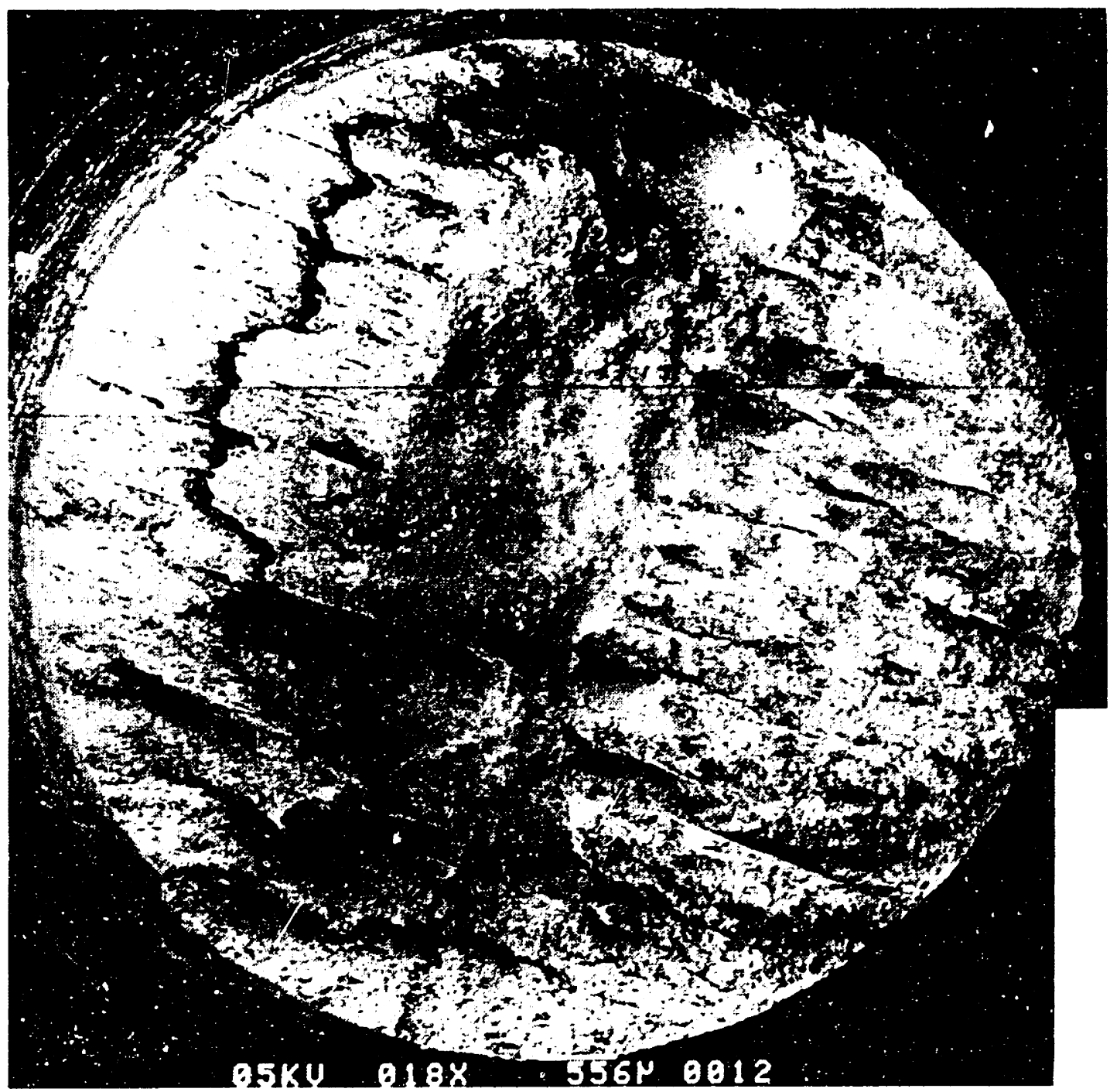

Figure 50. SEM micrograph showing the fracture surface of the failed notch from the $650^{\circ} \mathrm{C}$ round bar sample $20 \mathrm{cw} 31\left(469 \mathrm{MPa}, 7.3 \mathrm{~h}, 1000 \mathrm{ppm} \mathrm{O}_{2}\right.$ ). 


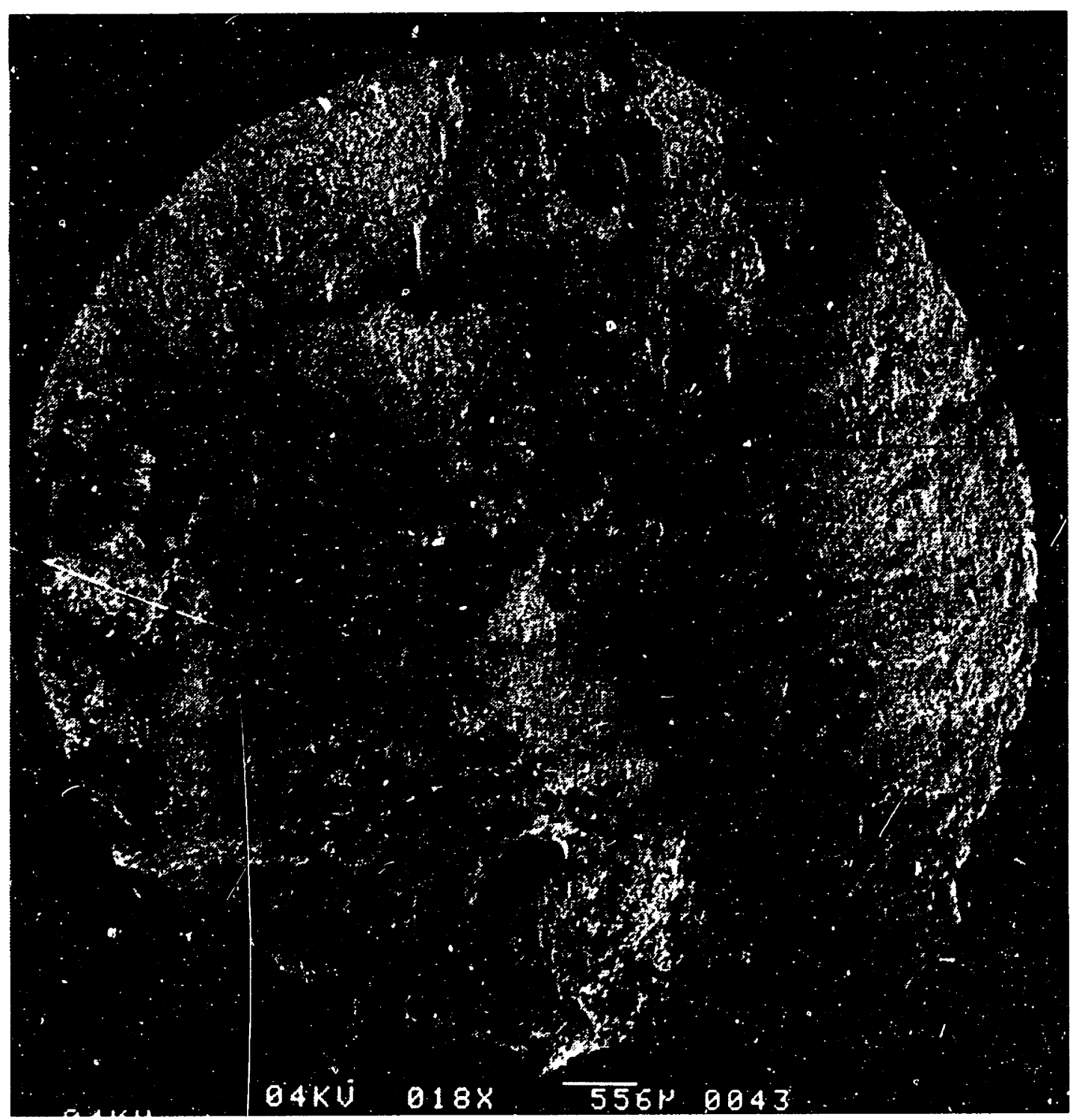

Figure 51. SEM micrograph of the failed notch in the $650^{\circ} \mathrm{C}$ round bar sample $1 \mathrm{~A}$ (vacuum heat treated at $650^{\circ} \mathrm{C}$ for $200 \mathrm{~h}$ before testing at $469 \mathrm{MPa}, 12.3 \mathrm{~h}, 1000 \mathrm{ppm} \mathrm{O}_{2}$ ). 


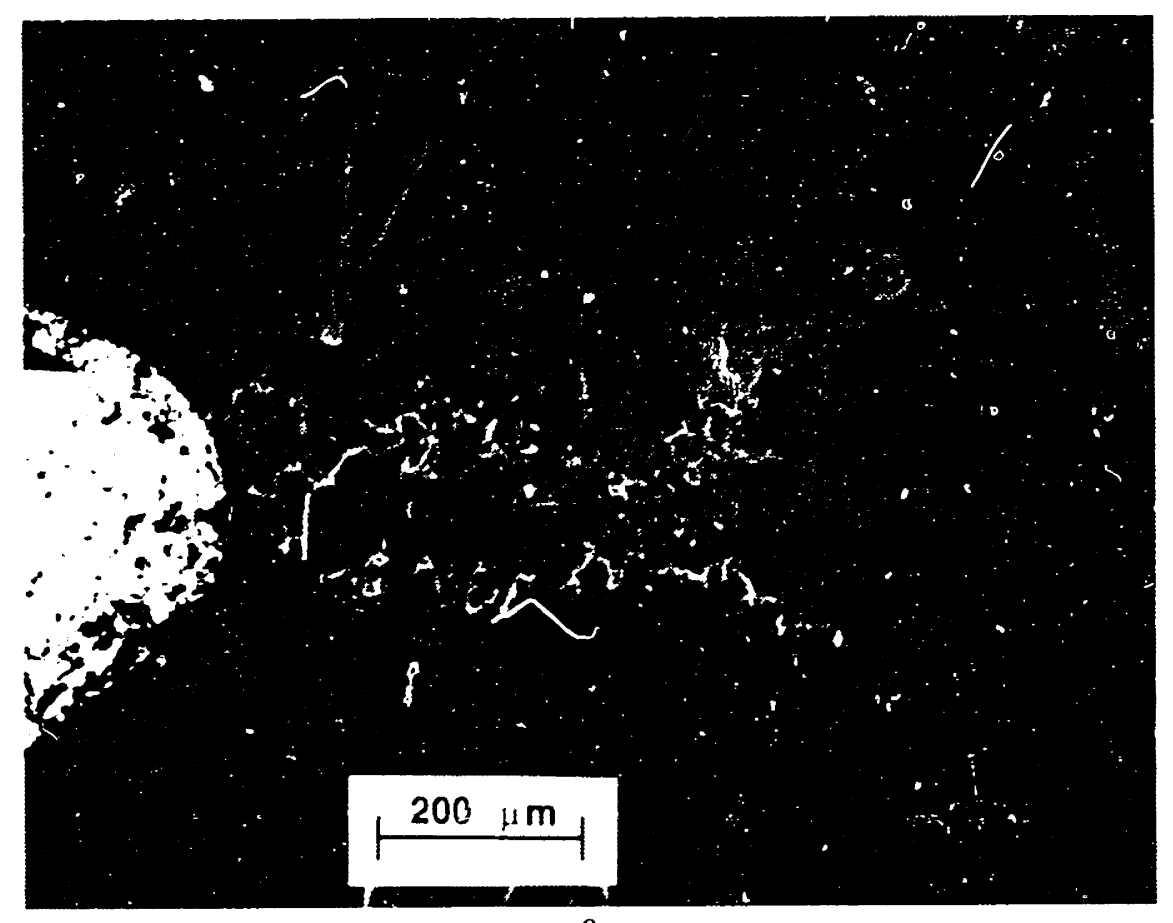

a

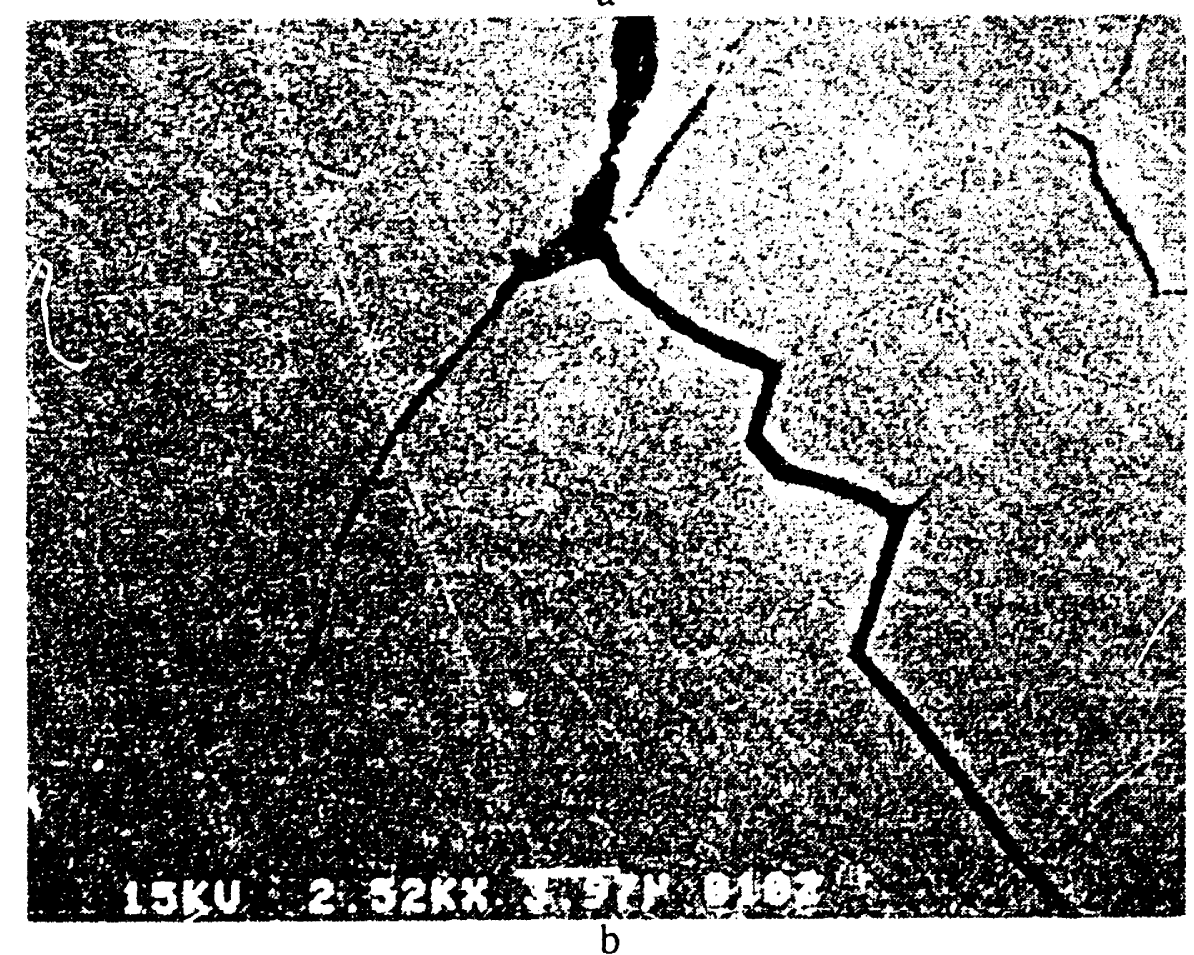

Figure 52. (a) Normarski optical micrograph of the crac's path at the unfailed notch in the $650^{\circ} \mathrm{C}$ round bar sample $10 \mathrm{cw} 2\left(469 \mathrm{MPa}, 8.2 \mathrm{~h}, 1000 \mathrm{ppm} \mathrm{O}_{2}\right.$ ), sample coated with evaporated carbon to highlight oxidized crack. (b) SEM micrograph from a portion of an oxidized crack path extending from the infailed notch in the $650^{\circ} \mathrm{C}$ round bar sample 20cw31 (469) MPa, $7.3 \mathrm{~h}, 1000 \mathrm{ppm} \mathrm{O}_{2}$ ). 
higher magnifications in the SEM the finer intergranular crack branches appear black or dark gray, as seen in Figure 52b. This effect is due to the presence of low atomic number element(s) or compounds such as oxides at the grain boundary. The regions appear dark because there are fewer secondary electron scattering events, resulting in fewer secondary electrons reaching the detector. The next section will present the results of analyses of these grain boundaries.

\section{F. Grain Boundary Analysis}

Round bar test samples are preferred for grain boundary analyses. The intact notch they provide is desirable not only because it preserves pre-failure microstructural features, but also, for the purposes of this study, intact grain boundaries. Grain boundaries that have not cracked open provide evidence of pre-failure chemistry and intergranular oxidation, if present, without having direct exposure to the environment. In cases where intact notches were not available, i.e. flat plate sample, only those affected grain boundaries most distant from the notch were selected for analysis.

Metallographic etchin's removes grain boundary material. In analyzing the grain bourdary chemistry of these samples, the grain boundaries were kept intact by automated mechanical polishing using diamond abrasives and polishes with no etching. The resulting surface is ideal for chemical analysis by EDS, but produces reduced contrast for imaging by SEM. As a result, the affected grain boundaries can be difficult to resolve. To enhance resolution carbon was vacuum evaporated onto the polished samples.

In order to establish which elements were predominant at the affected grain boundaries, an initial chemical analysis was performed by EDS using electron beam line scans across the grain boundaries. A line scan of the elements across two grain boundaries in a $650^{\circ} \mathrm{C}$ (1000 ppm oxygen, 4.05 hours) round bar sample is shown in Figure 53a. Oxygen is the only element that shows a definite peak at the grain boundaries, as seen from this line scan. An expanded oxygen line scan is shown in Figure 53b. Nickel and iron content show some reduction at the boundaries. To further define the grain boundary composition an EDS $x$-ray element map was acquired from a region near the notch in the same sample, and is shown in Figure 54. This map shows the segregation of oxygen to the grain boundaries, which are roughly outlined by the map. There is no segregation of chromium, titanium or aluminum to the grain boundaries. A reduction in nickel is evident. Iron is present at the boundaries and, in combination with oxygen, may indicate an iron oxide has formed there. The presence of a large, primary $(\mathrm{Nb}, \mathrm{Ti}) \mathrm{C}$ carbide is indicated in the upper left corner of the $\mathrm{Nb}$ and $\mathrm{Ti}$ maps. The presence of oxygen at the same location indicates that it has 


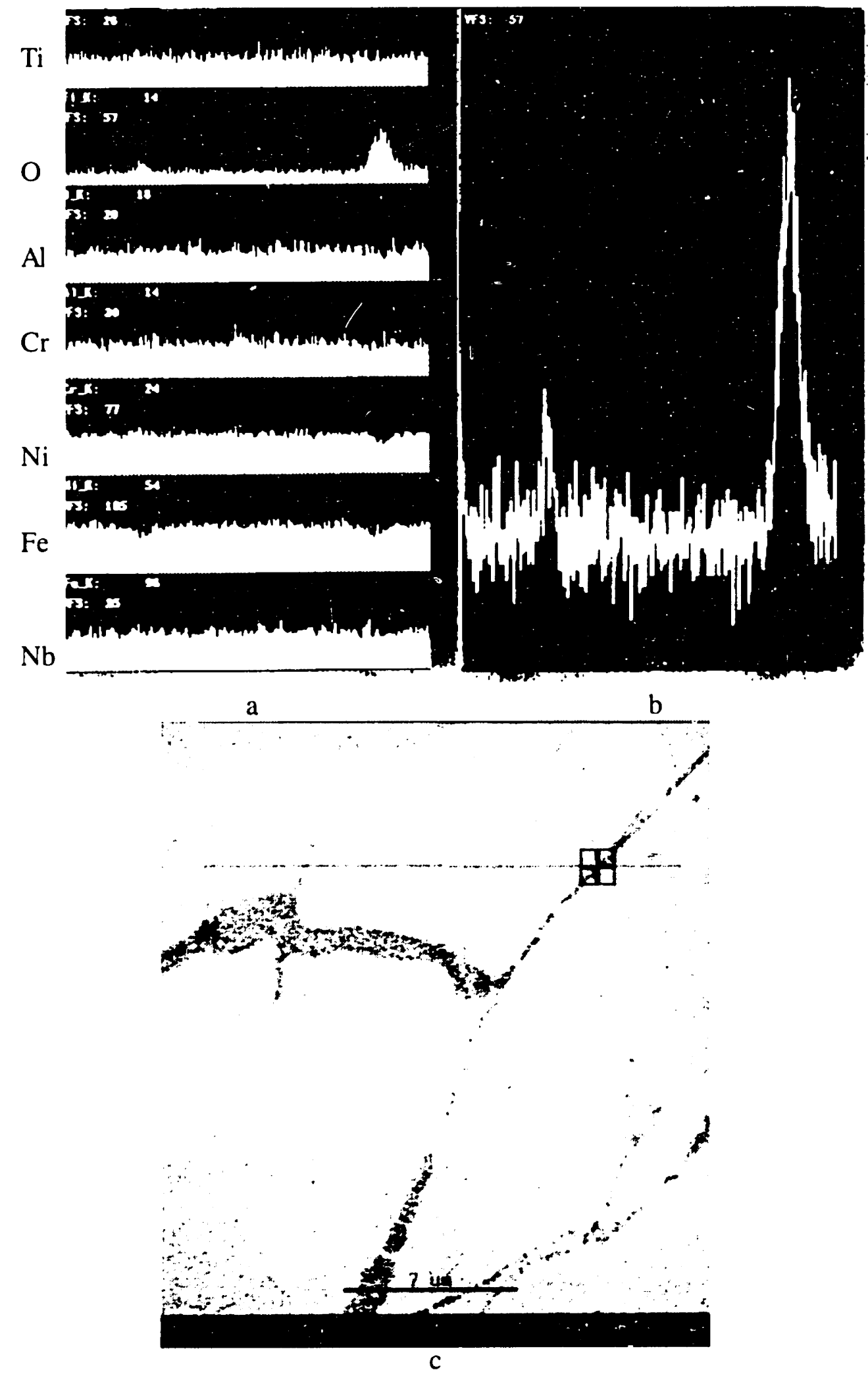

Figure 53. (a) Line scan profiles of elements across two grain boundaries in the $650^{\circ} \mathrm{C}$ sample 1B unfailed notch (1000 ppm O 2,4 hours ). (b) Enhanced oxygen line scan. (c) Area used for line scan across two grain boundaries, cursor marks spot at one boundary. 


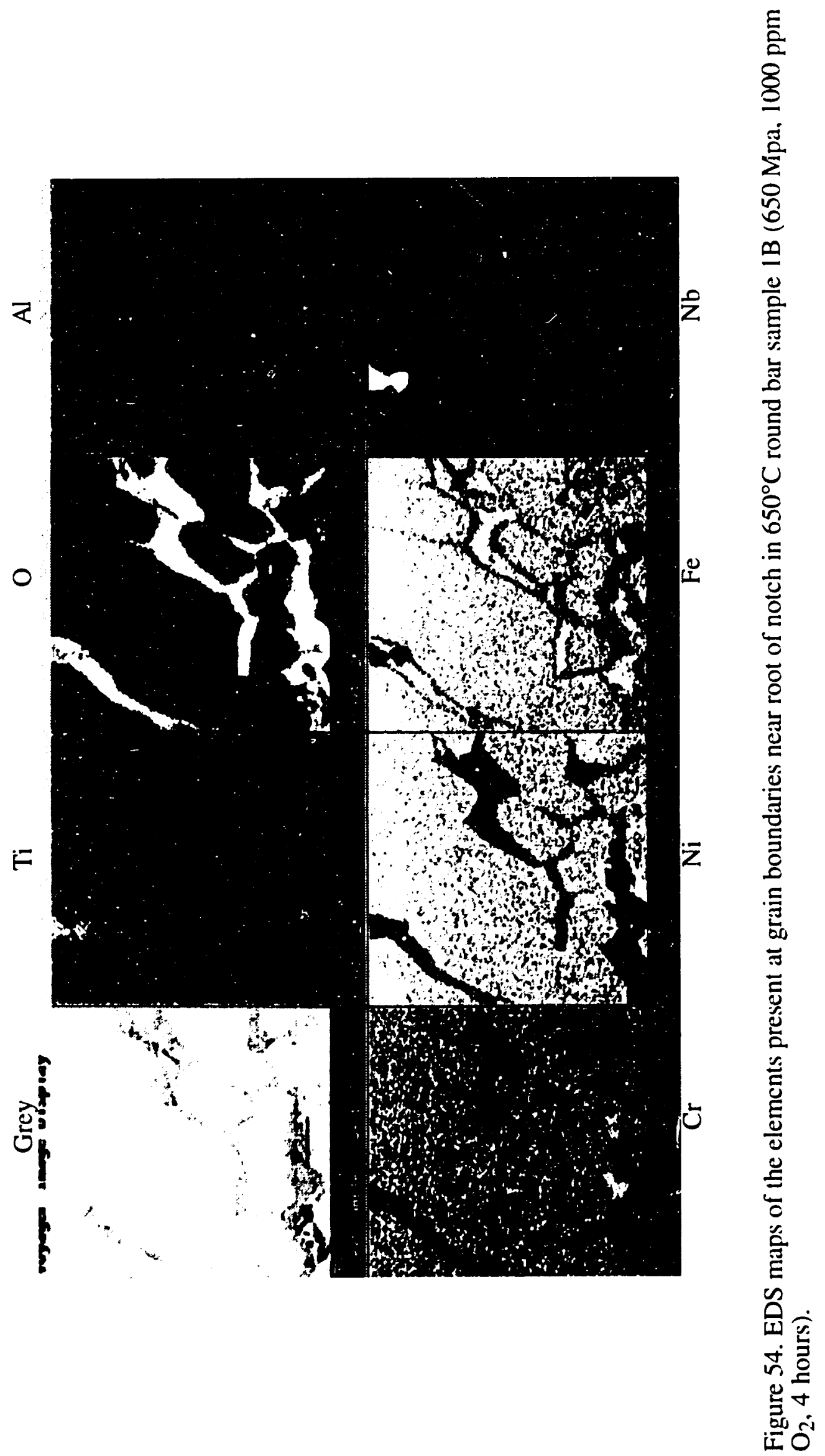


oxidized. The oxidation of niobium carbides has been shown to occur during intergranular oxidation of other superalloys. $[55,69]$ The grain boundaries examined above were close to the notch, and, hence, closer to oxygen present in the environment. Affected grain boundaries found further from the notch of the sample seen in Figure 52a are shown in Figure 55a. An enlarged oxygen x-ray map from this region is shown in Figure 55b. Oxygen is seen to outline the dark grain boundaries. A complete elemental map of the same region is shown in Figure 56. As seen in this map, no other element shows segregation to the grain boundaries in this sample.

The $\mathrm{x}$-ray compositional maps generally lack sufficient resolution to distinguish small concentration differences among the elements. Electron beam spot analyses were performed at high magnifications across affected grain boundaries to detect compositional differences at grain boundaries. A 100 second analysis time was used for each spot to insure a good statistical ratio of $\mathrm{x}$-ray counts for each element peak above background.

A $650^{\circ} \mathrm{C}$ round bar sample tested in $1000 \mathrm{ppm}$ oxygen (4 hours) was selected for grain boundary analysis. As seen in the micrograph shown in Figure 57a, and previously discussed, the affected grain boundaries in this sample are dark in appearance. An EDS composition analysis across the grain boundary shown in Figure 57b was performed at 7,500x. The white points shown in the micrograph are electron beam contamination spots marking the path of the beam. From the resulting composition profile, shown in Figure 58, it is evident that oxygen is present on the grain boundary. Nickel, iron and niobium show some reduction at the boundary, while chromium appears unaffected. A reduction in the weight percent of these elements at the grain boundary indicates that they have oxidized. Reaction with oxygen reduces their relative weight percents in the formation of oxide to levels below those of the matrix. A grain boundary composition profile obtained at $20,000 \mathrm{x}$ from an identical sample tested at $650^{\circ} \mathrm{C}$ in $1000 \mathrm{ppm}$ oxygen ( 12.3 hours), but at a lower stress, is shown in Figure 59. From the profile it is again evident that oxygen is present at the boundary and nickel shows some depletion at the boundary. In most cases, the composition profiles acquired across grain boundaries in the $650^{\circ} \mathrm{C}, 1000 \mathrm{ppm}$ oxygen, round bar samples did not show segregation of $\mathrm{Cr}, \mathrm{Ti}, \mathrm{Al}$, or $\mathrm{Nb}$. This could be attributed to a combination of factors, one of which is the relatively small sample volume being analyzed. Grain boundary widths at these magnifications ranged from 0.1 to 0.5 microns. Another is that the electron beam spot size is of the same magnitude relative to the grain boundary width, one limitation of EDS analyses in the SEM even at their smallest spot size condition. Lastly, these elements may not be segregated at the grain boundaries in sufficient quantities to distinguish them from the matrix. Generally, a \pm 0.5 weight percent difference is required. An increase in chromium and niobium was evident in a profille 

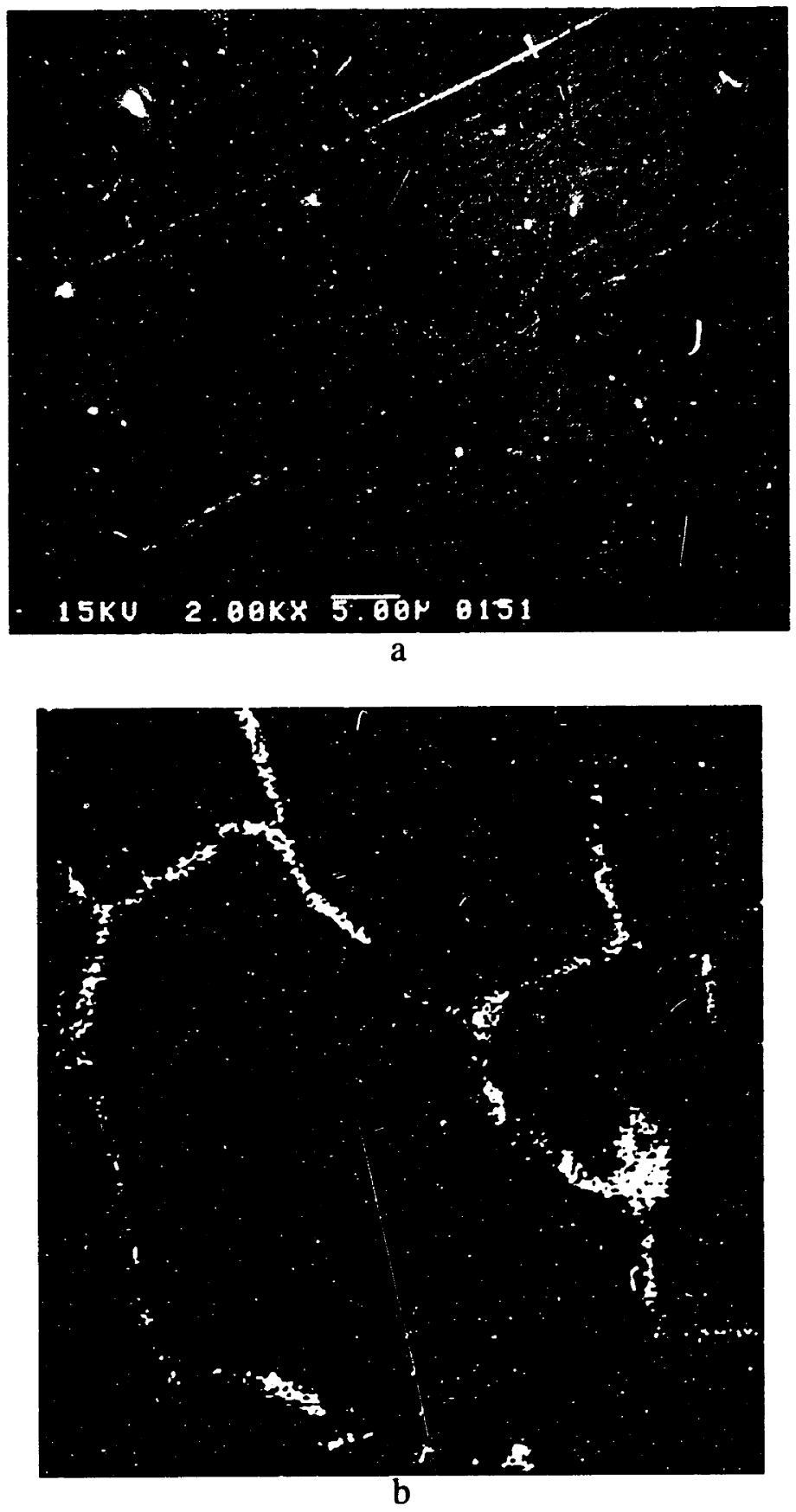

Figure 55. (a) SEM micrograph and (b) oxygen $\mathrm{x}$-ray map of grain boundaries in $650^{\circ} \mathrm{C}$ sample $10 \mathrm{cw}-2$ (10\% cold, work $\left.1000 \mathrm{ppm} \mathrm{O}_{2}, 469 \mathrm{MPa}\right) 8.2$ hours to failure. 


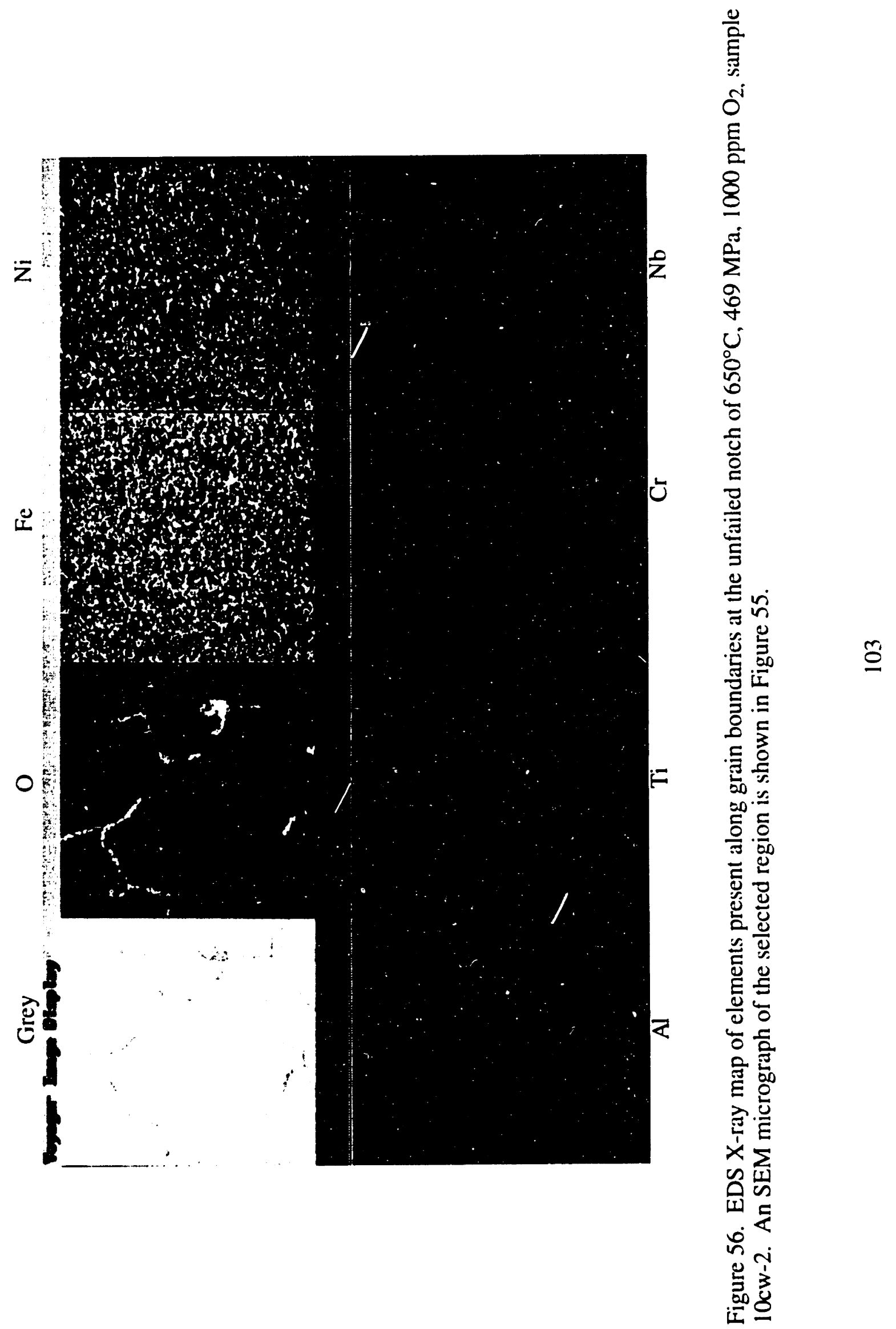



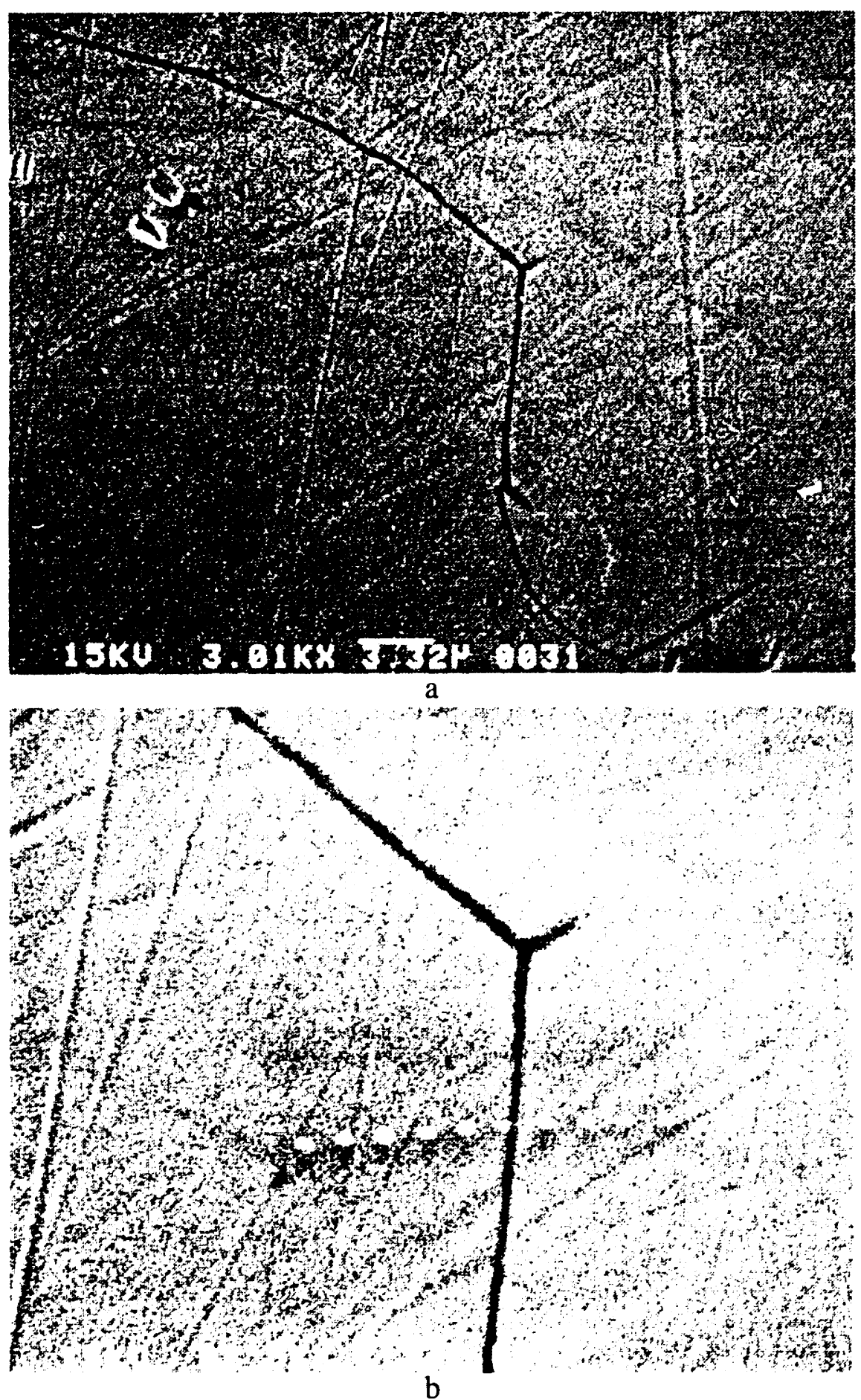

Figure 57. Affected grain boundaries in $650^{\circ} \mathrm{C}$ sample $1 \mathrm{~B}(1000 \mathrm{ppm} \mathrm{O}, 650 \mathrm{MPa}, 4$ hours to failure). (a) General region. (b) Grain boundary at triple point selected for EDS composition profile shown in Figures 58 and 59. 


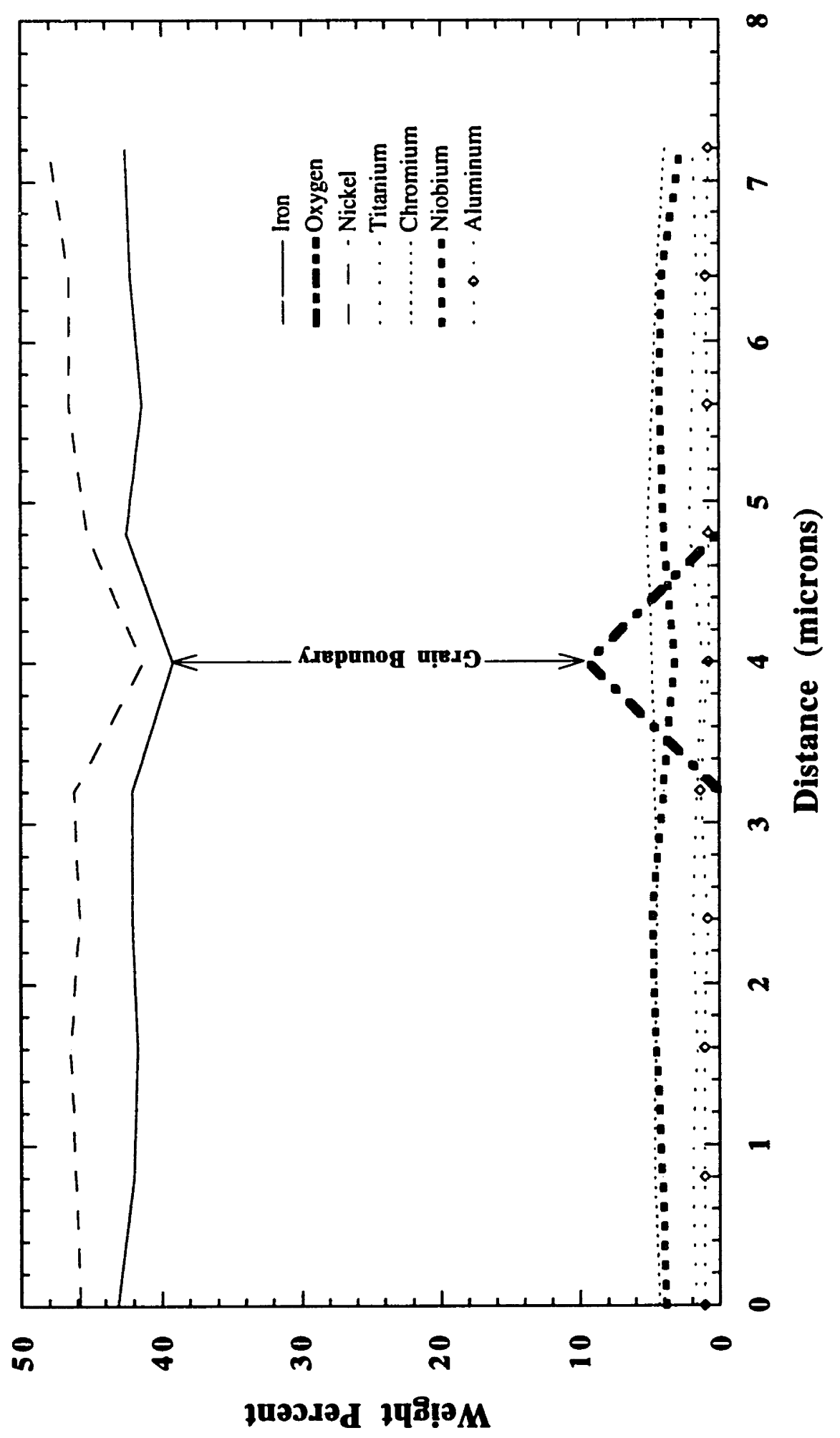

承

ํㅗㄹ

穹

잉

语

䓀高

㤎

융 믐

농

ลn

ธิ

苋

를

8 용

正遯

$\infty$

总它 


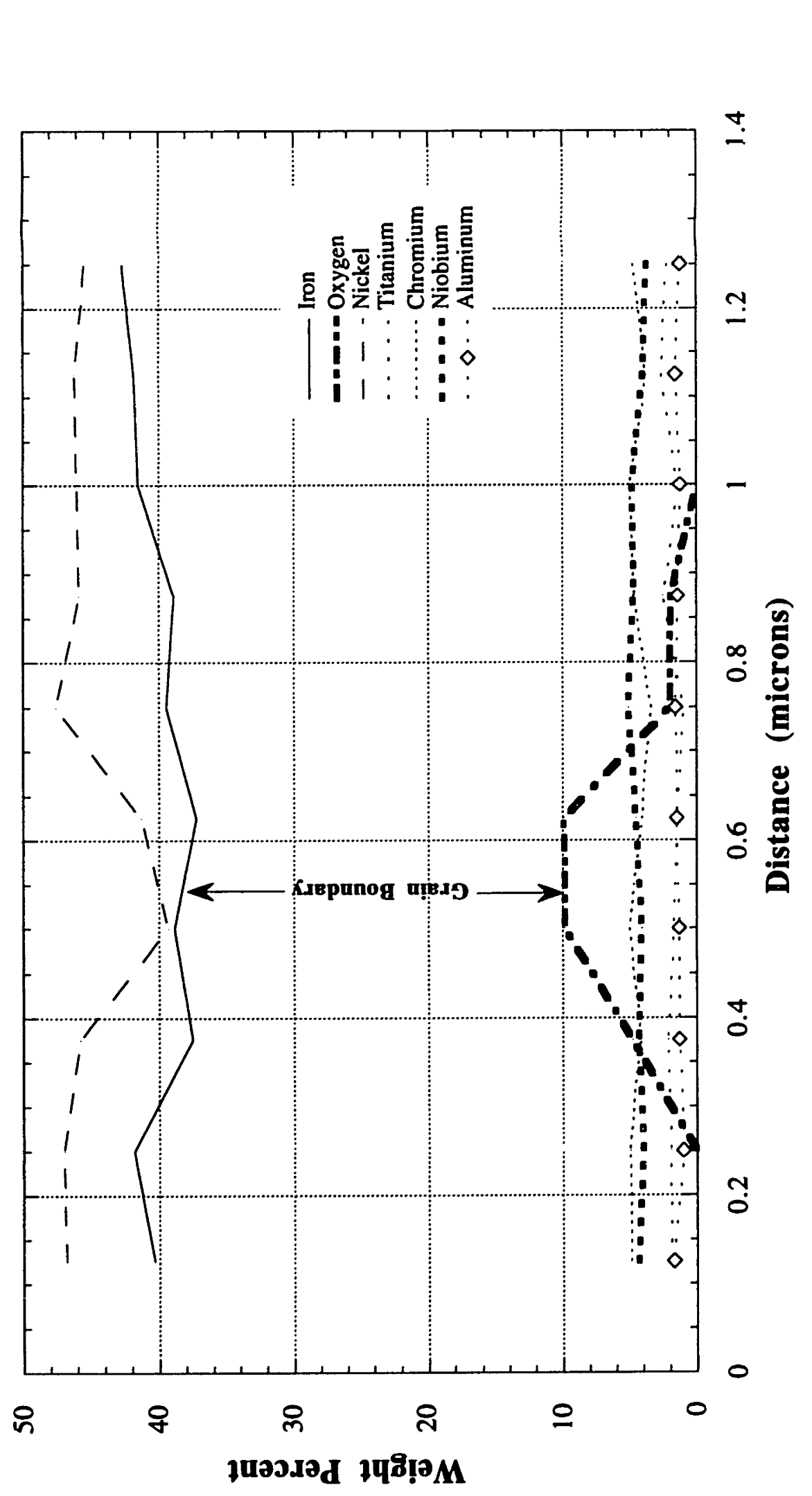

\begin{tabular}{l} 
을 \\
옹 \\
\hline
\end{tabular}

$\stackrel{m}{\check{c}}$

ชิ

옹

$\sum^{\infty}$

8

$\leq$

O

를

㚎

몽

0
0
0

อ

.$\Xi$

곡

8

들

品文

里

온

ส

융

노오

도 후

웡

을

웡

เิ็

도

它 
across the terminus of an affected grain boundary obtained at high magnification $(20,000 x)$. The composition profile for this sample is shown in Figure 60. Because of the very small grain boundary volume being analyzed, oxygen $\mathrm{x}$-rays were detected but was not sufficiently resolvable above the EDS spectrum background for analysis. The dark coloration of the boundary, however, indicated that it was affected.

A series of composition profiles along, rather than across, grain boundaries was performed to investigate whether chromium was present at grain boundaries. A grain boundary at the tip of the crack path obtained from a flat plate sample tested at $650^{\circ} \mathrm{C}$ in 38 ppm oxygen (122 hours) is shown in Figure 61a. The boundary, along with electron beam contamination spots, is shown enlarged in Figure $61 \mathrm{~b}$. The resulting profile along the grain boundary is shown in Figure 62. As can be seen in this profile, oxygen is preselit along the entire length of the grain boundary. As the grain boundary terminus is approached from the matrix, however, it is apparent that the concentration of chromium increases. A similar but less pronounced increase in niobium can also be seen. From the grain boundary orientation in the micrograph (left to right) in Figure $61 \mathrm{~b}$, the matrix point used is closer to a branch of the main crack and the environment. Higher oxygen and iron levels are present along the segment of boundary closest to the main crack and the environment, while the chromium concentration increases away from the main crack. Andrieu reported similar findings in alloy 718 and attributed them to the initial formation of chromium rich oxides in low oxygen potential environments found at the tip of cracks. [77, 79] A companion composition profile taken across the chromium rich portion of the grain boundary is shown in Figure 63 and confirms the concentration increase. A composition profile was obtained from a second $650^{\circ} \mathrm{C}$ flat plate sample tested in $1000 \mathrm{ppm}$ oxygen ( 28.3 hours) along the grain boundary shown in Figures 64a and 64b. From the profile seen in Figure 65, it can be seen that the chromium concentration along the entire crack has increased above the 4 weight percent level of the matrix. The concentration of niobium in the crack is also above the matrix level. Based on the composition profile, the oxide present at the beginning of the boundary, from where a grain can be seen pulled out in Figures $64 \mathrm{a}$ and $64 \mathrm{~b}$, is primarily an $(\mathrm{Fe}, \mathrm{Ni}) \mathrm{O}$ type oxide. A composition profile across the same grain boundary can be seen in Figure 66 and confirms the increase in chromium and oxygen. An analysis was performed on a round bar sample tested at $650^{\circ} \mathrm{C}$ in 1000 ppm oxygen (3.65 hours). The second notch in this sample had cracked open during testing and is shown in Figure 67a. The grain boundary selected for compositional analysis is shown in Figure 67b. From the profile for this boundary shown in Figure 68, it is apparent that in this sample there is no significant increase in the chromium concentration along the boundary. The profile does, however, show oxygen present along the boundary. 


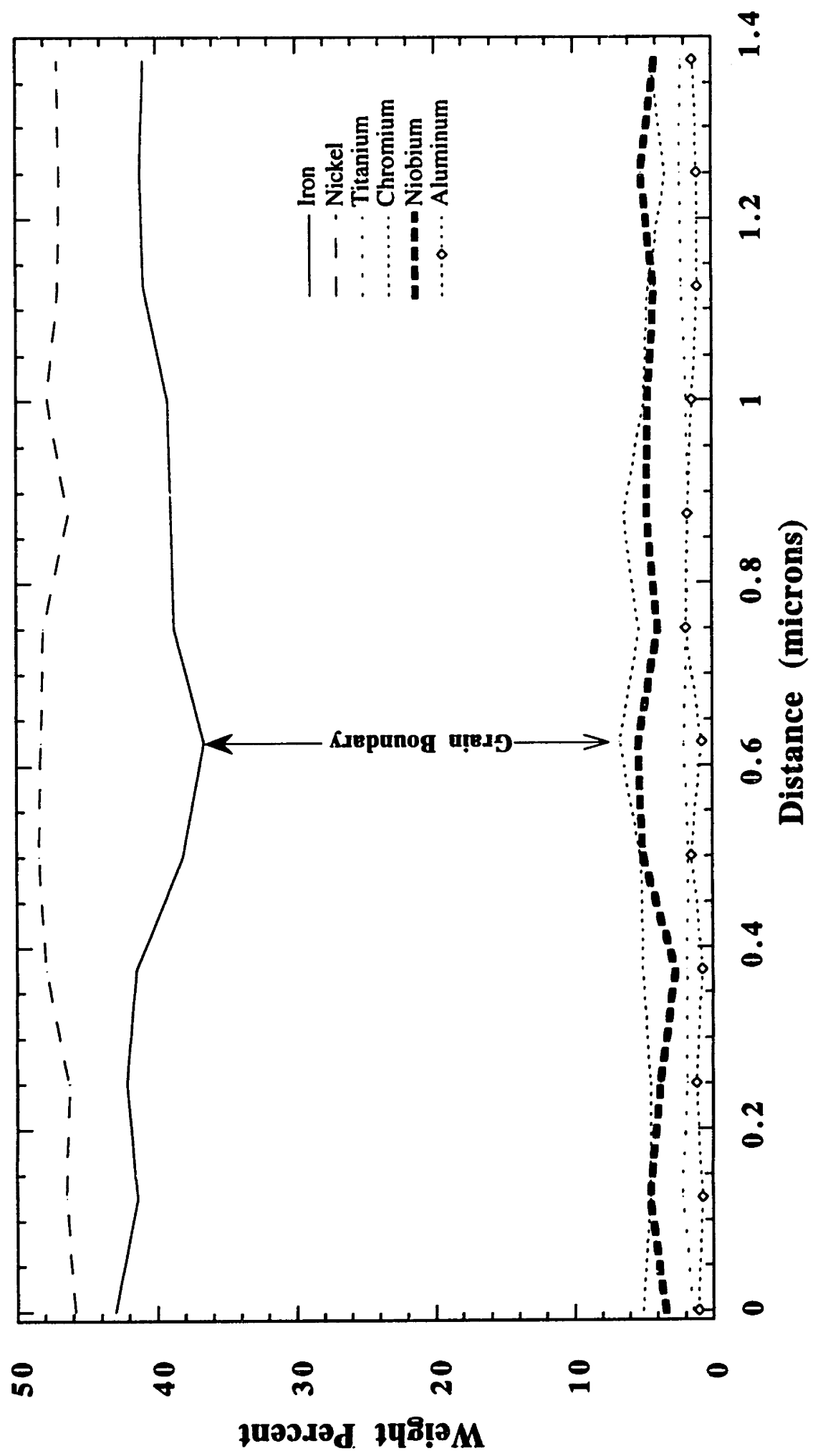

I

$\hat{0}$

명

हु

है

go

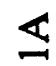

号

ํํㅇ

믈

บั

ชูำ

올

․ำ

옳

需文

造

若

ฐี

: 8

융

\%

退

옳

ชิ

응형

ஸे

뵈 틀

ชి

8 온

总 


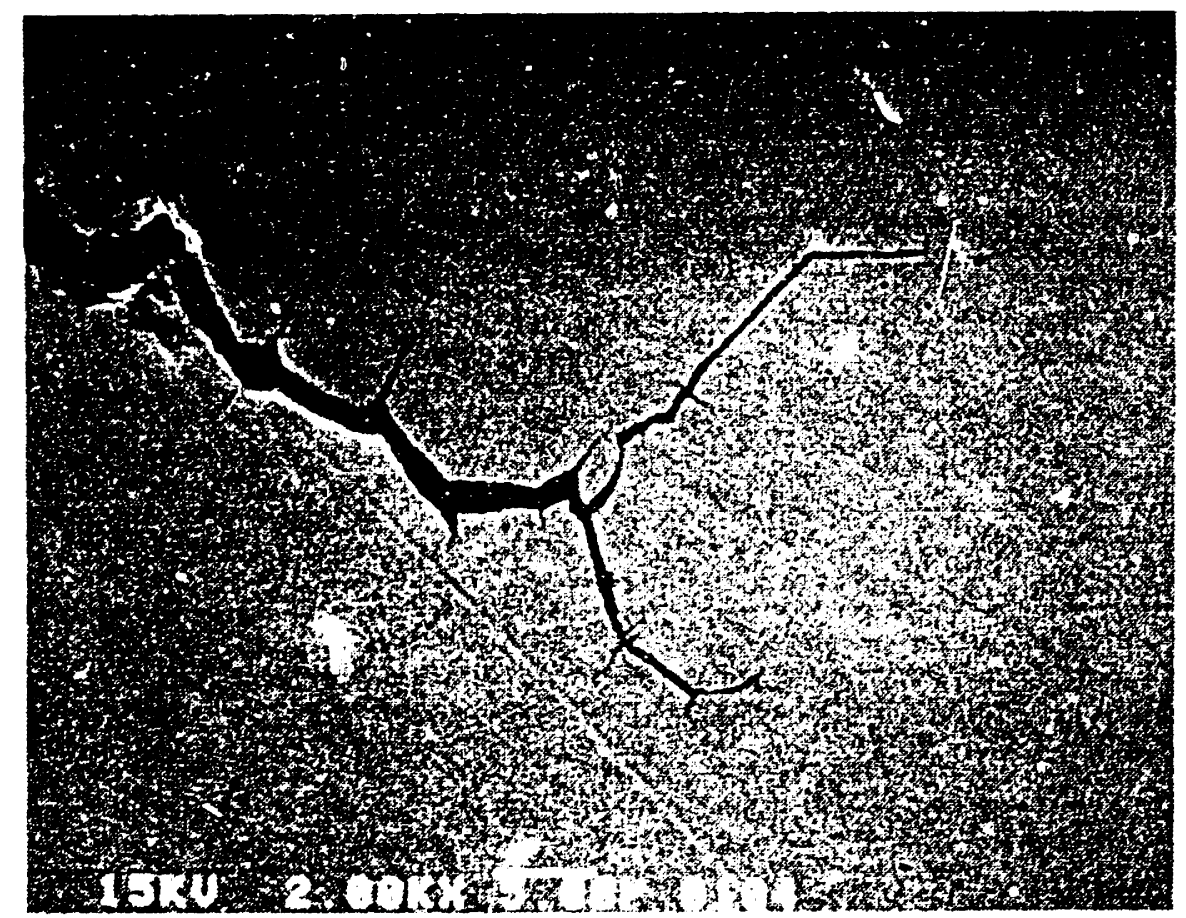

a

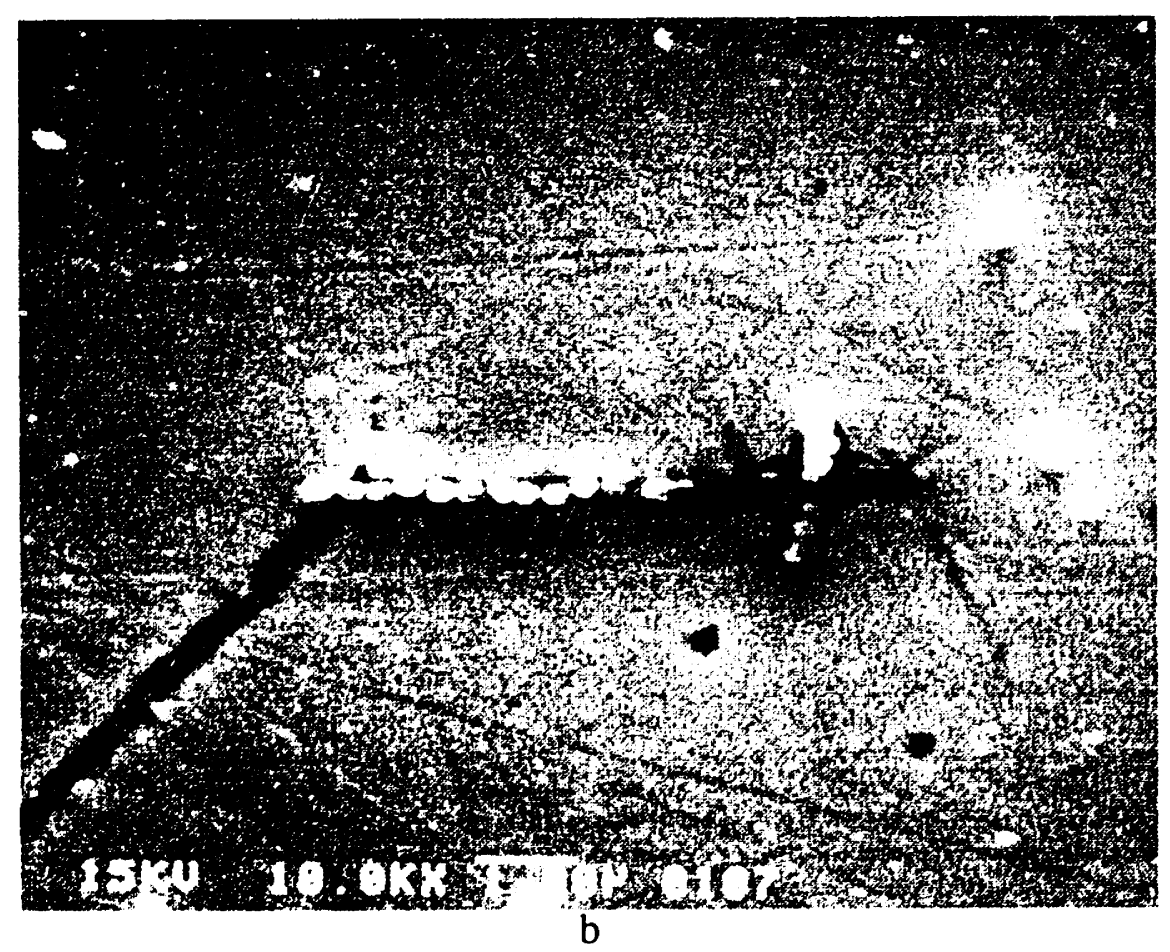

Figure 61. (a) SEM micrographs of oxidized grain boundaries in $650^{\circ} \mathrm{C}$ flat plate sample $62 \mathrm{P}(650 \mathrm{MPa}, 38 \mathrm{ppm} \mathrm{O}, 122$ hours to rupture). (b) Micrograph of grain boundary selected for compositional analysis by EDS. 


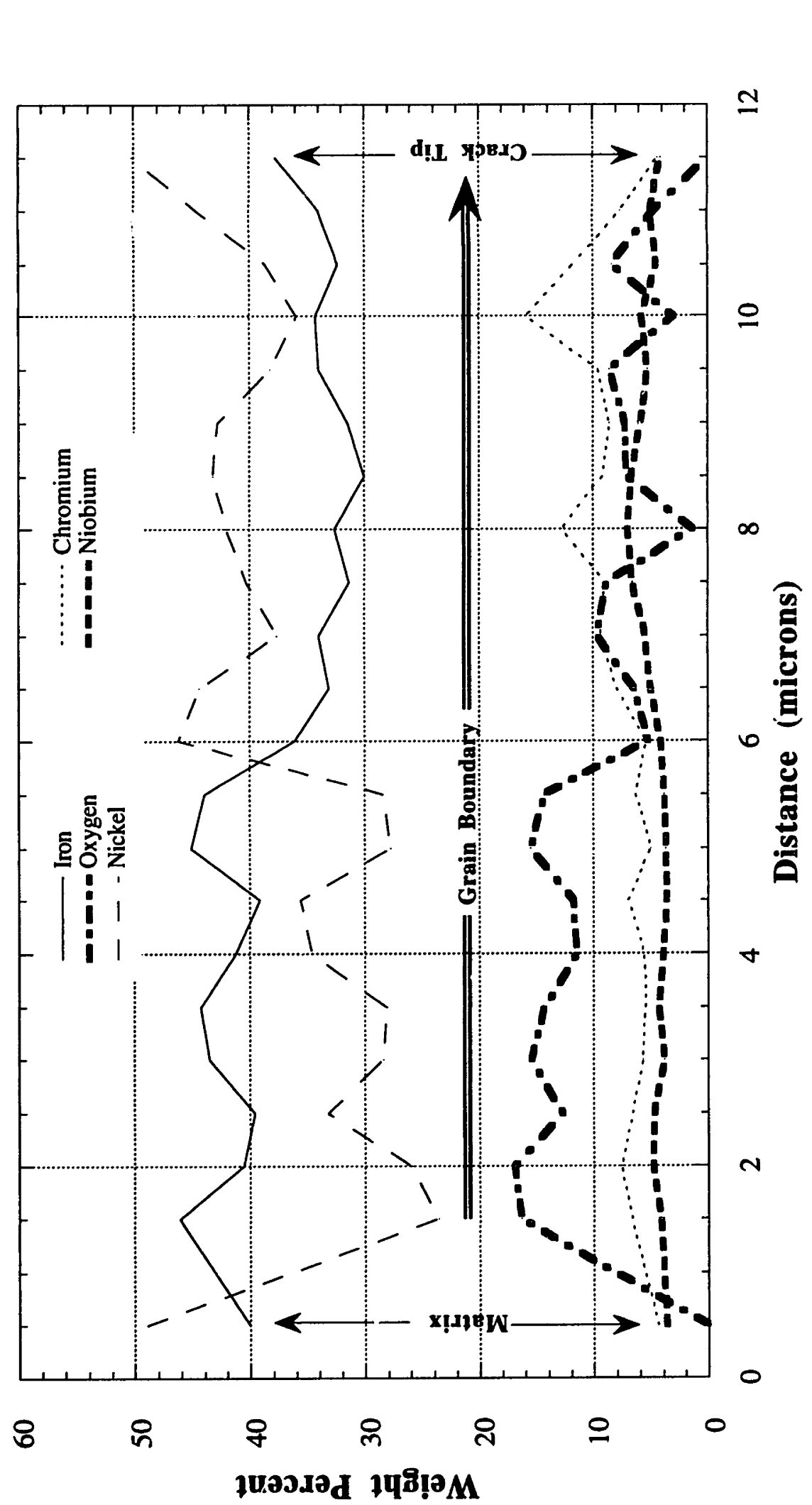

ชิธ

छี

品

की

运

늘

츤류

$\cong$

实

․․․․

흠.음

蛋

ㄴำ

을

เํํㅇ

혈

옹

일

흃

खै

in

D

8

도름ำ

휴요

응

प्ष्ठ 궁

멿

올

ठㅇ

它

นิ

田 0

ชิ่

옹 융

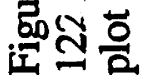




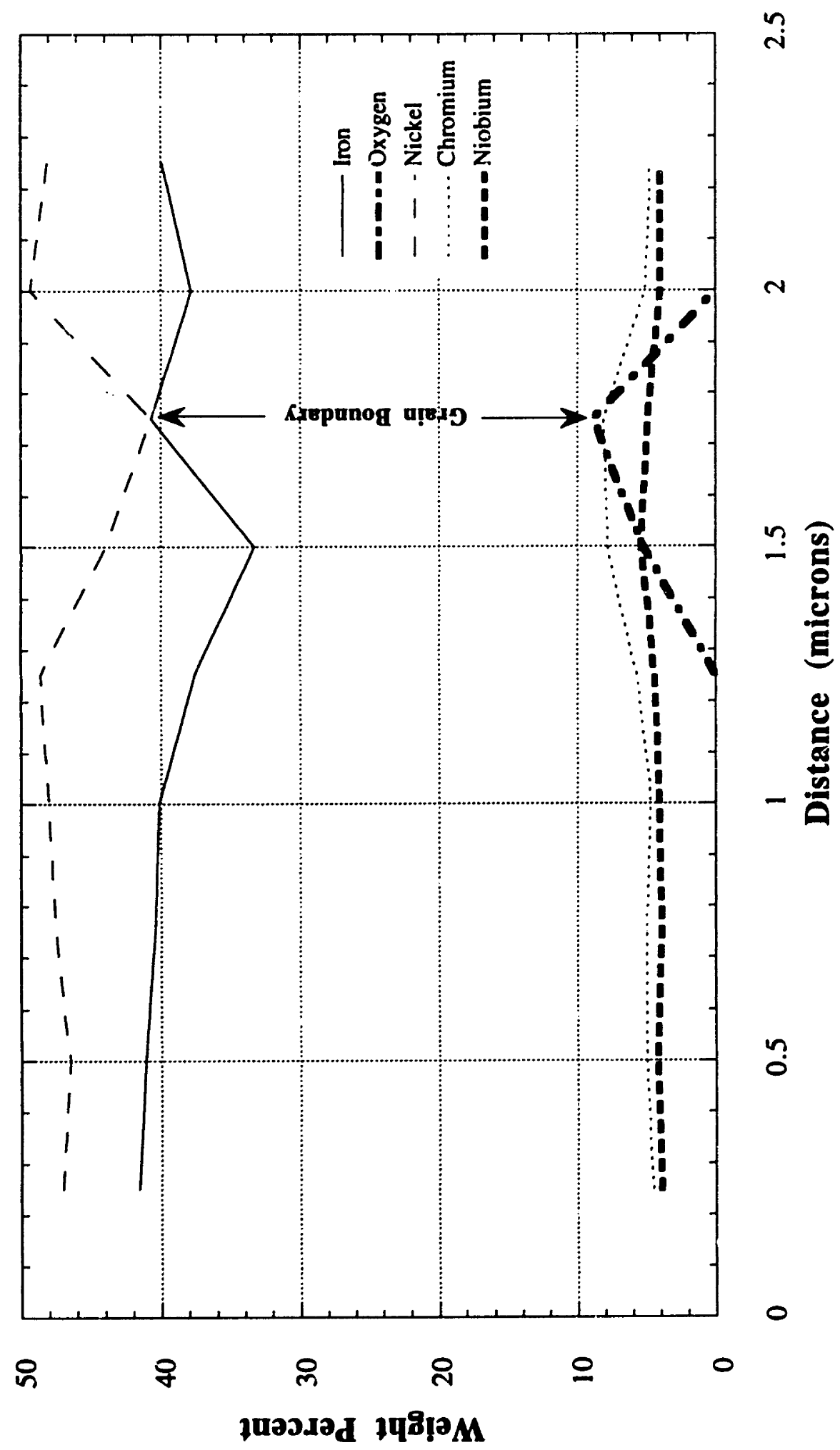

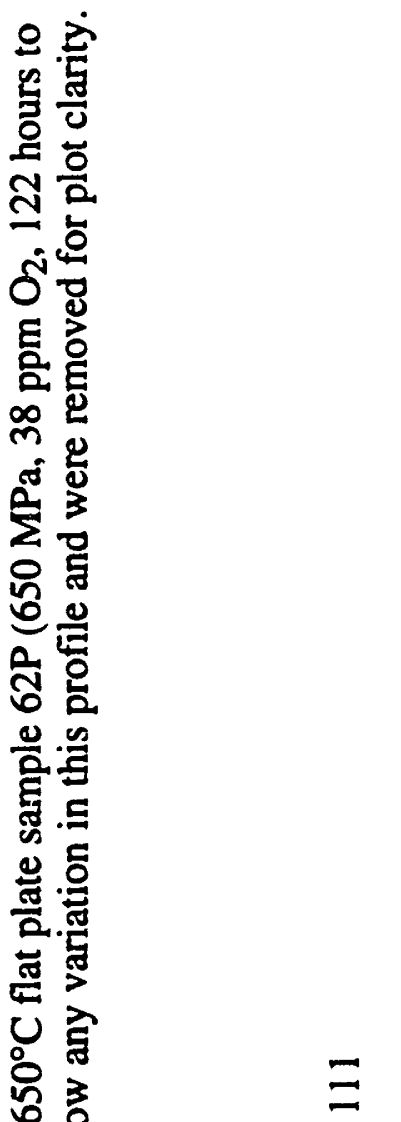




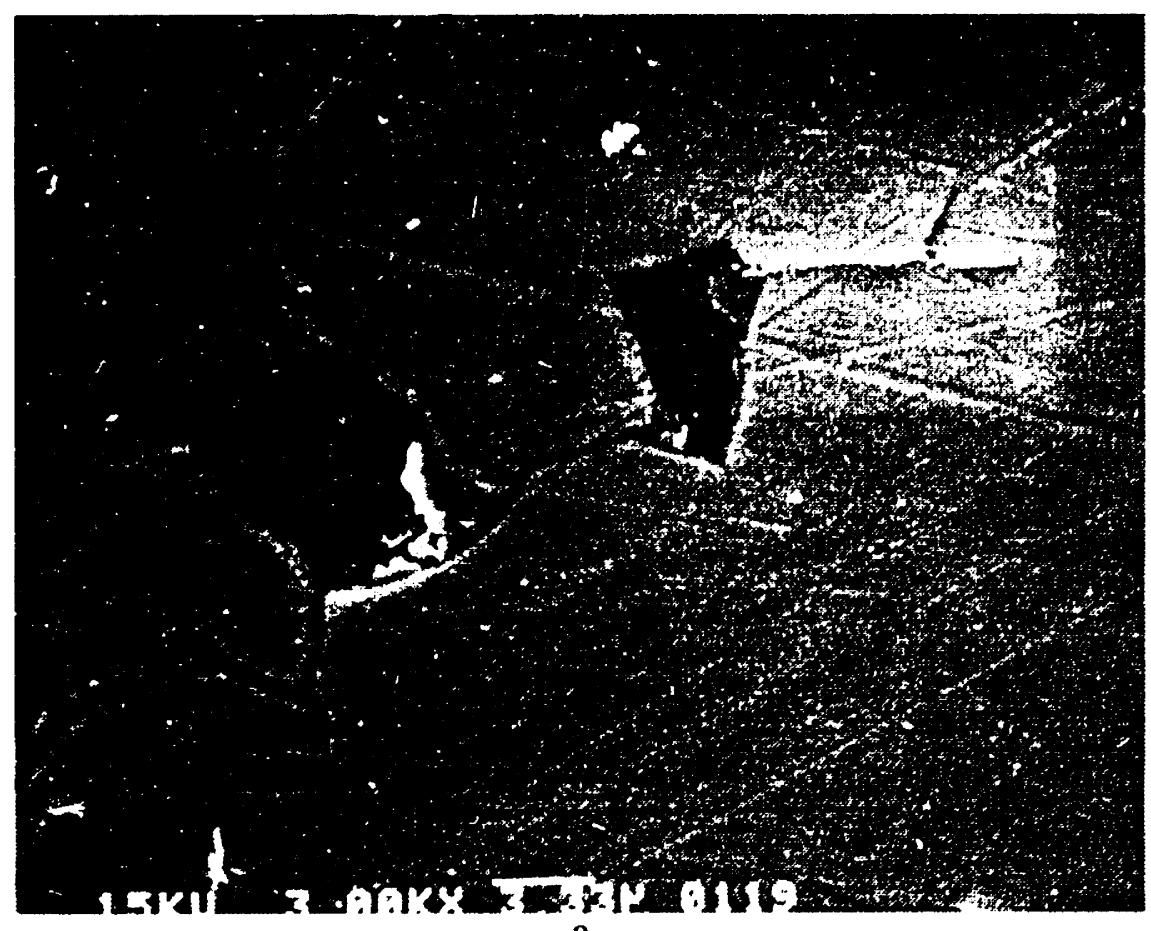

a

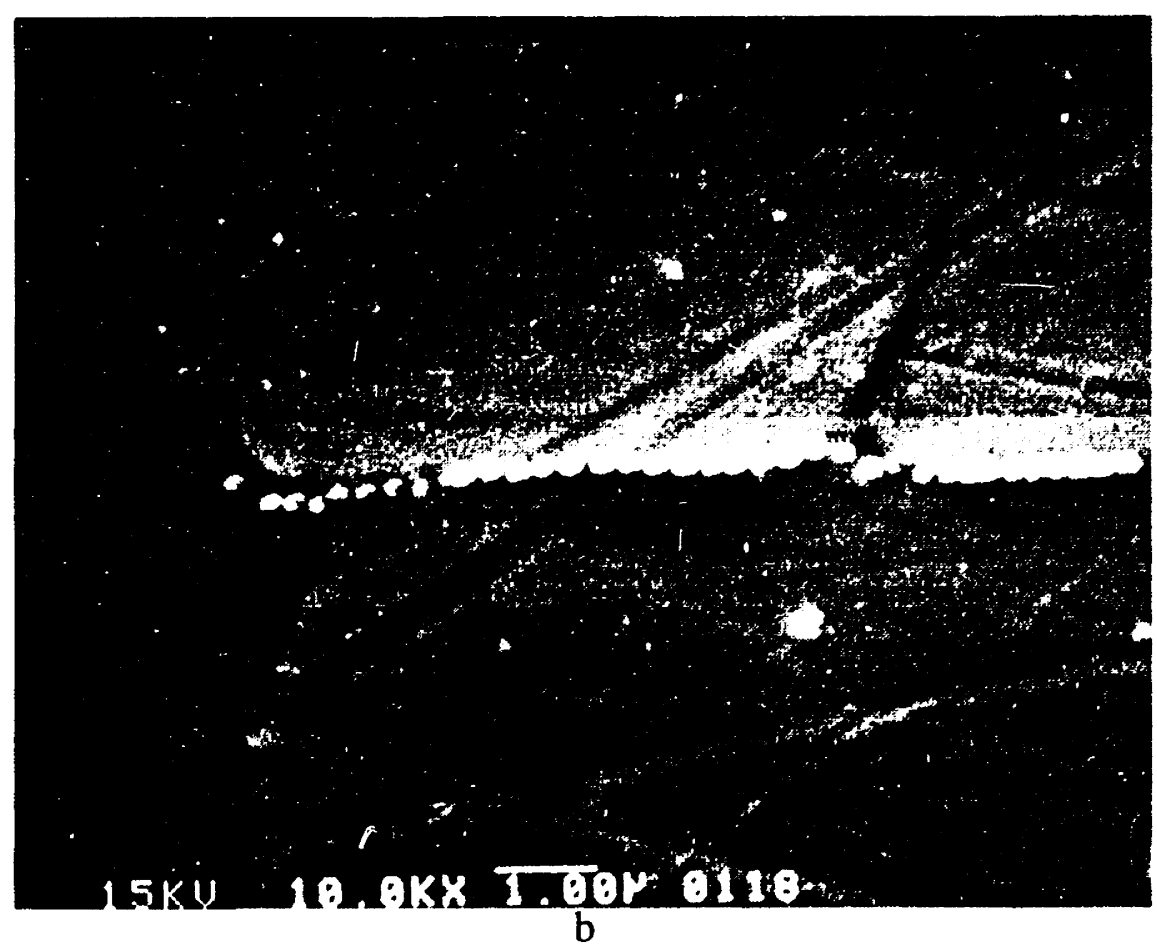

Figure 64. SEM micrographs of $650^{\circ} \mathrm{C}$ flat plate sample $49 \mathrm{P}(650 \mathrm{MPa}, 1000 \mathrm{ppm} \mathrm{O}$, 28.3 hour rupture time). (a) Affected grain boundary extending in from failed notch. (b) Grain boundary used for compositional analysis. 


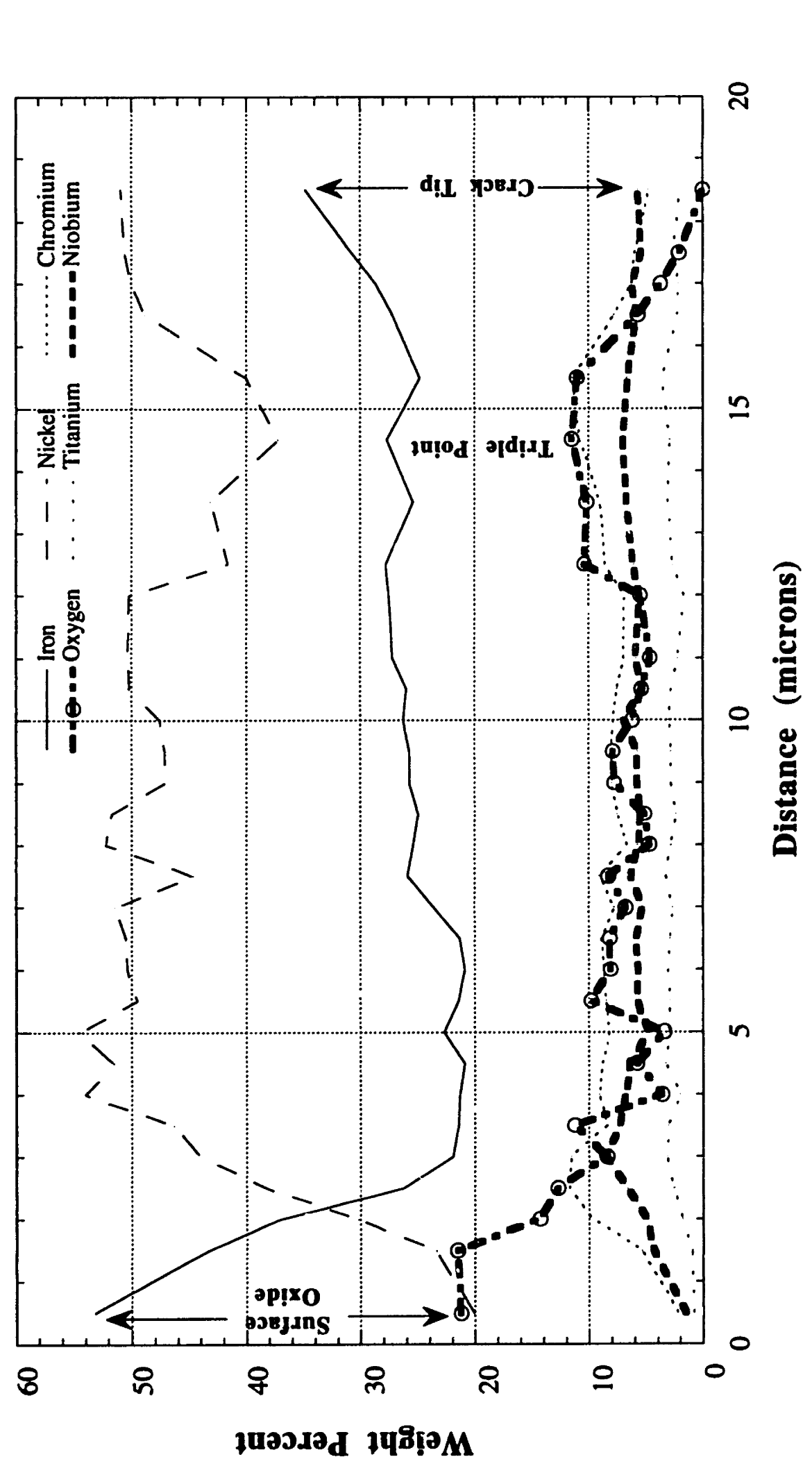

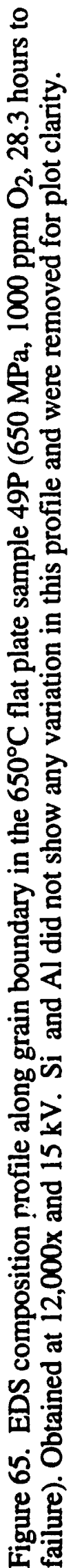




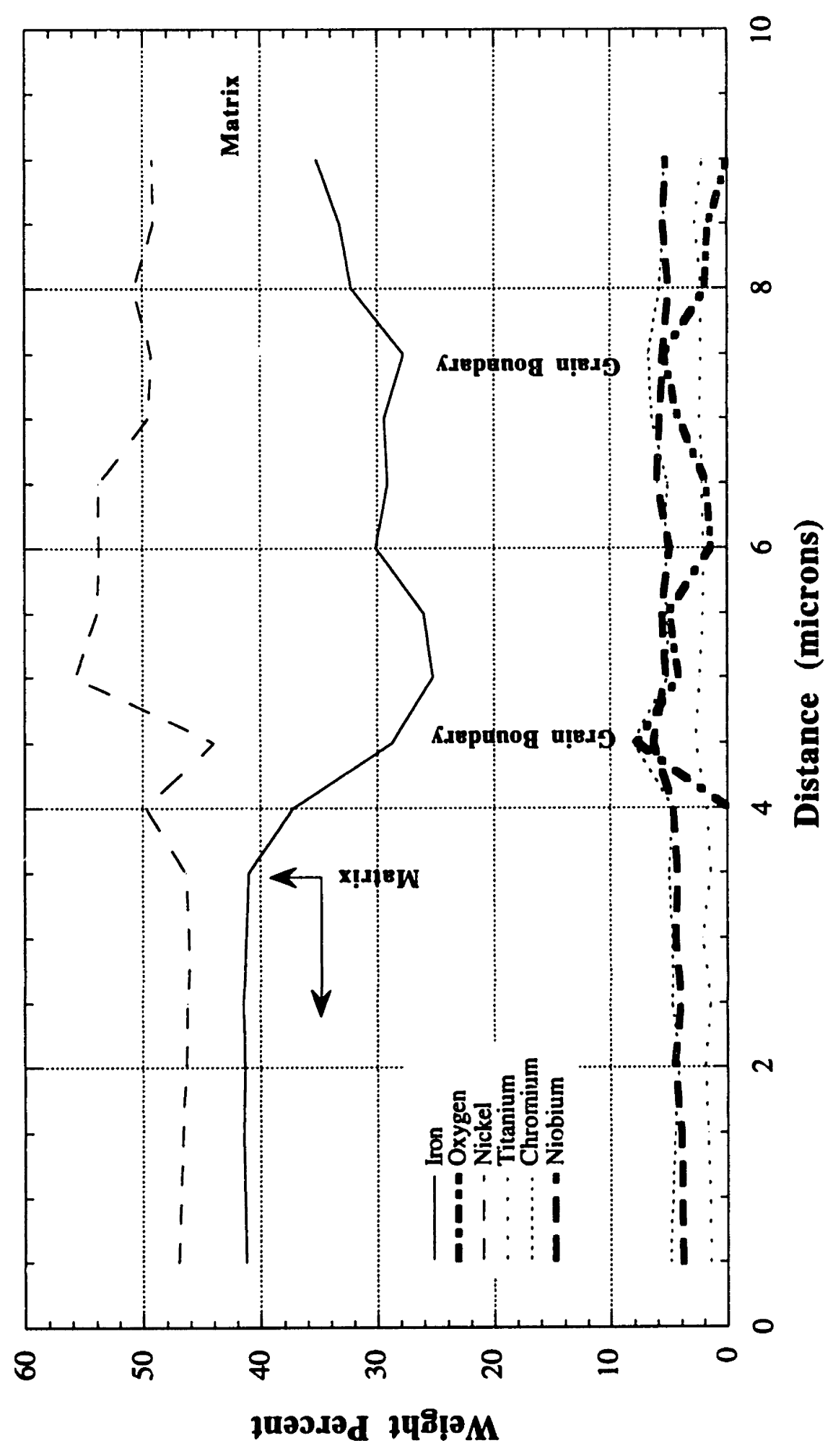

옹

ำ?

只

ร่ํㅡㅁ

통을

8

응

क

造

은

을

จิ 월

은

몽

胥

옴도

믐

壱

U

ํํำ

$\pm$

至

.5

동응

옥 암

준

돓 음

的

ه

늘

을 옹

응 용

8 i

픔

궁

๓

四

ช

ชิ 

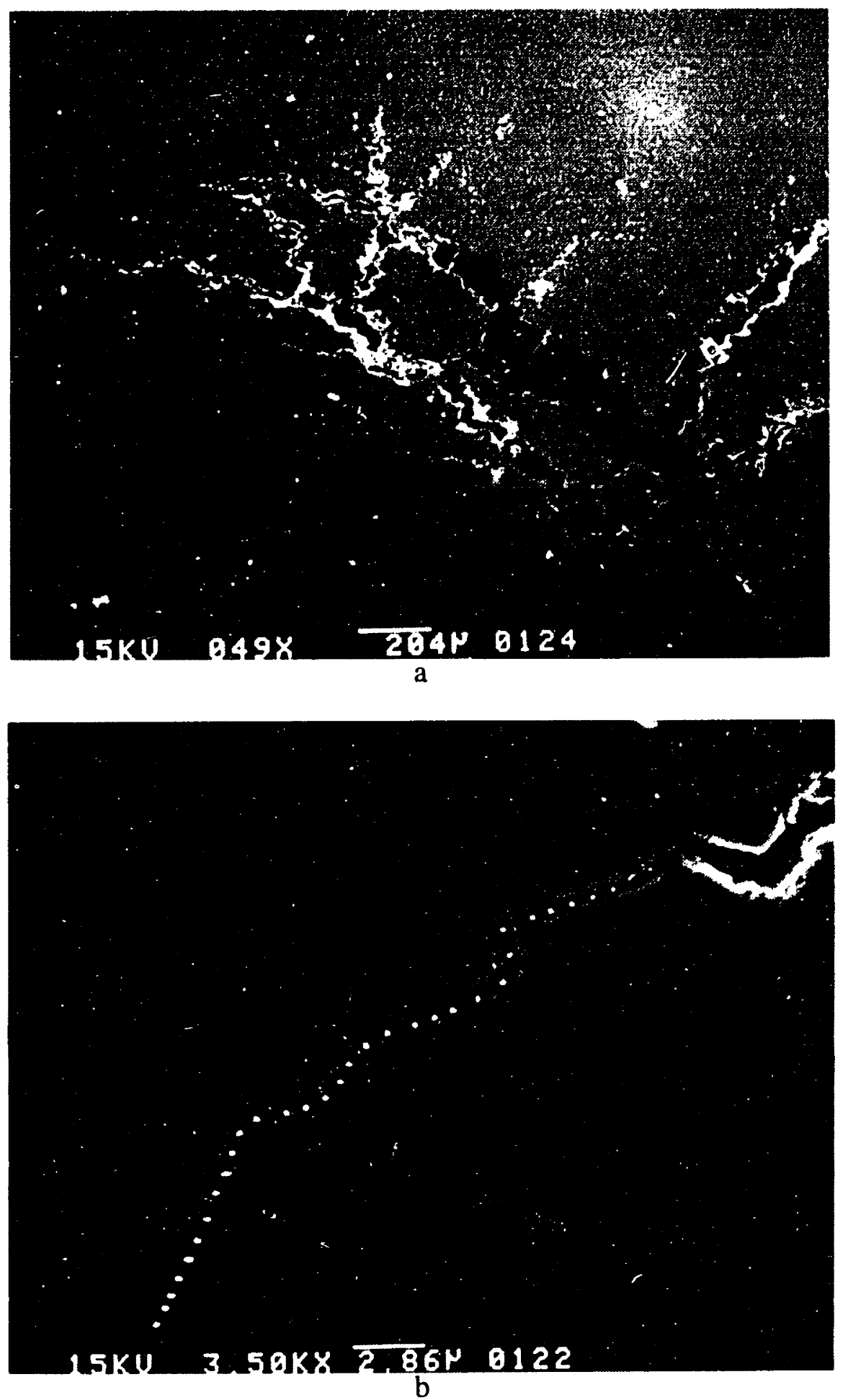

Figure 67. (a) SEM micrograph of crack at notch in round bar sample 20cw-24 (650 MPa, $1000 \mathrm{ppm} \mathrm{O}, 3.65$ hours to failure). (b) SEM micrograph of grain boundary at the farthest distance from notch used for compositional analysis. 


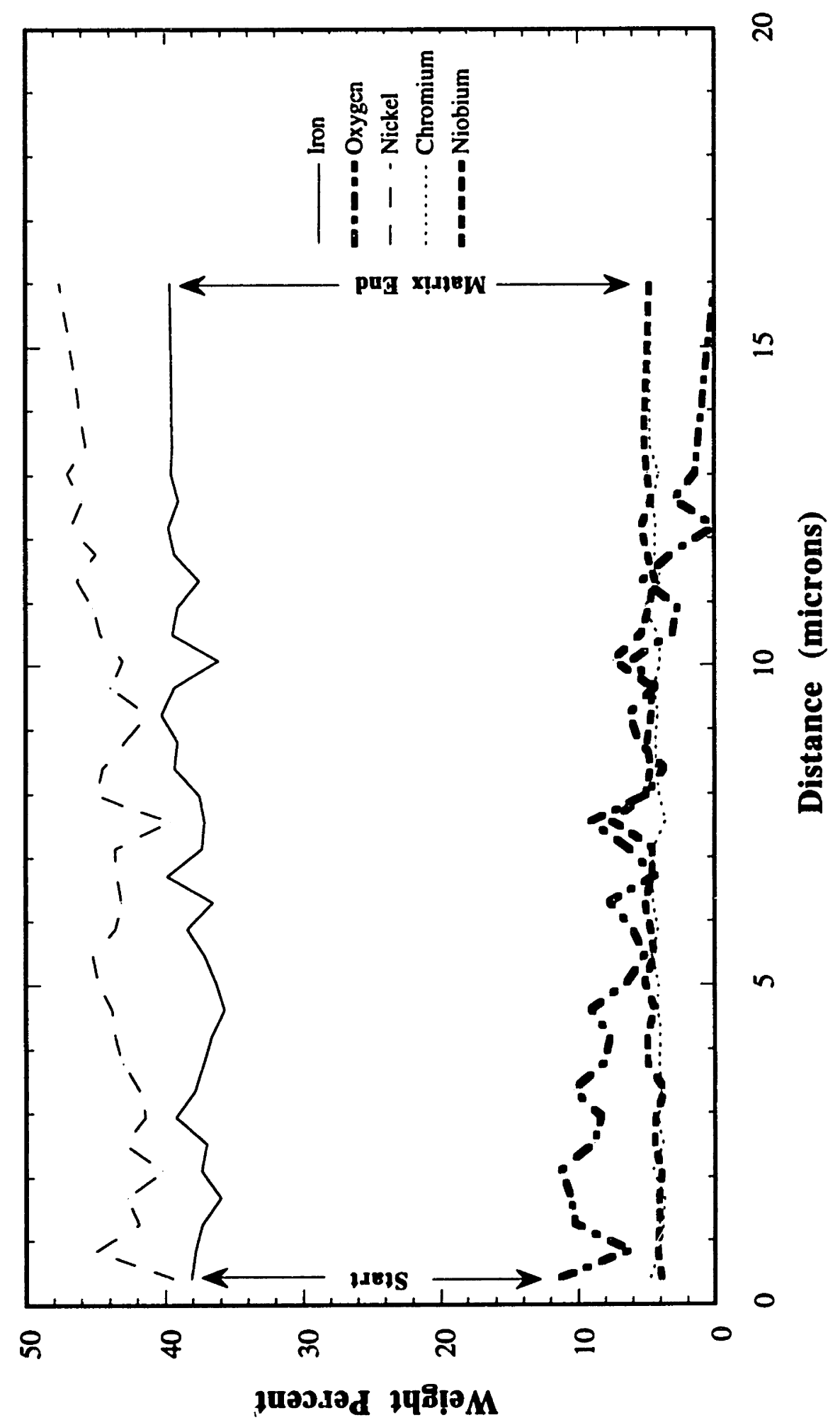

홍 옹

i o

ㅇํ음

통융

8 응

논

है

ㅇํ을

品

3 잉

유.

올

을.

동 드

尔

돈

국

온

U

응 음

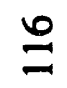

흠

․ㅗ음

준

옹 응

8.

䍃的

익

유

능 뭉

는

등ㅇㅇㅇ

든

응

통 엉

น สํํ

田完

$\infty \dot{0}$ 
The results from this round bar sample are consistent with the previously reported findings based on $\mathrm{x}$-ray maps and line profiles of affected grain boundaries in the other round bar samples tested at $650^{\circ} \mathrm{C}$ in $1000 \mathrm{ppm}$ oxygen. With the exception of small increases at the very terminus of the affected boundaries, as was previously shown, significant segregation of chromium to the grain boundaries in round bar samples was not evident. Chromium enrichment is, however, evident along grain boundaries in comparable $650^{\circ} \mathrm{C}$ flat plate samples that were also tested in $1000 \mathrm{ppm}$ oxygen. Aside from geometry, the main distinction between these two samples types is the time to failure, with the flat plate samples failing at longer times than equivalent round bar samples. Flat plate samples tested at lower oxygen concentrations also exhibited chromium concentrations at their grain boundaries that were from 2 to 10 weight percent above matrix levels. Chromium concentration was a function of position along the affected boundary, with the highest levels closest to the terminus. 


\section{G. Modification of Residual Stresses in C-Ring Test Samples}

A compilation of the $\mathbf{C}$-ring test results can be seen in Table 5. In this table, failure denotes intergranular cracking through the thickness of the ring. There were no failures among the six shot peened samples tested. Of the four stress relieved samples, none failed, and of the eight solution annealed samples tested, six, or $75 \%$, failed. A macrograph of the failed C-ring S37 is shown in Figure 69a. As can be seen from this figure, the crack extends across the width of the $\mathrm{C}$-ring at the apex of its ellipse. When the failed samples are broken open, the cracks can be seen to extend through the entire wall thickness, as shown in the SEM micrograph in Figure 69b.

Table 5. Alloy 908 C-Ring Test Results at $650^{\circ} \mathrm{C}, 6 \%$ Plastic Strain.

\begin{tabular}{|l|c|c|c|c|}
\hline \multicolumn{1}{|c|}{ Sample Condition } & Sample ID & $\begin{array}{c}\text { Vacuum } \\
\text { (Torr) }\end{array}$ & $\begin{array}{c}\text { Exposure Time } \\
\text { (hours) }\end{array}$ & Failure \\
\hline Solution Anneal + Bend & S29 & $3 \times 10^{-2}$ & 24 & yes \\
\hline Solution Anneal + Bend & S37 & $3 \times 10^{-2}$ & 24 & yes \\
\hline Solution Anneal + Bend + Stress Relieve & S48 & $4 \times 10^{-2}$ & 24 & no \\
\hline Solution Anneal + Bend + Stress Relieve & S49 & $4 \times 10^{-2}$ & 24 & no \\
\hline Solution Anneal + Bend + Shot Peen & S13 & $4 \times 10^{-2}$ & 24 & no \\
\hline Solution Anneal + Bend + Shot Peen & S20 & $4 \times 10^{-2}$ & 24 & no \\
\hline Solution Anneal + Bend & S26 & $3 \times 10^{-2}$ & 72 & yes \\
\hline Solution Anneal + Bend & S27 & $3 \times 10^{-2}$ & 72 & yes \\
\hline Solution Anneal + Bend + Stress Relieve & S47 & $4 \times 10^{-2}$ & 70 & no \\
\hline Solution Anneal + Bend + Stress Relieve & S50 & $4 \times 10^{-2}$ & 70 & no \\
\hline Solution Anneal + Bend + Shot Peen & S22 & $4 \times 10^{-2}$ & 70 & no \\
\hline Solution Anneal + Bend + Shot Peen & S18 & $4 \times 10^{-2}$ & 70 & no \\
\hline Solution Anneal + Bend & S28 & $3 \times 10^{-2}$ & 120 & yes \\
\hline Solution Anneal + Bend & S38 & $3 \times 10^{-2}$ & 120 & no \\
\hline Solution Anneal + Bend & S1 & $4 \times 10^{-2}$ & 200 & yes \\
\hline Solution Anneal + Bend & S2 & $4 \times 10^{-2}$ & 200 & no \\
\hline Solution Anneal + Bend + Shot Peen & S16 & $4 \times 10^{-2}$ & 200 & no \\
\hline Solution Anneal + Bend + Shot Peen & S19 & $4 \times 10^{-2}$ & 200 & no \\
\hline
\end{tabular}

Shot peening produces a thin layer of compressive residual stress to a depth of about one quarter to one half the shot diameter. [110] The dimpled surface texture produced by shot peening the $\mathrm{C}$-ring samples can be seen in Figure 70a. A SEM micrograph showing the apex of the shot peened C-ring S13 after testing is shown in Figure 70b. As can be seen in this figure, and when compared to the failed C-ring in Figure 69b, no cracking was observed in any of the shot peened samples tested. A comparison of surface cross sections from the three sample types was obtained from metallographic sections taken near the apex of the C-rings. Near surface cross sections that are representative of the three sample 


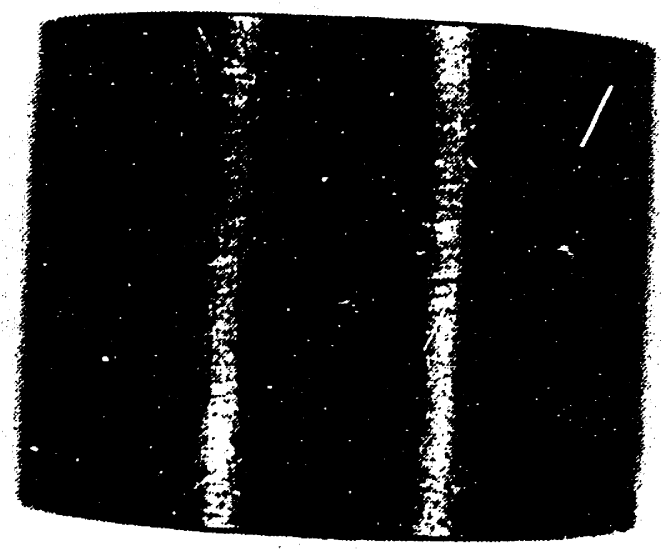

a

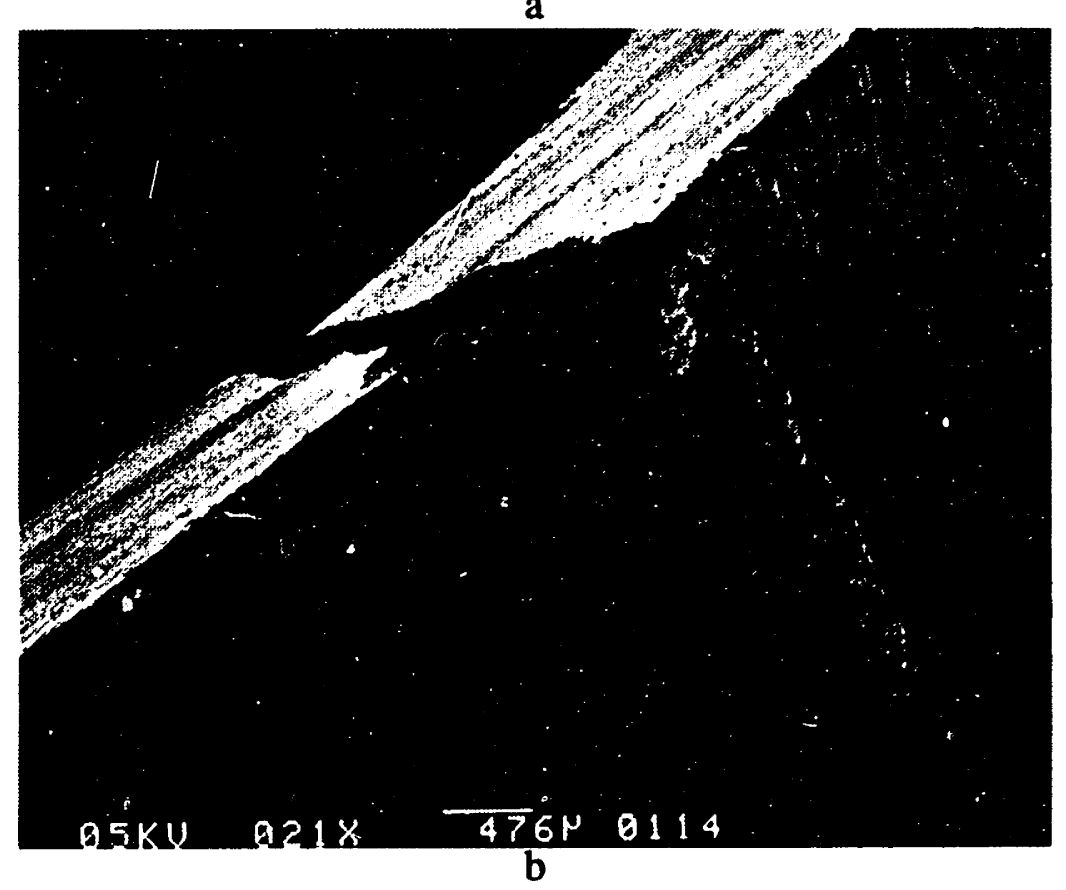

Figure 69. (a) Macrophoto of cracked C-ring S37, solution annealed starting condition, failed within 24 hours in a $3 \times 10^{-2}$ Torr vacuum at $650^{\circ} \mathrm{C}$. (b) SEM micrograph showing intergranular through crack in C-ring. 


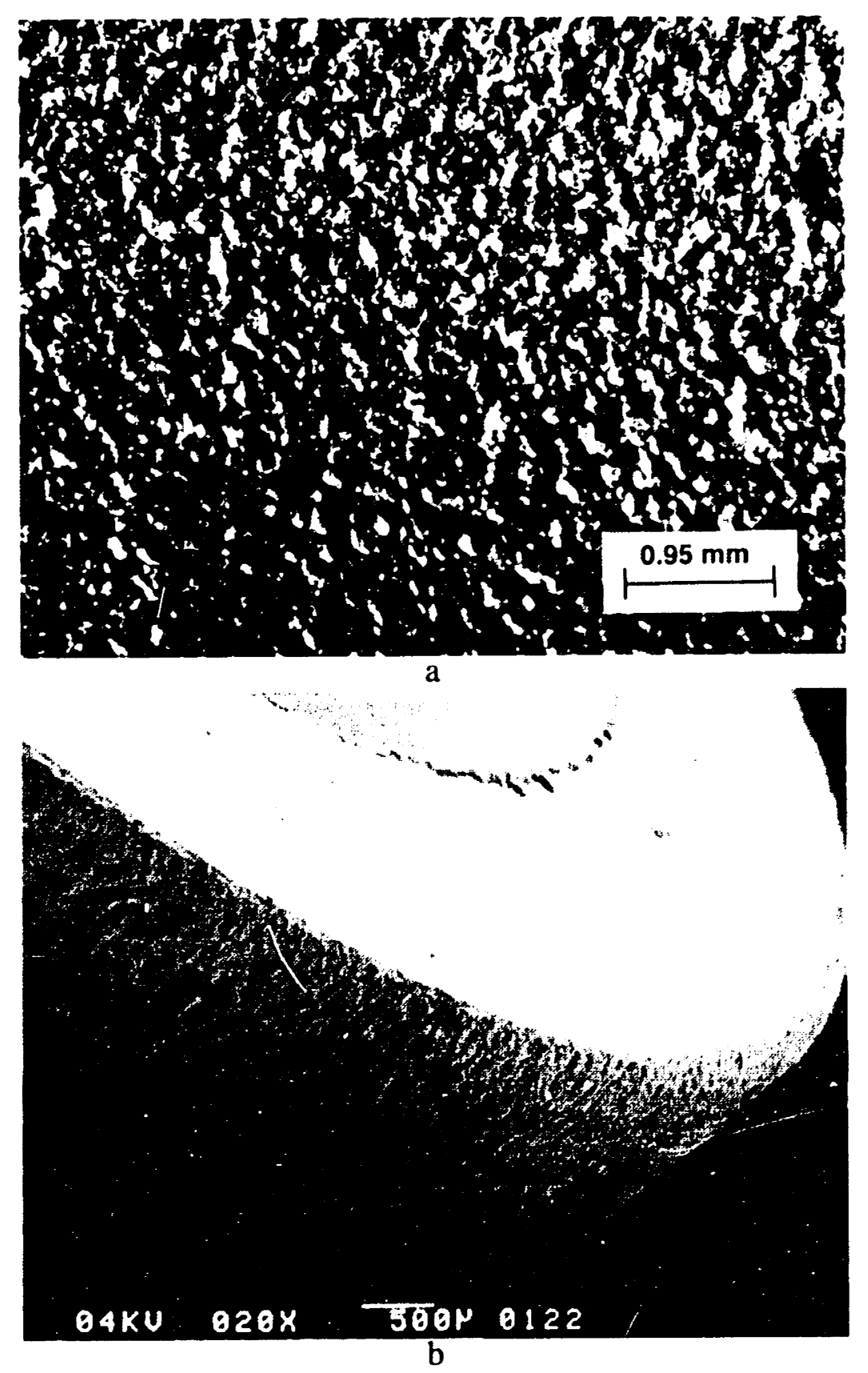

Figure 70. (a) Stereomicrograph showing dimpled surface of C-ring surface after shot peening. (b) SEM micrograph of shot peened surface at bend in C-ring S13 after 24 hours at $650^{\circ} \mathrm{C}$ in a $4 \times 10^{-2}$ Torr vacuum. 
types are shown in Figures 71a-c. As can be seen from Figures 71a and 71b, the solution annealed and stress relieved surfaces, respectively, appear similar. In cross section, the shot peened surface shows a deformed layer of material at the surface, as can be seen in Figures $71 \mathrm{c}$ and $71 \mathrm{~d}$. The shot peen size used in this experiment was $63 \mu \mathrm{m}$ in diameter. The depth of the deformed layer at the surface of these samples was estimated from micrographs of surface cross sections to be 20 to $30 \mu \mathrm{m}$ deep, approximately one third to one half the shot peen diameter. The maximum compressive stress that can obtained by shot peening is approximately one-half the material's yield strength. [110] For alloy 908 in the solution annealed condition this value would be approximately $-200 \mathrm{MPa}$.

Microhardness traces extending across the entire cross sections of these samples were also obtained and can be seen in Figures $7 \sim 7$, 74. As can be seen from in Figure 72, the microhardness trace across a shot peened sample shows an increase in hardness in the deformed layer at the surface. The stress relieved sample's microhardness decreases at the surface, shown in Figure 73, and is consistent with stress relief occurring there. A material can be stress relieved by heating it to a temperature where the yield strength of the material is the same or less than the value of the residual stress.[114] For ailoy 908 in the solution annealed condition, this value is approximately $400 \mathrm{MPa}$ at $650^{\circ} \mathrm{C}$. At this temperature the material can deform and relieve the stress through creep. It is important to note that the samples used in this study were cooled very slowly after the $650^{\circ} \mathrm{C} / 16$ hour stress relief heat treatment, and furnace cooling occurred under vacuum. Slow cooling is important so as not reintroduce residual stresses. The microhardness trace across the solution annealed and failed sample is shown in Figure 74 and shows no change in subsurface hardness.

The results of the $\mathbf{C}$-ring tests indicate that the elimination or reduction of the tensile residual stress component contributing to intergranular oxidation was responsible for preventing intergranular cracking. Another factor, that can contribute to these results may exist. Researchers have observed that changes in the surface stress state can alter the type of oxide formed. Shot peening produces $\mathrm{Cr}$ rich spinels versus ( $\mathrm{Fe}, \mathrm{Ni}$ ) O type oxides. [40, $77,78,115]$ Improved oxidation resistance of shot peened materials has also been observed. [115] In the case of $\mathrm{C}$-ring samples that had been used for metallographic preparation, and not preserved in a desiccator, rust $(\mathrm{FeO})$ was found to have formed on the solution annealed and the stress relieved surfaces but not on the shot peened surface. To determine whether this was due to $\mathrm{Cr}$ enrichment, chemical analysis was conducted on oxides electrolytically extracted from the surfaces of the C-rings. Shot peened, stress relieved, failed solution annealed and intact solution annealed samples were analyzed. The results of this analysis are shown in the plot seen in Figure 75. Oxides from the two 


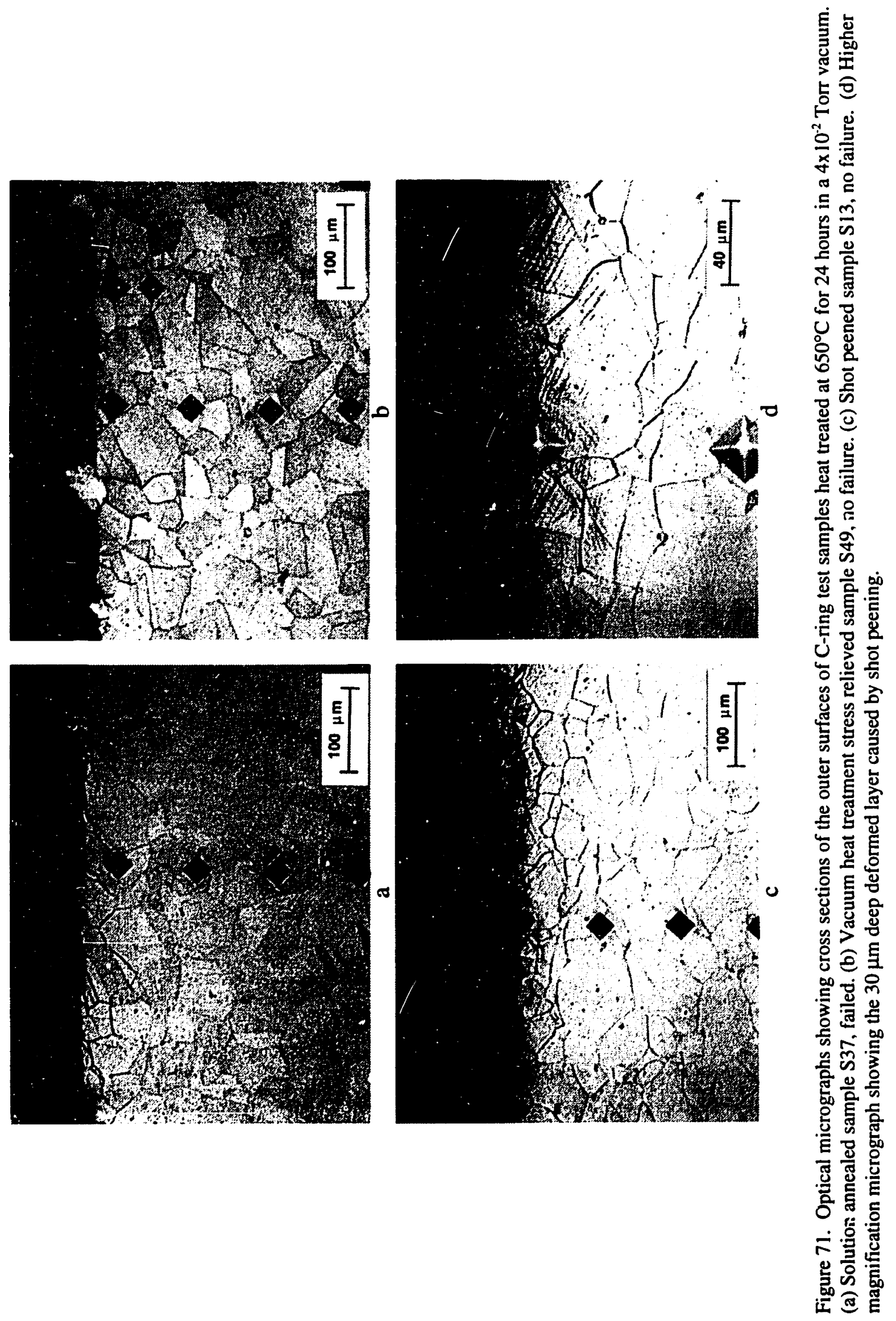




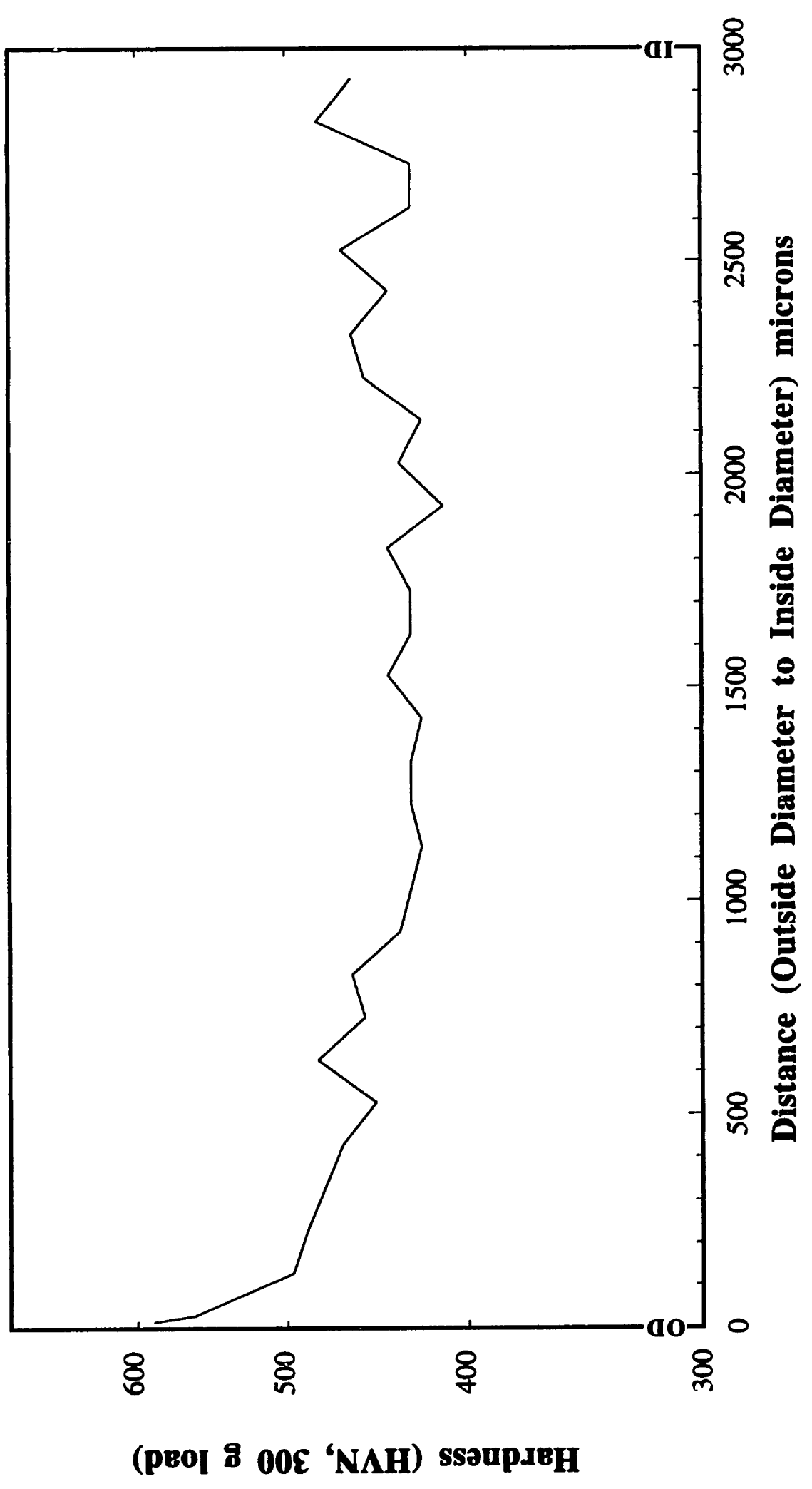

E 


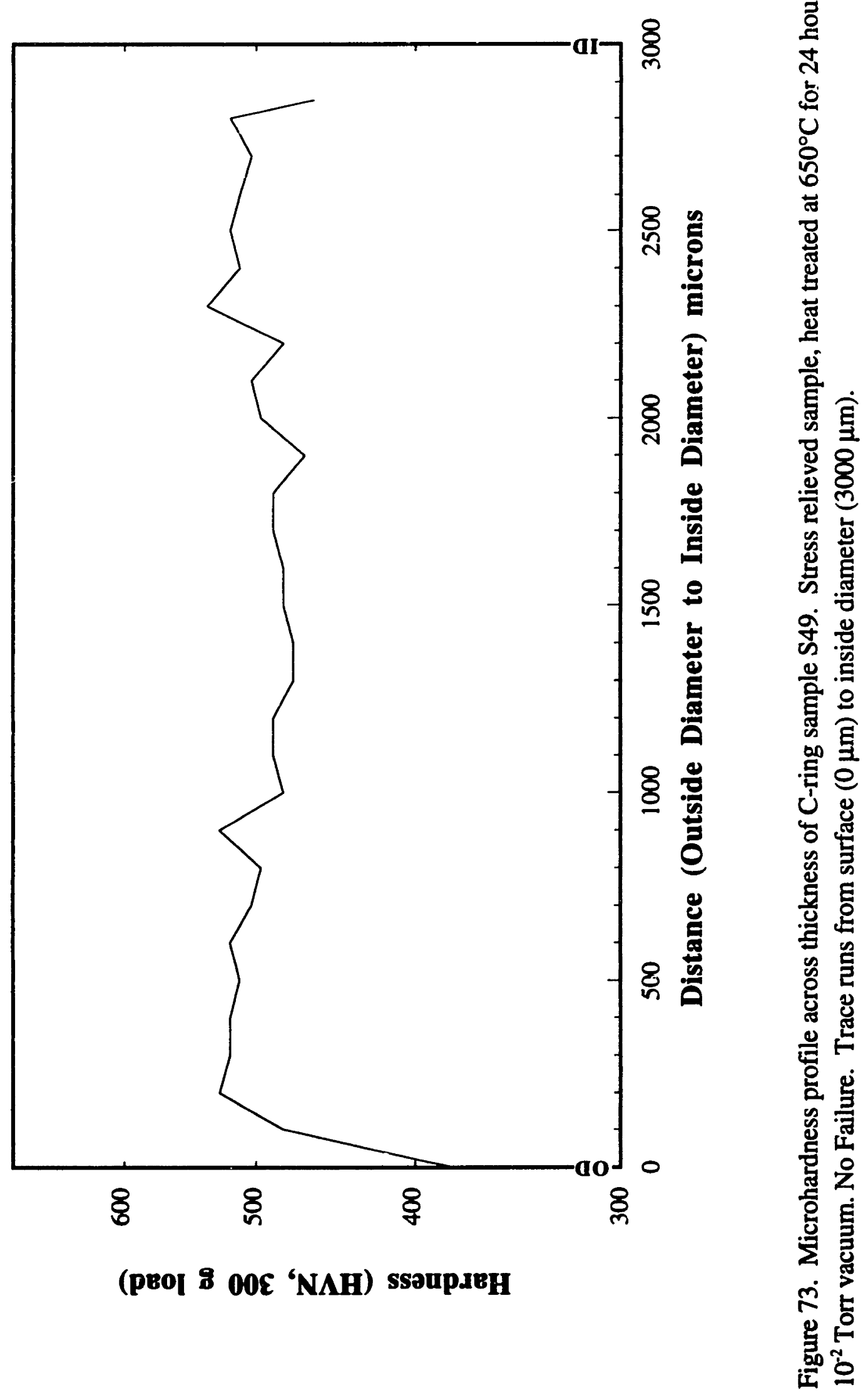




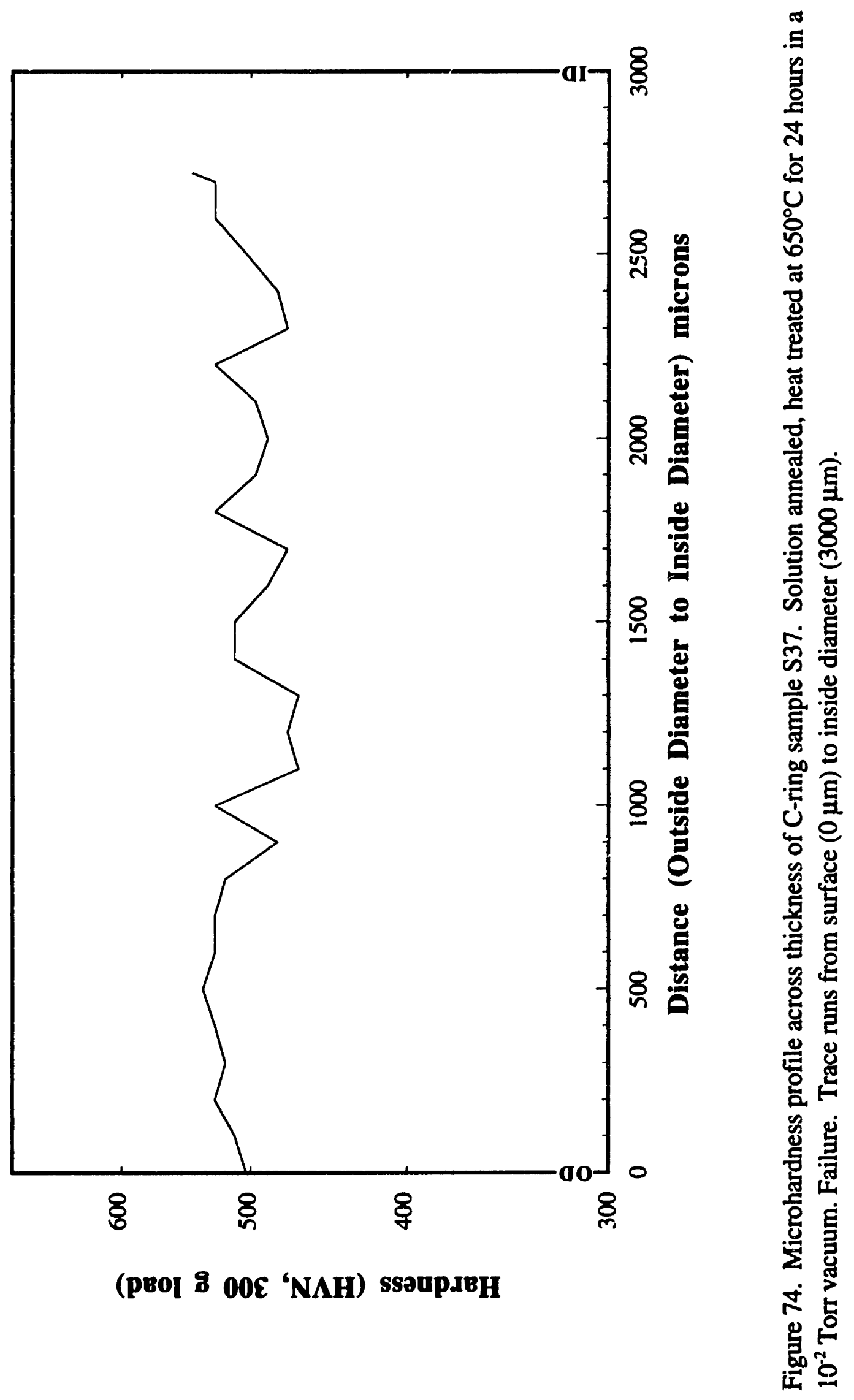




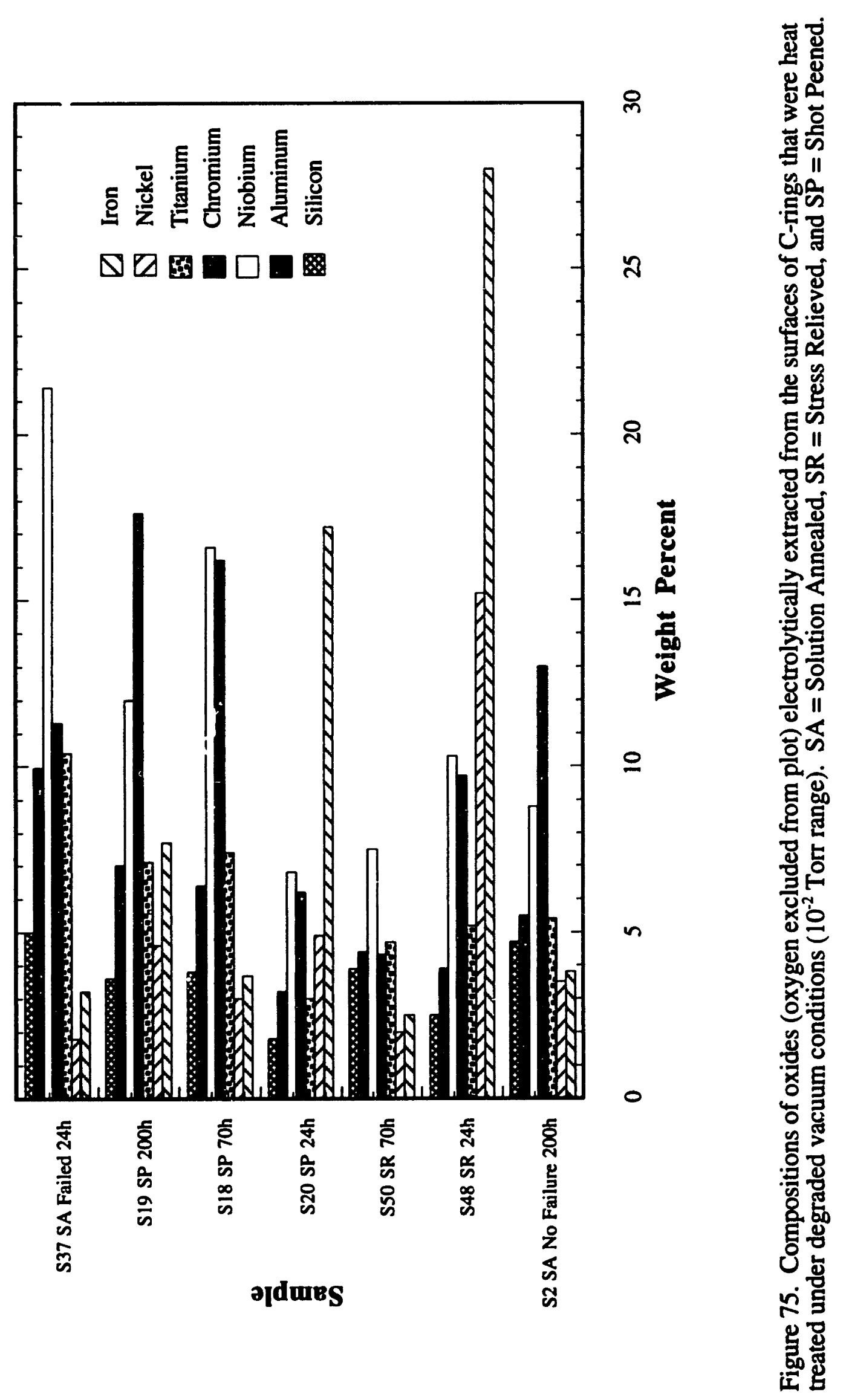


longest time shot peened samples have high concentrations of $\mathrm{Cr}$ and $\mathrm{Nb}$, with low concentrations of $\mathrm{Fe}$ and $\mathrm{Ni}$. The short time, 24 hour, oxide sample shows a higher $\mathrm{Fe}$ concentration, with $\mathrm{Cr}$ and $\mathrm{Nb}$ levels low but above the matrix concentration. The trend of increasing $\mathrm{Cr}$ concentration for the shot peened samples corresponds to longer exposure times, allowing more of the $\mathrm{Cr}$ rich oxide to form. The oxide obtained from the failed solution annealed sample shows very high concentrations of $\mathrm{Nb}$ and of the easily oxidized hardening elements, $\mathrm{Ti}$ and $\mathrm{Al}$. The concentration of $\mathrm{Cr}$ was well above the matrix concentration of 4 weight percent and exceeded that of the shot peened sample tested for an equivalent time. Interestingly, the solution annealed sample that did not fail shows a higher $\mathrm{Cr}$ concentration than the failed sample, but this may be due to a longer exposure time that allowed more of the oxide to form. The $\mathbf{2 4}$ hour stress relieved sample also showed a $\mathrm{Cr}$ concentration that was above that of the equivalent shot peened sample. It was initially thought that the stress relieved samples may have formed a $\mathrm{Cr}$-rich oxide during their high vacuum heat treatment. And that this contributed to the fracture resistance seen in these samples. This supposition is not confirmed by these results. The observation that applies to all these samples is that $\mathrm{Nb}$ and $\mathrm{Cr}$ are present in the oxides. In the case of the shot peened samples, $(\mathrm{Fe}, \mathrm{Ni}) \mathrm{O}$ is present initially ( 24 hours) and the amount of $\mathrm{Cr}$ rich oxide increases with increasing exposure time. The high $\mathrm{Cr}$ concentration found in the shot peened oxides may account for their relative corrosion resistance when left exposed to air. Based on these chemical analyses, however, modification of surface stresses, either through shot peening or stress relief, are responsible for the lack of intergranular fracture in these samples. The oxide compositions of the stress modified samples at short times (24 hours) are not sufficiently enriched in $\mathrm{Cr}$ compared to the failed solution annealed sample to contribute to the results seen.

Examination of the fracture surfaces from the failed $C$-ring revealed fine structure in the SEM that was obscured by oxidation in the stress rupture samples. The SEM micrograph shown in Figure 76 is a composite across the wall thickness (ID to OD) of the failed C-ring sample S37. As seen in this micrograph, the intergranular fracture path extends through the full thickness of the sample, with only a thin, $50 \mu \mathrm{m}$, ductile layer at the inside surface, produced when the sample was broken open for examination. Higher magnification micrographs show the intergranular fracture surface to be brittle in character, with no evidence of ductility on the surfaces of the exposed grain boundaries, as shown in Figures 77a and 77b. Slip lines and twin boundaries can be seen very clearly on the grain surfaces in these micrographs. Their appearance is enhanced due their decoration by small white particles. At high magnification in the SEM, there was no variation in the density of these 


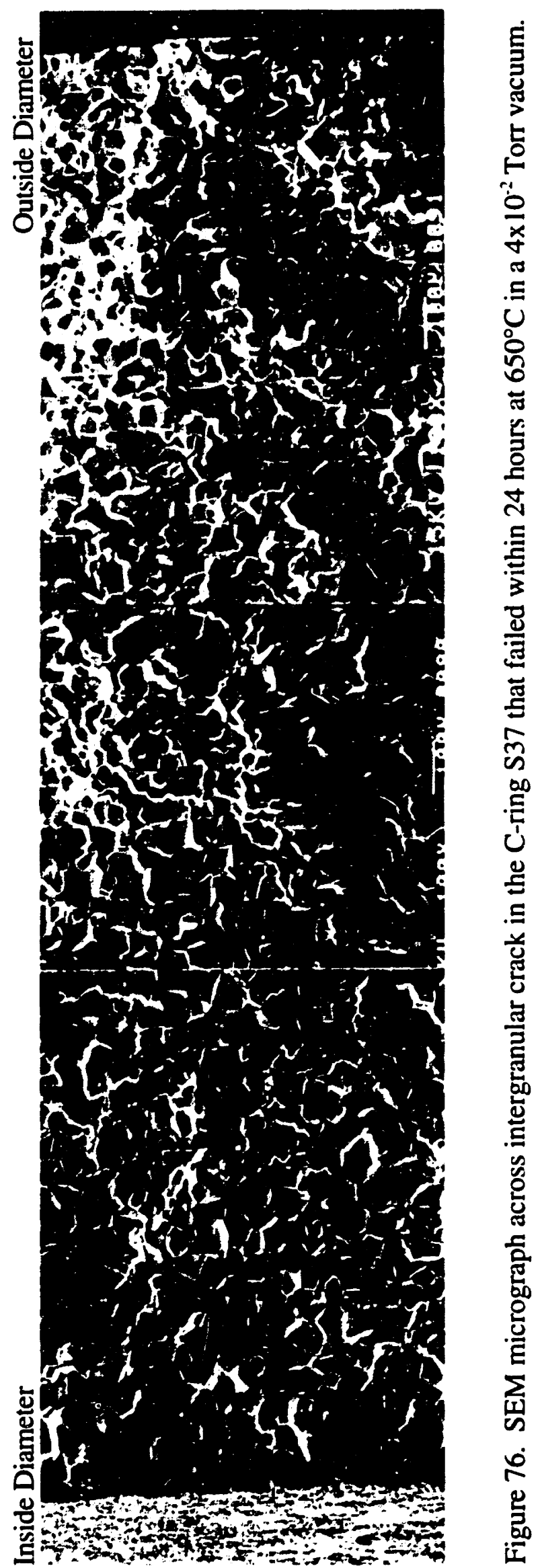




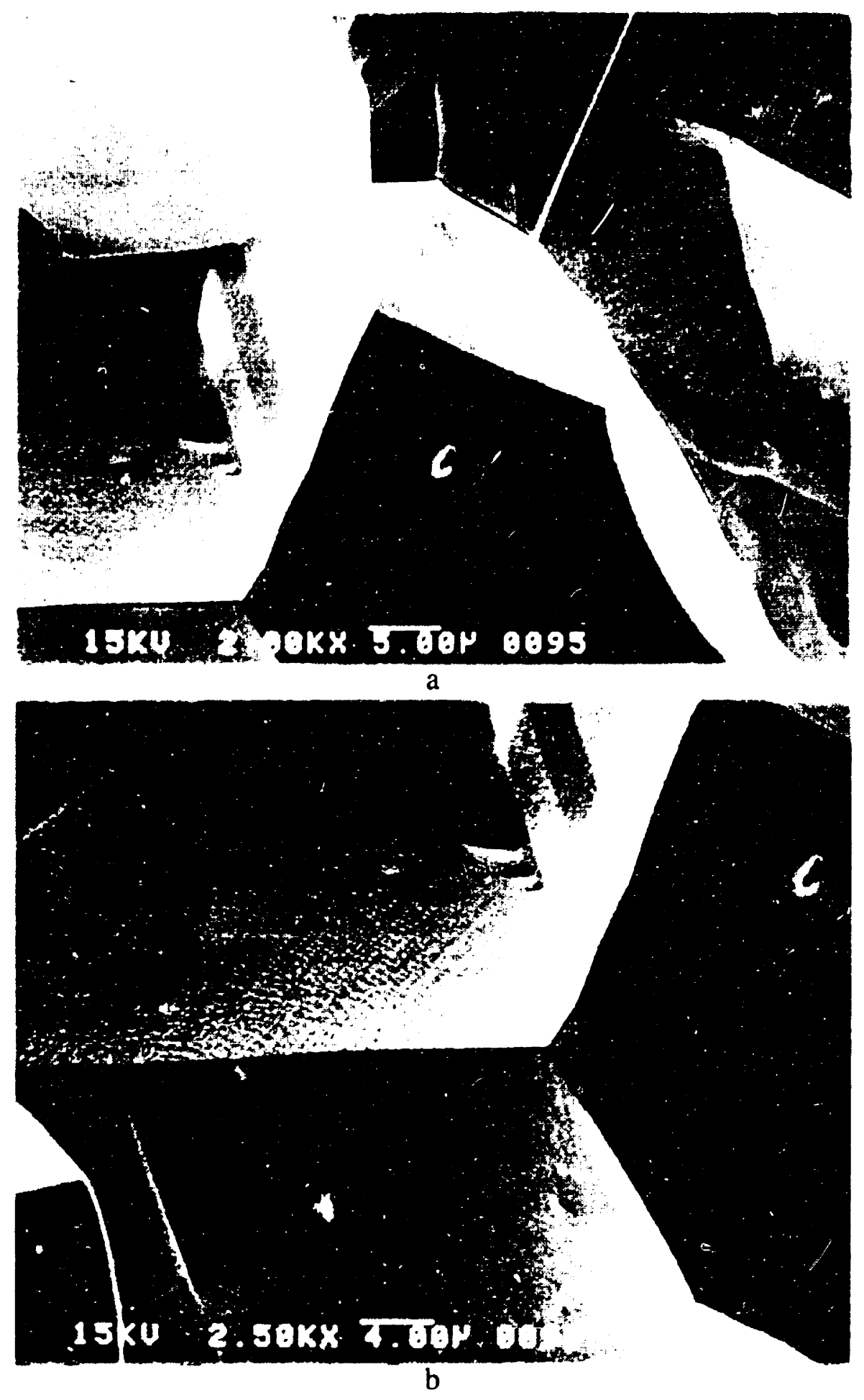

Figure 77. High magnification SEM micrographs taken near the inside diameter of the cracked cross section of C-ring S37 after failing within 24 hours at $650^{\circ} \mathrm{C}$ in a $4 \times 10^{-2}$ Torr vacuum. 
particles or fracture surface oxidation between the outside diameter and inside diameter of the sample. These particles and their association with slip lines in the material can be seen in Figures 78a. The high magnification micrograph seen in Figure $78 \mathrm{~b}$ clearly shows the decoration of slip lines by these particles. One stage, extraction replicas were made from the fracture surface in an attempt to identify these particles. The polymeric film used for the extraction was carbon coated after being stripped from the fracture. SEM examination of the replica using EDS showed that no particles had been extracted from the surface, indicating that they were well bonded to the surface. Insitu EDS analyses showed oxygen present in the particles but the concentrations of the other elements were at matrix levels. This result suggests that the particles have compositions that contain the two major matrix elements, i.e., $\mathrm{Ni}$ and $\mathrm{Fe}$, and have a stoichiometry close to the proportion of these elements in the matrix. C-ring experiments similar to these had been previously performed in commercial grade argon, and the fracture surfaces from these samples had shown fracture morphologies with similar decoration of slip lines as the degraded vacuum samples used in this study. The particles present on the argon tested samples, however, appeared to be coarser and hence easier to extract. SEM micrographs from the fracture surface of one of the $\mathrm{C}$-ring samples that had been tested at $550^{\circ} \mathrm{C}$ for 200 hours in a commercial grade argon atmosphere $\left(\mathrm{O}_{2} \leq 5 \mathrm{ppm}\right)$ are shown in Figures $79 \mathrm{a}$ and $79 \mathrm{~b}$. Fracture characteristics already discussed for the degraded vacuum sample are apparent. White particles decorating the slip lines are coarser in this sample, as seen in Figure 80a, and may have coarsened during the longer 200 hour heat treatment and with a steady supply of oxygen from the argon gas. A one stage replica taken from the fracture showed the particles to be very adherent but a small number were extracted, some of which can be seen in Figure 80b. Semi-quantitative EDS analyses were obtained from 9 of the extracted particles. The resulting composition, in weight percent, was determined to be $38.7 \pm 5 \% \mathrm{Fe}, 39 \pm 5.8 \%$ $\mathrm{Ni}$, and $21 \pm 6 \% \mathrm{O}$. To determine an approximate stoichiometry the atomic percent of these elements was $26 \pm 5 \% \mathrm{Fe}, 25 \pm 6 \% \mathrm{Ni}$, and $47.7 \pm 9.9 \% \mathrm{O}$, giving a compound with the formula $(\mathrm{Ni}, \mathrm{Fe}) \mathrm{O}$. Interestingly this is the same oxide stoichiometry reported by Andrieu to be present in the intergranular cracking regime of alloy 718 . [77, 78, 79] The SEM micrograph from a failed flat plate stress rupture is shown in Figure $80 \mathrm{c}$ as a comparison to the fractures seen in the $\mathrm{C}$-ring samples. The region shown in this micrograph is associated with a grain that had fallen out during metallographic preparation. As can be seen inside the missing grain cavity, the grain boundaries are oxidized more heavily than the $\mathrm{C}$-ring samples. The grain boundary oxide that can be seen in cross section 


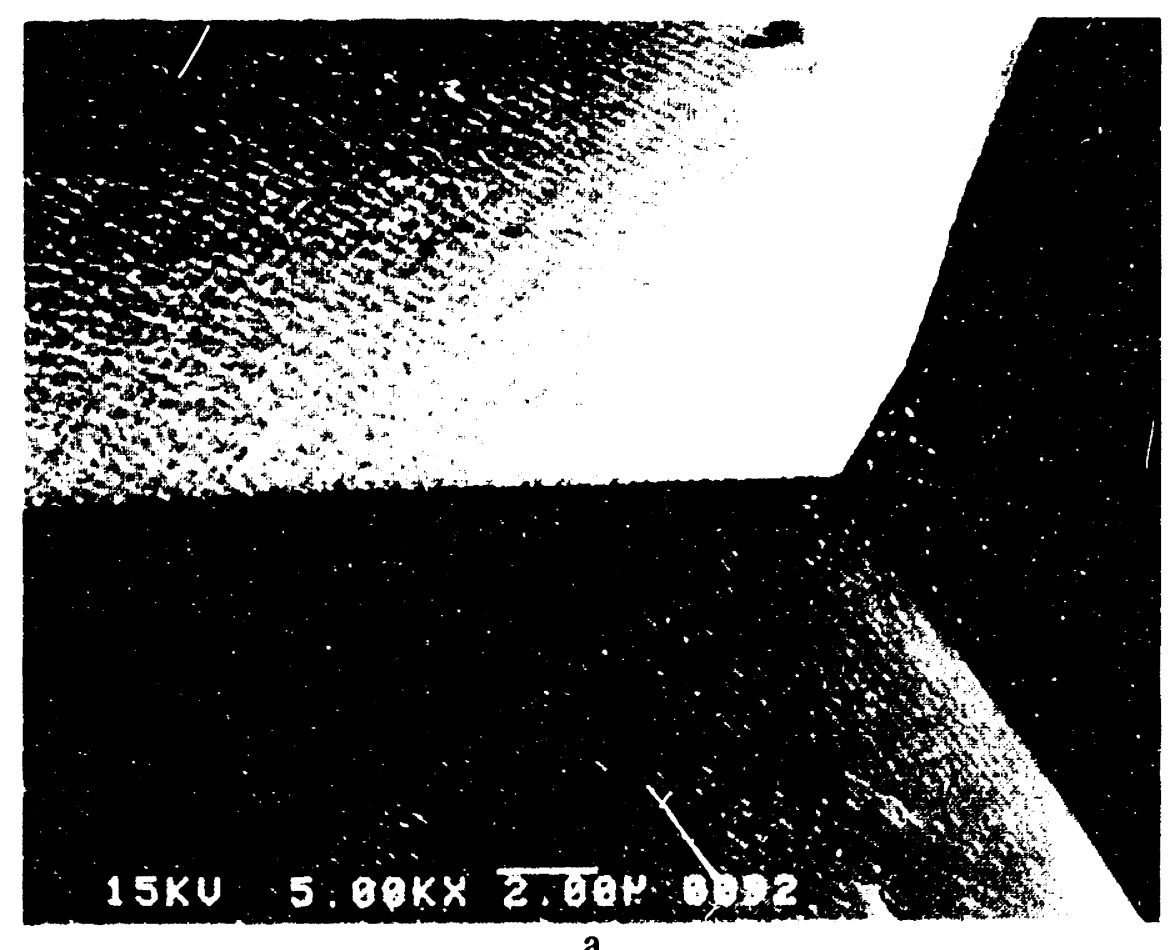

a

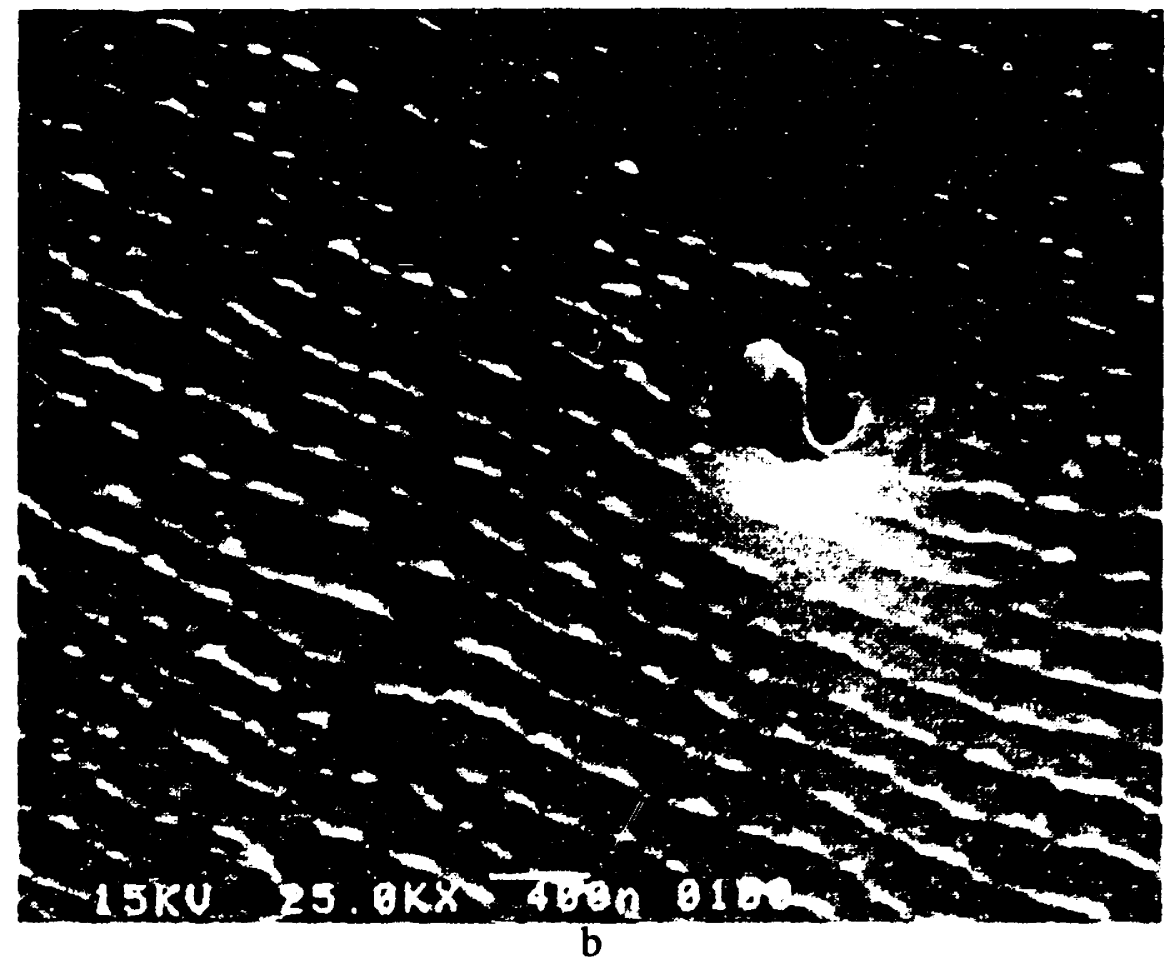

Figure 78. High magnification SEM micrographs taken along the cracked cross section of C-ring S37 after failing within 24 hours at $650^{\circ} \mathrm{C}$ in a $4 \times 10^{-2}$ Torr vacuum. (a) Near inside diameter. (b) Near outside diameter. 

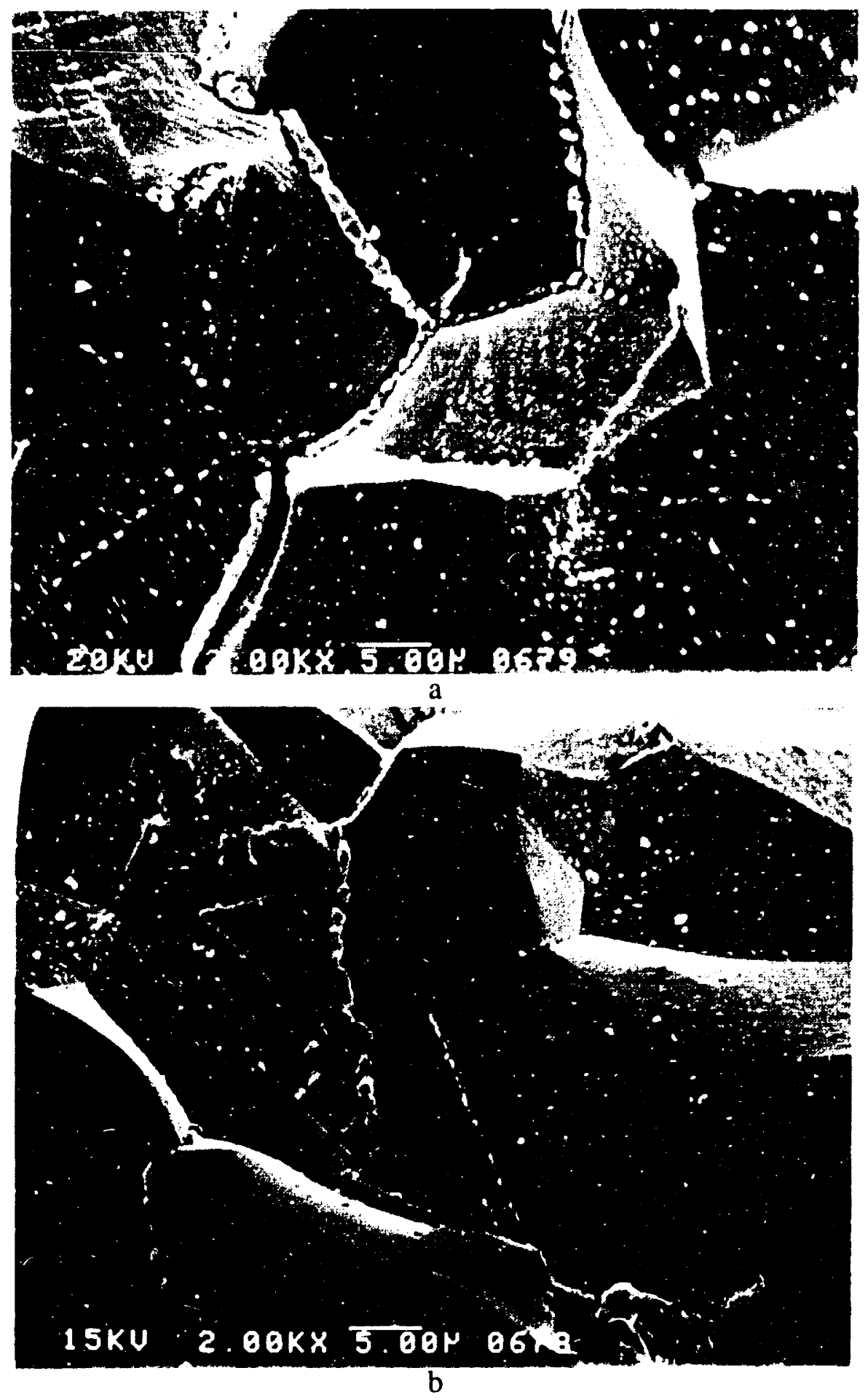

Figure 79. High magnification SEM micrographs taken of the intergranular fracture surface from a cross section of the C-ring C 33 after failing within 200 hours at $650^{\circ} \mathrm{C}$ in a commercial grade argon atmosphere. 


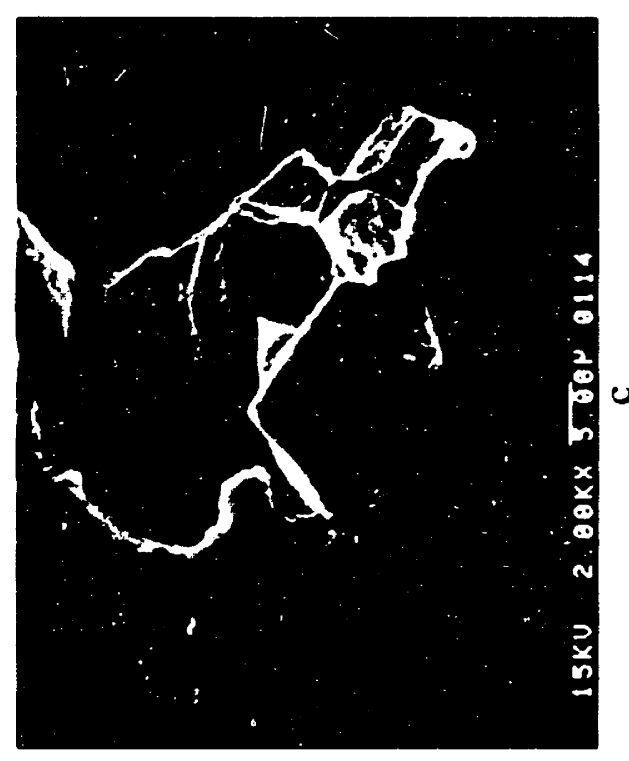

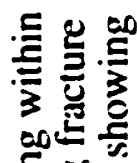
可氞焉 选完 氠 부을 뜰을 行政

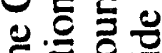
现 돕 ᄃ

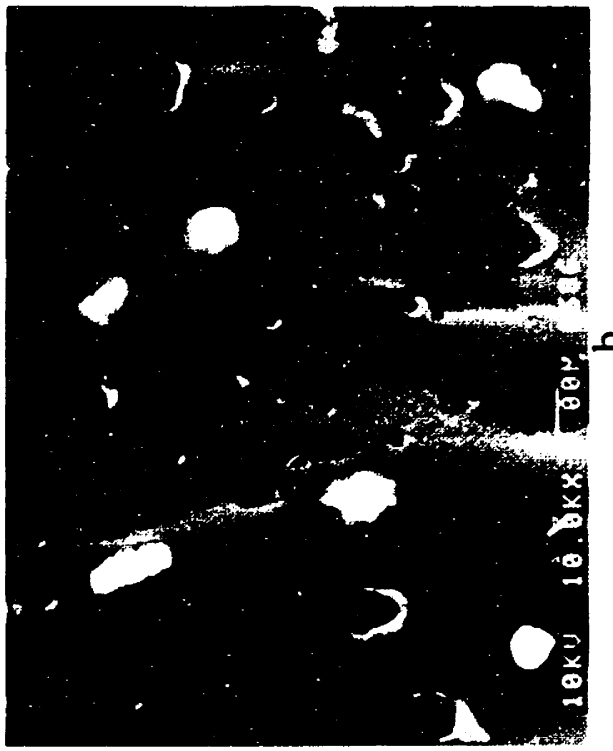

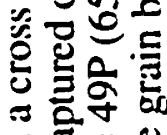

E ํํㄹ를

올 ․ㅡㄹ

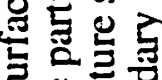

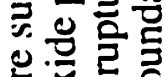

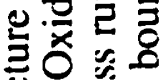

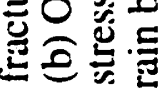
엉 禀异产

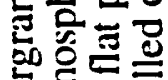

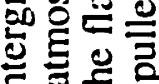
毛手 อ 동

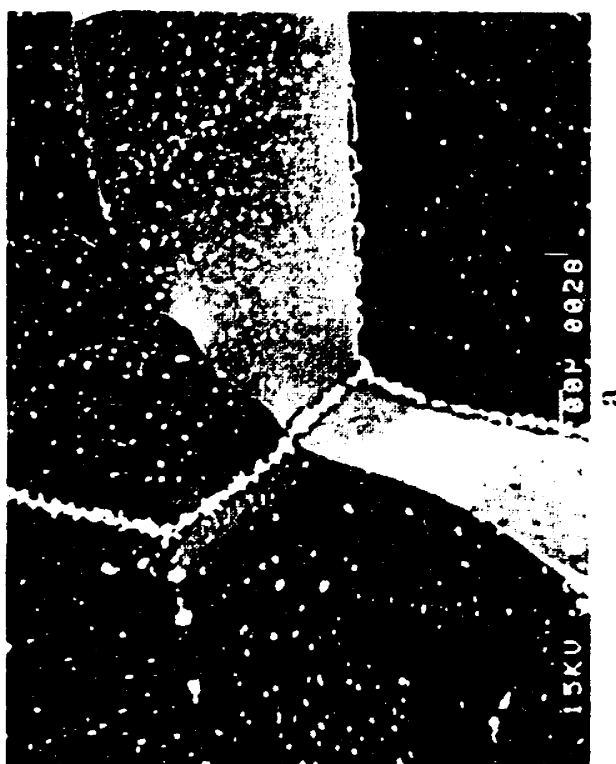
E 온엉 들 此战 궁ㅇㄴㄴ ㄴํㄴ 을 吾

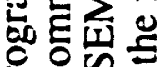
웡 饮 을 응 记苛 뜅을 늘 น ज记 ○ं U. 는을 엏

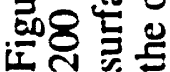


as a gray border around the intact grain boundaries is similar to the oxide seen along the boundaries in the $C$-ring micrograph shown in Figure 80a. 


\section{v. DISCUSSION}

This section is divided into two parts. The first part will discuss the stress rupture test results for alloy 908 and their implications for predicting safe heat treatment regimes for CICC magnets. Following it will be an analysis of the grain boundary oxygen embrittlement phenomenon based on experimental evidence obtained in this study. The results of this latter analysis will have more indirect but equally important consequences for CICC magnet heat treatment.

\section{A. Stress Rupture Tests}

For materials that exhibit some form of oxygen embrittlement, stress rupture data can be viewed from the perspective of a competition between the diffusion controlled processes of creep and intergranular embrittlement. Oxygen damage caused by intergranular oxidation, for example, can accelerate the creep rate and reduce ductility and life. This is because intergranular oxidation reduces the cross section over which the load is carried. [112] Similar observations were drawn from the alloy 908 stress rupture tests. When the creep rate was high, as it is at high temperatures and high loads, and the oxygen concentration low ( $<1 \mathrm{ppm})$, creep rupture predominated over the entire sample cross section. If the creep rate was lowered by lowering temperature or load and the oxygen concentration increased, the intergranular oxidation rate overtook creep initially. Then, when the sample cross section decreased sufficiently, the creep rate increased with the increased cross sectional load. The result is a decrease in total rupture life when compared with a low oxygen concentration sample at the same temperature and load. The change in sample cross section, as indicated by the ratio of ductile fracture area to total fracture area, with increasing oxygen concentration, is shown in Figure 35.

Alloy 908 stress rupture data presented in Figures 20 and 21 show that the rupture times for the flat plate samples were relatively independent of oxygen concentration for low $(\leq 1000 \mathrm{ppm}$ ) concentrations. The variation in rupture time with stress and temperature, however, was consistent with expected stress rupture behavior. Double notch round bar data shown in Figure 23 indicated that the rupture times for this sample geometry with $20 \%$ cold work are more sensitive to oxygen concentration. The long rupture time seen in the 3 ppm oxygen test for this sample geometry, however, precluded running additional tests to determine if this trend continued at lower $(\leq 3 \mathrm{ppm})$ oxygen concentrations. 
The fact that $\mathrm{C}$-ring test samples fail within relatively short times and at relatively low oxygen concentrations questions the predictive ability of stress rupture testing (based on time to failure) for environmentally assisted phenomena. As seen in Figures 34 and 36 the establishment of a threshold oxygen concentration for oxygen assisted intergranular cracking based on percent intergranular fracture, with zero percent indicating that intergranular cracking will not occur, is a more appropriate way to utilize this data. A zero percent intergranular fracture criterion is based on two basic considerations that must be applied in order to select a safe oxygen threshold. First, even at low $(\leq 1 \%)$ percentages of intergranular fracture, intergranular cracking was stopped because failure by creep rupture prevented further intergranular damage. In other (actual) situations, intergranular oxidation and crack propagation will continue until the sample fails or the stresses driving it are relieved. Second, the oxygen threshold values that other researchers have reported for a range of nickel-iron based superalloys, stainless steels and other fcc metals generally fall within a fairly narrow range. These researchers have determined this threshold based on dynamic test methods. The value determined for alloy 908 based on percent intergranular fracture falls well within this range.

In order further evaluate the predictive ability of the stress rupture data for alloy 908 to the CICC magnet application, it is necessary to examine the data using a time-temperature parametric relationship.

The stress rupture data as presented in Figures 20 and 23, cover relatively small time, temperature, and stress regimes for a given oxygen concentration. In most cases, creep rupture data are presented using a time-temperature parameter that correlates time, temperature, and stress, allowing the data to be extrapolated. [110,116, 117] One example of this is the extrapolation of stress rupture data to long times for components that will be in service for years or decades. Many time-temperature parameters have been developed to this end. $[116,117]$ The Larson-Miller parameter is the most commonly encountered of these. Since creep is a thermally activated process, the parameter was derived from the Airhenius equation. The final form of the Larson-Miller relationship is expressed as

$$
\frac{\Delta H}{R}=T(C+\log (t))
$$

where $\Delta H$ is the activation energy for creep, $R$ is the gas constant, $T$ is absolute temperature, $t$ is time, and $C$ is the material constant. In most cases the time is in hours.

For nickel-iron base superalloys the material constant $C$ is assumed to be 20 . A semilogarithmic plot of stress versus the Larson-Miller parameter, $\mathrm{T}(\mathrm{C}+\log t)$, using $\mathrm{C}=20$ is shown in Figure 81 for flat plate samples tested in low oxygen, argon atmospheres. 


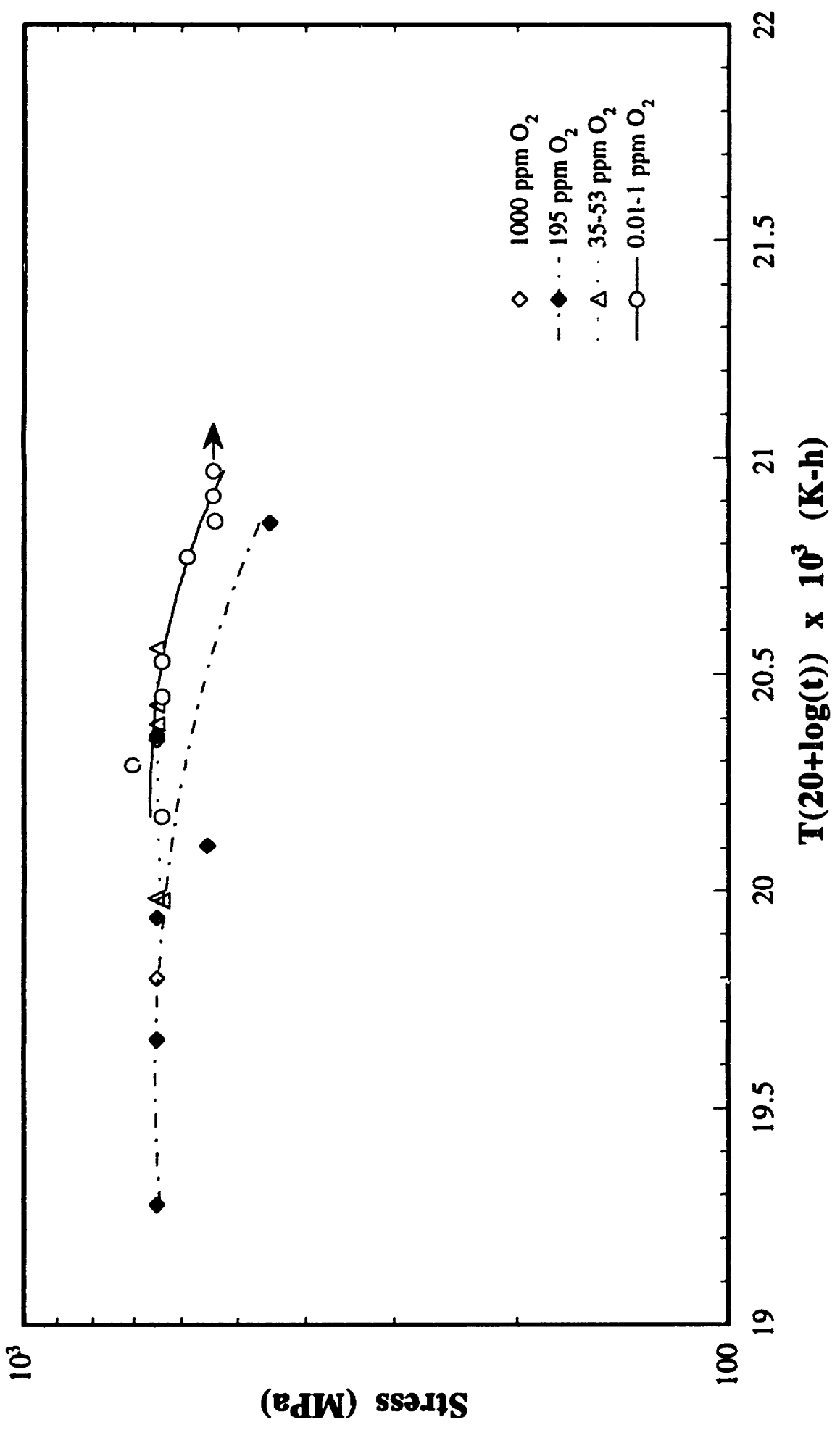

웜 
Because the alloy 908 flat plate stress rupture times were found to be relatively independent of oxygen concentration, the data in this plot have been grouped by oxygen concentration range. Branching or divergence can be seen in this plot for the $195 \mathrm{ppm}$ oxygen range. Woodford examined divergence between air and argon (low ppm oxygen) stress rupture data and found it to be an environmental effect, related to the greater loss of sample cross section in air by oxidation. [118] For the flat plate samples, branching was found to be a function of stress, temperature, and oxygen concentration, and reflects an increase in rupture life with decreasing stress for a given test temperature and oxygen concentration. The 195 ppm oxygen data, for example, show divergence primarily because some of these data was generated at $750^{\circ} \mathrm{C}$ and, for a given stress, increasing the test temperature produces rapid failure with less intergranular fracture. This is the general result of decreased tensile strength and increased ductility with increased temperature that has been experimentally verified for alloy 908. [109] This is illustrated in the micrographs shown in Figures 33a-c for 750,700 and $650^{\circ} \mathrm{C}$ tests at $650 \mathrm{MPa}$, respectively. The result is that the $750^{\circ} \mathrm{C}$ test samples fail in tension before the lower temperature samples and exhibit less intergranular fracture at comparable oxygen concentrations and stresses. This is apparent when comparing the times to rupture for the $650^{\circ} \mathrm{C} / 650 \mathrm{MPa}$ and $750^{\circ} \mathrm{C} / 650 \mathrm{MPa}$ data points in 195 ppm oxygen, 114.2 versus 0.06 hours, respectively, in Figure 22.

Flat plate air data for $5 \%$ cold work material from INCO are plotted along with the low ppm oxygen data in Figure 82. The position of the air data on the plot stems from rapid failure that is the result of a large loss (70-80\% in round bar samples in air) in crosssectional area due to intergranular oxidation. A similar plot for the round bar test data in air and at low oxygen concentrations is shown in Figure 83. This data shows better delineation with changing oxygen concentration. A transition in the round bar air data occurs between 200 and $300 \mathrm{MPa}$, at which air test samples can show rupture lives in excess of 1000 hours. The scatter in the rupture life in this range, however, is extreme, with some failures occurring in less than 1 hour for stresses below $300 \mathrm{MPa}$.[37] More test data in excess of 1000 hours would be required to verify this transition.

Data from both sample types and all test conditions are shown in Figure 84. In this plot the curves for both the air and low ppm oxygen in argon tests have been extrapolated to higher time-temperature parameters. A horizontal bar marks the ultimate tensile stress for alloy 908 at $650^{\circ} \mathrm{C}\left(586 \mathrm{MPa}\right.$ for $980^{\circ} \mathrm{C} / 1$ hour solution anneal). [109] The stresses sustained by the test samples are higher because notched samples can withstand higher stresses due to constraint against plastic flow. [113] Also, precipitation of the strengthening phase $\gamma^{\prime}$ occurs rapidly in this material, see Figure 19, producing an increase 


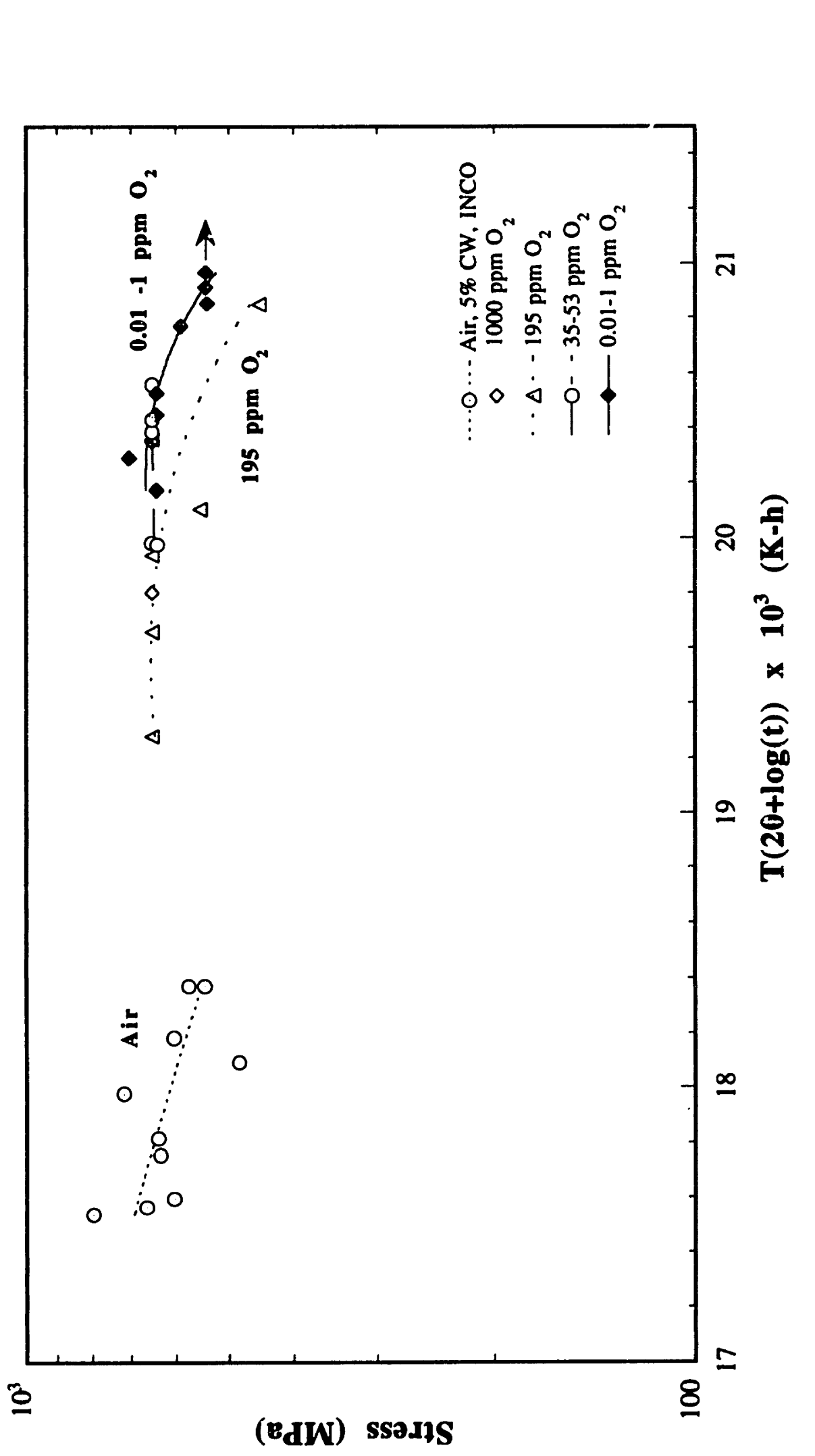

苛

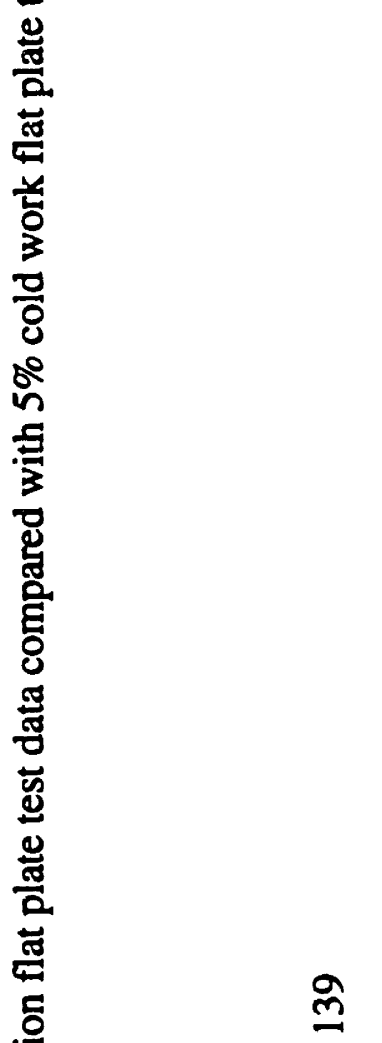

임

돈

ठ્ّ

5

突

흐응

㤐

을

$\stackrel{0}{=}$

동

든

0

는

들

을 


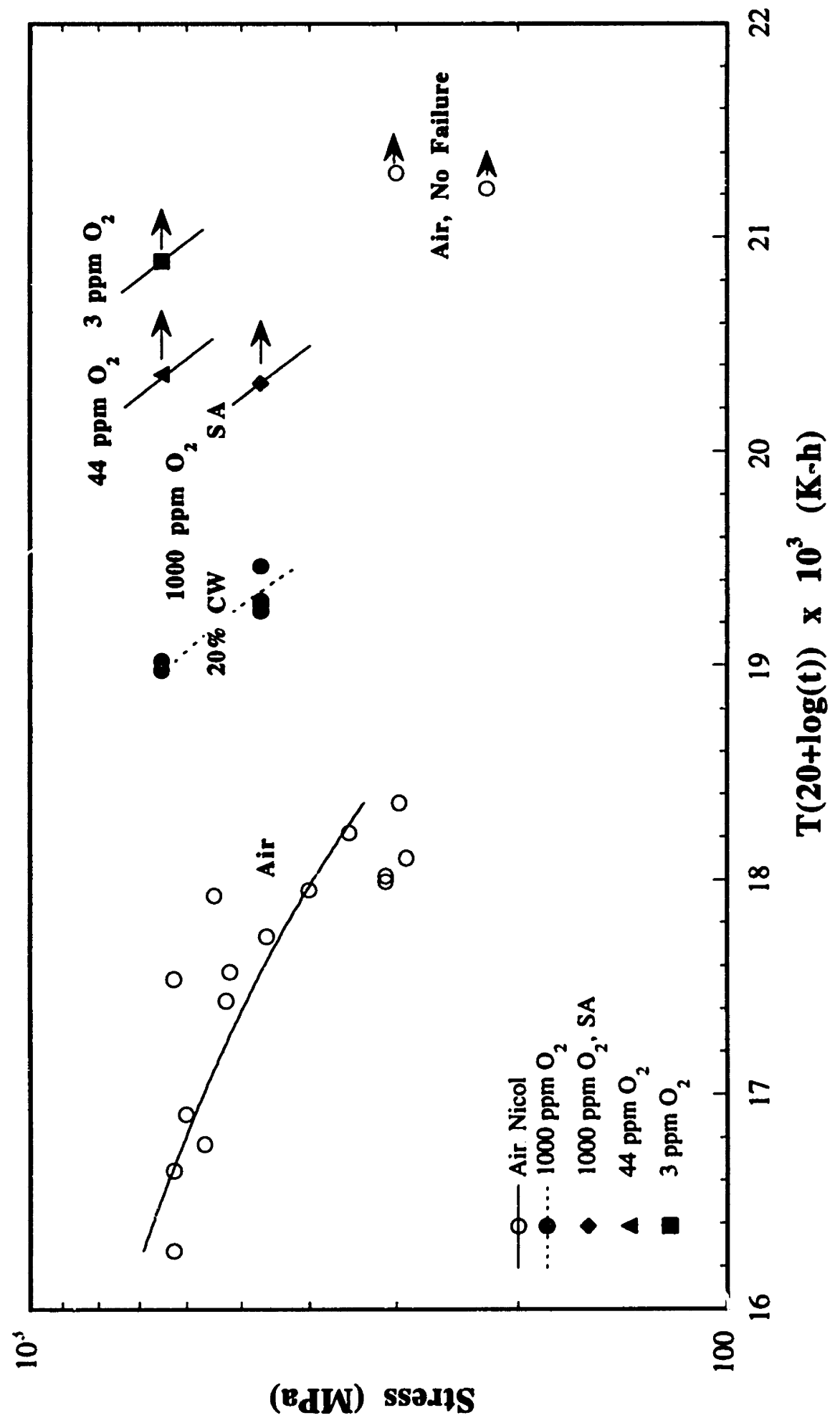

离

㰤

옹

范

Nㅡ

응

ธㄹ

유몽

온

똑

혼.

드.쪼

喦 冚

통

엉

요

동믕

रू०

흔은

몽

옹

농 믈

을

案亭

중

․․․

흘 통

$\sum_{1}$

농

$\checkmark 8$

도

\& 

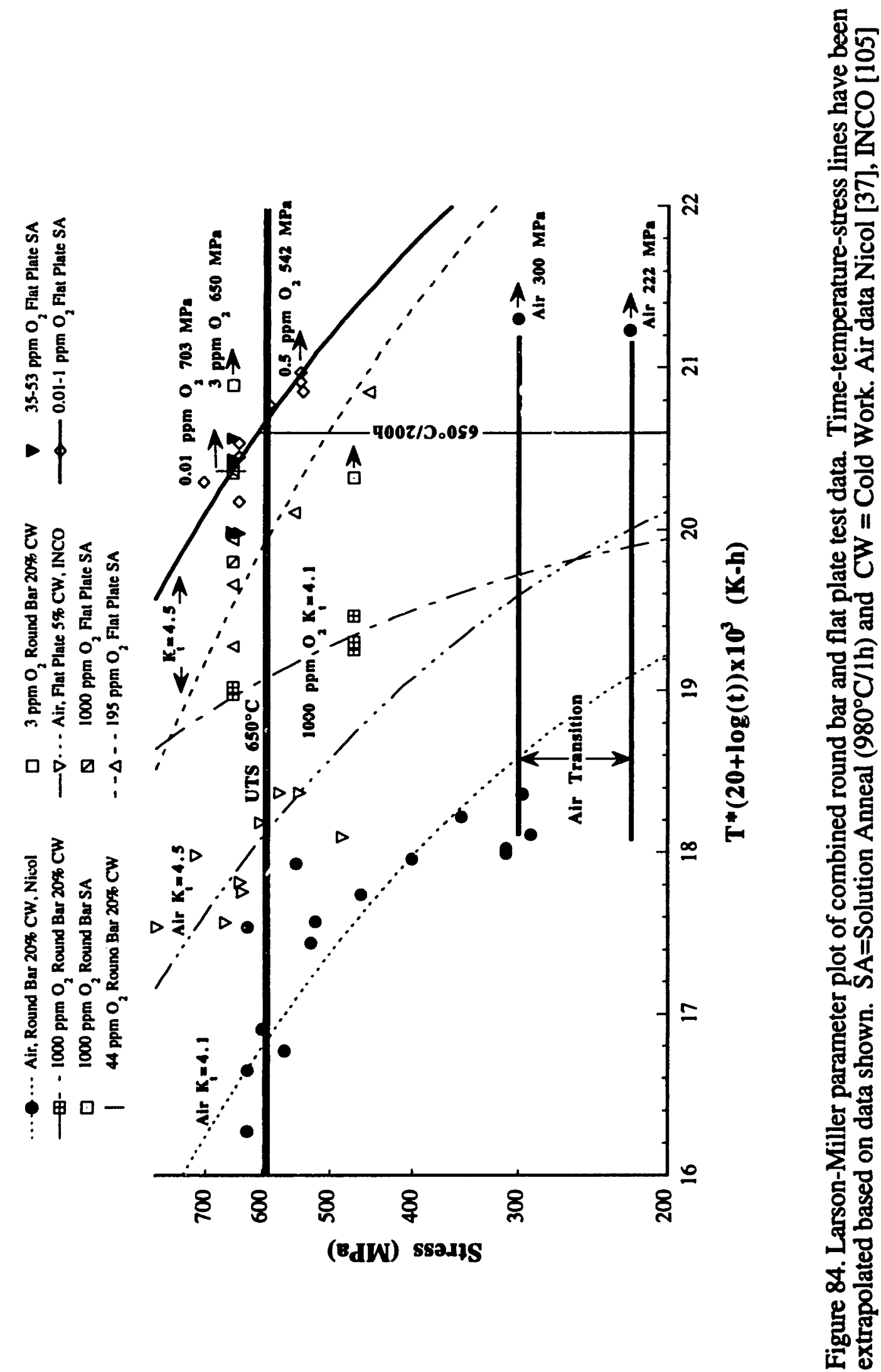
in tensile strength. The region between 300 and $222 \mathrm{MPa}$ marks the $650^{\circ} \mathrm{C}$ air transition regime for which the stresses are low enough to prevent rupture within 1000 hours. The two unfailed 1000 and 1200 hour air tests shown on the plot define this region. The right side of the plot is defined by the $0.01-1 \mathrm{ppm}$ oxygen line, the labeled data points to the right of this line either did not fail or exhibited no intergranular cracking. The percentage intergranular fracture increases to the left of this line with increasing oxygen concentration. This plot could be used for extrapolation to CICC heat treatment conditions. The timetemperature parameter for $650^{\circ} \mathrm{C} / 200$ hour $\mathrm{Nb}_{3} \mathrm{Sn}$ heat treatment, for example, would be $20.6 \times 10^{3} \mathrm{k}$-h and the stress at which rupture would occur is $604 \mathrm{MPa}$ in a 0.01-1 ppm oxygen atmosphere, indicated by the vertical line in the plot. Alternately, in a $195 \mathrm{ppm}$ oxygen atmosphere rupture would occur in 200 hours at $510 \mathrm{MPa}$. A magnet given a $550^{\circ} \mathrm{C} / 200$ hour $\mathrm{Sn}$ diffusion heat treatment would not fail in a 0.01-1 ppm oxygen atmosphere up to the ultimate strength at that temperature, or in air up to the $390 \mathrm{MPa}$ transition stress. While this observation may be true on the basis of time to rupture, in actuality some intergranular cracking may have occurred before final failure.

One problem with the presentation of published stress rupture data is that the mode of failure (transgranular versus intergranular) is not always given. In many cases, fractographic examination of the samples has not been performed. In air tests of nickel and nickel-iron base superalloys, intergranular crack propagation due to oxygen may account for most of the time to rupture, with final transgranular rupture occurring rapidly in the remaining cross section area. [70,71] In Figure 85 the data that were shown in Figure 81 have been replotted and in the legend labeled to show percent intergranular fracture. Comparing these plots, a transition in the 700 and $650^{\circ} \mathrm{C}$ data can be seen that corresponds to the decrease in percent intergranular fracture along the $0.01-1 \mathrm{ppm}$ oxygen concentration line. For these temperatures, tests performed to the right of the sloped $0.01-1 \mathrm{ppm}$ oxygen line will exhibit predominantly ductile transgranular fracture. Increasing the oxygen concentration moves the time-temperature parameter to the left of this line, and samples tested there will show an increased percentage intergranular fracture.

As discussed above, oxygen's most immediate effect on stress rupture data is to reduce the effective cross sectional area through intergranular oxidation. Woodford has suggested that the departure between air and argon data may be accounted for by correcting the Larson-Miller material constant, C, for loss of sample cross-section due to oxidation. [118] The alloy 908 data were examined using the graphical creep-rupture correlation that uses the convergence of isostress lines on a plot of $\log (t)$ versus $1 / T$ to determine a value for the material constant $C$, where the equation for the isostress line is given by 

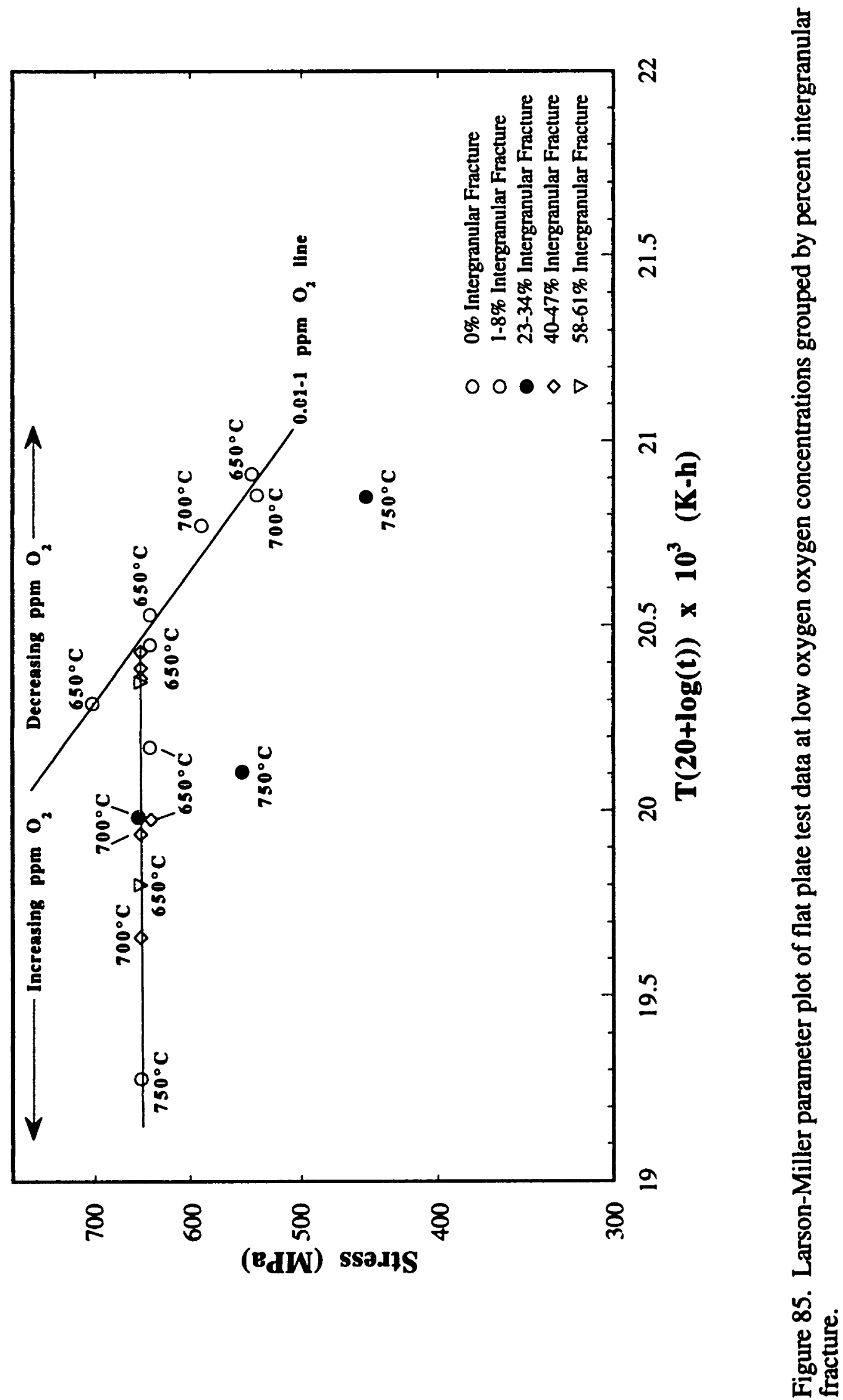


$$
\log (\mathrm{t})=-\mathrm{T}+\frac{\text { constant }}{\mathrm{T}} \cdot[110,117]
$$

A value for the material constant $\mathrm{C}$ based on oxygen concentration could not be directly determined from the data. This was primarily because there was no correlation between time to rupture and oxygen concentration for the flat plate test samples. It was found, however, that if each set of stress-temperature data was grouped by percent intergranular fracture, a correlation did exist. The rationale behind this approach assumes that, for notched stress rupture samples, the time to rupture is close to the time to initiate a crack. [55] This assumption has been validated for both round bar and flat plate samples of alloy 908 tested in air by Nicol and Sizek, respectively. [37, 105] Also, if the data are grouped by percent intergranular fracture, it can be assumed that, for the same load and temperature, the stress on the remaining ductile area at failure was equivalent.

The data groupings for the 650 and $540 \mathrm{MPa}$ isostress lines and their least squares fits are shown in Figure 86. In the plot seen in Figure 87, the $650 \mathrm{MPa}$ data groupings have been consolidated and isostress lines drawn by least squares fits to the data. The average of the intercepts for the two isostress lines was used to obtain a value of $\mathbf{3 0}$ for the material constant $C$. The low ppm oxygen flat plate data were replotted using the new LarsonMiller parameter $\mathrm{T}(30+\log t)$, and are shown in Figure 88. Comparison with Figure 81 shows the improved data fit using $\mathbf{C}=30$. By entering a time and temperature into the Larson-Miller parameter, the rupture stress can be read from the "master curve" shown in Figure 88. Alternately, if the stress and temperature are known, a time to rupture can be calculated. The time to rupture values obtained using $C=30$ show good correspondence to the experimental values for the flat plate samples. The time to rupture for flat plate samples at $650^{\circ} \mathrm{C}$ and $650 \mathrm{MPa}$, for example, is predicted to be 117 hours from the curve. From the experiments, the mean time to rupture at $650^{\circ} \mathrm{C}$ is $108.3 \pm 36$ hours at $651 \pm 18 \mathrm{MPa}$. In using this "master curve" it must be noted that it is applicable only to the midsection (0.1$1000 \mathrm{ppm}$ oxygen) of the sigmoidal curve shown in Figure 36. In the plateau below 0.1 ppm oxygen, environmental effects are absent and pure creep rupture is controlling. The second plateau, above $1000 \mathrm{ppm}$ oxygen, represents the regime where the rupture life is primarily controlled by a reduction in sample cross section (70-80\%) due to intergranular oxidation. 


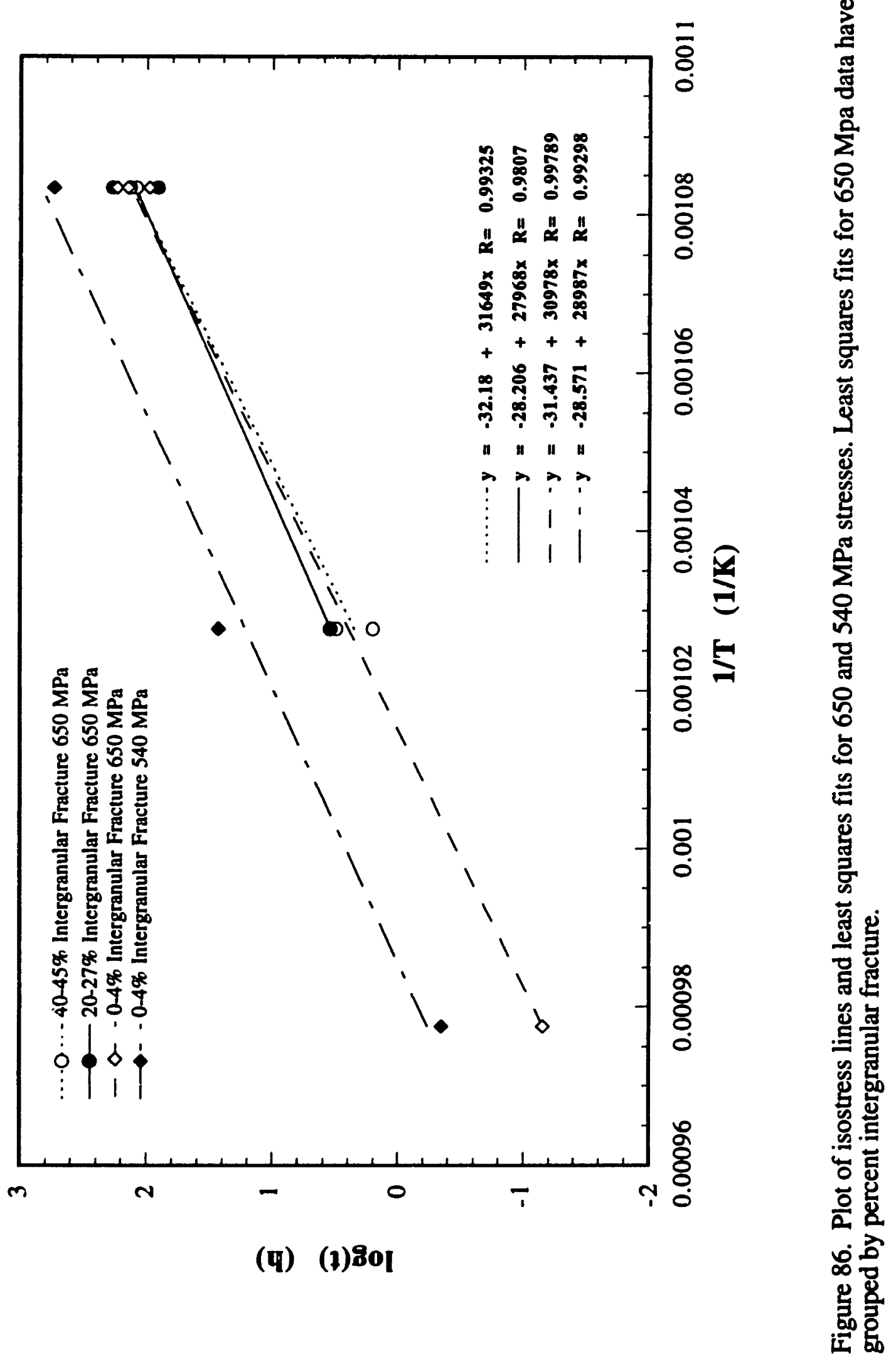




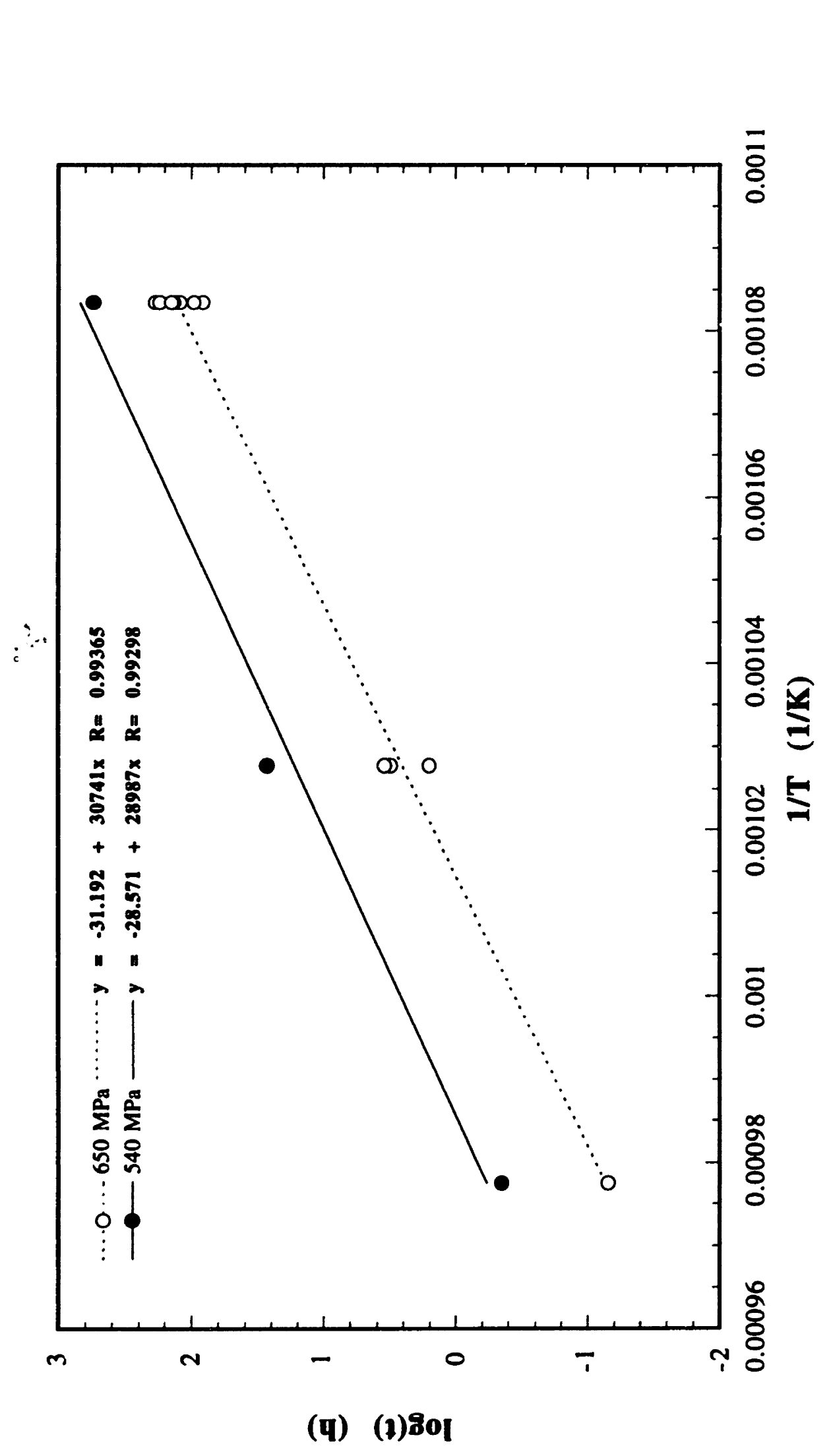

롤

ลิ

홍

与

.

啶

ถั

$\stackrel{0}{5}$

옹

ฐึّ

$\stackrel{乛}{5}$

$\ddot{8}$

兽

:

్ㅗํ

웅

E

乌్

郘

至

可

돓

品

E

象

\$્ง

号

등

흠 월

$\infty$

绐雪

诖 0 


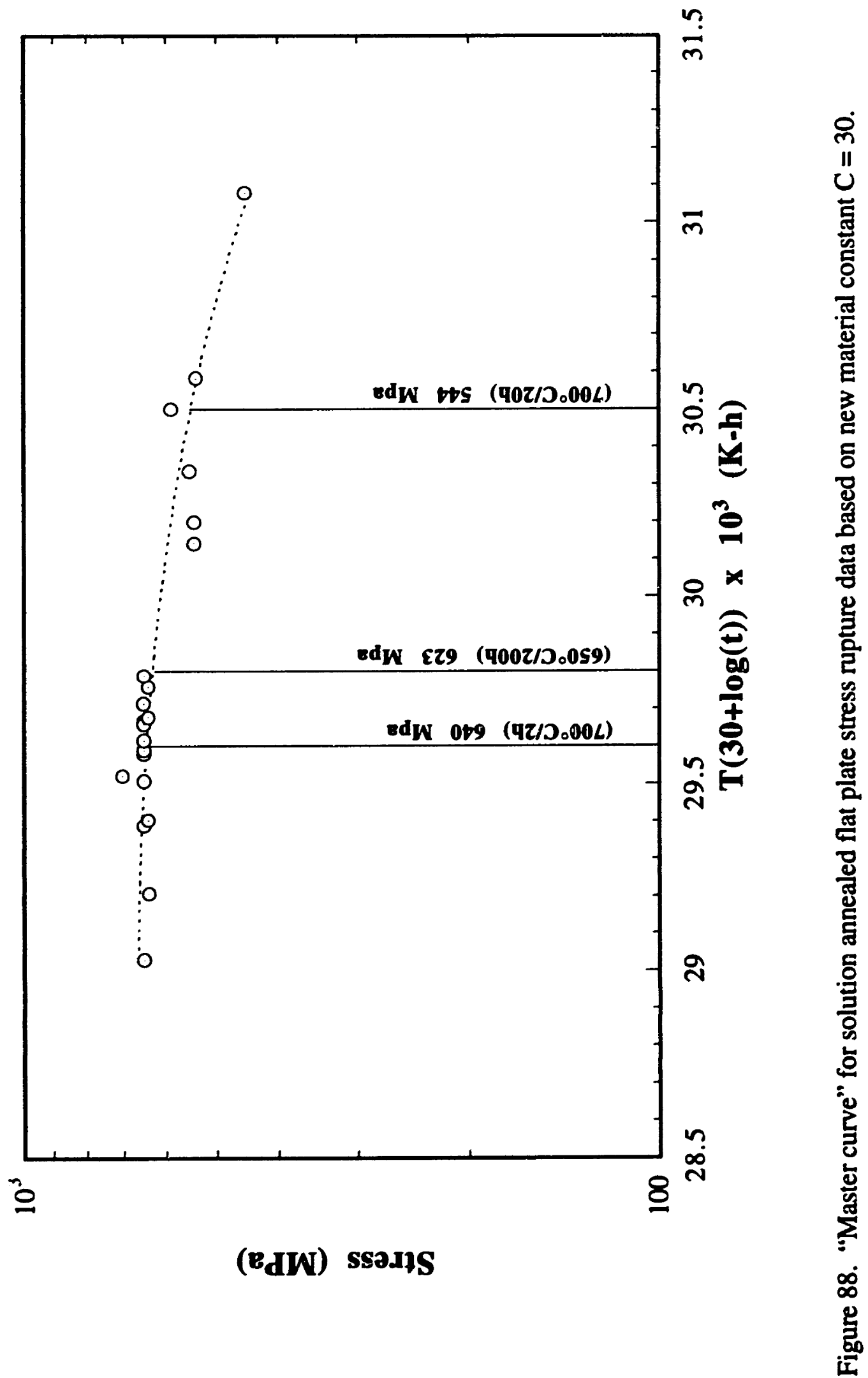




\section{B. Grain Boundary Analysis}

The factors affecting the transition between internal/intergranular oxidation and external oxidation are the oxygen partial pressure and the concentration of the oxidizable solute. In $\mathrm{Ni}-\mathrm{Cr}$ alloys and $\mathrm{Ni}-\mathrm{Fe}$ base superalloys the external, passivating, oxide is either $\mathrm{Cr}_{2} \mathrm{O}_{3}$ or $\mathrm{NiCr}_{2} \mathrm{O}_{4}$ (these concepts were discussed in section $\mathrm{F}$ of the Literature Review). This transition in mode of oxidation appears correlate with the oxygen concentration dependence observed for intergranular oxidation in alloy 908 . Of particular significance is the existence of a transition time to achieve a given depth of internal/intergranular oxidation. In matrix internal oxidation this time is linked to the nucleation and growth of oxide particles within the internal oxide zone. As the oxide particles in this zone coarsen, they act to block the diffusion paths for oxygen into the alloy. $[82,85]$ Oxygen diffusion into the alloy is effectively shut off once these oxide particles reach some critical volume fraction. [82, 85] The time required to reach this critical volume fraction determines the depth of internal oxidation. In an analogous manner, this work suggests that intergranular oxidation occurs within a subsurface zone. The depth of this zone is controlled by the oxygen concentration at the surface of the alloy. As with internal oxidation, the formation of intergranular oxides is required to block the intergranular diffusion of oxygen. As was discussed, the intergranular oxide formed in $\mathrm{Ni}$-high $\mathrm{Cr}$ alloys is typically $\mathrm{Cr}_{2} \mathrm{O}_{3}$. [96] Dilute (1-5 wt.\% Cr) $\mathrm{Ni}-\mathrm{Cr}$ alloys form varying proportions of $\mathrm{Cr}_{2} \mathrm{O}_{3}$ and $\mathrm{NiCr}_{2} \mathrm{O}_{4}$ intergranularly. [94] The predominant intergranular oxide deeper within the zone of internal/intergranular oxidation is $\mathrm{Cr}_{2} \mathrm{O}_{3}$. [94]

The above observations explain why $\mathrm{Cr}$ was present in the intergranular oxide at the terminus of oxidized grain boundaries in the long-time flat plate samples. The round bar test samples formed only (Ni,Fe)-type intergranular oxides. These samples failed in too short a time to develop $\mathrm{Cr}$-rich intergranular oxides. This is based on the internal oxidation model for the time required to form an oxide that can effectively block oxygen diffusion. An added factor in alloy 908 is the formation of oxides of $\mathrm{Nb}$. In alloy 718, Gao reported that formation of intergranular $\mathrm{Nb}_{2} \mathrm{O}_{5}$ films may contribute to environmentally enhanced intergranular fatigue crack growth. [56] The oxides of niobium are thermodynamically stable at low partial pressures of oxygen, lower than $\mathrm{Cr}_{2} \mathrm{O}_{3}$ in fact. Unlike $\mathrm{Cr}$-rich oxides, $\mathrm{Nb}$ oxides are non-protective, i.e., non-passivating.

Table 6 summarizes the compositions of surface and intergranular oxides obtained by EDS in the SEM for some of the stress-rupture samples. It should be noted that the oxygen potentials at the sample surface for all the tests done in this study are above the oxygen potentials for formation of most of the metallic oxides at $650^{\circ} \mathrm{C}$, based on the Ellingham 


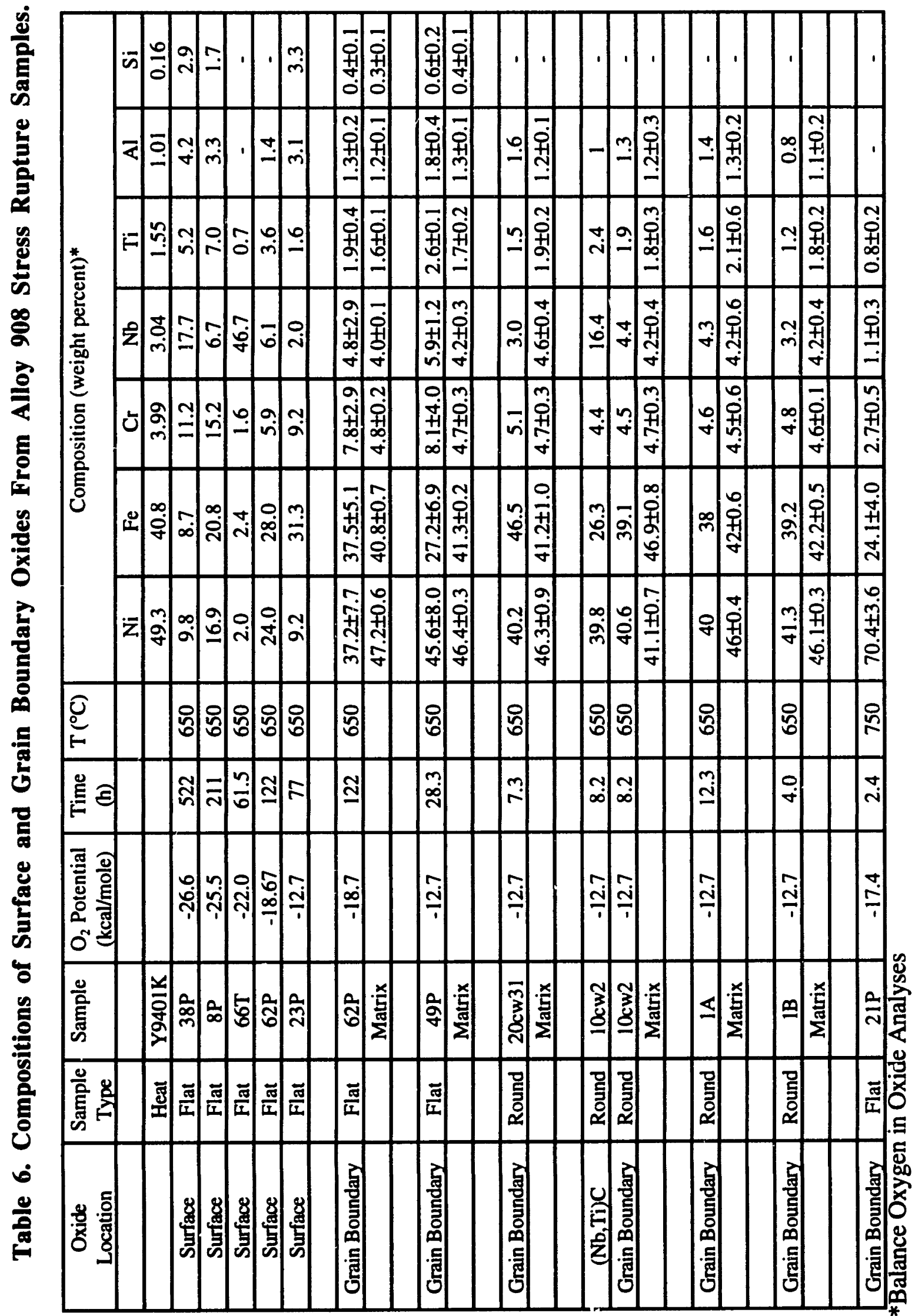


diagram. [119] The reported oxygen potentials, however, do not indical the oxygen potential below the surface oxide layer or along the grain boundaries. At these locations the oxygen potential is determined by the kinetics of oxygen diffusion through the external scale and along the grain boundaries. [86]

When comparing these compositions it must be remembered that these were insitu analyses taken from metallographic cross sections and should be compared on a relative basis to the material heat composition also shown in the table. This is because these analyses incorporate some of the matrix elements due to subsurface scattering of the SEM electron beam during EDS. From the surface oxide analyses shown in this table, it can be seen that the low oxygen potential test samples above $-12.7 \mathrm{kcal} / \mathrm{mole}\left(650^{\circ} \mathrm{C}, 1000 \mathrm{ppm}\right.$ oxygen) were enriched with respect to $\mathrm{Nb}$ and $\mathrm{Cr}$. Enrichment in the other thermodynamically stable elements ( $\mathrm{Al}, \mathrm{Ti}$, and $\mathrm{Si}$ ) can also be seen in some of these samples. The sample tested at an oxygen potential of $-12.7 \mathrm{kcal} / \mathrm{mole}$ shows enrichment of Cr but not $\mathrm{Nb}$.

The grain boundary oxide EDS compositions are shown along with their corresponding matrix EDS compositions in Table 6. As seen in this table, the grain boundary oxide formed in the $-18.7 \mathrm{kcal} / \mathrm{mole}$ oxygen potential $\left(650^{\circ} \mathrm{C}, 38 \mathrm{ppm}\right.$ oxygen) flat plate sample is enriched in $\mathrm{Cr}$, relative to the matrix. When comparing the matrix and grain boundary compositions, the elements $\mathrm{Ni}$ and $\mathrm{Fe}$ will appear diluted compared to their matrix compositions. This is because, by combining with oxygen to form oxides, the relative weight percents of these elements at the grain boundaries has decreased. The higher oxygen potential sample, $-12.7 \mathrm{kcal} / \mathrm{mole}$, is somewhat enriched in $\mathrm{Cr}$ and $\mathrm{Ti}$, but also contains a high $\mathrm{Ni}$ content, indicating that the oxide contains a combination of $\mathrm{Ni}, \mathrm{Cr}$ and Ti. In contrast, the intergranular oxides found in the round bar samples, show no enrichment of $\mathrm{Cr}$ relative to the matrix composition. This is in agreement with the EDS $\mathrm{x}$ ray analyses shown in Figures 53, 54, 56, 58, 59, and 68 for the round bar test samples. This difference between the two sample geometries may not be related to oxygen concentration. Comparison of equivalent oxygen potentials, $-12.7 \mathrm{kcal} / \mathrm{mole}$, still shows more $\mathrm{Cr}$ in the flat plate sample. It is more likely that the longer life of the flat plate sample, 28.3 hours versus that of the round bars, allowed $\mathrm{Cr}_{2} \mathrm{O}_{3}, \mathrm{NiCr} 2 \mathrm{O} 4$ and/or $\mathrm{Ni}(\mathrm{FeCr})_{2} \mathrm{O}_{4}$ to form on the grain boundary. This same time dependency was seen in the $\mathrm{C}$-ring samples as presented in the Results section. The presence of an oxidized primary (Nb,Ti)C carbide, at the grain boundary in the round bar sample $10 \mathrm{cw} 2$, can be seen in Table 6 . The $\mathrm{Nb}$, and, to a lesser extent, Ti enrichment in this analysis, along with the presence of oxygen, confirms this. The composition of the intergranular oxide found in $750^{\circ} \mathrm{C}$ flat plate sample is also shown in Table 6. At this temperature and oxygen potential (195 ppm 
oxygen), this sample shows predominately $\mathrm{Ni}$ enrichment, indicating the formation of a $\mathrm{Ni}$ rich oxide such as $\mathrm{NiO}$ under these test conditions.

Figures 41 through 44, in the Results section, demonstrate the presence of $\mathrm{Nb}$-rich intergranular oxides in alloy 908 after testing. Those results were similar to the results reported by Gao for alloy 718. [56] The sample that was examined, 38P, also showed $\mathrm{Nb}$ enrichment of its surface oxide, as shown in Table 6. This sample did not, however, fail. Oxidation of primary ( $\mathrm{Nb}, \mathrm{Ti}) \mathrm{C}$ carbides has been observed in many superalloys. [ 55, 56] This study also identified oxidation of $(\mathrm{Nb}, \mathrm{Ti}) \mathrm{C}$ as occurring in alloy 908 , as was illustrated in the EDS x-ray map shown in Figure 54. Bricknell and Woodford identified niobium as one of the primary constituents of the internal and grain boundary oxides found in alloy 903A (commercial designation 907). [28] Analysis for oxygen was not included in their study, allowing for the possibility that the grain boundary phase may not have been an oxide. Niobium did not appear to play a role in the round bar test results. These samples, as seen in Table 6, did not show $\mathrm{Nb}$ enrichment of the intergranular oxides. It is evident, however, that $(\mathrm{Ni}, \mathrm{Fe}) \mathrm{O}$ type oxides were present at the grains boundaries in these samples.

As was shown in Figures 46 and 47, for an interrupted flat plate test, the intergranular fracture surfaces were oxidized up to the intergranular-transgranular transition. No zone of embrittled, oxide free grain boundaries could be found beyond the existing oxidized crack. This observation indicates that the grain boundaries ahead of the crack are not inherently embrittled by oxygen and that grain boundary oxidation is a required part of the crack growth mechanism. The lack of long range oxygen embrittlement observed in alloy 908 is consistent with that from fatigue crack growth studies in other materials. In these studies, when fatigue specimens are tested sequentially in air then in vacuum the crack growth rate drops from the high rate in air as soon as vacuum is reestablished. [41, 42, 43, 53, 120] In the fatigue crack growth situation this indicates that the crack growth rates are dependent only upon the existing environment. Also the effect is limited to the crack tip region and is not dependent upon the long range diffusion and embrittlement by oxygen of grain boundaries ahead of the crack. $[53,57]$

Unstressed samples, tested along with their stressed counterparts, did not show any signs of intergranular embrittlement when fractured after testing at 650 and $700^{\circ} \mathrm{C}$. Tensile samples that were placed, unloaded, in the same environment and then tested in air showed no change in properties when compared with tensile samples heat treated in vacuum $\left(1 \times 10^{-5}\right.$ Torr) for similar times. The solution annealed $\left(980^{\circ} \mathrm{C} / 1\right.$ hour) samples exposed in the retort at $650^{\circ} \mathrm{C}$ for 188 hours in $35.5 \mathrm{ppm}$ oxygen, along with stress rupture sample 60P, showed a yield strength of $1050 \pm 70 \mathrm{MPa}$, ultimate strength of $1445 \pm 7 \mathrm{MPa}$, and an elongation of $17.5 \pm 0.7 \%$. This compares with a yield strength of $1075 \mathrm{MPa}$, ultimate 
strength of $1433 \mathrm{MPa}$, and an elongation of $15.5 \%$ for solution annealed alloy 908 heat treated at $650^{\circ} \mathrm{C}$ for 200 hours in vacuum. [109]

An activation energy for intergranular oxidation in air was calculated for alloy 908 .

This calculation was based on measurements of intergranular oxidation depth obtained from round bar test samples used in a prior study. [37] If it is assumed that the depth of oxidation increases parabolically with time then,

$$
\mathbf{X}^{2}=\mathbf{K t}
$$

where $\mathrm{x}$ is distance, $\mathrm{t}$ time and $\mathrm{K}$ is a kinetic factor that includes the diffusion coefficient of oxygen. $[98,112,121]$ The Arrhenius equation for $K$, where $Q_{g b}$ is the activation energy for intergranular oxidation, is given by

$$
K=K_{0} \exp \left(\frac{-Q_{g b}}{R T}\right) \text {. }
$$

Combining the two equations and rearranging gives

$$
\log \left(\frac{\mathrm{x}^{2}}{\mathrm{t}}\right)=\log \mathrm{K}_{\mathrm{o}}-\left(\frac{\mathrm{Q}_{\mathrm{gb}}}{2.3 \mathrm{R}}\right) \frac{1}{\mathrm{~T}}
$$

where the slope of an Arrhenius plot, $\log x^{2} / t$ versus $1 / T$, gives a value for $Q_{g b}$. A plot for the alloy 908 air stress rupture data is shown in Figure 89.

An intergranular activation energy, $Q_{\mathrm{gb}}$, of $202 \mathrm{~kJ} / \mathrm{mole}(48.2 \mathrm{kcal} / \mathrm{mole})$ in air, was calculated from this plot. The value of 908 can be compared with air $Q_{g b}$ values of 280 $\mathrm{kJ} /$ mole for Rene' 80 by Chang, $274 \mathrm{~kJ} / \mathrm{mole}$ for Ni 270 by Iacocca, $287 \mathrm{~kJ} / \mathrm{mole}$ in alloy 718 by Gao, and $335 \mathrm{~kJ} / \mathrm{mole}$ for a $20 \mathrm{Cr}-25 \mathrm{Ni}-\mathrm{Nb}$ stainless steel obtained by Emsley. [56, $61,98,121]$ The lower activation energy obtained for alloy 908 is related to the greater susceptibility of this material to intergranular oxidation in air. The times used for the air samples were relatively accurate, given that the time for intergranular crack growth was very rapid and accounted for most of the sample life. [37] A similar analysis for the low oxygen concentration flat plate samples was also carried out. The $\mathrm{Q}_{\mathrm{gb}}$ was calculated to be $492 \mathrm{~kJ} / \mathrm{mole}(118 \mathrm{kcal} / \mathrm{mole})$ in $195 \mathrm{ppm}$ oxygen. The Arrhenius plot used for this calculation is shown in Figure 90 . A $\mathrm{Q}_{\mathrm{gb}}$ of $537 \mathrm{~kJ} / \mathrm{mole}(128 \mathrm{kcal} / \mathrm{mole})$ was determined for all the flat plate samples in the 38-195 ppm oxygen range, and this plot is shown in Figure 91. These high values reflect a number of factors. One is that the activation energy for intergranular oxidation at low oxygen concentrations is higher. This is reflected in the longer times required to achieve a given depth of internal/intergranular oxidation as the oxygen concentration is decreased. The other main factor is related to the flat plate test samples themselves. As was discussed in the Results section, the time to failure in these samples was relatively independent of oxygen concentration. This was related to a sample geometry that produced a plane stress state at the notch that results in less constraint against 

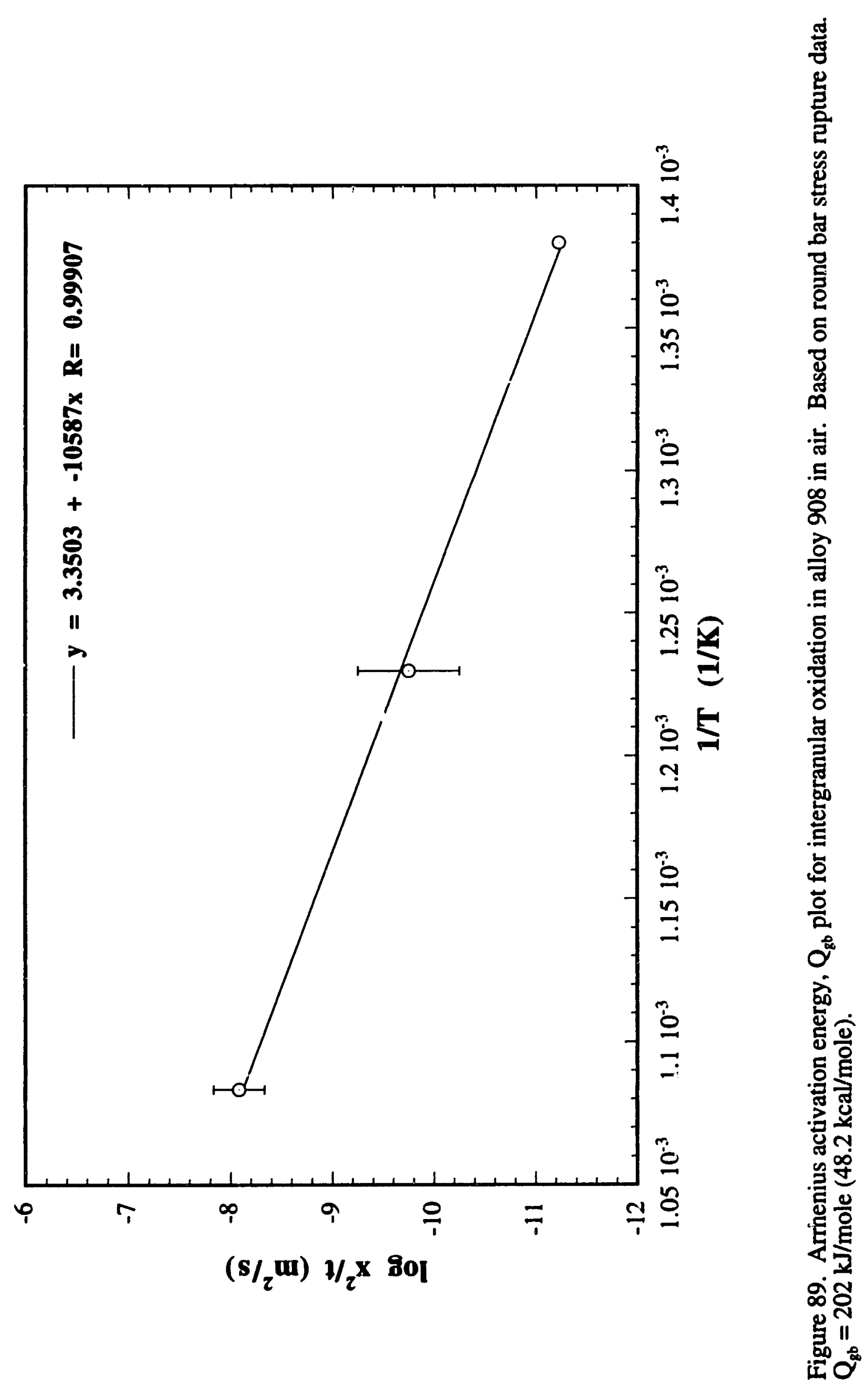


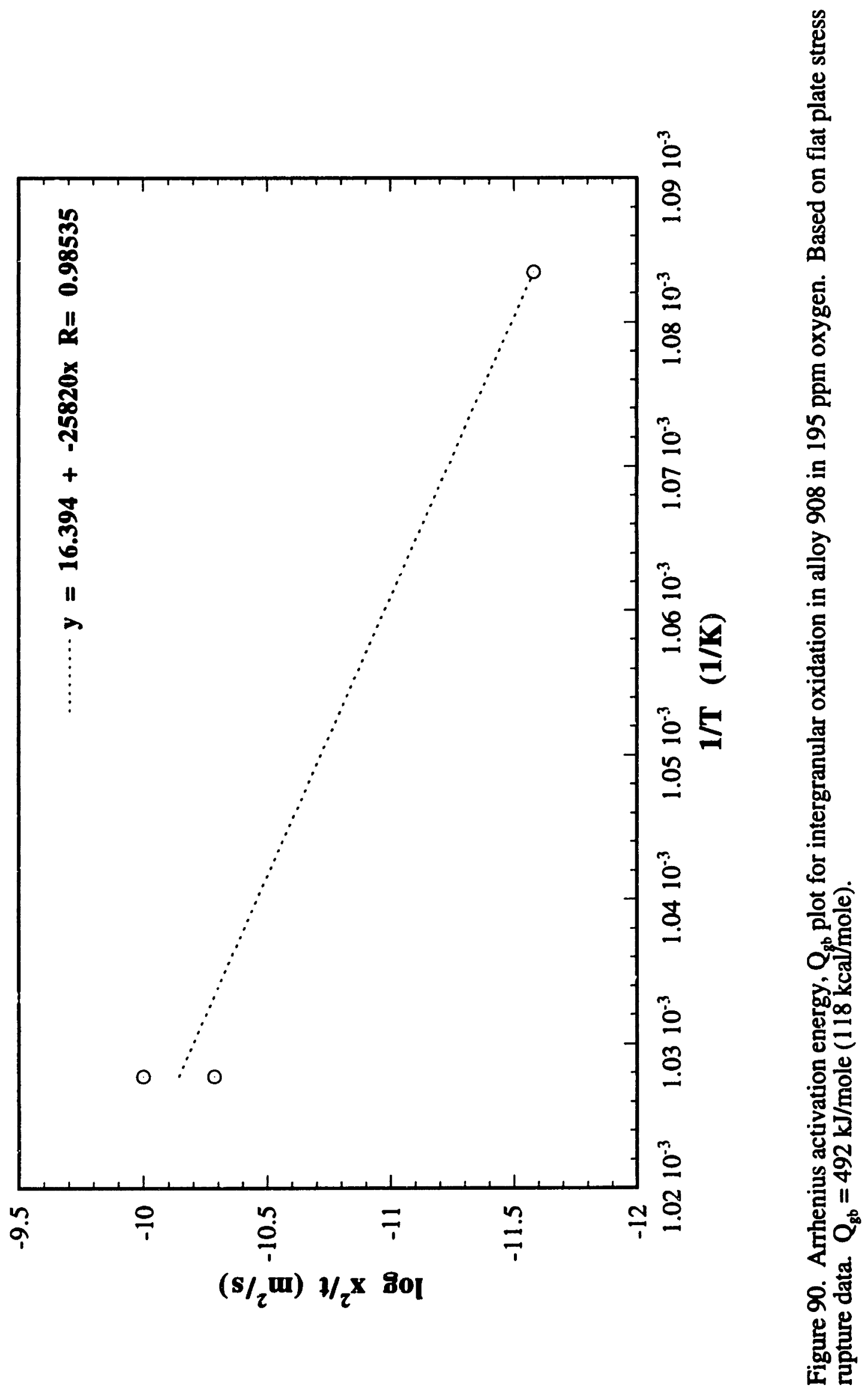




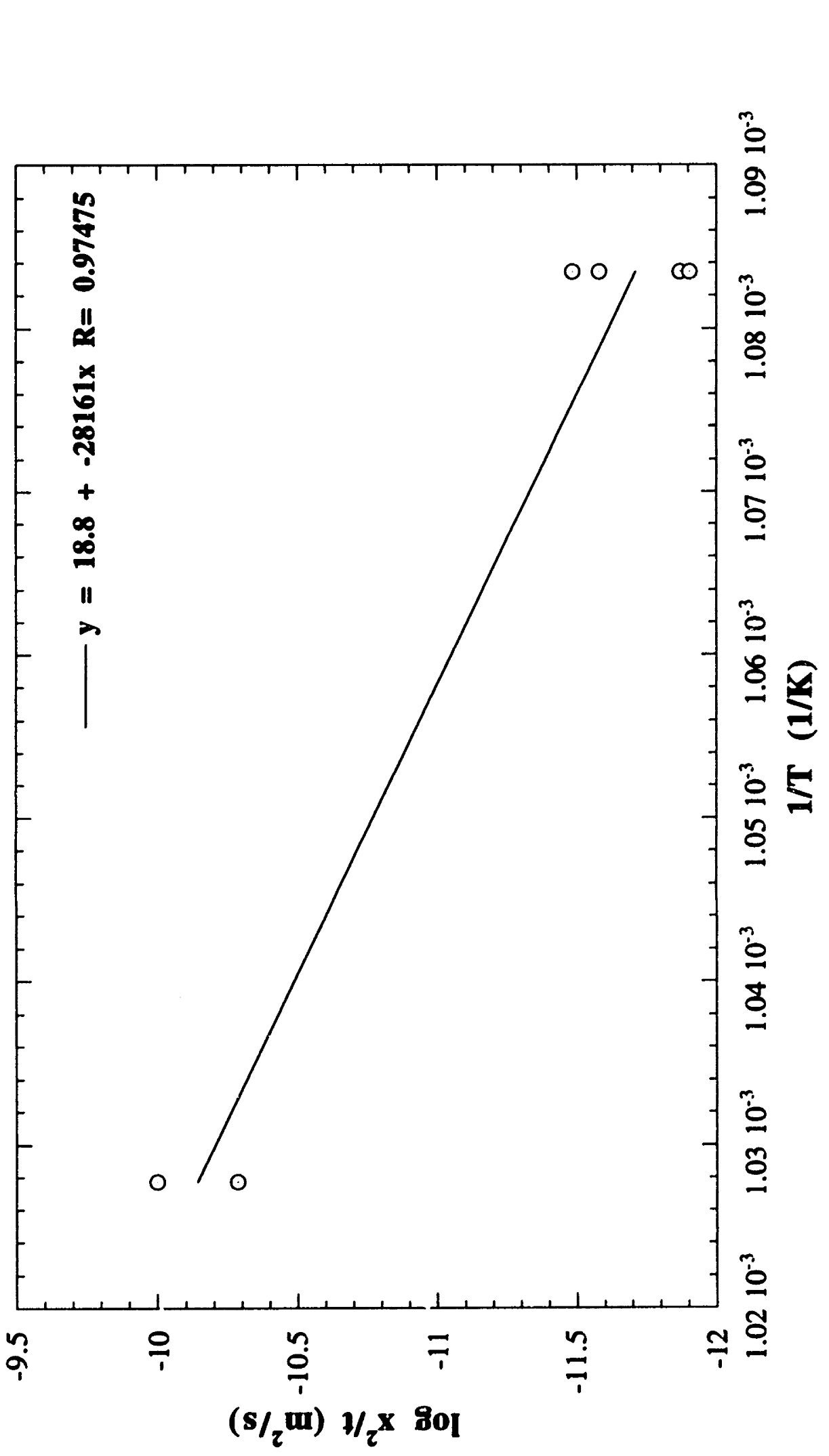

离

ชิ

몸

๖

$\stackrel{m}{m}$

.5

8

즐

.5

응

ชัญ

n

高

造

눙을

을

+co

$\div$

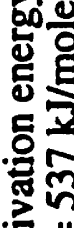

"巳

\&

造

द

$\dot{-1}$

르

实路

政哀 
plastic flow at the notch than in the triaxial stress state at the circumferential notch round in bar samples. [122] Because the flat plate rupture times were relatively constant for all oxygen concentrations the time component in the Arrhenius plots may not reflect the actual time for intergranular oxidation to occur. The time may instead be a combination of intergranular oxidation and plastic flow by creep. The depth of intergranular oxidation component, $\mathbf{x}$, is accurate and is related to the oxygen concentration present. This is seen in the percent intergranular fracture versus oxygen concentration relationship that was shown in Figure 34. A plot for the flat plate test data in the 6 to $1000 \mathrm{ppm}$ range is shown in Figure 92. In this plot the test data at each temperature has been combined and the scatter shown. The scatter in the $650^{\circ} \mathrm{C}$ data illustrates the change in depth of intergranular oxidation, $\mathrm{x}$, with changes in oxygen concentration. $\mathrm{A}_{\mathrm{gb}}$ of $508 \mathrm{~kJ} / \mathrm{mole}(121 \mathrm{kcal} / \mathrm{mole})$ was calculated from this plot and falls between the two other oxygen ranges reported for the flat plate samples.

\section{C-Ring Tests and Modification of Residual Stresses}

From the standpoint of simulating the residual stresses present in post fabrication conduits, the $\mathrm{C}$-ring test results have more applicability. Altering the residual stress state at the surface of alloy 908 can prevent intergranular cracking in alloy 908 . The effect of shot peening and stress relief are promising, although it is not clear whether this is simply a mechanical effect or has an effect on oxidation. Skelton and Bucklow observed that the oxidation rate of a low alloy steel increased due to surface working. [52] They ranked oxidation rates as surface worked < annealed < internally strained. Bainitic samples that were internally strained and then had their internal strains relieved by tempering showed oxidation rates comparable to annealed samples. [52] Surface deformation was reported to enhance $\mathrm{Cr}_{2} \mathrm{O}_{3}$ formation in in $\mathrm{Ni}-\mathrm{Cr}$ alloys conatining between 10 and $30 \mathrm{wt} . \% \mathrm{Cr}$. [116] Giggins, et al., attributed this to the fine grain size produced by recrystallization of deformed surface layers at 900 and $1100^{\circ} \mathrm{C}$. [116] Reports of enhanced $\mathrm{Cr}$-rich oxide formation that occurs in superalloys and stainless steels after shot peening appear to support this conclusion. [77, 115] A similar enrichment in $\mathrm{Cr}$ was found in the long time shot peened alloy $908 \mathrm{C}$-ring samples. In this case, however, an association between improved SAGBO resistance and the presence of a $\mathrm{Cr}$-rich oxide layer could not be demonstrated. This is because the beneficial effect of shot peening came in the short term ( 24 hour tests), where no substantial $\mathrm{Cr}$ enrichment was observed. Solution annealed samples that did not fail, and were tested for long times ( 200 hours) showed similar increases in $\mathrm{Cr}$ concentration in their surface oxides. It is apparent from these results that 


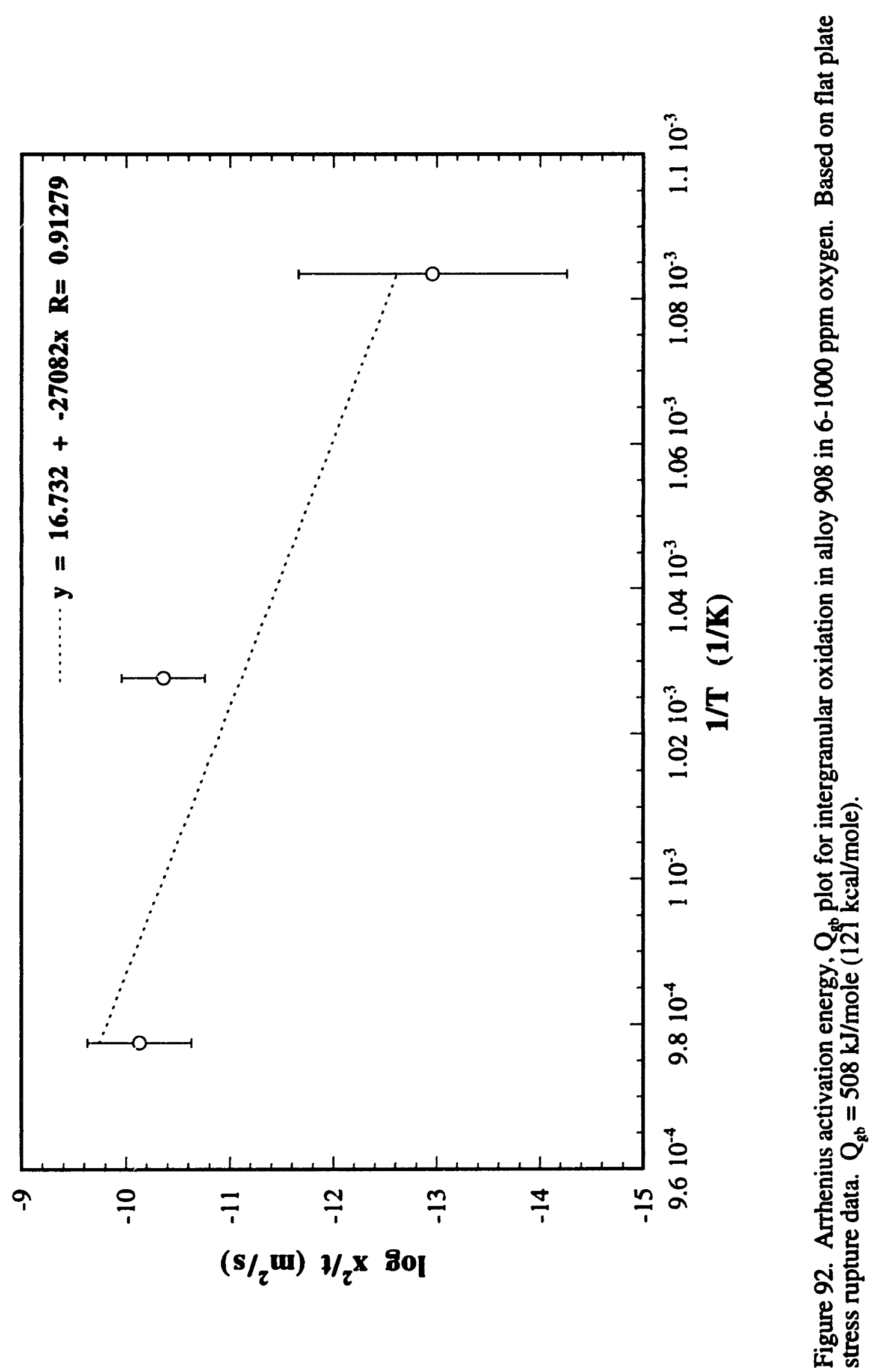


shot peening, or stress relief, act to mechanically alter the surface residual stress state. This was of particular benefit to SAGBO prevention because these methods suppress cracking during short times, before a sufficiently developed $\mathrm{Cr}$-rich passivating surface oxide can form to protect the material. The deformed surface layer in the shot peened samples did not recrystallize at $650^{\circ} \mathrm{C}$. Niobium enrichment was not detected in the intergranular oxides found on the C-ring fracture surfaces. It's presence in the surface oxide may indicate that a porous, non-passivating oxide formed, and that it was not a sufficient barrier to oxygen diffusion to prevent intergranular oxidation and cracking.

Andrieu and Pineau's oxidation cracking mechanism also has application to the results of this study, in particular, the increase in the chromium concentration as the $\mathrm{C}$-ring test time increased. $[40,78]$ In short time tests, 24 hours, ( $\mathrm{Ni}, \mathrm{Fe}) \mathrm{O}$ oxide was shown to be present on the $\mathrm{C}$-ring fracture surfaces. Based on their kinetic argument, the long time samples show $\mathrm{Cr}$ enrichment, and had reached the transition time, $\mathrm{t}_{\mathrm{p}}$, required to nucleate and grow $\mathrm{Cr}$-rich oxides. The short time samples were below the transition time for $\mathrm{Cr}$ rich oxide formation, formed ( $\mathrm{Ni}, \mathrm{Fe}) \mathrm{O}$ intergranular oxides, and cracked faster than the rate of $\mathrm{Cr}$ passivation. 


\section{Analysis of Stress Accelerated Grain Boundary Oxidation}

It is proposed that stress accelerated grain boundary oxidation can be modeled as an internal oxidation process. The basis for this proposal was introduced in section $F$ of the Literature Review. In stress accelerated grain boundary oxidation, low temperatures $\left(<1000^{\circ} \mathrm{C}\right)$ and application of tensile stress, favor grain boundary diffusion over lattice diffusion. The result is internal/intergranular oxidation that follows the internal/matrix oxidation model. The assumptions that serve as the basis of this proposed mechanism are:

- Intergranular oxidation in stress rupture samples continues until the sample fails, i.e., until final fast ductile fracture. This was demonstrated in this thesis.

- At low temperatures, and under an applied tensile stress, grain boundary diffusion is dominant $\left(D_{\text {lace }} \ll<D_{k 0}\right)$. The fact than non-stressed material used in these experiments did not exhibit intergranular oxidation supports the necessity of tensile stresses to further enhance intergranular oxidation.

- The "internal oxidation zone" at low temperatures and under tensile stress manifests itself as intergranular oxidation.

- The intergranular oxidation zone penetrates to the same depth as predicted for internal oxidation. Because $D_{\text {bemice }} \ll<D_{k b}$, no internal (matrix) oxidation occurs.

- Analogous to internal (matrix) oxidation, the transition from internal to external oxidation is promoted by lowering the surface oxygen concentration and/or increasing the $\mathrm{Cr}$ concentration in the alloy.

- Also analogous to internal oxidation in $\mathrm{Ni}-\mathrm{Cr}$ alloys, the nucleation and growth of intergranular $\mathrm{Cr}_{2} \mathrm{O}_{3}$ and $\mathrm{NiCr}_{2} \mathrm{O}_{4}$ precipitates serves to block the diffusion path for oxygen.

- The external oxide layer formed at the low oxygen concentrations ( $\leq 1000 \mathrm{ppm}$ ) used in these experiments was thin $(<0.2 \mu \mathrm{m})$ or incomplete. Also, tensile loading will rupture this external oxide layer. Based on these observations, it can be assumed that diffusion through the external scale is not rate limiting. This allows the problem to be treated as internal oxidation in the absence of an external scale. 


\section{Definition of terms:}

- $\mathrm{N}_{\mathrm{cr}}{ }^{(0)}$ is the mole fraction of chromium in the alloy.

- $\mathrm{N}_{\mathrm{O}}{ }^{(\mathrm{S})}$ is the mole fraction of oxygen at the surface.

- $\mathrm{N}_{\mathrm{O}}$ is the mole fraction oxygen in the base metal.

- $\mathrm{N}_{\mathrm{G}}$ is the mole fraction of chromium.

- $D_{0}$ is the diffusion coefficient for oxygen.

- $\mathrm{D}_{\mathrm{c}}$ is the diffusion coefficient for chromium.

- $\mathrm{D}_{\mathrm{gb}}{ }^{0}$ is the grain boundary diffusion coefficient for oxygen.

- $\mathrm{D}_{\mathrm{gb}}{ }^{\mathrm{C}}$ is the grain boundary diffusion coefficient for chromium.

- $v$ is the stoichiometric ratio of oxygen to metal atoms in the oxide precipitate.

- $\xi$ is the depth of the zone of internal oxidation.

- $\mathbf{x}$ is the distance from the outer surface.

- $t$ is the reaction time required to form an internal oxide zone of depth $\xi$.

- $\gamma$ is a time-independent dimensionless parameter, for isotnermal oxidation at constant oxygen pressure.

The following derivation for the depth of internal oxidation follows that of Rapp. [82] Under diffusion control and in the absence of an external scale, the depth of the internal oxidation zone is a parabolic function of time, is given by,

$$
\xi=2 \gamma\left(D_{0} t\right)^{1 / 2} \text {. [82] }
$$

Rapp has solved the one-dimensional diffusion equations for oxygen and for some oxidizable alloying element, in this case chromium. For oxygen,

$$
\frac{\partial N_{o}}{\partial t}=D_{o} \frac{\partial^{2} N_{o}}{\partial x^{2}}
$$

the boundary conditions used are

$$
\begin{array}{ll}
N_{o}=N_{o}(s) & \text { for } x=0, t>0 \\
N_{0}=0 & \text { for } x \geq \xi, t>0 .
\end{array}
$$

For chromium the diffusion equation is,

$$
\frac{\partial N_{C_{r}}}{\partial t}=D_{C r} \frac{\partial^{2} N_{C_{r}}}{\partial x^{2}}
$$


and the boundary conditions applied are

$$
\begin{array}{ll}
N_{c t}=N_{c t}{ }^{(0)} & \text { for } x>0, t=0 \\
N_{c}=0 & \text { for } x \leq \xi, t>0 .
\end{array}
$$

The solutions obtained by Rapp are

$$
\begin{aligned}
& N_{O}=N_{O}^{(S)}\left\{1-\frac{\operatorname{erf}[x / 2]\left(D_{0} t\right)^{1 / 2}}{\operatorname{erf} \gamma}\right\} \\
& N_{C_{r}}=N_{C_{r}}^{(0)}\left\{1-\frac{\operatorname{erf}[x / 2]\left(D_{C_{r}} t\right)^{1 / 2}}{\operatorname{erf} \gamma \phi^{1 / 2}}\right\} .
\end{aligned}
$$

In these equations $\phi=D_{\boldsymbol{d}} / \mathrm{D}_{\mathrm{c}}$.

If an insoluble and stoichiometric oxide precipitates at the front of the zone of internal oxidation, the flux of oxygen atoms arriving from the surface must be equivalent to the flux of $\mathrm{Cr}$ arriving from the bulk alloy and,

$$
\lim _{\varepsilon \rightarrow 0}\left[-D_{0}\left(\frac{\partial N_{0}}{\partial x}\right)_{x=\xi-\varepsilon}=-v D_{C}\left(\frac{\partial N_{C r}}{\partial x}\right)_{x=\xi+\varepsilon}\right] .
$$

Substituting equations (9) and (10) into equation 11 gives

$$
\frac{\partial N_{0}}{\partial t}=\frac{\exp \left(\gamma^{2}\right) \operatorname{erf} \gamma}{\phi^{1 / 2} \exp \left(\gamma^{2} \phi\right) \operatorname{erfc}\left(\gamma \phi^{12}\right)} \text {. }
$$

Rapp obtained a solution for $\gamma$ for the case where,

$$
\frac{D_{C_{r}}}{D_{0}} \ll \frac{N_{0}^{(S)}}{N_{C r}^{(0)}} \ll 1
$$

which is shown graphically in Figure 93. [82] This simplifies equation (12) to

$$
\gamma \equiv\left[\frac{\mathrm{N}_{\mathrm{O}}^{(S)}}{2 \vee \mathrm{N}_{\mathrm{C}}^{(0)}}\right]^{\frac{1}{2}} .
$$

Finally, substituting the expression for $\gamma$ into equation (6) gives an expression for the depth of internal oxidation,

$$
\zeta \cong\left[\frac{2 N_{0}^{(S)} D_{0}}{v N_{G}^{(0)}} t\right]^{\frac{1}{2}} .
$$

The validity of the condition stated in equation 13 and illustrated in Figure 93 can be verified for the formation of an intergranular oxidation zone of depth $\xi$. The micrograph shown in Figure 94 is from a cross section near the surface of a heat treated alloy 905 sample, composition given in Table 1. This material has no $\mathrm{Cr}$ and low $\mathrm{Al}$ concentration. The intergranular and surface oxides that form in this material have been identified as 


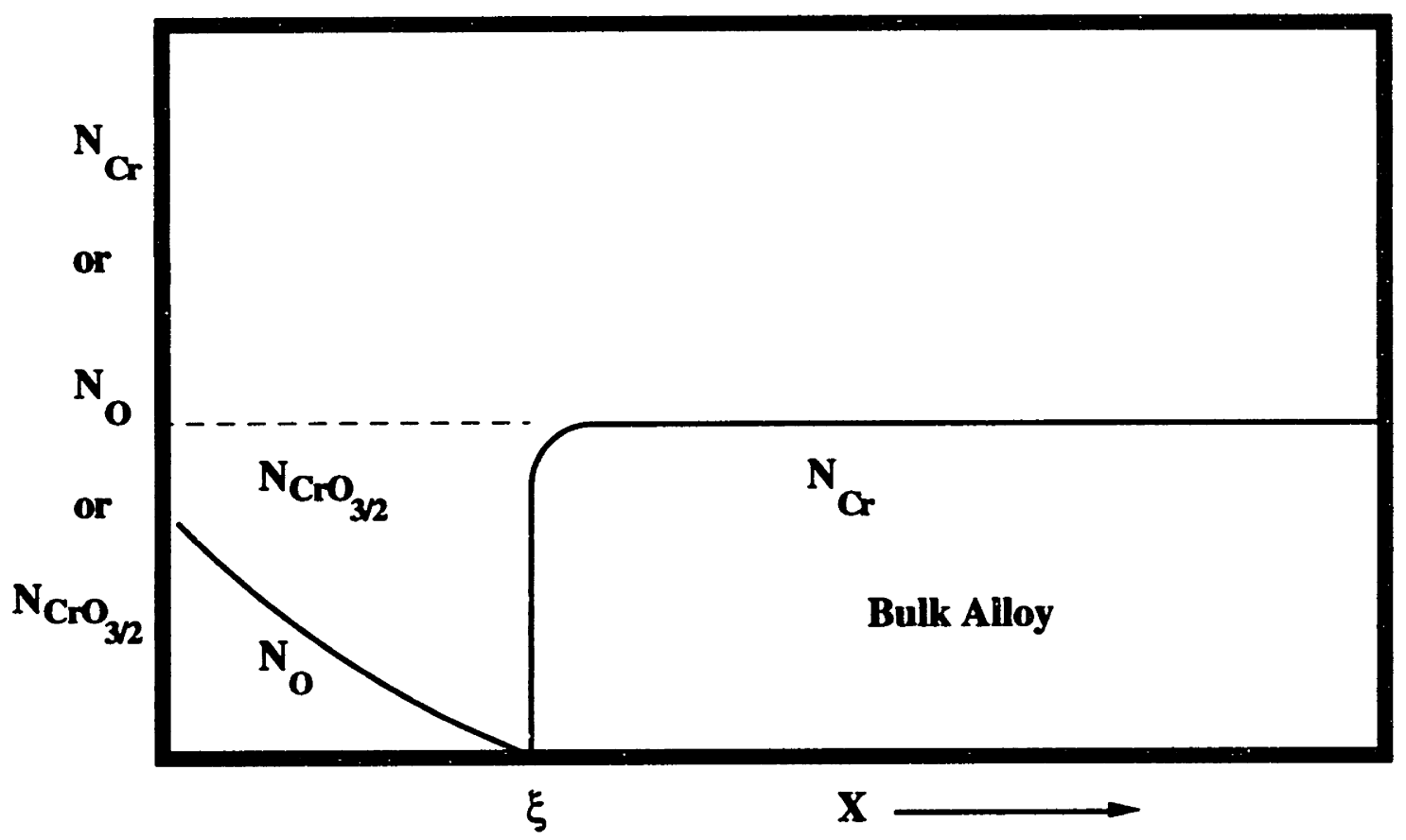

Figure 93. Concentration profile for the exclusive internal oxidations of alloys for the case where $\frac{D_{0}}{D_{0}} \ll \frac{N_{0}^{(S)}}{N_{C r}^{()}} \ll 1$. From Rapp. [82]

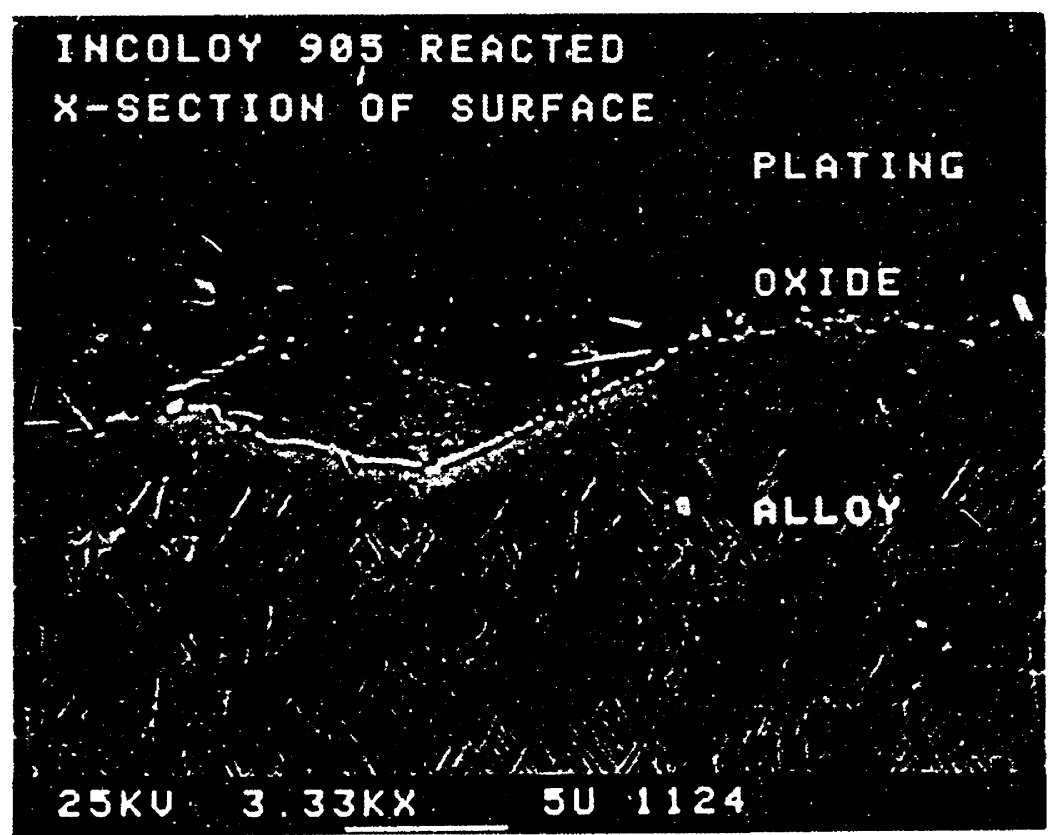

Figure 94. SEM micrograph showing cross section through the oxidized surface of heat treated alloy 905. 
$\mathrm{Nb}_{2} \mathrm{O}_{5}$. [1] Extended time heat treatments rapidly overage the $\gamma^{\prime}$ (bct $\mathrm{Ni}_{3} \mathrm{Nb}$ ) precipitate in this material. [1] This rapid coarsening lends itself to using the $\gamma^{\prime}$ as a marker for niobium distribution using SEM. Coarse platelets of $\gamma^{\prime \prime}$ can be seen in the lower portion of the micrograph and oxide precipitates can be seen along the grain boundaries. As the surface oxide develops, the intergranular oxidation zone extends into the alloy and the depletion of $\mathrm{Nb}$ from the matrix can be seen as a zone denuded of coarse $\gamma$.' As illustrated, the intergranular oxidation zone penetrates to the same depth as the solute depleted zone in this material. The data given in Table 2 provide another verification of the profile in Figure 93. From that data, at low temperatures $\left(<800^{\circ} \mathrm{C}\right)$, the $\mathrm{Cr}$ concentration at the front of internal oxidation in $\mathrm{Ni}-\mathrm{Cr}$ alloys does not drop off steeply.

For the conditions used in this thesis, the mole fraction of $\mathrm{Cr}, \mathrm{N}_{\mathrm{c}}{ }^{(0)}$, is fixed at 0.045 . The concentration of oxygen at the surface of the stress rupture samples was measured. From Sievert's law $\mathrm{N}_{\mathrm{o}}{ }^{(\mathrm{S})} \propto\left(\mathrm{P}_{\mathrm{O} 2}\right)^{1 / 2}$. For $\mathrm{Cr}_{2} \mathrm{O}_{3}$ forming as an intergranular oxide $\mathrm{v}=3 / 2$. If grain boundary diffusion dominates under conditions at which stress accelerated grain boundary oxidation occurs, then equation (15) becomes

$$
\xi \cong\left[29.6 \mathrm{~N}_{O}^{(S)} D_{g b}^{0} \mathrm{t}\right]^{\frac{1}{2}} \text {. }
$$

A value for the grain boundary diffusion of oxygen, $\mathrm{D}_{\mathrm{gb}}{ }^{\circ}$, can be estimated for alloy 908 from

$$
D_{g b}=1.0 \exp \left(-9.35 \frac{T_{m}}{T}\right)_{c m^{2} s^{-1} ; 1.0<T_{m} / T<2.4 .[89]}
$$

For alloy 908 at $650^{\circ} \mathrm{C}, \mathrm{T}_{\mathrm{m}} \mathrm{T}=1.77$, and $\mathrm{D}_{\mathrm{gb}}=6.5 \times 10^{-8} \mathrm{~cm}^{2} \mathrm{~s}^{-1}$. The depth of intergranular oxidation in the flat plate material was calculated as a function of surface oxygen concentration and experimental test time using equation (16). Intergranular oxidation depths for the round bar material were calculated using an analogous equation derived for cylindrical samples

$$
\frac{\left(r_{1}\right)^{2}}{2}-\left(r_{2}\right)^{2} \ln \left(\frac{r_{1}}{r_{2}}\right)+\frac{1}{2}=\frac{2 N_{O}^{(S)} D_{g b}^{O}}{v N_{G r}^{o}} t
$$

where $r_{1}$ is the sample radius and $r_{2}$ is the un-oxidized core radius. [92] The values obtained were plotted with the experimental measurements of intergranular oxidation depth and are shown in Figure 95. The calculated values follow the trend of the experimental values. At low oxygen concentrations the depth of intergranular oxidation is at or near zero. This is the point at which the external/intergranular transition occurs. The depth of intergranular oxidation then increases as the concentration of oxygen at the surface 

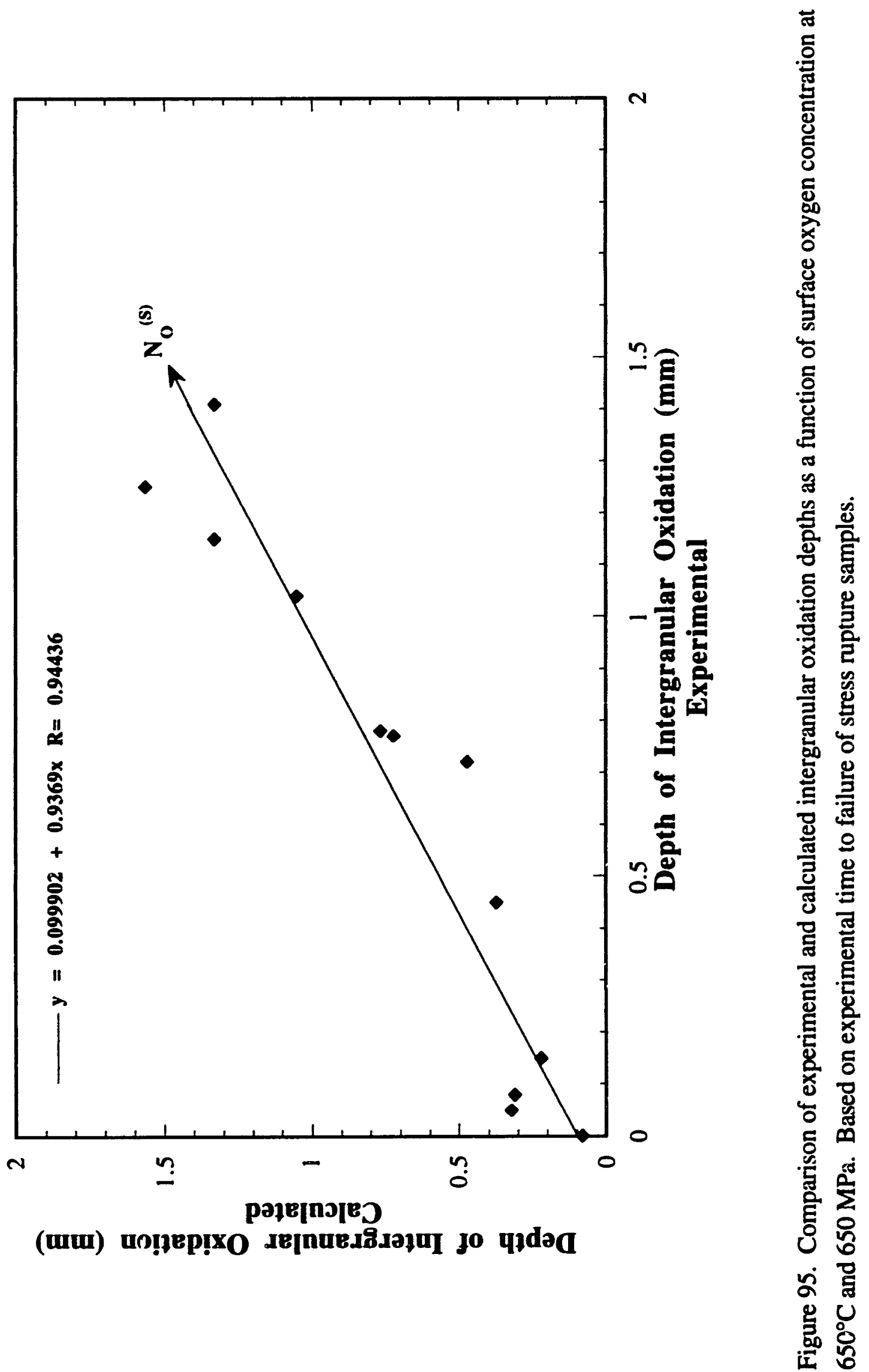

艺 
increases. The time to achieve the experimental intergranular oxidation depths of were calculated using equation (16). A plot of these data are shown in Figure 96. A line has been drawn on the plot to show the estimated oxygen concentration at which the transition from external to internal oxidation occurs. To the left of this line, $\mathrm{N}_{\mathrm{o}}{ }^{(\mathrm{S})} \mathrm{D}_{\mathrm{gb}}{ }^{0} \ll \mathrm{N}_{\mathrm{cc}}{ }^{(0)} \mathrm{D}_{\mathrm{gb}}{ }^{\mathrm{Cr}}$ and external oxidation is prevalent. [85] In this region, below approximately $1 \mathrm{ppm}$ oxygen, $\mathrm{N}_{\mathrm{o}}{ }^{(\mathrm{S})}$ controls oxidation. To the right of this line $\mathrm{N}_{\mathrm{a}}{ }^{\left({ }^{(0)}\right.}$ controls intergranular oxidation. Below $1 \mathrm{ppm}$ oxygen the alloy passivates by external scale formation, in this analysis assumed to be $\mathrm{Cr}_{2} \mathrm{O}_{3}$. Above $1000 \mathrm{ppm}$ oxygen the assumption that an external oxide layer is not present is no longer valid and diffusion through the external oxide is rate limiting. Under these conditions the second plateau in the sigmoidal curve develops. In some cases the experimental times to the right of the line were somewhat longer than those calculated. In the stress rupture tests, intergranular oxidation proceeded to the depth predicted by internal oxidation theory. As was discussed earlier, ductile creep rupture of the remaining cross section contributed to the final failure times measured in these experiments. A schematic of the intergranular oxidation zone, of depth $\xi$, developed under tensile loading, is shown in Figure 97. Following internal oxidation theory, the intergranular oxidation zone stops at depth $\xi$ after sufficient oxide $\left(\mathrm{Cr}_{2} \mathrm{O}_{3}\right.$ or $\left.\mathrm{NiCr}_{2} \mathrm{O}_{4}\right)$ has precipitated to block further diffusion of oxygen. The time required to produce a $0.5 \mathrm{~mm}$ deep zone of intergranular oxidation in alloys 718,908 , and 903 , as a function of oxygen concentration, are compared in Figure 98. As evident in this figure, increasing $\mathbf{N}_{\mathrm{c}}{ }^{(0)}$ increases the time required to attain the same depth of intergranular oxidation. The higher activation energy calculated for intergranular oxidation at low oxygen concentrations is reflected in Figure 98. The time required to form a $0.5 \mathrm{~mm}$ zone of intergranular oxidation is longer at low oxygen concentrations than in air. This indicates that a greater barrier to intergranular oxidation exists under low oxygen conditions. As discussed above, the barrier to intergranular oxidation below $1 \mathrm{ppm}$ oxygen is related to the transition from intergranular to external oxidation. A comparison of Figure 37 in the Results section, to Figure 98 shows why the percent intergranular fracture in alloy 908 lies above the alloy 718 data. It is expected that under equivalent loading conditions, alloy 908 will show greater a intergranular oxidation depth (and percent intergranular fracture) than alloy 718. Chromium plays an analogous role in stress corrosion cracking in aqueous systems. The data shown in Figure 99 are from a study on the effect of grain boundary $\mathrm{Cr}$ concentration on percent intergranular cracking in $\mathrm{Ni}-\mathrm{Cr}$-Fe alloys. [123] The data were obtained from constant extension rate tests (CERT) at room temperature in $0.017 \mathrm{M} \mathrm{Na}_{2} \mathrm{~S}_{4} \mathrm{O}_{6}$. [123] As can be seen in this figure, there is a direct correlation between percent intergranular 

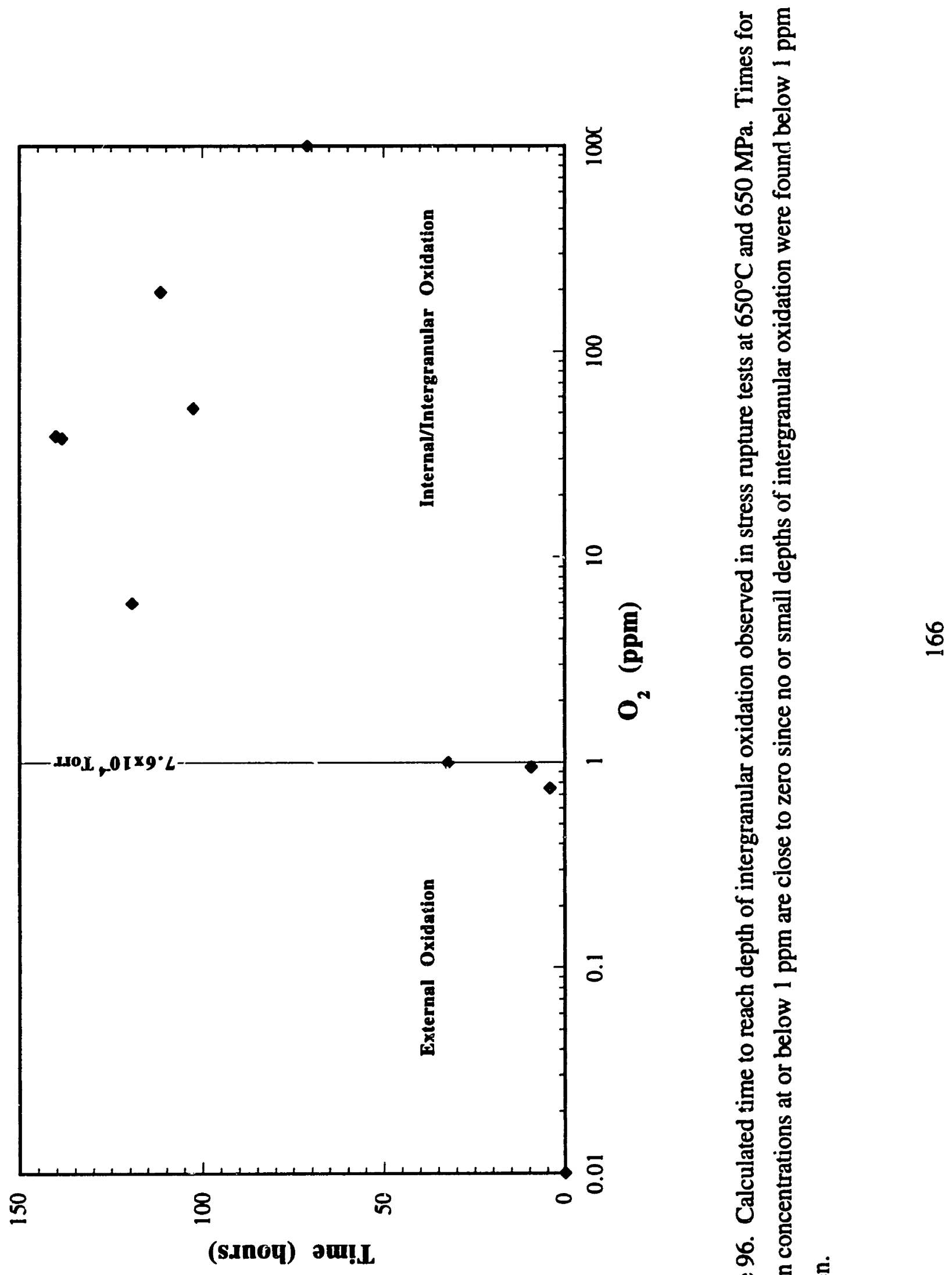
fracture (or depth of intergranular cracking) and the grain boundary $\mathrm{Cr}$ concentration.

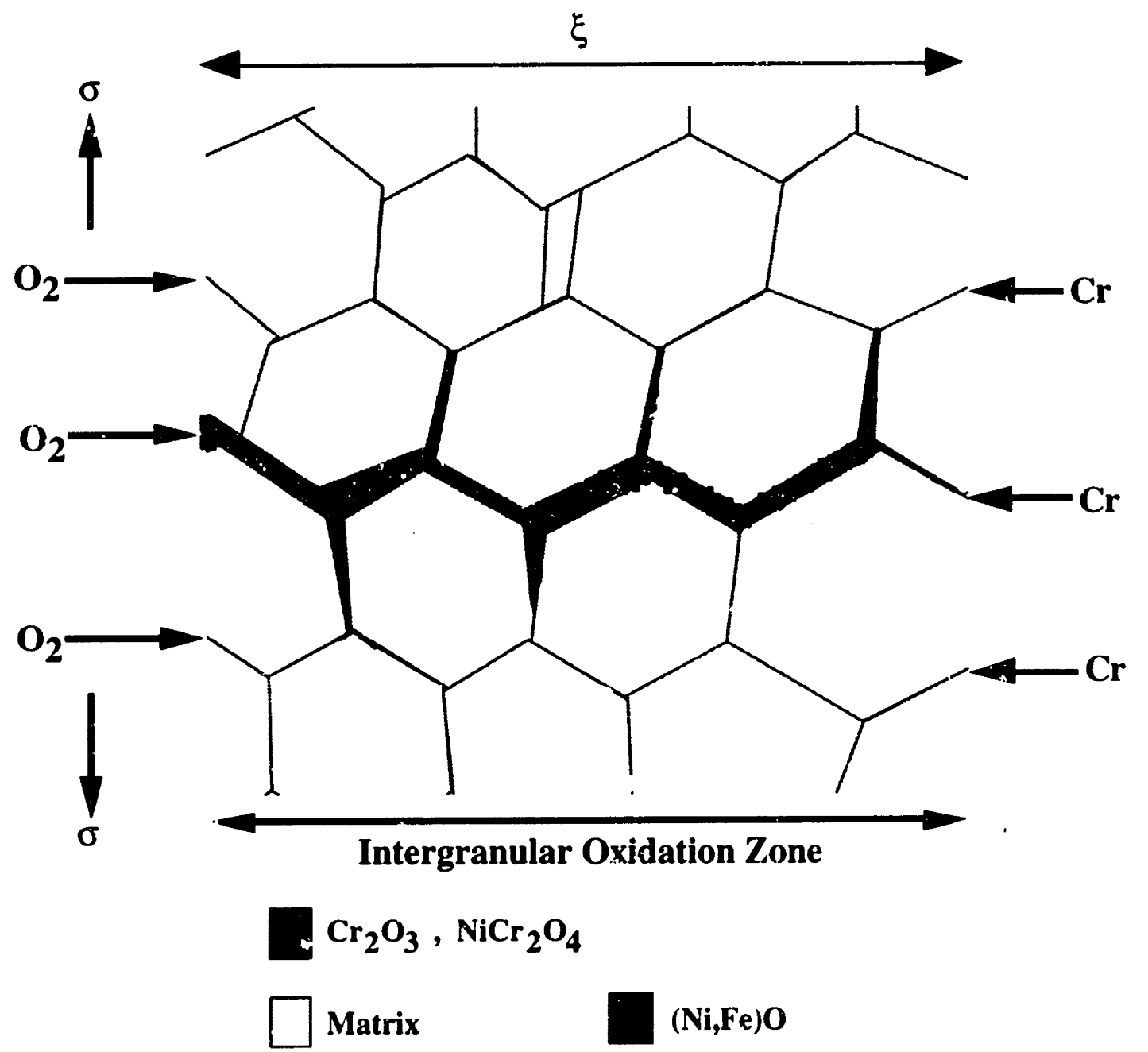

Figure 97. Intergranular oxidation zone (of depth $\xi$ ) developed under tensile loading.

Translated to fatigue loading, for a fixed oxygen concentration, $\mathrm{da} / \mathrm{dN}$ will be greater in the lower $\mathrm{N}_{\mathrm{cr}}{ }^{(0)}$ alloys. This is because the depth of intergranular oxidation aeveloped ahead of the crack tip will be greater. As the grain boundary area increases the effects of intergranular oxidation on $\mathrm{da} / \mathrm{dN}$ should also increase. The increase in $\mathrm{da} / \mathrm{dN}$ in alloy 718 , under intergranular oxidation conditicns, with decreasing grain size has been demonstrated in alloy 718. [47] Due to rupture of the external scale during crack advance the assumption that an external oxide is absent exists during fatigue loading. 

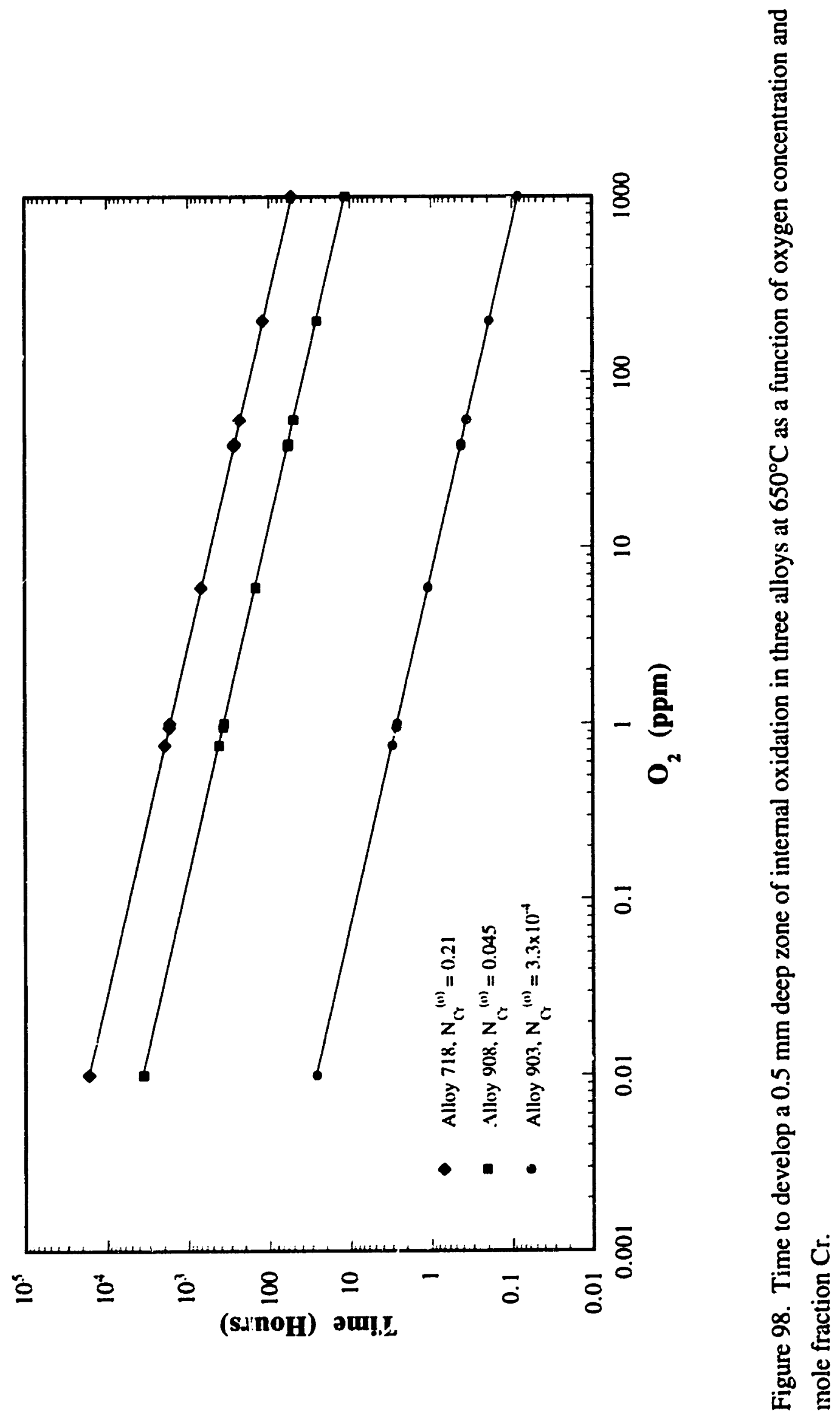


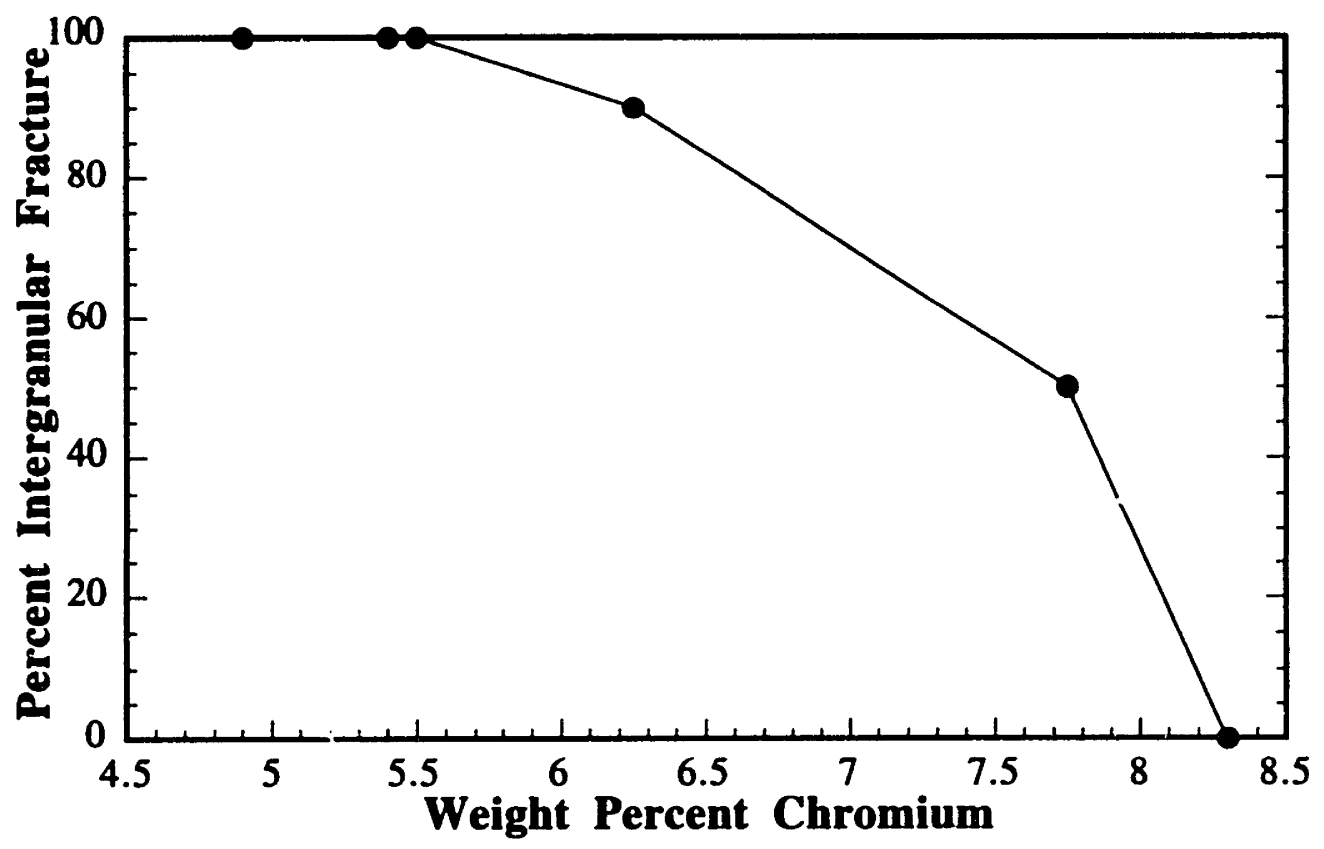

Figure 99. Percent intergranular fracture as a function of grain boundary $\mathrm{Cr}$ level in Ni-CrFe alloys obtained from constant extension rate tests at room temperature in $0.017 \mathrm{M}$ $\mathrm{Na}_{2} \mathrm{~S}_{4} \mathrm{O}_{6}$ (extension rate $2.5 \times 10^{-5} \mathrm{~mm} / \mathrm{s}$ ). From Was [123]. 


\section{SUMMARY}

At equivalent loads and oxygen concentrations, the round bar material failed in shorter times than the flat plate material. The intergranular oxide that formed was predominately (Ni,Fe)O type in the round bar material. Time to rupture in the flat plate material was independent of oxygen concentration over the 0.01-1000 ppm oxygen range examined. In this same geometry, the stress rupture test conditions provided a competition between creep rupture and loss of sample cross section due to intergranular oxidation. This observation corresponds to a creep damage mechanism based on loss of internal section by intergranular oxidation, following the methodology of Ashby and Dyson. [112] The intergranular oxides in these samples contained higher concentrations, of $\mathrm{Cr}$ and $\mathrm{Nb}$ as based on EDS results. A strong correlation between oxygen concentration and percent intergranular fracture was observed and is similar to the results reported for alloy 718 under slow strain rate tensile loading. $[77,78]$ In each case, the percent intergranular fracture is related to the depth of intergranular oxidation that can occur under tensile loading at a given oxygen concentration. Based on percent intergranular fracture, a conservative value for the partial pressure of oxygen of $1 \times 10^{-4}$ Torr is recommended for the heat treatment of alloy 908 under residual or applied stresses. Overall, with the exception of providing a threshold of oxygen concentration based on percent intergranular fracture, the stress rupture test results are more strongly dependent on the sample geometries and test method itself. It is not recommended that the time to failure generated by these tests be used to predict the expected heat treatment life at different oxygen partial pressures unless a clear understanding of the stress state in a fully wound Cable-In-Conduit-Conductor magnet is developed.

Based on the results of this study intergranular oxidation precedes cracking. Crack advance occurs after the intergranular oxide cracks in tension. All the materials examined in this study failed by stress assisted intergranular oxidation. The grain boundaries associated with intergranular fracture, either in the stress rupture samples or $\mathrm{C}$-ring samples, were oxidized. This was also the case for grain boundaries found at intact notches in failed round bar samples. Even fracture surfaces that did not have a continuous oxide film coverage, in C-ring samples, showed signs of oxide precipitation on slip planes of the intergranularly fractured grain surfaces. The oxides formed at the grain boundaries were predominantly of the $(\mathrm{Fe}, \mathrm{Ni}) \mathrm{O}$ type. High temperature oxidation research on $\mathrm{Ni}-\mathrm{Fe}$ base superalloys has shown these oxides to be permeable to oxygen.

The role of tensile stress, as suggested by intergranular oxidation studies, may simply be to accommodate the volumetric expansion that occurs as the intergranular oxides form. 
In Cr-containing alloys, the kinetics of the intergranular oxidation mechanism are especially important. The depth of the intergranular oxidation zone that develops in an alloy is dependent upon both the oxygen partial pressure at the surface of the sample and the $\mathrm{Cr}$ content of the alloy. Whether a transformation from internal to external (surface passivation) oxidation occurs is also dependent on these two parameters.

In alloy 908 , the amount $\mathrm{Cr}$ incorporated into the intergranular and surface oxides increases with increasing stress rupture life. The measured intergranular oxidation depths in alloy 908 were calculated using an analysis approach developed for internal oxidation. Agreement between the experimental and calculated depths, as a function of oxygen concentration, was verified. Based on this analysis, the time required to reach a given depth of intergranular oxidation is dependent upon the growth of $\mathrm{Cr}$-rich oxides. Analogous to internal oxidation, these oxides act to block oxygen diffusion. The formation of these oxides is controlled by chromium grain boundary diffusion and the weight percent $\mathrm{Cr}$ in the alloy. The weight percent $\mathrm{Cr}$ dependency observed in high temperature intergranular oxidation follows that observed for intergranular stress corrosion cracking in aqueous environments.

The results found in this study can be related to the role of $\mathrm{Nb}$-rich intergranular phases in reducing stress accelerated grain boundary oxidation in low-Cr or $\mathrm{Cr}$ free alloys. As these phases grow during heat treatment they act as intergranular barriers to oxygen diffusion. Alternately, by oxidizing, these phases can also act as oxygen traps. This was as was observed for primary $(\mathrm{Nb}, \mathrm{Ti}) \mathrm{C}$ carbides that oxidized in alloy 908 .

Based on this study and a literature review of a wide variety of $\mathrm{Ni}$ and $\mathrm{Ni}$ - $\mathrm{Fe}$ base superalloys, if stresses can not be controlled, then heat treatment should occur in a $1 \times 10^{-4}$ Torr or better vacuum for reliable protection against SAGBO. Modification of surface residual stresses through shot peening appears to be a relatively simple solution to the SAGBO problem. Stress relief in vacuum is less of an alternative because it requires that a high vacuum furnace vacuum be used. This solution does, however, suggest that leaks that develop in a vacuum furnace after a stress relief period may be of little consequence.

Some solutions to the stress assisted intergranular oxidation cracking seen in low coefficient of expansion superalloys in order of practical application to Cable-In-ConduitConductor magnets are;

- Place the surface of the conduit in compression,

- Keep the oxygen partial pressure below $1 \times 10^{-4}$ Torr,

-Eliminate residual stresses by stress relief,

- Introduce localized $\mathrm{Cr}$ enrichment, either through plating or ion implantation of $\mathrm{Cr}$, 
-Add oxygen getter elements that segregate to grain boundaries $(\mathrm{B}, \mathrm{Zr}$, etc.). 


\section{CONCLUSIONS}

\section{Applied}

- Control of furnace atmosphere chemistry during heat treatment is essential for the successful heat treatment of alloy 908 .

- An oxygen partial pressure below $1 \times 10^{-4}$ Torr is required to successfully heat treat an alloy 908 Cable-In-Conduit-Conductor magnet.

- For stress rupture testing of low coefficient of expansion superalloys, an oxygen concentration threshold based on zero percent intergranular fracture is a better indicator of the potential for intergranular fracture during heat treatment than one based on time to rupture.

- The elimination of residual tensile surface stresses by applying compressive residual stresses through shot peening or reduction in tensile stresses through vacuum stress relief heat treatments eliminates stress accelerated grain boundary oxidation in C-ring bend samples.

\section{Stress Accelerated Grain Boundary Oxidation}

- The mechanism for high temperature intergranular fracture in alloy 908 is stress assisted intergranular oxidation cracking.

- The percent intergranular fracture in alloy 908 increases with increasing oxygen concentration.

- This result can be correlated to that observed in other $\mathrm{Ni}-\mathrm{Fe}$ and $\mathrm{Ni}$ base superalloys and is controlled both by the concentration of oxygen in the environment and the concentration of $\mathrm{Cr}$ in the alloy.

- Long range, intergranular oxygen embrittlement was not observed in alloy 908 .

- The fact than non-stressed material used in these experiments did not exhibit intergranular oxidation supports the proposal that tensile stresses enhance intergranular oxidation. 
- The concentration of $\mathrm{Cr}$ incorporated into intergranular and surface oxides increases with increasing test duration. These results are consistent with internal oxidation theory.

- Internal oxidation, at low temperatures $\left(<800^{\circ} \mathrm{C}\right)$ and under an applied tensile stress manifests itself as intergranular oxidation in alloy 908.

- The intergranular oxidation zone penetrates to the same depth as calculated for internal oxidation with $D=D_{g^{b}}^{o}$. Because $D_{\text {lartice }} \ll<D_{g b}$, no internal (matrix) oxidation occurs.

- Analugous to internal (matrix) oxidation, the transition from internal to external oxidation is promoted by lowering the surface oxygen concentration and/or increasing the $\mathrm{Cr}$ concentration in the alloy.

- Also analogous to internal oxidation in $\mathrm{Ni}-\mathrm{Cr}$ alloys, the nucleation and growth of intergranular $\mathrm{Cr}_{2} \mathrm{O}_{3}$ and $\mathrm{NiCr}_{2} \mathrm{O}_{4}$ precipitates serves to block the diffusion path for oxygen.

- High temperature, stress assisted intergranular oxidation cracking is prevalent in most $\mathrm{Ni}-\mathrm{Fe}$ and $\mathrm{Ni}$ base superalloys. Its effect diminishes with increasing $\mathrm{Cr}$ concentration.

- This failure mechanism's dependence on chromium concentration is similar to that observed for intergranular stress corrosion cracking in aqueous environments. 


\section{FUTURE WORK}

The flat plate test samples cffer little in the way of predictive ability as related to SAGBO. Further work should continue with the round bar configuration, but only to establish a fundamental data base for thick wall extruded conduit designs.

Most data reported in the literature is from fatigue and creep crack growth studies. Fatigue experiments are not directly applicable to the Cable-In-Conduit-Conductor situation; one cycle consisting of heat treatment, and creep crack growth studies may be preferable. If fatigue crack growth rate studies are carried out, they must be done under controlled oxygen partial pressures, low $(<0.05 \mathrm{~Hz})$ frequency, and the effect of hold time should be investigated.

It should also be investigated if the low coefficient of expansion of these superalloys contributes to their susceptibility to stress assisted oxidation by preventing relaxation of stresses at the crack tip through thermal expansion. This is because, under static loading, the growing intergra zular oxide can generate a stress field on the grain boundary ahead of the crack that allows further oxidation and crack advance.

Finally, the effect of tensile stress on the grain boundary diffusion coefficient for oxygen should be determined. Using internal oxidation methodology, an activation energy for grain boundary oxygen diffusion could be calculated from the depths of intergranular oxidation as a function of stress and temperature. This experiment would have to employ a constant stress test procedure. 


\section{APPENDIX}

Table 1A. Nominal Compositions of Some Superalloys

\begin{tabular}{|c|c|c|c|c|c|c|c|c|c|c|c|}
\hline Alloy & \multicolumn{10}{|c|}{ Composition (weight percent) } \\
\hline & $\mathrm{Fe}$ & $\mathrm{Cr}$ & $\mathrm{Ni}$ & $\mathrm{Co}$ & $\mathrm{Nb}$ & $\mathrm{Ti}$ & $\mathrm{Al}$ & $\mathrm{Mo}$ & $\mathrm{W}$ & $\mathrm{C}$ & $\mathrm{Si}$ \\
\hline 617 & - & 22.0 & 54 & 12.5 & - & - & 1.0 & 9.0 & - & 0.07 & - \\
\hline Waspaloy & - & 19.5 & 58.0 & 13.5 & - & 3.0 & 1.3 & 4.3 & - & 0.08 & - \\
\hline Astroloy & - & 15.0 & 55.0 & 17.0 & - & 3.5 & 4.0 & 5.3 & - & 0.06 & - \\
\hline MAR-M200 & - & 9.0 & 60.0 & 10.0 & 1.0 & 2.0 & 5.0 & - & 12.0 & 015 & - \\
\hline 738 & - & 16.0 & 61 & 8.5 & 0.9 & 3.4 & 3.4 & 1.7 & 2.6 & 0.17 & - \\
\hline X-750 & 7.0 & 15.5 & 73.0 & - & 1.0 & 2.5 & 0.7 & - & - & 0.04 & 0.2 \\
\hline 718 & 18.5 & 19.0 & 52.5 & - & 5.1 & 0.9 & 0.5 & 3.0 & - & 0.04 & 0.2 \\
\hline
\end{tabular}




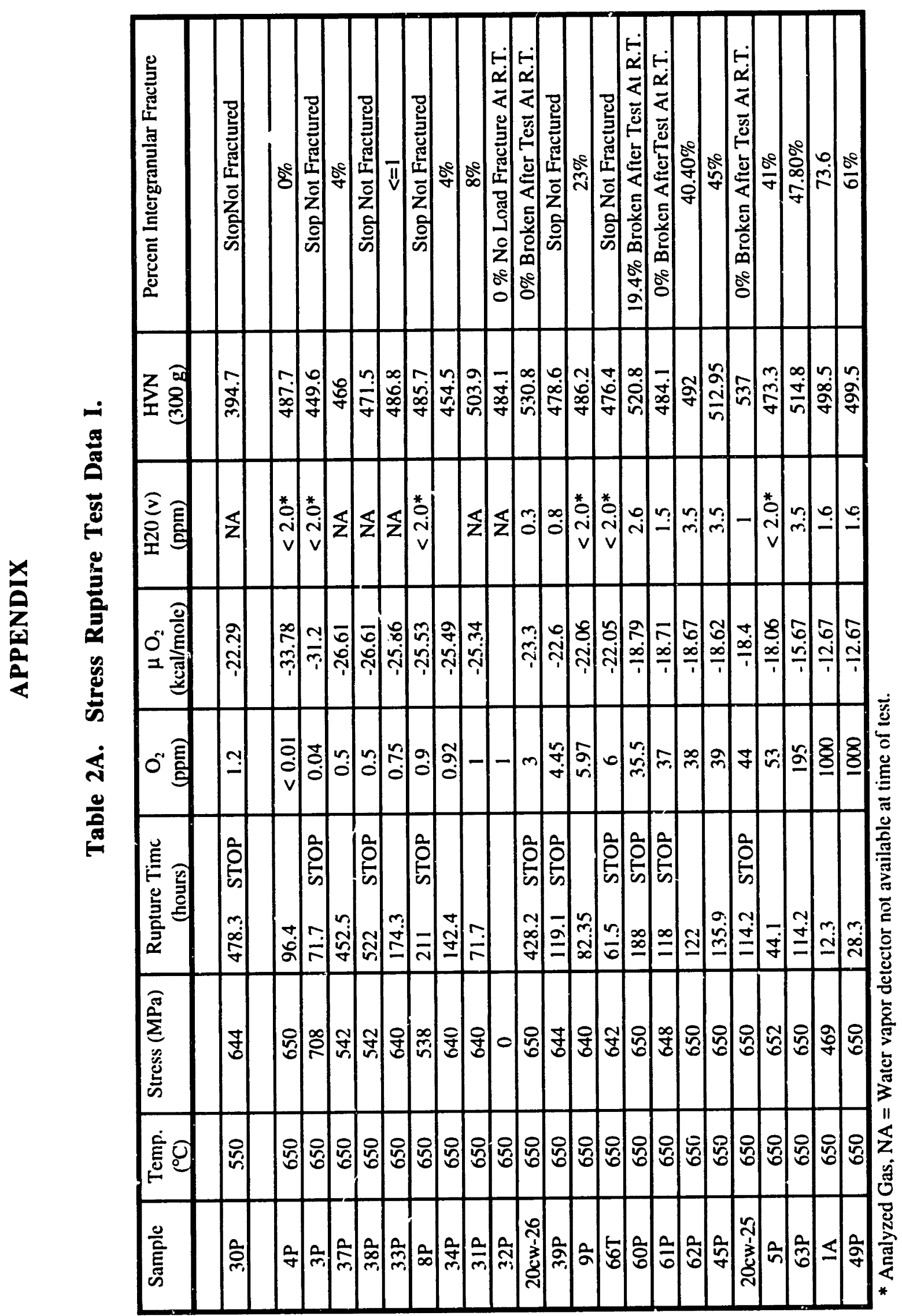




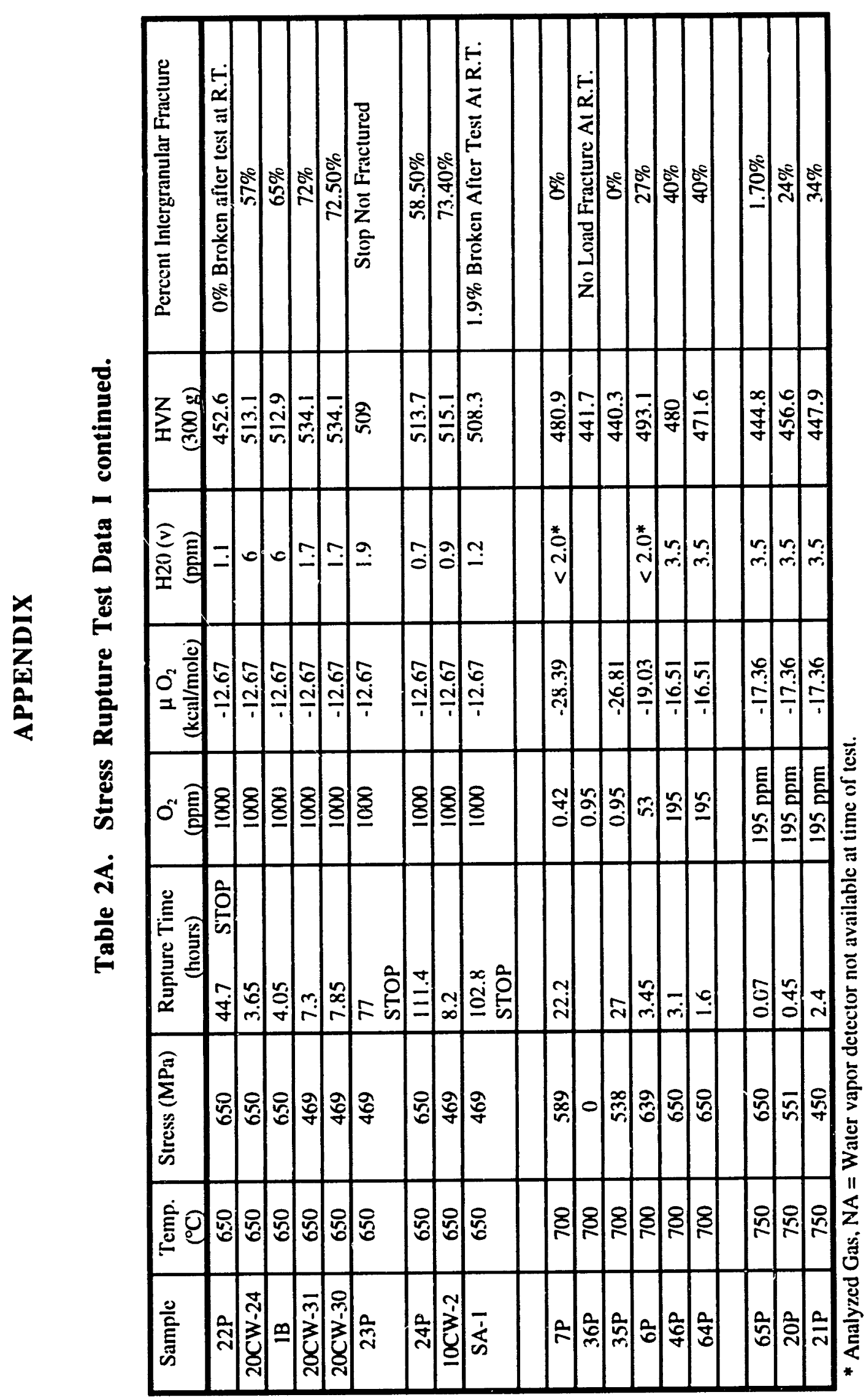




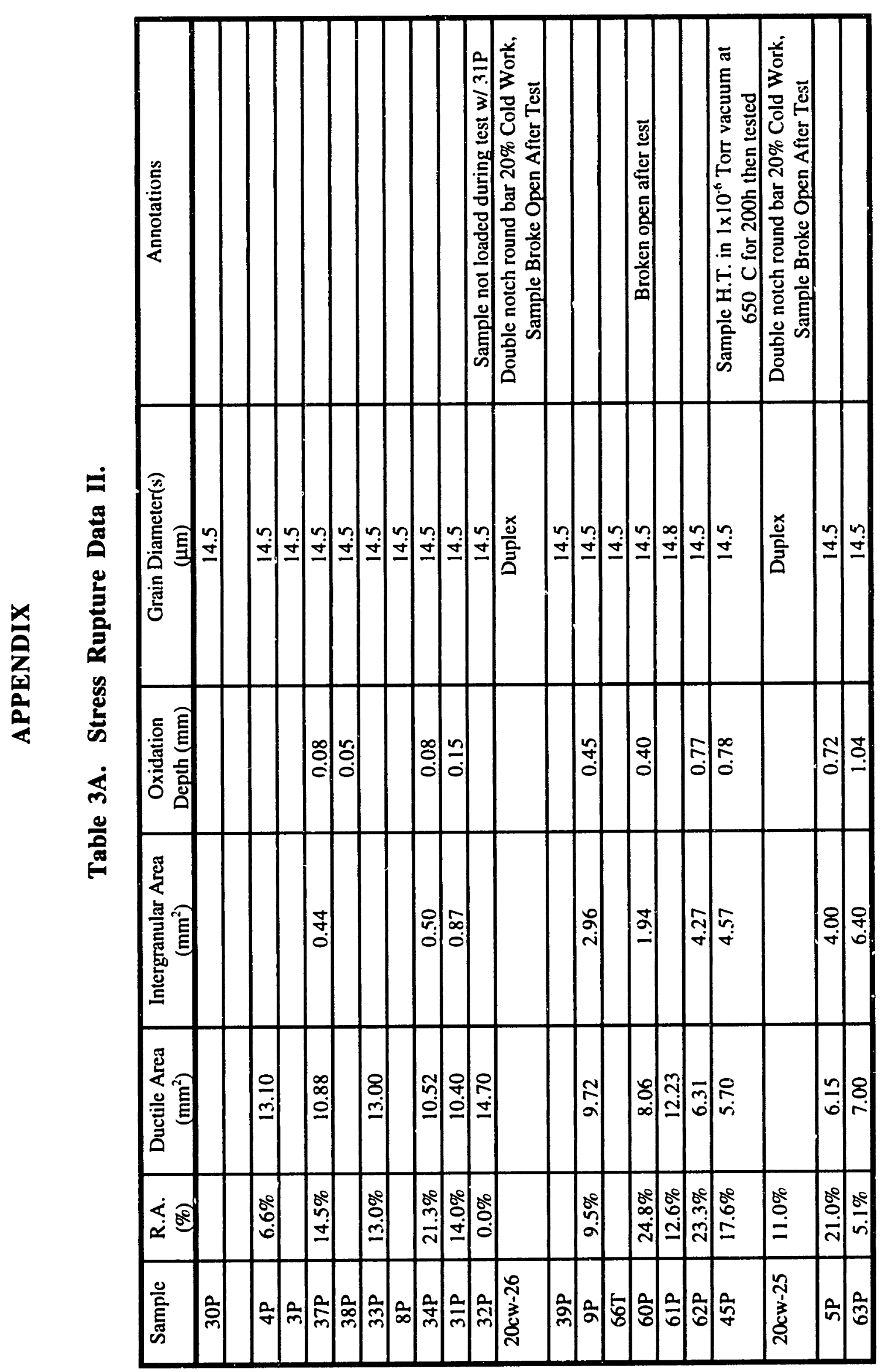




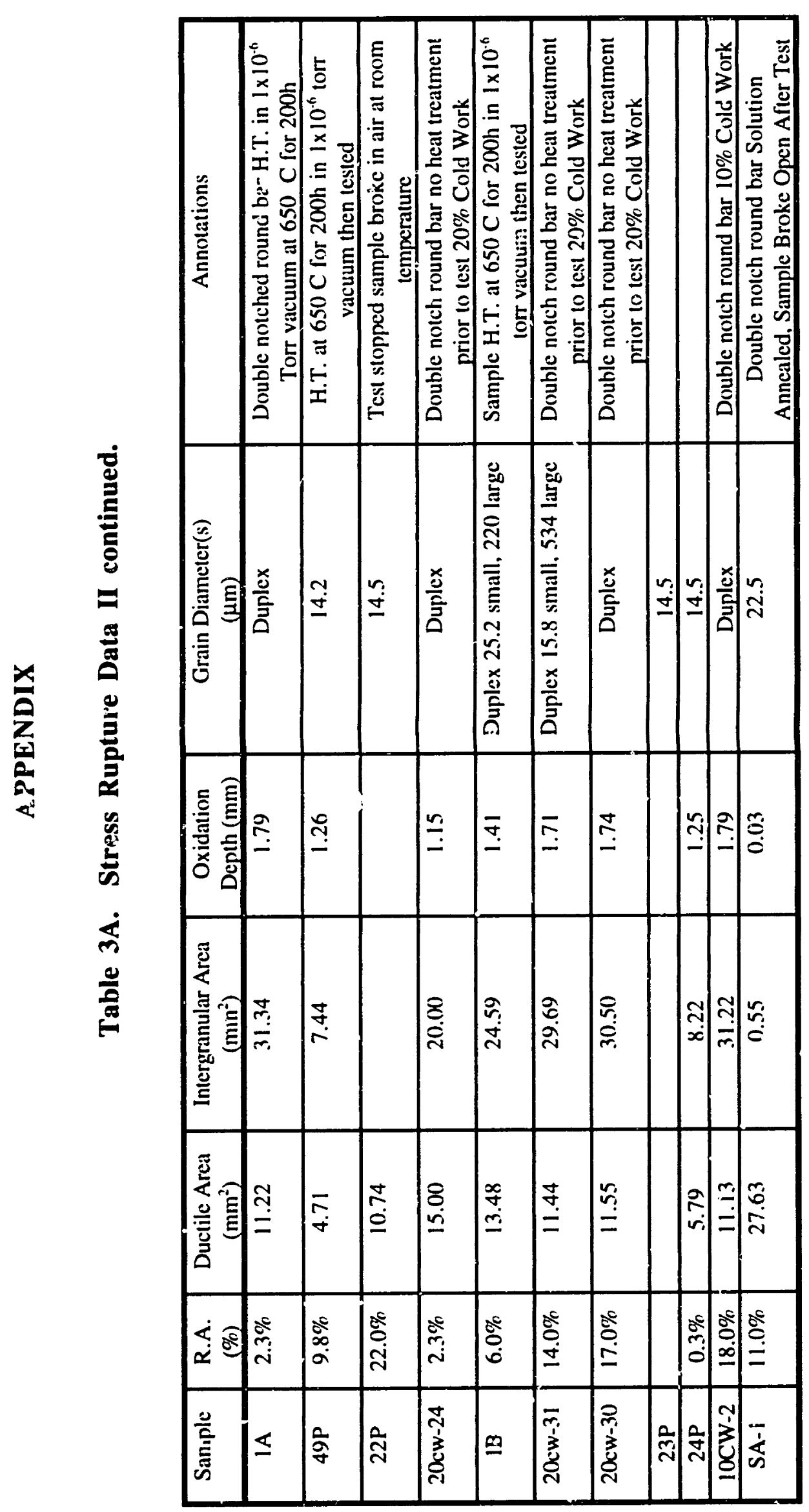




\section{REFERENCES}

1. M.M. Morra, "Alloy 908, A New High Strength, Low Coefficient of Thermal Expansion Alloy for Cryogenic Applications", S.M. Thesis, Massachusetts Institute of Technology, February, 1989

2 M.M. Morra, R.G. Ballinger, J.L. Martin, M.O. Hoenig, and M.M. Steeves, "Incoloy® 9XA, A New Low Coefficient of Thermal Expansion Sheathing Alloy for Use in ICCS Magnets", Advances in Cryogenic Engineering Materials, Yol. 34, A.F. Clark and R.P. Reed, eds., 1987, pp 157-164

3. M.M. Morra, R.G. Ballinger, and I.S. Hwang, "Incoloy® 908, A. Low Coefficient of Expansion Alloy for High Strength Cryogenic Applications: Part 1-Physical Metallurgy", Met.Trans. A, December 1992, pp. 3177-3192

4. S.K. Hwaing, F.C. Hull and J.M. Wells, "Thermal Expansion of Alloys Used in Power Generation", EPRI RD-3685, Project 2426-1, September 1984

5. A. Katsuki, "A survey of Theories of Invar", Physics and Applications of Invar Alloys. Part I, Honda Memorial Series on Materials Science, No. 3, Maruzen Compary, LTD, Tokyo, i978, pp. 32.50

6. H. Fujimori, "Thernal Expansion and Magnetovolume Effects of Invar Alloys", Physics and Applications of Invar Alloys, Part II, Honda Memorial Series on Materials Science, No. 3, Maruzen Company, LTD, Tokyo, 1978, pp. 80-96

7. F. Onc, "Relation Between the Thermal Expansion Coefficient and the Magnetization in Fe-Ni Invar Alloys", J. Phys. Soc. Japan, Vol. 47, No. 5, November 1979, pp. $1480-1485$

8. N.J. Carr, Jr., 'Invar and Volume Magnetostriction", J. Magn. and Magn. Mat., Vol. 10, 197ৎ, . pp. 197-204

9. S.K. Hwang, F.C. Hull and J.M. Wells, "Effects of the Allcying Elements on the Thermal Expansion Coefficients of Non Magnetic Ni-Base Alloys and Austenitic Steels", Superalloys 1984, Proc. 5th Int. Sym. on Superalloys, Seven Springs, PA, ASM, Metals Park, OH, 1984, pp. '785-794

10. D.R. Muzyka, C.R. Whitney, and D.K. Schlosser, "Physical Metallurgy and Properties of a New Controlled-Expansir, 1 Superalloy"' J. Metals, Vol. 27, July 197. pp. 11-15

11. F.C. Hawkes, "Investigation of a Precipitation Hardening Elinvar". J. Appl. Phys., Supplement to Vol. 30, No. 4, April 1959, pp. 206S-207S

12. M.M. Steeves, T.A. Painter, M. Takaysu, R.N. Randall, J.E. Tracey, I.S. Hwang, and M.O. Hoeni", "The US Demonstration Poloidal Coil, IEEE Trans. Mag., Vol. 27, No. 2, March 1991, pp. 2359-2372

13. M.M. Steeves, M.O. Hoenig, M. Takayasu, R.N. Randall, J.E. Tracey, J.R. Hale, M.M. Morra, L. Hwaıg and P. Marti. "Progress in th: Manufacture of the US-DPC Test Coil", IEEE Tru 0S. Mag., Vol. 25, No. 2, March 1989, pp. 1738-1741 


\section{REFERENCES}

14. M.M. Steeves, T.A. Painter, J.E. Tracey, M.O. Hoenig, M. Takayaasu, R.N. Randall, M.M. Morra, I.S. Hwang and P. Marti, "Further Progress in the Manufacture of the US-DPC Test Coil", 11 th International Conference on Magnet Technology, Tsukuba, Japan, 818, 1989

15. M.M. Steeves. M.O. Hoenig, J.V. Minervini, C.R. Gibson, M.M. Morra, J.L. Martin, R.G. Ballinger, S. Autier, T. Ichihara, R. Randall, M. Takayasu, and J. R. Hale, "The US-DPC, A Poloidal Coil Test Insert for the Japanese Demonstration Poloidal Coil Test Facility", IEEE Trans. Mag., Vol. 24, No. 2, March 1988, pp. $1307-1310$

16. M.M. Steeves, M.O. Hoenig and C.J. Cyders, "Effect of Incoloy® 903 and Tantalum Conduits on Critical Current in Nb3Sn Cabled-In-Conduit Conductors", Adv. in Cryogenic Engineering, Vol. 30, R.P. Reed and A.F. Clark, eds., 1984, pF. 883890

17. M.M. Steeves, M.O. Hoenig and C.J. Cyders, "Effects of Inco'oy ${ }^{\circledR} 903$ and Tantalum Conduits on Critical Currents in Nb3Sn Cable-In Conduit-Conductors", U.S. DOE Contract DE-AC02-78ET-51013, 1983

18. J.W. Ekin, "Mechanical Properties and Strain Effects in Superconductors", SupeiconductorMaterials Science, S. Foner and B.B. Schwartz, eds., Plenum Press, 1981, pp. $455-510$

19. J.W. Ekin, "Electromechanical Research on Cable-In-Conduit Conductors", (Report SR-724-34-84), NBS, Colorado, 1984

20. M.O. Hoenig, M.M. Steeves and C.J. Cyders, "Nb3Sn Internally Cooled Cabled Superconductor (ICCS) Technclogy", J. de Physique, 1984, pp. 403-406

21. M.M. Morra, I.S. Hwang, R.G. Ballinger, M.M. Steeves, and M.O. Hoenig, "Effect of Cold Work and Heat Treatment on the 4K Tensile, Fatigue and Fracture Toughness of Incoloy 908", Proceedings of the 11 th International Conference on Magnet Technology, Tsukuba, Japan, 818, pp. 731-736, 1989

22. M. Suenaga, "Metallurgy of Continuous Filamentary A 15 Superconductor", Superconductor Materials Science, S. Foner and B.B. Schwartz, eds., Plenum Press, 1981, pp. 201-274

23. J.W. Ekin, "Superconductors", Materiais at Low Temperatures, eds. R.P. Reed and A.F. Clark, (1983), pp. 465-513

24. P. Sanger et. al., "The Trials and Tribulations of Fabricating the Pipe for the 'Rope in a Pipe' $\mathrm{Nb}_{3} \mathrm{Sn}$ Superconductor", Advances in Cryogenic Engineering, Vol. 28, R.P. Reed and A.F. Clark, eds.,1982, pp. 751-757

25. R.G. Ballinger, "Effects of Furnace Environment on Incoloy@ 903 Performance", Paper presented at ICCS Conductor Sheath Task Group Meeting, LLNL, March 8, 1985 


\section{REFERENCES}

26. L.T. Summers, "Evaluation of Several Iron-Based Superalloys for Use as Conductor Sheath Material for ICCS Nb3Sn Superconductors",LLNL Report, July 5, 1985

27. L.T. Summers, and E.N.C. Dalder, "An Investigation of the Cryogenic Mechanical Properties of Low Thermal Expansion Superalloys", Advances in Cryogenic Engineering, Vol. 28, R.P. Reed and A.F. Clark, eds., 1986, pp. 73-80

28. R.H. Bricknell and D.A. Woodford, "Environmental Effects in the Iron Base Alloy IN903A", General Electric Company, Schenectady, N.Y., Report Number 80CRD268, 1980

29. R.H. Bricknell and D.A. Woodford, "Grain Boundary Embrittlement of the Iron-Base Superalloy IN903A", Met. Trans., Vol. 12A, 1981, pp. 1673-1680

30. D.F. Smith, E.F. Clustworthy, D.G. Tipton, and W.L. Mankins, "Improving the Notch-Rupture Strength of Low-Expansion Superalloys", Superalloys 1980, Proc. 4th Int. Sym. on Superalloys, Seven Springs, PA, ASM, Metals Park, OH, 1980, pp. $521-530$

31. C.J. McMahon and L.F. Coffin, Jr., "Mechanisms of Damage and Fracture in HighTemperature, Low-Cycle Fatigue of a Cast Nickel-Bas. d Superalloy", Met. Trans. A, Vol. 1, 1970, pp. 3443-3450

32. D.A. Woodford and R.H. Bricknell, "Environmental Embrittlement of High Temperature Alloys By Oxygen", Treatise on Materials Science and Technology, C.L. Briant and S.K. Banerji, eds., Academic Press, NY, 1983, pp. 157-199

33. K. Sato and T. Ohno, "Development of Low Thermal Expansion Superalloys", Superalloys 1992, Proc. 7th Int. Sym. on Superalloys, Seven Springs, PA., ASM Metals Park, OH, 1992, pp. 247-255

34. E.A. Wanner and D.A. DeAntonio, "Development of A New Controlled Thermal Expansion Superalloy with Improved Oxidation Resistance", Superalloys 1992, Proc. 7th Int. Sym. on Superalloys, Seven Springs, PA, ASM, Metals Park, OH, 1992, pp. 237-246

35. R. Cozar and A. Pineai, "Morphology of $\gamma$ " and $\gamma$ " Precipitates and Thermal Stability of Inconel 718 Type Alloys", Met. Trans., Vol. 4, 1973, pp. 47-59

36. D.F. Smith, J.S. Smith, and S. Floreen, "A Silicon-Containing Low-Expansion Alloy with Improved Properties", Superalloys 1984, Proc. 5th Int. Sym. on Superalloys, Seven Springs, PA, ASM, Metals Park, OH, 1984, pp. 591-600

37. S. Nicol, "Stress-Rupture Properties of Incoloy 908 in Air", B.S. M.E. Thesis, Worcester Polytechnic Institute, July 1993

38. T. Ericsson, "Review of Oxidation Effects on Cyclic Life At Elevated Temperature", Canadian Met. Quarterly, Vol. 18, 1979, pp. 177-195 


\section{REFERENCES}

39. M. Gell and D.J. Duquette, "The Effects of Oxygen on Fatigue Fracture of Engineering Alloys", Corrosion Fatigue: Chemistry. Mechanics and Microstructure, A.J. McEvily and R.W. Stuehle, NACE, Houston, TX, 1972, pp. 366-378

40. A. Pineau, "Elevated-Temperature Creep-Fatigue Cracking Interactions in Relation to Oxidation Effects", Nace 10, EICM Prrceedings, pp 111-122

41. F.E. Fujita, "Oxidation and Dislocation Mechanisms in Fatigue Crack Formation", Fracture of Soiids, Vol. 20, D.C. Drucker and J.J. Gilman, eds., Interscience Publishers, 1963, pp. 657-670

42. R.M.N. Pelloux, "Mechanisms of Formation of Ductile Fatigue Striations", Trans. ASM, Vol. 62, 1969, pp. 281-285

43. H.H. Smith and P. Shahinian, and M.R. Achter, "Fatigue Crack Growth Rates in Type 316 Stainless Steel at Elevated Temperature as a Function of Oxygen Pressure", Trans. Met. Soc. of AIME, Vol. 245, May 1969, pp. $947-953$

44. M.R. Achter, G.J. Danek, Jr., and H.H. Smith, "Effect on Fatigue of Gaseous Environments Under Varying Temperature and Pressure", Trans. Met. Soc. of AIME, Vol. 227, Dec. 1963, pp. 1296-1301

45. S. Floreen and R.H. Kane, "An Investigation of the Creep-Fatigue-Environment Interaction in a Ni-Base Superalloy", Fatigue of Eng. Mat. and Struct., Vol. 2, pp. $401-412$

46. H.F. Merrick and S. Floreen, "The Effects of Microstructure on Elevated Temperature Crack Growth in Nickel-Base Alloys", Met. Trans. A, Vol. 9A, Feb. 1978, pp. 231 236

47. J.P. Pedron and A. Pineau, "The Effect of Microstructure and Environment on the Crack Growth Behavior of Inconel 718 Alloy at $650^{\circ} \mathrm{C}$. Under Fatigue, Creep and Combined Loading, Mater. Sci. and Eng., 56, 1982, pp. 143-156

48. H. Ghonem and D. Zheng, "Depth of Intergranular Oxygen Diffusion During Environment-Depende.t Fatigue Crack Growth in Alloy 718", Mater. Sci. and Eng., A150, 1992, pp. $151-160$

49. H.H. Smith. and D.J. Michel, "Fatigue Crack Propagation and Deformation Mode in Alloy 718 at Elevated Temperatures", Ductility and Toughress Considerations in Elevated Temperature Service. MPC-8, G.V. Smith, ed., The American Society of Mechanical Engineers, NY, 1978, pp. 225-246

50. K.M. Chang, "Metallurgical Control of Fatigue Crack Propagation in Alloy 718", Superalloys 718,625, 706, and Various Derivatives, E.A. Loria, ed., The Minerals, Míetals \& Materials Society, 1991, pp. 447-456

51. H. Ghonem, T. Nicholas and A. Pineau, "Elevated Temperature Fatigue Crack Growth in Alloy 718 . Part I: Effects of Mechanical Variables", Fatigue Fract. Engng. Mater. Struct., Vol. 16, No. 5, 1993, pp. 565-576 


\section{REFERENCES}

52. R.P. Skelton and J.I. Bucklow, "Cyclic Oxidation and Crack Growth During High Strain Fatigue of Low Alloy Steel", Metal Science, February 1978, pp. 64-70

53. K. Sadananda and P. Shahinian, "The Effect of Environment on the Creep Crack Growth Behavior of Several Structural Alloys, Mater. Sci. and Eng., 43, 1980, pp. 159-168

54. A. Diboine and A. Pineau, "Creep Crack Initiation and Growth in Inconel 718 alloy at $650^{\circ} \mathrm{C}$, Fatigue Fract. Engng. Mater. Struct. Vol. 10, No. 2, 4, 1987, pp. 141-151

55. K.R. Bain and R.M. Pelloux, "Effect of Environment on Creep Crack. Growth in PM/HIP Rene'95", Met.Trans., Vol. 15A, 1984, pp. 381-388

56. M. Gao, D.J. Dwyer and R.P. Wei, "Chemical And Microstructural Aspects of Creep Crack Growth in Inconel 718 Alloy", Superalloys $718,625,706$ and Various Derivatives, E.A. Loria, ed., The Minerals, Metals \& Materials Society, 1994, pp. $581-592$

57. K. Sadananda and P. Shahinian, "High Temperature Time-Dependent Crack Growth", Micro and Macro Mechanics of Crack Growth, K. Sadananda, B.B. Rath and D.J. Michel, eds., The Metallurgical Society of AIME, Warrendale, PA 1982, pp. 119-130

58. K. Sadananda and P. Shahinian, "Effect of Environment on High Temperature Crack Growth Behavior of Several Nickel-Base Alloys", Corrosion of Nickel-Base Alloys, ASM, 1984, pp.101-115

59. A. Ghonem, T. Nicholas and A. Pineau, "Elevated Temperature Fatigue Crack Growth in Alloy 718 - Part II: Effects of Environmental and Material Variables", Fat. Fract. Engng. Mater. Struct., Vol. 16, No. 0, pp. 577-590, 1993

60. S. Floreen and R.H. Kane, "Efffects of Environment on High Temperature Fatigue Crack Growth in a Superalloy", Met.Trans., Vol. 10, 1979, pp. 1745-1751

61. W.H. Chang, "Tensile Embrittlement of Turbine Blade Alloys After HighTemperature Exposure", Superalloys Processing, AIME, MCIC-72-10, 1972, pp. V1-V41

62. R.H. Bricknell and D.A. Woodford, "The Embrittlement of Nickel Following High Temperature Air Exposure", General Electric Company, Schenectady, NY, Report Number 80CRD164, 1980

63. R.H. Bricknell and D.A. Woodford, "Embrittlement of Nickel Following High Temperature Air Exposure", Met.T1ans., Vol. 12A, 1981, pp. 425-433

64. R.H. Bricknell and D.A. Woodford, "The Mechanism of Cavity Formation During Oxidation of Nickel", Acta Metall., Vol. 30, 1982, pp. 257-264

65. D.A. Woodford and R.H. Bricknell, "Grain Boundary Penetration of Oxygen in Nickel and the Effect of Boron Additions", Met.Trans., Vol. 12A, 1981, pp. 14671475 


\section{REFERENCES}

66. M.C. Pandey, D.M.R. Taplin, M.F. Ashby, and B.F. Dyson, "The Effect of Prior Exposure-Time On Air-Environment/Creep Interactions", Acta. Merall., Vol. 34, No. 11,1986, pp. $2225-2233$

67. R.H. Bricknell and D.A. Woodford, "The Effect of High Temperature Air Exposure on the Stress Rupture Life of Nickel and Cobalt Base Superalloys", Superalloys 1980 , Proc. 4th Int. Sym. on Superalloys, Seven Springs, PA, ASM, Metals Park, OH, 1980 , pp. 633-641

68. D.A. Woodford, "Environmental Damage of a Cast Nickel Base Superalloy", Met.Trans., Vol. 12A, 1981, pp. 299-308

69. J. Reuchet and L. Remy, "Fatigue Oxidation Interaction in a Superalloy - Application to Life Prediction in High Temperature Low Cycle Fatigue", Met. Trans. Vol. 14A, Jinuary 1993, pp. 141-149

70. D. J. Wilson, "Sensitivity of the Creep-Rupture Properties of Waspaloy Sheet to Sharp-Edged Notches in the Temperature Range 1000-1400 'F", J. Basic Eng., March 1972, pp. 13-21

71. D.J. Wilson, "Relationship of Mechanical Characteristics and Microstructural Features to the Time-Dependent Edge-Notch Sensitivity of Inconel 718 Sheet", J. Eng. Mater. and Tech., April 1973, pp. 112-123

72. C.J. Moss and J.W. Martin, "The Effect of Grain Boundary $\gamma$ ' Precipitation on the Stress Rupture Behavior of Nimonic PE16", Materials Forum, 15, 1991, pp. 324332

73. K.A. Heck, D.F. Smith, M.A. Holderby, and J.S. Smith, "Three-Phase Controlled Expansion Superalloys With Oxidation Resistance", Superalloys 1992, Proc. 7th Int. Sym. on Superalloys, Seven Springs, PA, ASM, Metals Park, OH, 1992, pp. 217226

74. M.G. Lozinskiy, G.M. Volkogon and N.Z. Pertsoviskiy, "Investigation of the Influence of Zirconium Additions on the Ductility and Deformation Structure of Nickel Over a Wide Temperature Range", Russian Met., Vol. 5, 1967, pp. 72-81

75. P. Scott and M. LeCalvar, "Some Possible Mechanisms of Intergranular Stress Corrosion Cracking of Alloy 600 in PWR Primary Water", Presented at EPRI A.lloy 600 PWSCC Experts Meeting, Warrenton, VA, March 6-9, 1993

76. H.H. Smith and P. Shahinian, "Environmental Effects on Fatigue-Crack Growth Rates in Silver", J. Inst. of Metals, Vol. 99, 1971, pp. 243-247

77. E. Andrieu, "Influence de L'environmeni sur la propagation des fissures dans un superalliage base nickel, L'Inconel 718", Thesis, Ecoie des Mines de Paris, 1987

78. E. Andrieu, R. Molins, H. Ghonem, and A. Pineau, "Intergranular Crack Tip Oxidation Mechanism in a Nickel-Based Superalloy", Materials Science and Engineering, A154, 1992, pp. 21-28 


\section{REFERENCES}

79. E. Andrieu, G. Hochstetter, R. Molins, and A. Pineau, "Oxidation Mechanisms in Relation To High Temperature Fatigue Crack Growth Properties of Alloy 718", Superalloys 718, 625,706, and Various Derivatives, E.A. Loria, ed., The Minerals, Metals \& Materials Society, 1994, pp. 619-631

80. H. Ghonf.m and D. Zheng, "Oxidation-Assisted Fatigue Crack Growth Behavior in Alloy 718 - Part I. Quantitative Modeling", Fatigue Fract. Engng. Mater. Struct., Vol. 14, ivo. 7, 1991, pp. 749-760

81. D. Zheng and H. Ghonem, "Oxidation-Assisted Fatigue Crack Growth Behavior in Alloy 718 - Part II. Applications", Fatigue Fract. Engng. Mater. Struct. Vol. 14, No. 7, 1991, pp. 761-768

82. R.A. Rapp, "Kinetics, Microstructures and Mechanisms of Internal Oxidation - Its Effect and Prevention in High temperature Alloy Oxidation", Proc. 21 st Conference, National Assosiation of Corrosion Engineers, St. Louis, MO, March 1965, pp. 382 400

83. G. E. Wasielewski and R.A. Rapp, "High Temperature Oxidation", The Superalloys, C.T. Sims and W.C. Hagel, eds., John Wiley \& Sons, 1972, pp 287-316.

84. F.H. Stott, G.C. Wood, Y. Shida, D.P. Whittle and B.D. Bastow, "The Development of Internal and Intergranular Oxides in Nickel-Chromium-Aluminum Alloys at High Temperature", Corrosion Science, Vol. 21, No. 8, 1981, pp. 599-624

85. J.H. Sivisher, "Internal Oxidation", Oxidation of Metals and Alloys, ASM, OH, 1970, pp. 235-267

86. F.S. Pettit, C.S. Giggins, J.A. Goebel, and E.J. Felten, "Oxidation and Hot Corrosion Resistance", Alloy and Microstructural Design, J.K. Tien and G.S. Ansell, eds., Academic Press, NY, 1976, pp 349-402

87. G.J. Lloyd and J.W. Martin, "The Diffusivity of Oxygen in Nickel Determined by Internal Oxidation of Dilute Ni-Be Alloys", Metal Science Joumal, Vol. 7, 1973, p. 74

88. G.J. Lloyd and J.W. Martin, "The Diffusivity of Oxygen in Nickel Determined by Internal Oxidation of Dilute Ni-Be Alloys", Metal Science Journal, Vol. 6, 1972, pp. $7-11$

89. J.C. Hwang and R.W. Balluffi, "On a Possible Temperature Dependence of the Activation Energy for Grain Boundary Diffusion in Metals", Scripta Met., Vol. 12, 1978, pp. 709-714

90. Y. Shida, G.C. Wood, F.H. Stott, D.P. Whittle, and B.D. Bastow, "Intergianular Oxidation and Internal Void Formation in Ni-40\% Cr Alloys", Corrosion Science, Vol. 21, No. 8, 19£1, pp. 581-597

91. C.S. Giggins and F.S. Pettit, "Oxidation of Ni-Cr Alloys Between $800^{\circ}$ and $1200^{\circ} \mathrm{C}$ ", Trans TMS AIME, Vol. 245, December 1969, pp. 2495-2507. 


\section{REFERENCES}

92. N. Birks, Introduction to High Temperature Oxidation of Metals, Edward Arnold Publishers, LTD, London, 1983.

93. C.S. Giggins and F.S. Pettit, "The Effect of Alloy Grain-Size and Surface Deformation on the Selective Oxidation of Chromium in $\mathrm{Ni}-\mathrm{Cr}$ Alloys at Temperatures of $900^{\circ}$ and $1100^{\circ} \mathrm{C} "$, Trans TMS AIME, Vol. 245, December 1969 , pp. 2509-2514.

94. G.C. Wood, F.H. Stott, D.P. Whittle, Y. Shida, and B.D. Bastow, "The HighTemperature Internal Oxidation and Intergranular Oxidation of Nickel-Chromium Alloys", Corrosion Science, Vol. 23, No. 1, 1983, pp. 9-25

95. F.H. Stott, Y. Shida, D.P. Whittle, G.C. Wood and B.D. Bastow, "The Morphological and Structural Development of Internal Oxides in Nickel-Aluminum Alloys at High Temperatures", Oxidation Of Metals, Vol. 18, Nos. 3/4, 1982, pp. 127-146

96. Y. Shida, F.H. Stott, B.D. Bastow, D.P. Whittle and G.C. Wood, "Devolopment of Preferential Intergranular Oxides in Nickel-Aluminum Alloys at High Temperatures", Oxidation of Metals, Vol. 18, Nos. 3/4, 1982, pp.93-113

97. S. Guruswamy, S.M. Park, J.P. Hirth, and R.A. Rapp, "Internal Oxidation of Ag-In Alloys: Stress Relief and the Influence of Imposed Strain", Oxidation of Metals, Vo:. 26, Nos.1/2, 1986 pp. $77-100$

98. A.M. Emsley and M.P. Hill, "Intergranular Oxidation of Silicon in $20 \mathrm{Cr}-25 \mathrm{Ni}$ Niobium-Stabilized Stainless Steel at 1140-1230K", Oxidation of Metals, Vol. 34, Nos. $3 / 4,1990$, pp. $351-360$

99. K. Mino, A. Ohtomo, and Y. Saiga, "The Effect of Stressing on the Intergranular Oxidation of Inconel 617", J Japan Inst. Metals, Vol. 44, No. 12, pp. 1397-1403

100. C.T. Liu and K. S. Kumar, "Ordered Intermetallic Alloys, Part I: Nickel and Iron Aluminides", J. Mietals, Vol. 45, No. 5, May 1993, pp.38-44

101. C.A. Hippsley and J.H. DeVan, "A Study of High Temperature Crack Growth in Nickel-Aluminide", Acta Metall., Vol. 37, No. 5, 1989, pp. 1485-1496

102. C.T. Liu, C.L. White and E.H. Lee, "Effect of Test Environment on Ductility and Fracture Behavior of Boron-Doped $\mathrm{Ni}_{3} \mathrm{Ai}$ at $600^{\circ} \mathrm{C}$.", Scripta Met., Vol. 19, No. 10, 1985, pp. 1247-1250

103. C.T. Liu, C.L. White and J.A. Horton, "Effect of Boron on Grain Boundaries in $\mathrm{Ni}_{3}$ Al", Acta. Metall., Vol. 33, No. 2, 1985, pp. 213-229

104. C.T. Liu and C.L. White, "Dynamic Embrittlement of Boron-Doped $\mathrm{Ni}_{3} \mathrm{Al}$ Alloys at $600^{\circ}$ C", Acta. Metall., Vol. 35, No. 3, 1987, pp. 643-649

1C5. J.H. Weber and H. Sizek, Private Communication from Inco Alloys Int., Huntington, WV, May 27, 1993 


\section{REFERENCES}

106. I.P. Vasatis and R.M. Pelloux, "dc Potential Drop Technique in Creep Stress Rupture Testing", J. Metals, October 1985, pp. 44-49

107. ASTM Book of Standards, E292-83

108. J.I. Goldstein, D.E. Newbury, P.Echlin, D.C. Joy, C. Fiori and E. Lifshin, Scanning Elecrron Microscopy and X-Ray Microanalysis. A Text for Biologists, Materials Scientists, and Geologists, Plenum Press, 1984, pp. 46

109. L.S. Toma, M.M. Steeves, and R.P. Reed, Incoloy Alloy 908 Data Handbook, M.I.T. Plasma Fusion Center Report \# PFC/RR-94-2, March 1994

110. R.W. Hertzberg, Deformation and Fracture Mechanics of Enginefring Materials, J.W. Wiley and Sons, NY, 1976

111. H.E. Boyer, ed., Atlas of Creep and Stress-Rupture Curves, ASM International, Metals Park, $\mathrm{OH}, 1988$

112. M.F. Asby and B.F. Dyson, "Creep Damage Mechanics and Micromechanics", Advances in Fracture Research (Fracture 84), S.R. Valluri, D.M.R. Taplin, P. Ramarao, J.F. Knot, R. Dubey, eds., Vol. 1, Pergamon Press, NY, 1984, pp. 3-30

1i3. S.T. Rolfe and J.M. Barsom, Fracture and Fatigue Control in Structures, Applications of Fracture Mechanics, Prentice-Hall, NJ, 1977

114. G.E. Dieter, Mechanical Metallurgy, McGraw-Hill, Inc., 1976

115. S. Leistiko, "Chances and Limitations of Improved Corrosion Resistance in Oxidising Gases By Cold Working Pre-treatment of Austenitic Cr Ni-Steels", Behavior of High Temperature Alloys in Aggressive Environments, I. Kirman, J.B. Mariott, M. Merz, P.R. Sahm, and D.P. Whittle, eds, The Metals Society, London, 1979, pp. 197-207

116. R.M. Goldhoff, "The Evaluation of Elevated Temperature Creep and Rupture Strength Data: An Historical Perspective", Characterization of Materials for Service at Elevated Temperatures, G.V. Smith, ed., ASME, NY, 1978, pp. 247-265

117. J.B. Conway, Numerical Methods foi: Creep and Rupture Analysis, Gordon and Breach, NY, 1967

118. D.A. Woodford, "Creep and Rupture of an Advanced Fiber Strengthened Eutectic Composite Superalloy", Met. Trans. A, Vol. 8A, April 1977, pp. 639-650.

119. R.G.H. Record, "Oxygen Potential Monitoring of Treatment Atmospheres", Metals and Materials, January 1971, pp. 25-30.

1'20. H.H. Smith and P. Shahinian, "Effect of An Oxygen Atmosphere on Cyclic Hardening in Type 316 Stainless Steel", Met. Trans. A, Vol. 1, July 1970, pp. 20072009. 


\section{REFERENCES}

121. R.G. Iacocca and D.A. Woodford, "The Kinetics of Intergranular Oxygen Penetration in Nickel and tts Relevance to Weldment Cracking", Met. Trans., Vol. 19A, 1988, pp. 2305-2313.

122. D.R. Hayhurst and G.A. Webster, "An Overview on Studies of Stress State Effects During Creep of Circumferentially Notched Bars", Technique for Multiaxial Creep Testing, D.J. Gooch and I.M. How, eds., Elsevier, Ltd., 1986, pp. 137-175.

123. G.S. Was, "The Influence of Grain Boundary Chemistry on IGA and IGSCC in Nickel-Base Alloys", Proc. Int. Conference on Environmental Degradation of Engineering Materials III, Penn. State Univ., 1987, pp. 241-251. 